US Army Corps

of Engineers

Waterways Experiment

Station

\title{
Damage Progression on Rubble-Mound Breakwaters
}

\author{
by Jeffrey A. Melby
}

Approved For Public Release; Distribution Is Unlimited

$T$
7

ch

$99-17$ 
The contents of this report are not to be used for advertising, publication, or promotional purposes. Citation of trade names does not constitute an official endorsement or approval of the use of such commercial products.

The findings of this report are not to be construed as an official Department of the Army position, unless so designated by other authorized documents. 


\title{
Damage Progession on Rubble-Mound Breakwaters
}

\author{
by Jeffrey A. Melby \\ U.S. Army Corps of Engineers \\ Waterways Experiment Station \\ 3909 Halls Ferry Road \\ Vicksburg, MS 39180-6199
}

\section{Final report}

Approved for public release; distribution is unlimited

Prepared for U.S. Army Corps of Engineers

Washington, DC 20314-1000

Under Civil Works Research Work Unit 32792 


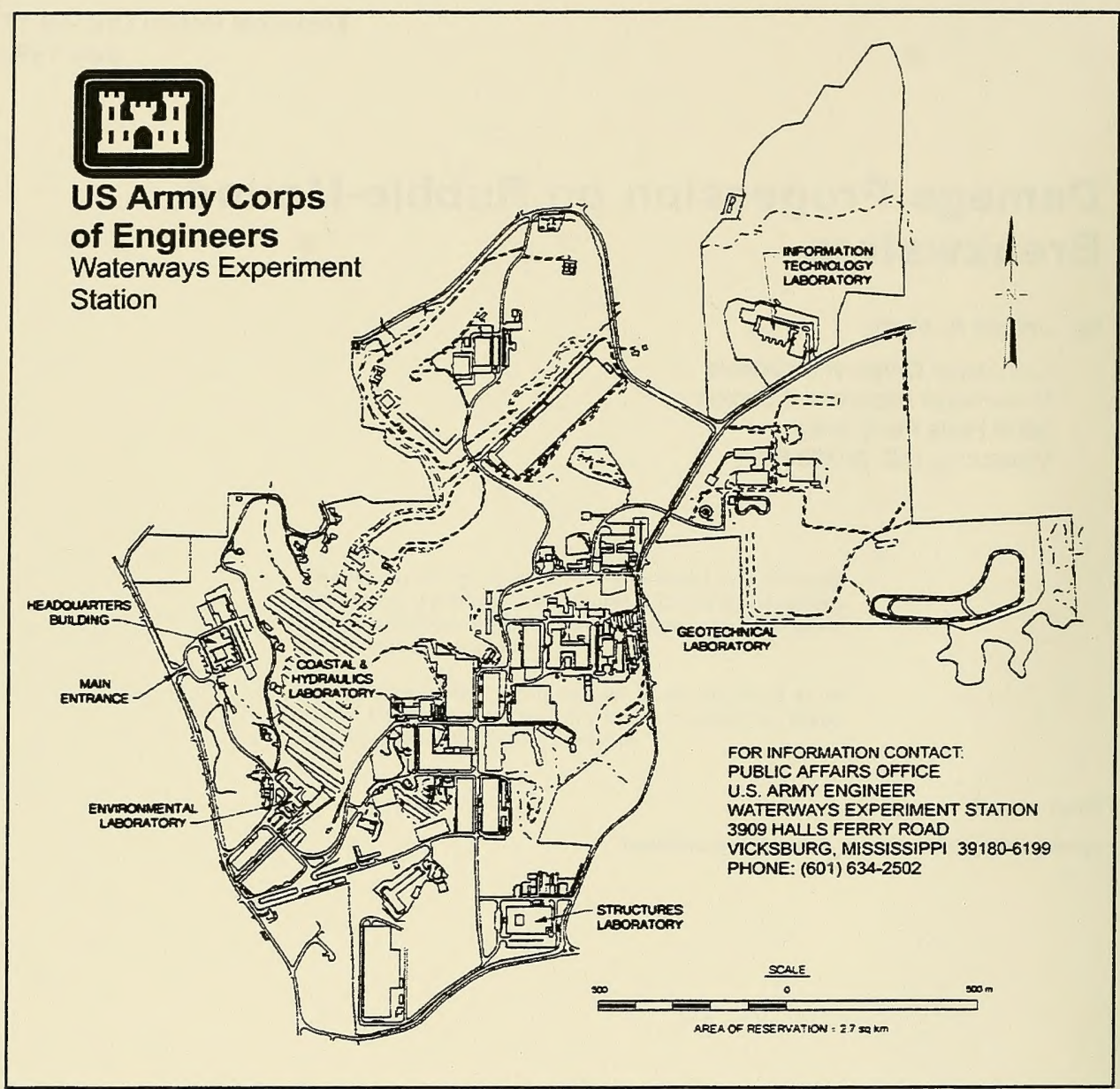

\section{Waterways Experiment Station Cataloging-in-Publication Data}

Melby, Jeffrey A.

Damage progression on rubble-mound breakwaters / by Jeffrey A. Melby ; prepared for

U.S. Army Corps of Engineers.

216 p. : ill. ; $28 \mathrm{~cm}$. -- (Technical report ; CHL-99-17)

Includes bibliographic references.

1. Rubble-mound breakwaters -- Stability -- Testing. 2. Breakwaters -- Stability --

Testing. 3. Coastal engineering. 4. Flumes -- Testing. 5. Hydrodynamics. I. United

States. Army. Corps of Engineers. II. U.S. Army Engineer Waterways Experiment

Station. III. Coastal and Hydraulics Laboratory (U.S. Army Engineer Waterways

Experiment Station) IV. Title. V. Series: Technical report (U.S. Ammy Engineer

Waterways Experiment Station) ; CHL-99-17.

TA7 W34 no.CHL-99-17 


\section{TABLE OF CONTENTS}

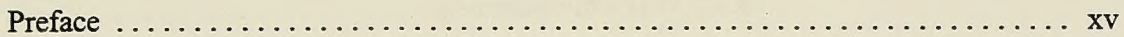

Chapter

$1 \quad$ INTRODUCTION $\ldots \ldots \ldots \ldots \ldots \ldots \ldots \ldots \ldots \ldots \ldots \ldots \ldots \ldots$

2 INCIPIENT STABILITY OF BREAKWATER ARMOR UNITS $\ldots \ldots \ldots 6$

2.1 Armor Stability Equations $\ldots \ldots \ldots \ldots \ldots \ldots \ldots \ldots \ldots \ldots \ldots$

2.2 Armor Incipient Motion Studies . . . . . . . . . . . . . . . 10

2.3 Experimental Setup ............................ 12

2.4 Incipient Motion Observations . . . . . . . . . . . . . . . . 17

2.5 Experimental Measurements . . . . . . . . . . . . . . . . 18

2.6 Incipient Motion Prediction .......................... 22

2.7 Conclusions from Incipient Motion Study $\ldots \ldots \ldots \ldots \ldots \ldots \ldots \ldots .32$

3 HISTORICAL DAMAGE MEASUREMENT AND DESCRIPTION .. 33

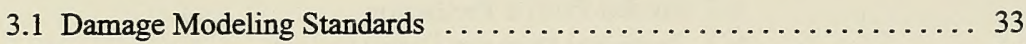

3.2 Damage Measurement Methods ..................... 34

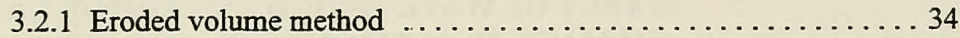

3.2.2 Stone count method ........................ 40

3.2.3 Recent damage measurement methods $\ldots \ldots \ldots \ldots \ldots \ldots .40$

3.3 Damage Measurement Experiments . ................... 41

3.4 Damage Progression Prediction . . . . . . . . . . . . . . . 44

3.5 Variability in Stability Results $\ldots \ldots \ldots \ldots \ldots \ldots \ldots \ldots \ldots \ldots \ldots$

4 DETERIORATION EXPERIMENT $\ldots \ldots \ldots \ldots \ldots \ldots \ldots \ldots \ldots \ldots$

4.1 Overview . . . . . . . . . . . . . . . . 53

4.2 Experimental Setup .......................... 54 


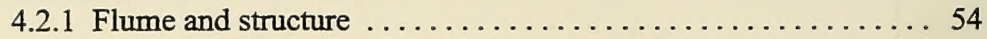

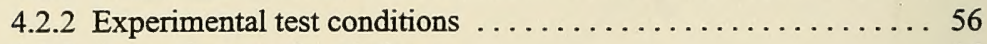

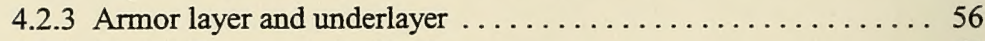

4.2.4 Model-Prototype similitude .................. 60

4.3 Wave Generation and Measurement in Initial Experiment ......... 62

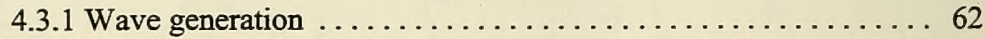

4.3.2 Wave measurement ...................... 64

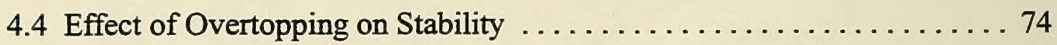

4.5 Armor Profiler and Profile Measuring Technique ............. 74

5 DAMAGE MEASUREMENTS $\ldots \ldots \ldots \ldots \ldots \ldots \ldots \ldots \ldots \ldots \ldots \ldots \ldots$

5.1 Overview $\ldots \ldots \ldots \ldots \ldots \ldots \ldots \ldots \ldots \ldots \ldots \ldots \ldots \ldots . \ldots . \ldots \ldots$

5.2 Damage and Eroded Profile Parameters . . . . . . . . . . . 83

5.3 Probability Density Functions of Damage, Eroded Depth, and Cover Depth .............................. 85

5.4 Temporal Damage Development $\ldots \ldots \ldots \ldots \ldots \ldots \ldots \ldots \ldots \ldots$

5.5 Characteristics of Profile Erosion $\ldots \ldots \ldots \ldots \ldots \ldots \ldots \ldots \ldots \ldots \ldots \ldots \ldots \ldots$

6 DAMAGE AND ERODED PROFILE PREDICTION $\ldots \ldots \ldots \ldots, 110$

6.1 Damage Variability . . . . . . . . . . . . . . . . . . . 110

6.2 Eroded Profile Prediction $\ldots \ldots \ldots \ldots \ldots \ldots \ldots \ldots \ldots \ldots \ldots \ldots \ldots \ldots \ldots$

6.3 Temporal Damage Development ..................... 117

7 EFFECT OF WAVE PERIOD AND ARMOR GRADATION ON DAMAGE PROGRESSION

7.1 Experimental Setup and Test Conditions ................ 127

7.2 Probability Density Functions of Damage, Eroded Depth, and Cover Depth . . . . . . . . . . . . . . . . . . . . 131

7.3 Damage Variability . . . . . . . . . . . . . . . . . . . . 133

7.4 Eroded Profile Prediction . . . . . . . . . . . . . . . . . . 134

7.5 Temporal Damage Development ....................... 139

8 SUMMARY AND CONCLUSIONS $\ldots \ldots \ldots \ldots \ldots \ldots \ldots \ldots \ldots \ldots$ 
Appendix

A SUMMARY OF WAVE MEASUREMENTS $\ldots \ldots \ldots \ldots \ldots \ldots \ldots$

B SUMMARY OF DAMAGE AND PROFILE MEASUREMENTS $\ldots 187$

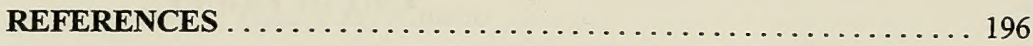

SF 298 


\section{LIST OF FIGURES}

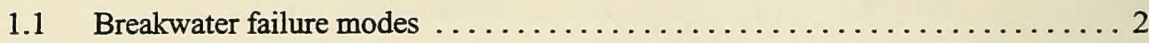

2.1 Flume plan (top) and profile (bottom) views for incipient motion

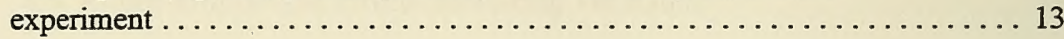

2.2 Definition sketch for typical structure profile $\ldots \ldots \ldots \ldots \ldots \ldots \ldots \ldots \ldots$

2.3 Velocity time series for one wave period with $\tilde{H}_{t}=12 \mathrm{~cm}, \tilde{T}=1 \mathrm{~s}, d_{t}=24 \mathrm{~cm}$ and $d_{L}=8.8 \mathrm{~cm}$ measured $1 \mathrm{~cm}$ outside the armor layer $\ldots \ldots \ldots \ldots \ldots$

2.4 Velocity vector for one wave period for armor lifting measured $1 \mathrm{~cm}$ outside the armor layer with $\bar{H}_{t}=8.4 \mathrm{~cm}, \bar{T}=2 \mathrm{~s}, d_{t}=24 \mathrm{~cm}$, and $d_{L}=17 \mathrm{~cm} . \ldots \ldots 20$

2.5 Vertical velocity time series outside (top) and inside (bottom) armor layer with $\tilde{H}_{t}=12 \mathrm{~cm}, \bar{T}=1 \mathrm{~s}, d_{t}=24 \mathrm{~cm}$, and $d_{L}=8.8 \mathrm{~cm}$ for the outer measurement and $d_{L}=13 \mathrm{~cm}$ for the inner measurement $\ldots \ldots \ldots \ldots \ldots 20$

2.6 Measurement locations for vertical velocities shown in Figure $2.5 \ldots \ldots \ldots 21$

2.7 Maximum vertical velocity versus the square root of wave steepness for wave periods $\bar{T}=1$ and $2 \mathrm{~s}$ and relative depths $r d=0.36,0.5$, and $0.7 \ldots \ldots \ldots 22$

2.8 Vertical variation of vertical velocity under a steep wave front across the armor layer as a function of wave steepness

2.9 Photographs of sphere motion during a typical incipient motion experiment for Plan 4

2.10 Incipient motion criterion (Equation 2.14 with $v_{c}=61.8 \mathrm{~cm} / \mathrm{s}$ ) versus wave steepness

3.1 Sketch of breakwater profile with definition of eroded area and depth of cover 
3.2 Damage, characterized as eroded volume, as a function of monochromatic wave height for angular stone (SPM 1984) . . . . . . . . . . . . 46

3.3 Hudson stability coefficient versus relative depth for angular armor stone exposed to irregular waves (Carver and Wright 1991) ............. 52

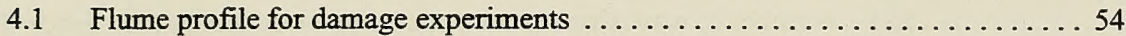

4.2 Model structure cross section for damage experiments $\ldots \ldots \ldots \ldots \ldots 54$

4.3 Photograph of model structures before testing $\ldots \ldots \ldots \ldots \ldots \ldots \ldots$

4.4 Armor and underlayer stone mass distributions for initial experiment . . . . . 58

4.5 Flume profile near structure with nearshore wave gage layout $\ldots \ldots \ldots \ldots 65$

4.6 Wave height variation throughout Waves 1,2 , and 3 at $11.9 \mathrm{~cm}$ toe depth $\ldots 71$

4.7 Wave height variation throughout Waves 4,5 , and 6 at $15.8 \mathrm{~cm}$ toe depth $\ldots 71$

4.8 Plan (top) and profile (bottom) views of breakwater profiler $\ldots \ldots \ldots \ldots 75$

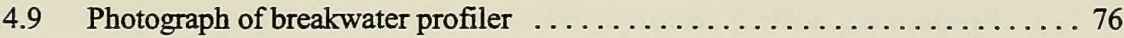

5.1 Sketch of breakwater profile with definition of damage parameters $\ldots \ldots \ldots 84$

5.2 Probability density function for normalized damage $S^{*}$ for Series $A^{\prime}, B^{\prime}$, and $C^{\prime} \ldots \ldots \ldots \ldots \ldots \ldots \ldots \ldots \ldots \ldots \ldots \ldots \ldots$

5.3 Probability density function for normalized eroded depth $E^{*}$ for

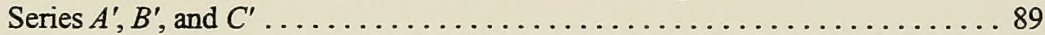

5.4 Probability density function for normalized cover depth $C^{*}$ for

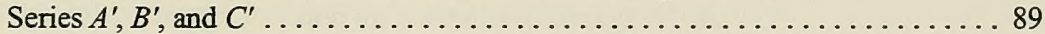

5.5 Photographs of undamaged structures prior to Series $A^{\prime} \ldots \ldots \ldots \ldots \ldots$

5.6 Profiles at beginning of Series $A^{\prime}$, damage level of $\bar{S} \approx 0 \ldots \ldots \ldots . \ldots 92$

5.7 Profiles midway through Series $A^{\prime}$, damage level of $\bar{S}=6.5 \ldots \ldots \ldots . \ldots 9$

5.8 Profiles following completion of Series $A^{\prime}$, damage level of $\bar{S}=12.8 \ldots \ldots 94$ 
5.9 Photographs of structures following completion of Series $A^{\prime}$, damage level of $\bar{S}=12.8$

5.10 Number of waves versus mean damage \pm one standard deviation for Series $A^{\prime}$

5.11 Number of waves versus mean damage \pm one standard deviation for Series $B^{\prime}$

5.12 Number of waves versus mean damage \pm one standard deviation for Series $C^{\prime}$

5.13 Number of waves versus mean maximum eroded depth \pm one standard deviation for Series $A^{\prime}$

5.14 Number of waves versus mean minimum cover depth \pm one standard

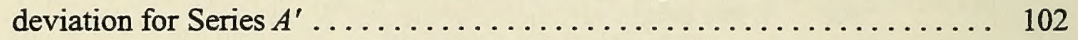

5.15 Number of waves versus mean maximum eroded length for Series $A^{\prime} \ldots \ldots 102$

5.16 Mean damage versus mean maximum eroded depth and mean minimum

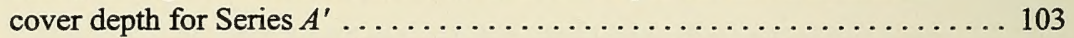

5.17 Mean damage versus mean maximum eroded length for Series $A^{\prime} \ldots \ldots \ldots 104$

5.18 Number of waves versus mean maximum eroded depth \pm one standard

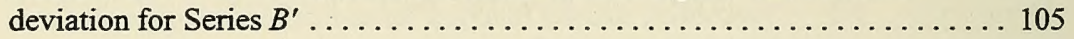

5.19 Number of waves versus mean maximum eroded depth \pm one standard deviation for Series $C^{\prime}$.

5.20 Number of waves versus mean minimum cover depth \pm one standard deviation for Series $B^{\prime}$

5.21 Number of waves versus mean minimum cover depth \pm one standard deviation for Series $C^{\prime}$

5.22 Number of waves versus mean maximum eroded length for Series $B^{\prime}$

5.23 Number of waves versus mean maximum eroded length for Series $C^{\prime}$

5.24 Mean damage versus mean maximum eroded depth and mean minimum cover depth for Series $B^{\prime}$ 
5.25 Mean damage versus mean maximum eroded depth and mean minimum

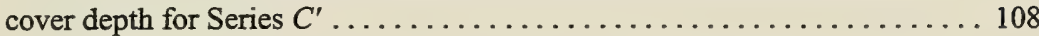

5.26 Mean damage versus mean maximum eroded length for Series $B^{\prime} \ldots \ldots \ldots 109$

5.27 Mean damage versus mean maximum eroded length for Series $C^{\prime} \ldots \ldots \ldots 109$

6.1 Prediction of damage variability, characterized by the standard deviation, as a function of mean damage for Series $A^{\prime}, B^{\prime}$, and $C^{\prime} \ldots \ldots \ldots \ldots \ldots \ldots 11$

6.2 Prediction of mean maximum eroded depth as a function of mean damage for Series $A^{\prime}, B^{\prime}$, and $C^{\prime} \ldots \ldots \ldots \ldots \ldots \ldots \ldots \ldots \ldots \ldots \ldots \ldots \ldots \ldots \ldots \ldots \ldots \ldots \ldots \ldots$

6.3 Prediction of standard deviation of maximum eroded depth as a function of mean damage for Series $A^{\prime}, B^{\prime}$, and $C^{\prime} \ldots \ldots \ldots \ldots \ldots \ldots \ldots \ldots \ldots \ldots \ldots \ldots \ldots \ldots$

6.4 Prediction of mean of eroded length as a function of mean damage for

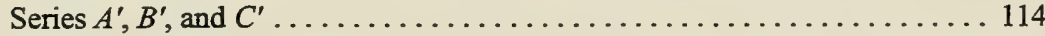

6.5 Prediction of mean minimum cover depth as a function of mean damage for

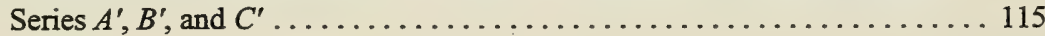

6.6 Prediction of standard deviation of minimum cover depth as a function of mean damage for Series $A^{\prime}, B^{\prime}$, and $C^{\prime} \ldots \ldots \ldots \ldots \ldots \ldots \ldots \ldots \ldots \ldots \ldots \ldots \ldots$

6.7 Damage prediction relations compared to data for Series $A^{\prime} \ldots \ldots \ldots 125$

6.8 Damage prediction relations compared to data for Series $B^{\prime} \ldots \ldots \ldots \ldots 126$

6.9 Damage prediction relations compared to data for Series $C^{\prime} \ldots \ldots \ldots \ldots 126$

7.1 Stone mass distributions for riprap and underlayer $\ldots \ldots \ldots \ldots \ldots \ldots \ldots$

7.2 Probability density function for normalized damage $S^{*}$ for Series $D^{\prime}, E^{\prime}, F^{\prime}$, and $G^{\prime} \ldots \ldots \ldots \ldots \ldots \ldots \ldots \ldots \ldots \ldots \ldots \ldots \ldots \ldots \ldots \ldots \ldots \ldots \ldots \ldots$

7.3 Probability density function for normalized eroded depth $E^{*}$ for Series $D^{\prime}, E^{\prime}, F^{\prime}$, and $G^{\prime}$

7.4 Probability density function for normalized cover depth $C^{*}$ for Series $D^{\prime}, E^{\prime}, F^{\prime}$, and $G^{\prime} \ldots \ldots \ldots \ldots \ldots \ldots \ldots \ldots \ldots \ldots \ldots \ldots \ldots \ldots \ldots \ldots \ldots \ldots$

7.5 Prediction of damage variability, characterized by the standard deviation, as a function of mean damage for Series $B^{\prime}, D^{\prime}, E^{\prime}, F^{\prime}$, and $G^{\prime}$ 
7.6 Prediction of mean maximum eroded depth as a function of mean damage for Series $B^{\prime}, D^{\prime}, E^{\prime}, F^{\prime}$, and $G^{\prime}$

7.7 Prediction of standard deviation of maximum eroded depth as a function of mean damage for Series $B^{\prime}, D^{\prime}, E^{\prime}, F^{\prime}$, and $G^{\prime}$

7.8 Prediction of mean maximum eroded length as a function of mean damage for Series $B^{\prime}, D^{\prime}, E^{\prime}, F^{\prime}$, and $G^{\prime} \ldots \ldots \ldots \ldots \ldots \ldots \ldots \ldots \ldots \ldots \ldots \ldots \ldots \ldots \ldots \ldots \ldots \ldots$

7.9 Prediction of mean minimum cover depth as a function of mean damage for Series $B^{\prime}, D^{\prime}, E^{\prime}, F^{\prime}$, and $G^{\prime}$

7.10 Prediction of standard deviation of minimum cover depth as a function of mean damage for Series $B^{\prime}, D^{\prime}, E^{\prime}, F^{\prime}$, and $G^{\prime} \ldots \ldots \ldots \ldots \ldots \ldots \ldots \ldots \ldots$

7.11 Damage prediction relations compared to data for Series $D^{\prime} \ldots \ldots \ldots \ldots . .140$

7.12 Damage prediction relations compared to data for Series $E^{\prime} \ldots \ldots \ldots \ldots 140$

7.13 Damage prediction relations compared to data for Series $F^{\prime} \ldots \ldots \ldots \ldots 141$

7.14 Damage prediction relations compared to data for Series $G^{\prime} \ldots \ldots \ldots \ldots 141$

7.15 Damage prediction relations compared to data for Series $D^{\prime}$ including damage initiation adjustment

7.16 Damage prediction relations compared to data for Series $E^{\prime}$ including damage initiation adjustment

7.17 Damage prediction relations compared to data for Series $F^{\prime}$ including damage initiation adjustment

7.18 Damage prediction relations compared to data for Series $G^{\prime}$ including damage initiation adjustment

A.1 Wave generator command signals for six wave cases. The original signal was $900 \mathrm{sec}$ but $10 \mathrm{sec}$ was clipped from either end for analysis and this figure shows the shortened time series.

A.2 Spectra of wave generator command signals for Waves 1,2 , and 3 for $11.9 \mathrm{~cm}$ toe depth 
A.3 Spectra of wave generator command signals for Waves 4,5 , and 6 for

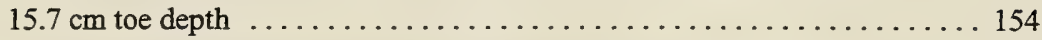

A.4 Wave 1 time series from wave gages. The original signal was $900 \mathrm{sec}$ but $10 \mathrm{~s}$ was clipped from either end for analysis and this figure shows the shortened time series.

A.5 Wave 2 time series from wave gages. This figure shows the shortened time series as in Figure A.4.

A.6 Wave 3 time series from wave gages. This figure shows the shortened time series as in Figure A.4.

A.7 Wave 4 time series from wave gages. This figure shows the shortened time series as in Figure A.4.

A.8 Wave 5 time series from wave gages. This figure shows the shortened time series as in Figure A.4.

A.9 Wave 6 time series from wave gages. This figure shows the shortened time series as in Figure A.4.

A.10 Wave 1 incident and reflected spectra from wave gages $\ldots \ldots \ldots \ldots 161$

A.11 Wave 2 incident and reflected spectra from wave gages $\ldots \ldots \ldots \ldots 2$

A.12 Wave 3 incident and reflected spectra from wave gages $\ldots \ldots \ldots \ldots \ldots 163$

A.13 Wave 4 incident and reflected spectra from wave gages $\ldots \ldots \ldots \ldots \ldots 164$

A.14 Wave 5 incident and reflected spectra from wave gages $\ldots \ldots \ldots \ldots \ldots$

A.15 Wave 6 incident and reflected spectra from wave gages $\ldots \ldots \ldots \ldots \ldots 6$

A.16 Wave 7 incident and reflected spectra from wave gages $\ldots \ldots \ldots \ldots . \ldots 167$

A.17 Wave 8 incident and reflected spectra from wave gages $\ldots \ldots \ldots \ldots \ldots 8$

A.18 Wave 9 incident and reflected spectra from wave gages $\ldots \ldots \ldots \ldots \ldots$

A.19 Wave 10 incident and reflected spectra from wave gages $\ldots \ldots \ldots \ldots \ldots$

A.20 Wave 11 incident and reflected spectra from wave gages $\ldots \ldots \ldots \ldots 171$ 
A.21 Wave 12 incident and reflected spectra from wave gages 172

A.22 Wave 13 incident and reflected spectra from wave gages $\ldots \ldots \ldots \ldots 173$

A.23 Wave 14 incident and reflected spectra from wave gages 174

A.24 Wave 15 incident and reflected spectra from wave gages 175

A.25 Wave 16 incident and reflected spectra from wave gages 176

A.26 Wave 17 incident and reflected spectra from wave gages 177

A.27 Wave 18 incident and reflected spectra from wave gages 178

A.28 Wave 19 incident and reflected spectra from wave gages 179

A.29 Wave 20 incident and reflected spectra from wave gages 180

A.30 Wave 21 incident and reflected spectra from wave gages 181

A.31 Wave 22 incident and reflected spectra from wave gages 182

A.32 Wave 23 incident and reflected spectra from wave gages 183

A.33 Wave 24 incident and reflected spectra from wave gages 184

A.34 Wave 25 incident and reflected spectra from wave gages 185

A.35 Wave 26 incident and reflected spectra from wave gages 186 


\section{LIST OF TABLES}

$2.1 \quad$ Experimental Plans for Incipient Motion Experiments .............. 14

2.2 Ranges of Measured Physical Quantities and Common Dimensionless

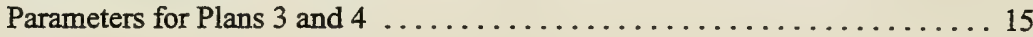

2.3 Summary of Convection Measurement Experiment Results with $\cot \theta=2$,

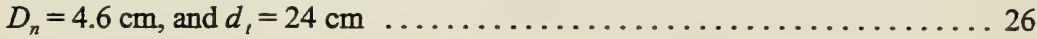

2.4 Summary of Incipient Motion Experimental Results $\ldots \ldots \ldots \ldots \ldots \ldots$

3.1 Jackson (1968) Breakwater Damage from Table 7.9 of SPM (1984) ...... 45

4.1 Experimental Conditions for Initial Damage Experiment $\ldots \ldots \ldots \ldots \ldots 57$

4.2 Wave Generation in Initial Damage Experiment .................. 63

4.3 Nearshore Wave Statistics for Incident Spectra and Related Parameters with Structure in Place . . . . . . . . . . . . . . . . . . . . . . . . 68

4.4 Nearshore Wave Statistics for Incident Time Series and Related Parameters with Structure in Place . . . . . . . . . . . . . . . . . . . . . . 69

5.1 Summary of Test Series for Initial Damage Experiment ............ 81

6.1 Depth-Limited Wave Damage Data from Van der Meer (1988) ........ 119

7.1 Summary of Test Series for Damage Experiments $\ldots \ldots \ldots \ldots \ldots \ldots \ldots$

7.2 Summary of Incident Wave Characteristics $\ldots \ldots \ldots \ldots \ldots \ldots \ldots \ldots \ldots \ldots$

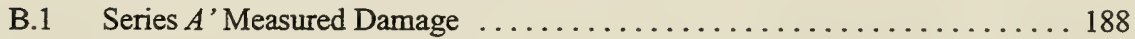

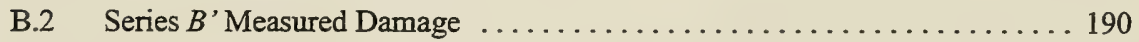

B.3 Series $C^{\prime}$ Measured Damage $\ldots \ldots \ldots \ldots \ldots \ldots \ldots \ldots \ldots \ldots \ldots \ldots \ldots \ldots \ldots \ldots$ 


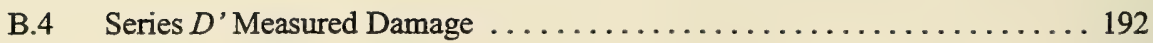

B.5 Series $E^{\prime}$ Measured Damage $\ldots \ldots \ldots \ldots \ldots \ldots \ldots \ldots \ldots \ldots \ldots \ldots \ldots \ldots \ldots \ldots$

B.6 Series $F^{\prime}$ Measured Damage $\ldots \ldots \ldots \ldots \ldots \ldots \ldots \ldots \ldots \ldots \ldots \ldots \ldots \ldots \ldots \ldots \ldots$

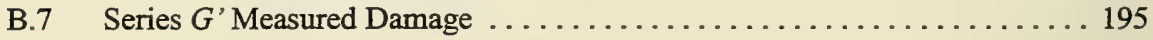




\section{Preface}

Funding for work discussed in this report was provided by the Coastal Navigation and Damage Reduction Program (CNSDR), which is part of the Civil Works Research and Development Program, Headquarters, U.S. Army Corps of Engineers (HQUSACE). The research was funded directly by CNSDR Work Unit 32792, "Reliability-Based Design and Evaluation of Coastal Rubble Structures" at the Coastal and Hydraulics Laboratory (CHL) of the U.S. Army Engineer Waterways Experiment Station (WES), Vicksburg, MS, a complex of five laboratories of the U.S. Army Engineer Research and Development Center (ERDC). The CHL was formed in October 1996 with the merger of the WES Coastal Engineering Research Center and the Hydraulics Laboratory. Dr. James R. Houston was the Director of the CHL, and Mr. Charles C. Calhoun, Jr. (retired), was the Assistant Director.

The CNSDR Coordinator was Mr. David Mathis, Directorate of Research and Development, HQUSACE. Messrs. John Bianco, Barry Holliday, and Charles Chesnutt served as HQUSACE Program Monitors. Ms. Carolyn Holmes, CHL, was the Program Manager. Dr. Jeffrey A. Melby, CHL, was the Principal Investigator of Research Work Unit 32792.

The studies were done under the direct supervision of Mr. C. Gene Chatham, Jr., Chief, Navigation and Harbors Division, and Mr. D. D. Davidson (retired), Chief, Coastal Structures Branch, CHL. Mr. Davidson and Dr. Steven A. Hughes, CHL, provided technical review of this report.

This report is a dissertation in partial fulfillment of the requirements for the degree of Philosophy from the University of Delaware, Newark, DE. The author would like to thank Professor Nobuhisa Kobayashi, University of Delaware, for serving as chairman of his dissertation committee and for his tireless contributions to the research reported herein. Further, the author would like to thank other members of his dissertation committee: Professors Tony Dalrymple, Richard Garvine, and Michael Chajes, all of the University of Delaware. The author gratefully acknowledges and commends the efforts of Messrs. John Winkelman, U.S. Army Engineer District, San Francisco, and Willie Dubose, $\mathrm{CHL}$ in this project. Mr. Winkelman was directly involved with planning the 
study and designed the automated profiler as partial fulfillment of an M.S. degree in engineering from the University of Rhode Island. Mr. Dubose conducted much of the experimental program.

At the time of publication of this report, Commander of ERDC was

COL Robin R. Cababa, EN. This report was prepared and published at the WES complex of ERDC.

The contents of this report are not to be used for advertising, publication, or promotional purposes. Citation of trade names does not constitute an official endorsement or approval of the use of such commercial products. 


\section{Chapter 1}

\section{INTRODUCTION}

This thesis addresses the stability of coastal rubble mound stone armor layers exposed to water waves. The most common coastal rubble mounds are breakwaters, jetties, and revetments. Breakwaters usually have a large part of their length oriented perpendicular to the direction of wave travel and their primary purpose is to produce a quiescent area in their lee for ship anchorage or beach sheltering. Jetties are usually oriented parallel to the direction of wave travel and are used to produce an artificial channel or inlet. This channel is usually an entrance to a harbor and is used for commercial or leisure water-craft navigation. Revetments typically armor coastal or riverside slopes that would otherwise erode when exposed to water waves. These waves could be a result of local or distant storms or they could be due to ship wakes.

Breakwater failure can occur due to a number of different failure modes. The dominant failure modes are shown in Figure 1. Of these, seaside armor stability on a traditional rubble mound is critical to the integrity and functionality of breakwaters and is therefore the focus of the present study. Breakwater stone-armor layer stability is unique from other structural design in that it is highly variable, and this variability is 


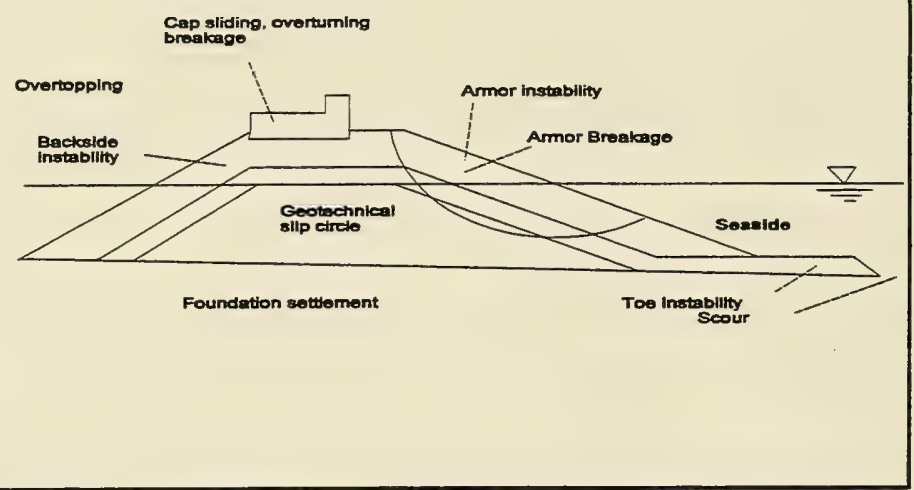

Figure 1.1. Breakwater failure modes

complex and difficult to quantify for the wide range and many permutations of the many variables involved. The variability is dependent on the stochastic nature of both the armor boundary conditions and loading. Boundary conditions are the points of contact underneath and between the armor stones. The boundary conditions are uncertain because of the irregular stone shape and stone placement. The geotechnical characteristics of the foundation are also often uncertain. The loading of engineering interest is primarily due to incident storm waves that vary with storm intensity and storm location. The impact of the waves varies with water level and local bathymetry. The local water level varies with tide and storm surge. Waves can dislodge armor units by uplifting, rolling, or sliding individual units or by causing en masse movement of the entire armor layer. Armor units can be dislodged from the upslope layer without jeopardizing the integrity of the armor layer. But if enough armor units move and the 
underlayer is exposed, then the breakwater can erode quickly. This structural integrity threshold is uncertain because damage, defined by the eroded volume, may be focused at a point or distributed over a broad area. Because the toe forms a foundation for the armor layer, if the toe armor is mobile, then the entire armor layer can mobile. How the armor layer responds to armor movement at the toe is quite variable.

The variability in both the loading and boundary conditions demands the consideration of the randomness of each stochastic parameter. Many clients, including the U.S. Army Corps of Engineers, now mandate that a risk analysis be done as part of major breakwater rehabilitation studies. This requirement is intended to provide a standardized engineering economic analysis technique for comparing competing alternatives. The engineering performance study that must form the basis of the risk analysis is often accomplished using a reliability analysis, where the reliability, or conversely, the probability of failure, is quantified for each alternative. In the reliability analysis, all alternatives that fall below a predefined level of reliability are either modified or discarded. For example, a breakwater may have several alternative armor layer designs including randomly-placed stone, pattern-placed stone, and randornlyplaced concrete armor units. Each of these alternatives will have a different associated cost and a different probability of failure for the design single storm or sequence of storms. Determining the probability of failure through instability of the armor layer requires knowledge of the rate of deterioration or the rate at which stones are displaced, which has not been quantified for breakwater armor layers. Reliability methods have 
only recently been adapted to breakwater design, and very little data exist to support prediction of rubble-mound deterioration. Despite the many hundreds, and perhaps thousands, of studies on breakwater armor stability, there have been few generalized studies of long-term deterioration of traditional rubble-mound armor layers. Moreover, there have been no generalized studies of deterioration due to variations in storm sequences using random waves. Finally, damage experiments to date have been primarily conducted with nonbreaking waves, which is atypical of many environments in which breakwaters are constructed.

The purpose of this study was to first identify the primary mechanisms of stone instability and damage development when the breakwater armor layer is exposed to depth limited, breaking waves. Chapter 2 discusses initiation of stone movement. A relation for predicting the initiation of stone movement when exposed to vertical uplift of normally-incident plunging breaking waves is presented in Chapter 2. The equation is verified using data from a small-scale two-dimensional flume physical model study. This portion of the research effort qualitatively addresses incipient motion of stone armor. This section includes the traditional development of a stability prediction equation and some insight into the effect of wave steepness on instability.

A primary goal of this study was to establish predictive relations for damage development on traditional breakwater sections for single storms and for storm sequences given depth-limited normally-incident waves. Chapter 3 introduces the subject with a discussion of historical stability and damage development physical model 
measurements and the relations derived from these past studies. In Chapter 4, a new flume study is discussed where breakwater profiles were measured as damage progressed on a breakwater cross section exposed to normally-incident depth-limited breaking waves. A new device for measuring breakwater profiles is discussed in some detail. New parameters are defined for prescribing the engineering characteristics of the eroded profile. In Chapter 5, measurements from this study are discussed in detail. In Chapter 6, profile and wave data are analyzed to produce spatial and temporal relations for predicting the mean and standard deviation of eroded area, eroded depth, eroded length, and remaining cover depth on a breakwater that is exposed to normally-incident depth-limited wave conditions. These equations should be valuable in support of reliability analyses as part of comprehensive risk analyses. 


\section{Chapter 2}

\section{INCIPIENT STABILITY OF BREAKWATER ARMOR UNITS}

\subsection{Armor Stability Equations}

Extensive research on breakwater armor stability has produced many empirical stability models. PIANC (1976) provides a summary of early stability models based on regular wave experiments. PIANC (1992) provides a discussion of more recent irregular-wave-based models. The most widely known empirical stability model was developed by Hudson $(1958,1959)$, following the pioneering work of Iribarren (1938) and is typically seen in the following form

$$
W=\frac{\gamma_{a} H^{3}}{K_{D}\left(S_{a}-1\right)^{3} \cot \theta}
$$

where

$$
\begin{aligned}
& W=\text { weight of armor unit } \\
& \gamma_{a}=\text { specific weight of armor unit material } \\
& H=\text { design wave height at structure toe } \\
& K_{D}=\text { tabulated empirical stability coefficient } \\
& S_{a}=\text { specific gravity of armor unit material } \\
& \theta=\text { seaside angle of armor slope relative to horizontal }
\end{aligned}
$$


Hudson also expressed this equation in a slightly different form as

$$
N_{s}=\left(K_{D} \cot \theta\right)^{1 / 3}=\frac{H}{\left(S_{a}-1\right) D_{n 50}}
$$

where $N_{s}$ is the dimensionless stability number and $D_{n 50}=\left(W_{50} / \gamma_{\mathrm{a}}\right)^{1 / 3}$ is termed the nominal stone diameter. Hudson did not use the nominal stone diameter variable. It was used by both Thomson and Shuttler (1976) and Van der Meer (1988) who noted that $D_{n 50}$ is the length of a side of a cube with volume equivalent to that of the median in the stone weight distribution. A glance at equations 2.1 and 2.2 shows that stone movement due to wave forcing, characterized by the wave height, is resisted primarily by the stone weight. As shown by Hudson (1958), Ahrens and McCartney (1975), Van der Meer (1988) and others, the wave shape, structure porosity, armor shape, and structure cross-sectional shape all affect the wave force. Hudson also noted that the resistance to movement is affected by the friction between armor units, stone shape, upslope armor layer weight, and armor slope. Equation 2.1 is preferable from a physical perspective because it maintains the inertial form of the forces, which is appropriate for armor stability. But equation 2.2 combines the stability coefficient with the structure slope, which is desirable because the stability coefficient is a function of the structure slope (e.g. Shore Protection Manual (SPM) 1984). This second form also presents the stone stability equation in a form that is similar to sediment transport formulae. This will be discussed further later in this chapter. 
In equation 2.2 , the stability number is a convenient scale for characterizing the incident wave height relative to armor stone size. It is typically in the range of 1 to 4 for stable or marginally stable rubble mound breakwaters (Van der Meer 1988). The SPM (1984) provides $K_{D}$ values for various armor layers at different slopes on breakwater trunks and heads exposed to breaking and nonbreaking waves. Zero-damage $K_{D}$ values are typically used corresponding to less than 2 percent by count, or five percent by volume, of the armor in a layer being displaced. Using this no-damage guidance from the SPM (1984), the stability number is in the range of 1 to 1.6 for angular stone armor layers at slopes of $1 \mathrm{~V}: 2 \mathrm{H}$ or steeper exposed to breaking waves. The SPM specifies $K_{D}$ values up to 2.2 for stone armor layers at slopes of $1 \mathrm{~V}: 3 \mathrm{H}$ exposed to nonbreaking waves. So for most stable coastal breakwaters, the stability number covers a narrow range from 1 to 2.5 . For deformable structures where the armor stone is expected to be mobile, such as S-shaped breakwaters and berm breakwaters, Van der Meer (1988) suggests $N_{s}=3-6$.

Hundreds of studies have been conducted to quantify the single empirical parameter $K_{D}$ in equation 2.1 for the wide variety of prototype conditions that might exist. Originally Hudson only explicitly included the effect of regular wave height, structure slope, and armor stone specific weight. Hudson found no clear effect of wave period on armor stability for the nonbreaking regular wave conditions he and his colleagues tested. They simply determined $K_{D}$ corresponding to the lowest stability condition over a range of typical wave periods. The Hudson equation has been 
extended to include the effects of irregular breaking and nonbreaking waves and wave period (Ahrens 1975, Ahrens and McCartney 1975, Carver and Wright 1991, SPM 1984), various armor layer types and armor gradation (e.g. SPM 1984), and number of waves (Medina and McDougal 1988).

Other regular-wave stability formulations that have been utilized in recent years include Hedar (1960, 1986), Ahrens and McCartney (1975), and Losada and Gimémenz-Curto (1979). Ahrens (1975), Ahrens and McCartney (1975), Losada and Gimémenz-Curto (1979), and Pilarczyk and Den Boer (1983) all showed dependence of wave period on stability number for regular waves. Each of these authors showed that minimum stability occurred for surf similarity numbers or Iribarren numbers between 2 and 4 , corresponding to plunging to collapsing breakers. The surf similarity number was defined as $\xi=\tan \theta /(H / L)^{1 / 2}$ where $\theta=$ structure slope, $H=$ regular wave height, and $L=$ local or deep water wave length. Thompson and Shuttler (1975) conducted an extensive series of irregular-wave armor stability experiments. Their conclusions on damage progression were insightful and are discussed in the next chapter. Using Thompson and Shuttler's data and data from his own experiments, Van der Meer (1988) developed a stability model which explicitly included wave period, structure permeability, storm duration and damage for a single design storm. The Hudson and Van der Meer equations will be discussed further in the following chapters. The above mentioned stability models predict minor damage reasonably well, although poor predictions are common. Pfeiffer (1991) compared the models of Hudson (1958), 
Hedar (1986), Losada and Gimémenz-Curto (1979), and Van der Meer (1988). Pfeiffer found that the Hudson equation and the Losada and Gimémenz-Curto equations performed the best when compared to field data, but none of the equations matched the prototype records all that well. Pfeiffer also noted that none of the stability models mentioned above are specifically suited for predicting extended damage.

\subsection{Armor Incipient Motion Studies}

The empirical stability models of Iribarren (1938), Hudson (1958), and others are based on a free body analysis of an armor unit undergoing forcing due to shallow-water waves. Early stability models assumed 1) the principal wave force was due to down- or up-rush on an unsheltered and unrestrained unit, 2) the wave force was drag dominant, and 3) the drag force would be critical if the maximum horizontal fluid velocity was used, which was considered to be proportional to the shallow-water incident wave celerity. But for an intact structure and prior to initiation of incipient motion, the armor units are typically partially hidden and restrained from up or down slope movement; so lift, inertia, and convection across the armor layer must be considered. Moreover, Sawaragi et al. (1982) showed that the maximum fluid velocity on a rubble mound was not necessarily proportional to the wave celerity. Sigurdsson (1962) made force measurements on armor composed of spheres set on extremely steep slopes with an impermeable underlayer and derived incipient equations of motion; but concluded by stating that the dominant mechanism of initiation of armor motion was still unknown and required further investigation. Although many authors have 
measured wave kinematics on armor layers and the resulting forces, including Mizutani et al. (1992), Torum and Van Gent (1992), Torum (1994), and Cornett and Mansard (1994), there have been few observations of incipient movement of armor units discussed in the literature. As such, the relationships between incipient motion, wave kinematics, and forces on armor units are still unknown.

Melby (1987) and McDougal et al. (1988) discussed a model for predicting the wave forces on dolos concrete armor units and the resulting incipient motion of a lone dolos in one of two orientations. Their model utilized linear wave theory and Morison forcing (Morison et al. 1950) with added mass coefficients for wave slamming from Kaplan and Silbert (1976) and Kaplan (1979). Kobayashi et al. (1990) presented a numerical model for predicting the displacement of armor on a traditional rubble mound. The shallow water wave model interacted with a permeable flow model and hydrodynamic drag, inertia, and lift forces were computed using a Morison formulation. The model was limited to forces parallel to the structure because only depth-averaged velocities were predicted by this one-dimensional model. Torum and Van Gent (1992) discussed a similar wave model and compared it to velocity measurements above a berm breakwater. Torum (1994) discussed the measurements further. Although twodimensional velocities were measured, vertical flow in the breaking wave was not modeled numerically. In addition, Torum noted that the inertial force was not well defined by the traditional inertia term of the Morison equation. Cornett and Mansard (1994) described an experiment where forces were measured on a panel of stones. This 
approach was unique and yielded insight into the average frictional force on sections of the armor layer. They found that the frictional force tending to dislodge armor units was greatest below the still water level and that the character of the force depended strongly on the type of wave breaking.

This chapter discusses a series of physical model experiments to identify and develop predictive models for breakwater armor incipient motion and to relate this motion to existing empirical stability relationships. The experiments were conducted in wave flumes at the Waterways Experiment Station in Vicksburg, Mississippi. The first experiment consisted of measuring wave-induced fluid velocities on and within the armor layer and runup/down. In addition, free surface oscillations were measured while observing armor motion on stone and Core-Loc armor. The observations from this early study led to an incipient motion experiment using a fixed-sphere armor layer with several loose spheres placed at various depths within the armor layer. A dominant incipient armor motion mode and predictive stability equation were verified.

\subsection{Experimental Setup}

The initial experiments were conducted to determine the nature of armor incipient motion and surrounding flow. The instrumentation included a laser Doppler velocimeter (LDV), high-resolution video, and runup and vertical free-surface-piercing gages near and within the armor layer. The experiments discussed in this chapter for

incipient motion were all carried out using regular monochromatic waves. Data analysis 
was performed on short segments of between five and ten uniform waves to develop clear relationships between wave parameters and armor motion.

The primary study was conducted in a $46-\mathrm{m}$ long by $0.46-\mathrm{m}$ wide by $1-\mathrm{m}$ deep flume, with an offshore slope of $1 \mathrm{~V}: 30 \mathrm{H}$ (Figure 2.1). A conventional rubble mound cross section was constructed with various seaward slopes and armor types (Figure 2.2). Table 2.1 lists the different test plans. In this thesis, only the sphere and stone armor plans will be discussed (Test Plans 3 and 4 ) in order to maintain continuity with the stone layer damage discussion in subsequent chapters. For Plans 3 and 4 , velocity measurements, sampled at $100 \mathrm{hz}$, were made throughout the water column from the toe to two armor dimensions above the still water level. The ranges of physical quantities and common dimensionless parameters for Plans 3 and 4 are listed in Table 2.2 .

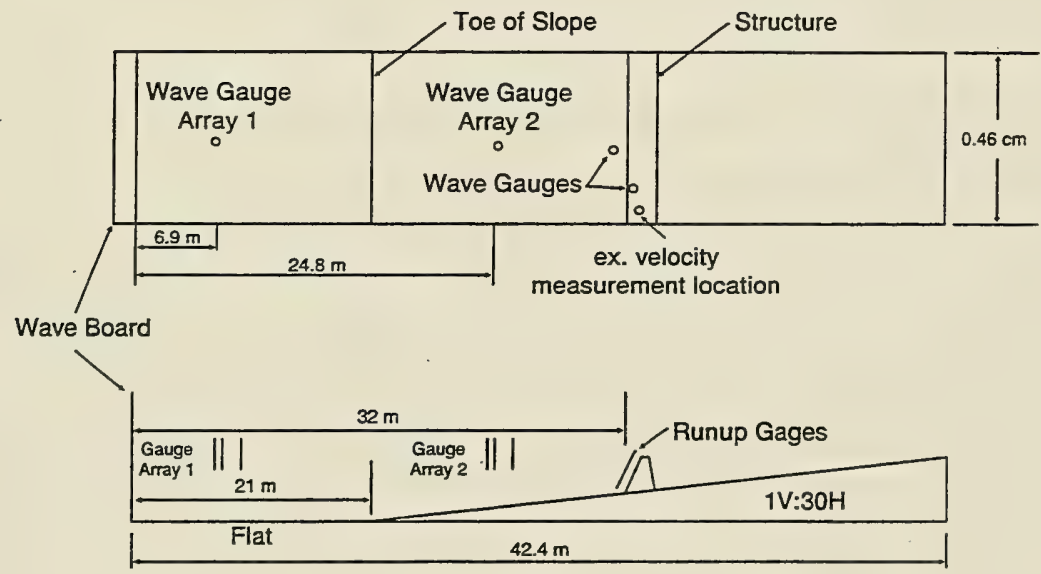

Figure 2.1. Flume plan (top) and profile (bottom) views for incipient motion experiment 
Sea Side $\quad \mid \stackrel{14 \mathrm{~cm}}{ } \quad$ Harbor Side

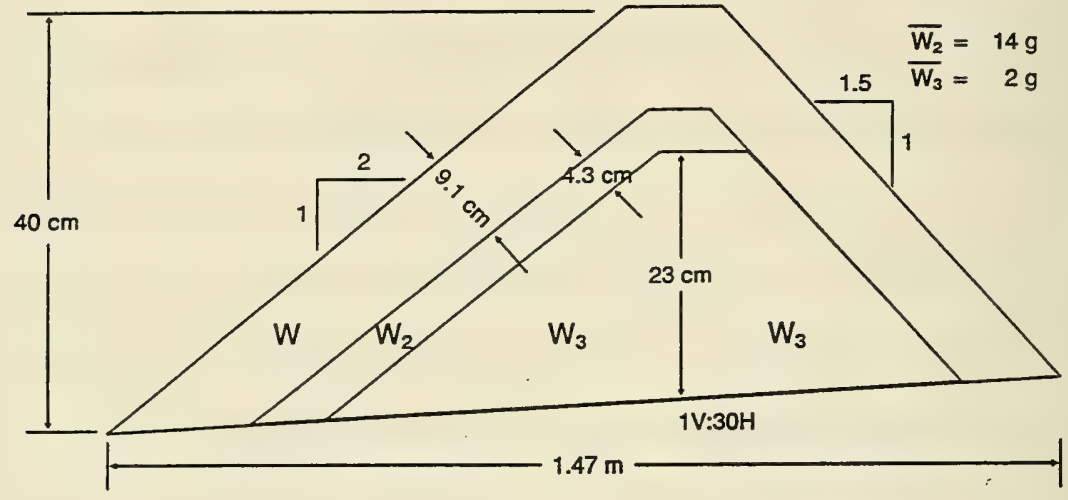

Figure 2.2. Definition sketch for typical structure profile

Table 2.1

Experimental Plans for Incipient Motion Experiments

\begin{tabular}{|c|c|c|c|c|c|c|c||}
\hline \hline Plan & $\begin{array}{c}\text { Armor } \\
\text { Type }\end{array}$ & $\begin{array}{c}\text { Armor } \\
\text { Weight } \\
\mathbf{W , g}\end{array}$ & $\begin{array}{c}\text { Nominal } \\
\text { Armor } \\
\text { Dia. } \\
\mathbf{D}_{\mathbf{n}}=(\mathbf{V})^{1 / 3} \\
\mathbf{c m}\end{array}$ & $\begin{array}{c}\text { Struc- } \\
\text { ture } \\
\text { Slope, } \\
\mathbf{c o t} \theta\end{array}$ & $\begin{array}{c}\text { Off- } \\
\text { shore } \\
\text { Slope } \\
\mathbf{c o t} \alpha\end{array}$ & $\begin{array}{c}\text { Runup } \\
\text { down } \\
\text { Meas. }\end{array}$ & $\begin{array}{c}\text { Force } \\
\text { Meas. }\end{array}$ \\
\hline \hline 1 & Core-Loc & 220 & 4.6 & 1.33 & 100 & no & no \\
\hline 2 & Core-Loc & 105 & 3.6 & 1.5 & 20 & no & no \\
\hline 3 & Stone & 200 & 4.6 & 2.0 & 30 & yes & no \\
\hline 4 & Sphere & 58 & 3.03 & 2.0 & 30 & yes & no \\
\hline 5 & Sphere & 212 & 5.6 & 2.0 & 30 & yes & yes \\
\hline
\end{tabular}




\begin{tabular}{|c|c|}
\hline \multicolumn{2}{|c|}{$\begin{array}{l}\text { Table } 2.2 \\
\text { Ranges of Measured Physical Quantities and Common Dimensionless } \\
\text { Parameters for Plans } 3 \text { and } 4\end{array}$} \\
\hline Parameter & Range \\
\hline Wave height at toe, $H_{t}$ & 2.4 to $18 \mathrm{~cm}$ \\
\hline Wave period, $T$ & 0.75 to $4.0 \mathrm{sec}$ \\
\hline Water depth at toe, $h_{f}$ & E5 to $24 \mathrm{~cm}$ \\
\hline $\begin{array}{l}\text { Wave steepness, } S_{z}=H_{t} / L_{0} \\
L_{0}=\text { deepwater wave length }\end{array}$ & 0.007 to 0.1 \\
\hline $\begin{array}{l}\text { Surf similarity parameter, } \xi=\tan \alpha /\left(H_{1} / L_{0}\right)^{1 / 2} \\
\tan \alpha=1 / 30=\text { beach slope }\end{array}$ & 0.1 to 1.4 \\
\hline $\begin{array}{l}\text { Surf similarity parameter, } \xi=\tan \theta /\left(H_{R} L_{0}\right)^{1 / 2} \\
\tan \theta=1 / 2=\text { structure slope }\end{array}$ & 1.5 to 21 \\
\hline Relative depth, $h_{\mathrm{f}} \Omega_{0}$ & 0.009 to 0.28 \\
\hline Relative wave height, $H_{t} / h_{t}$ & 0.06 to 0.88 \\
\hline
\end{tabular}

The LDV was a two-watt argon-ion two-component device assembled by the Dantec Corporation. Here, two-component describes the fact that the LDV measured velocities in two orthogonal directions. For this study, these directions were always vertically upward and horizontal, in the direction of wave propagation. The LDV worked in the back-scatter mode using a non-intrusive probe which contained both the emission and receiving optics. The benefits of this device included nonintrusive measurements, small measurement volume, clean drop-outs, high sampling rate, and no required calibration. Drop-outs were situations where there was no measurable backscattered signal (e.g. when the laser beams crossed at a point above water, after the wave crest had passed and the probe was above the level of the wave trough). During a drop-out, the LDV would produce a constant signal at the last measured value. Because 
only the peak measured velocity values were used herein, drop-outs did not pose a particular problem.

For this experiment, the LDV probe was pointed through the glass flume wall into the voids within the armor layer and measurements were made of the internal flow within the porous media. Many of the voids between armor units were more than a nominal armor diameter deep, so measurements could be made outside the flume wall boundary layer. One drawback to the LDV was the requirement of a full time operator with continuous attention to detail. Also, because of the small measurement volume, small changes in measurement location in the sheltered region behind a stone or within the armor layer often yielded large variations in measured average peak velocities. Therefore, the instrument required many measurements to map the flow field. So data analysis requirements were substantial for this experiment.

The wave heights were determined using free surface measurements from a vertical capacitance-type gage positioned at the location of the structure toe with no structure in place. Synthetic rubberized horse-hair mats were placed landward of the structure location to absorb the waves. The sampling rate for free surface measurements was $20 \mathrm{hz}$. The zero-downcrossing wave height was computed as the average height from a burst of approximately ten regular waves. 


\subsection{Incipient Motion Observations}

Several dominant incipient motion modes were identified during the stone stability experiment in Plan 3, Table 2.1. The following descriptions pertain to initial armor motion on an intact, as-built structure. Rolling was the only mode of motion for stones on the toe. Although both onshore and offshore motion was observed, the toe units always moved out of the layer in the onshore direction. Armor near the still water level was more likely to displace than armor in other areas. This appeared to be due to the fact that the armor was loosened in this area due to high velocities in the breaking wave jet. Once loosened, the motion would depend on the armor shape and its position. If the armor shape was flat, then the armor unit would flop back and forth until it rolled out of the armor layer, generally rolling upslope during uprush. If the armor shape was rounded, which was normally the case, the armor units would jump vertically under the steep wave face if the wave was severely plunging or collapsing. If the wave was surging, then loose units would only be displaced if they were exposed. There did not appear to be sufficient lift in downrush or uprush flows along the armor layer to displace the stones unless they were odd shaped (flat). The only displacement mechanism observed for rounded stones sufficiently hidden in the armor layer was uplift under the steep wave face.

These observations indicated that a fluid velocity or acceleration component in the vertical direction is normally required to initiate armor motion for hidden armor units. Additionally, this early qualitative study indicated that, for a given wave height, 
incipient motion was primarily influenced by wave shape, stone position, stone exposure, and stone looseness.

\subsection{Experimental Measurements}

Throughout the experiments, vertical and horizontal wave velocities were measured in the vicinity of the armor layer. Figure 2.3 shows typical time series of the horizontal and vertical velocities on the structure measured for one run of plan 3 with the following characteristics: $\bar{H}_{t}=12 \mathrm{~cm}, \bar{T}=1 \mathrm{~s}, d_{t}=24 \mathrm{~cm}$, and $d_{L}=8.8 \mathrm{~cm}$, where $\ddot{H}_{t}$ is the average wave height measured at the toe, $\bar{T}$ is the average wave period, $d_{t}$ is the toe water depth, and $d_{L}$ is the depth of the laser measurement. The laser measurement was made $1 \mathrm{~cm}$ outside the armor layer, measured perpendicular to the outer armor layer profile line. The sign convention is such that the horizontal velocity is positive seaward while the vertical velocity is positive upward. Typically for these measurements, the horizontal velocity signal was considerably smoother than the vertical velocity signal, due primarily to the small amplitude of the vertical velocity relative to the horizontal velocity and the relatively large amount of turbulence near the armor layer. Figure 2.4 shows a velocity vector time series over one wave period, measured $1 \mathrm{~cm}$ outside the armor layer profile line for one run of plan 3 with the following characteristics: $\ddot{H}_{t}=8.4$ $\mathrm{cm}, \bar{T}=2 \mathrm{~s}, d_{t}=24 \mathrm{~cm}$, and $d_{L}=17 \mathrm{~cm}$. Also shown is the wave profile at the point of maximum vertical velocity. The plot shows a large vertical velocity just below the steep wave front. Observed maximum stone movement for this wave profile position is also shown. Figure 2.5 shows an example of vertical velocities outside and inside the armor 
layer. These measurements were also made during one run of plan 3 with the following characteristics: $\bar{H}_{t}=12 \mathrm{~cm}, \bar{T}=1 \mathrm{~s}, d_{t}=24 \mathrm{~cm}$, and $d_{L}=8.8 \mathrm{~cm}$ for the external measurement and $d_{L}=13 \mathrm{~cm}$ for the internal measurement. The measurement locations for these time series are shown in Figure 2.6, where the structure slope is $1 \mathrm{~V}: 2 \mathrm{H}$. Here it is clear that the velocities within the armor layer are highly irregular due to turbulence.

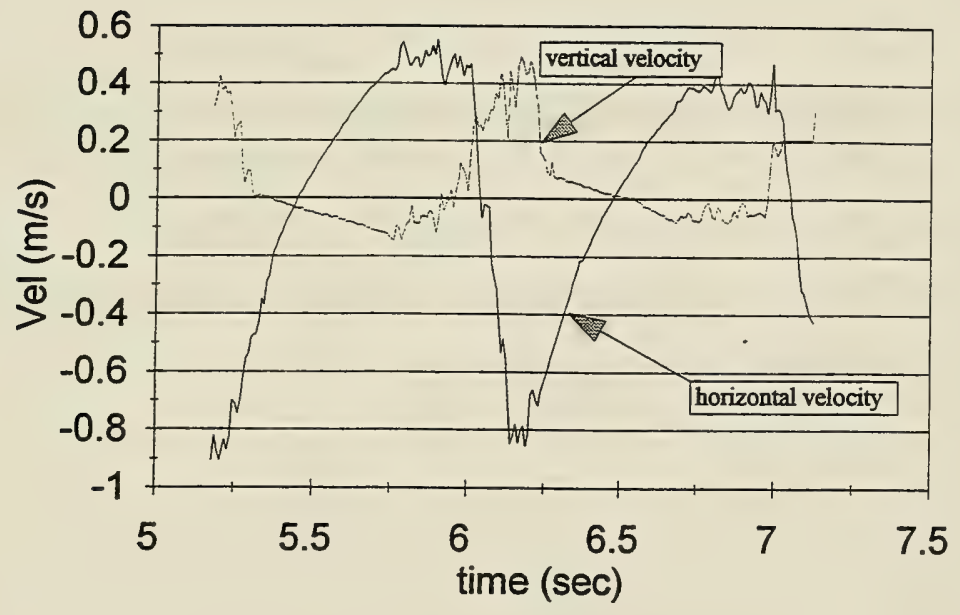

Figure 2.3. Velocity time series for one wave period with $\bar{H}_{t}=12 \mathrm{~cm}, \bar{T}=1 \mathrm{~s}, d_{t}=24 \mathrm{~cm}$ and $d_{L}=8.8 \mathrm{~cm}$ measured $1 \mathrm{~cm}$ outside the armor layer 


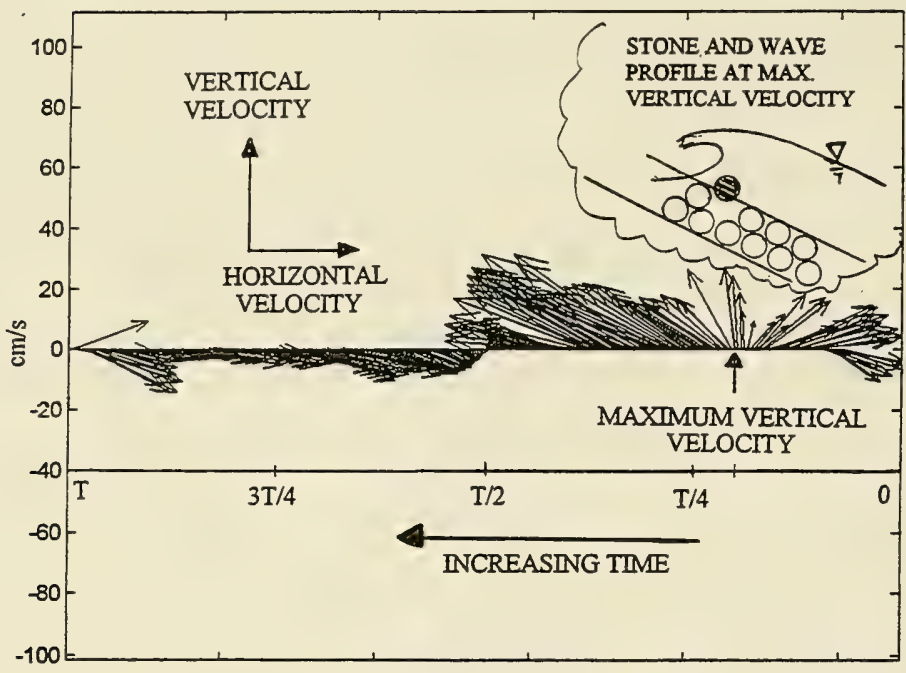

Figure 2.4. Velocity vector for one wave period for armor lifting measured $1 \mathrm{~cm}$ outside the armor layer with $\bar{H}_{t}=8.4 \mathrm{~cm}, \bar{T}=2 \mathrm{~s}, d_{t}=24 \mathrm{~cm}$, and $d_{L}=17 \mathrm{~cm}$
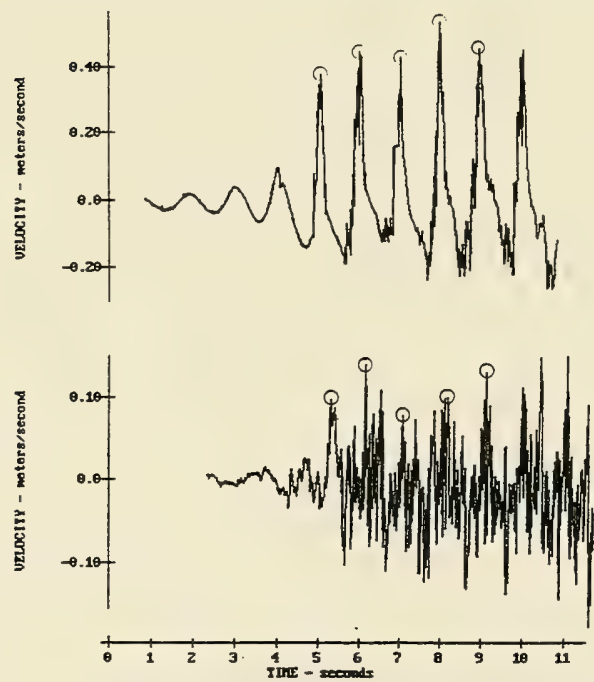

Figure 2.5. Vertical velocity time series outside (top) and inside (bottom) armor layer with $\tilde{H}_{t}=12 \mathrm{~cm}, \bar{T}=1 \mathrm{~s}, d_{t}=24 \mathrm{~cm}$, and $d_{L}=8.8 \mathrm{~cm}$ for the outer measurement and $d_{L}$ $=13 \mathrm{~cm}$ for the inner measurement 


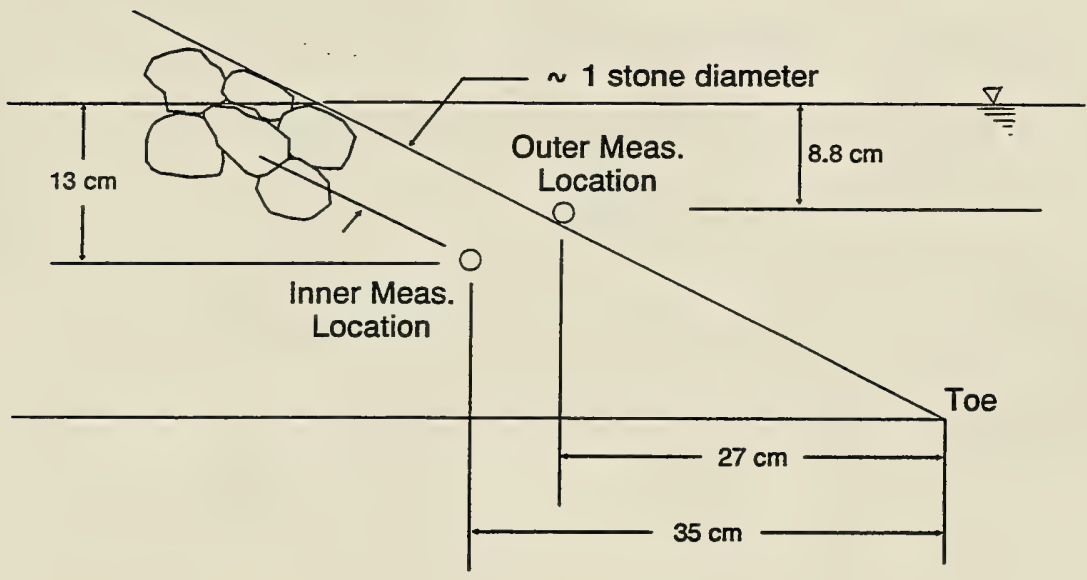

Figure 2.6. Measurement locations for vertical velocities shown in Figure 2.5

Figure 2.7 shows a typical plot of vertical velocity $v_{\mathrm{L} / 3} /\left(g \mathrm{H}_{t}\right)^{1 / 2}$, measured 1 $\mathrm{cm}$ outside the armor layer at various depths, versus the square root of wave steepness, where $v_{1 / 3}$ is the average of the highest one-third peak velocities for the burst of regular waves, $g=$ gravitational acceleration, structure slope $=1 \mathrm{~V}: 2 \mathrm{H}$, and $L_{o}=$ deep water wave length. For simplicity, $v$ is used instead of $v_{1 / 3}$ in Figure 2.7 and hereafter. Relative laser depth, $r d=d_{L} / d_{t}$, is the ratio of the depth of the laser to the depth at the toe, measured from the still water level. As noted by Sawaragi et al. (1982), maximum non-dimensional velocities commonly occurred for collapsing to plunging breaking waves. Pilarczyk and Den Boer (1983) showed minimum stability for 1V:2H slope occurred for $\xi=3.3$. In this case, this point occurs at $\left(H / L_{o}\right)^{1 / 2}=0.15$, which is near the 
maximum measured velocity for the waves with $\bar{T}=2 \mathrm{~s}$. The peak vertical velocities for given wave period decreased with increase of $r d$ in this figure.

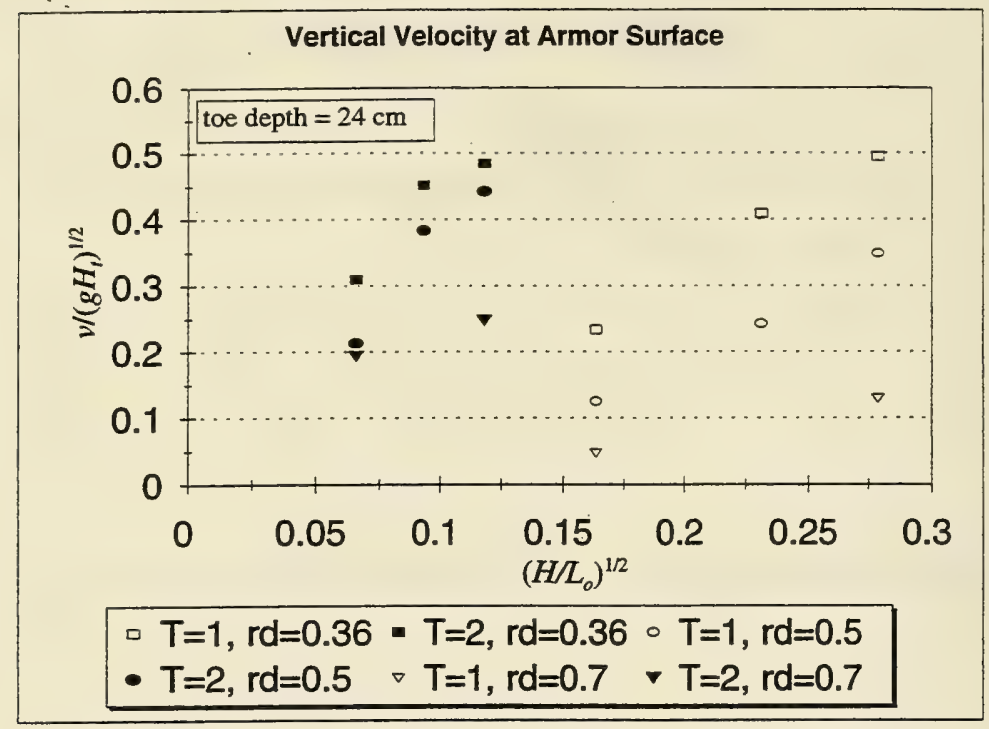

Figure 2.7. Maximum vertical velocity versus the square root of wave steepness for wave periods $\bar{T}=1$ and $2 \mathrm{~s}$ and relative depths $r d=0.36,0.5$, and 0.7

\subsection{Incipient Motion Prediction}

The previous experimental results indicated that one of the dominant incipient motion modes was due to the vertical force occurring under the steep wave front. The balance of forces for vertical incipient armor motion with no external restraints yields the equality between the submerged armor weight and the vertical fluid force; $W^{\prime}=F_{v}$. The vertical force at the steep wave front can be described by the Morison equation (Morison et al. 1950). 


$$
F_{v}=\frac{\rho}{2} A C_{D} v^{2}+\rho V C_{m} \frac{d v}{d t}
$$

where $\rho=$ fluid density, $A=$ cross sectional area of armor unit in direction of flow, $C_{D}=$ drag coefficient, $v=$ peak vertical velocity just above the armor layer as plotted in Figure 2.7, $V=$ armor unit volume, $C_{m}=$ inertia coefficient, and $d v / d t=$ total fluid acceleration. The drag force, the first term on the right side of Equation 2.3, can be expressed as a function of the armor nominal diameter, $D_{n}$, by introducing an armor shape factor, $K_{A}$, as follows

$$
A=K_{A} D_{n}^{2}
$$

The drag force in Equation 2.3 is then given by

$$
F_{D}=\rho D_{n}^{2} C_{D}^{\prime} v^{2} ; C_{D}^{\prime}=\frac{K_{A} C_{D}}{2}
$$

where the nominal diameter was previously defined as

$$
D_{n}=V^{1 / 3}=\left(\frac{W}{\gamma_{r}}\right)^{1 / 3}
$$

where $W=$ armor weight and $\gamma_{\mathrm{r}}=$ armor specific weight.

At the point of maximum vertical fluid velocity, the local vertical fluid acceleration, $\partial v / \partial t$, and horizontal velocity, $u$, are negligible. As such, the total acceleration reduces to a convective term. 


$$
\left(\frac{d v}{d t}\right)_{\max }=\left(\frac{\partial v}{\partial t}+u \frac{\partial v}{\partial x}+v \frac{\partial v}{\partial y}\right)_{\max } \approx v \frac{\partial v}{\partial y}
$$

where $x=$ horizontal coordinate and $y=$ vertical coordinate. If we assume the convective acceleration across the armor layer to vary linearly vertically, then the acceleration can be expressed as

$$
\left(\frac{d v}{d t}\right)_{\max } \approx v \frac{\partial v}{\partial y}=K_{c} \frac{v^{2}}{D_{n}}
$$

where $K_{c}$ is an empirical coefficient of order unity. The maximum inertial fluid force in Equation 2.3 can thus be reduced to

$$
F_{i}=\rho D_{n}^{2} C_{m}^{\prime} v^{2}
$$

with

$$
C_{m}^{\prime}=K_{c} C_{m}
$$

Substituting Equations 2.5 and 2.9 into the stability criterion $W^{\prime}=F_{v}$ with $W^{\prime}=\rho g\left(S_{r^{-}}\right.$ 1) $D_{n}^{3}$ yields a stability relation in form similar to Shields criterion (e.g. Raudkivi 1990) for the initiation of motion of sediment particles

$$
\frac{v_{c}^{2}}{D_{n} g\left(S_{r}-1\right)}=\left(C_{D}^{\prime}+C_{m}^{\prime}\right)^{-1}
$$


where $S_{r}=$ armor specific gravity, $g=$ acceleration of gravity, and $v_{c}=$ critical vertical velocity at which armor just begins to lift. In terms of $N_{s}$ from Equation 2.2, Equation 2.11 becomes

$$
N_{s}=\frac{H_{c}}{D_{n}\left(S_{r}-1\right)}=\frac{g H_{c}}{v_{c}^{2}}\left(C_{D}^{\prime}+C_{m}^{\prime}\right)^{-1}
$$

where $H_{c}=$ critical wave height at toe. It is interesting to note that the stability number is primarily a function of the Froude number, $v_{c} /\left(g H_{c}\right)^{1 / 2}$. This formula ties the traditional stability relations to local vertical velocity measurements.

Based on results of detailed velocity measurements in the interior and just outside the armor layer, the vertical velocity gradient was found to be proportional to the ratio of the vertical velocity and the armor diameter, as assumed in Equation 2.8. The empirical convection coefficient is $K_{c}=0.90$ for this experiment. This is shown in Figure 2.8 for a group of experiments summarized in Table 2.3. All experiments listed in Table 2.3 were conducted with a seaward slope of $1 \mathrm{~V}: 2 \mathrm{H}, D_{n}=4.6 \mathrm{~cm}$, and $d_{t}=24$ $\mathrm{cm}$. The velocity values are positive peaks from the aligned inner and outer vertical velocity time series. In Table 2.3 , the velocity gradient $\Delta v / \Delta y=\left|\left(v_{o}-v_{i}\right) /\left(y_{0}-y_{i}\right)\right|$, where $v_{o}=$ outer peak velocity, $v_{i}=$ inner peak velocity, $y_{i}=$ inner velocity measurement elevation, $y_{o}=$ outer velocity measurement elevation. 


\section{Table 2.3}

Summary of Convection Measurement Experiment Results with $\cot \theta=2$, $D_{n}=4.6 \mathrm{~cm}$, and $d_{t}=24 \mathrm{~cm}$.

\begin{tabular}{|c|c|c|c|c|c|c|c|c|}
\hline $\begin{array}{c}\text { Measure- } \\
\text { ment } \\
\text { Location }\end{array}$ & $\begin{array}{c}\text { Wave } \\
\text { Height } \\
\text { cm }\end{array}$ & $\begin{array}{c}\text { Wave } \\
\text { Period } \\
\text { s }\end{array}$ & $\begin{array}{c}\text { Outer } \\
\text { Laser } \\
\text { Depth } \\
\text { cm }\end{array}$ & $\begin{array}{c}\text { Outer } \\
\text { Velocity } \\
v_{0} \\
\mathrm{~cm} / \mathrm{s} \\
\end{array}$ & $\begin{array}{c}v_{0} / D_{n} \\
1 / s\end{array}$ & $\begin{array}{c}\text { Inner } \\
\text { Laser } \\
\text { Depth } \\
\text { cm }\end{array}$ & $\begin{array}{c}\text { Inner } \\
\text { Velocity } \\
v_{i} \\
\mathrm{~cm} / \mathrm{s} \\
\end{array}$ & $\begin{array}{c}\Delta v / \Delta y \\
1 / s\end{array}$ \\
\hline $\begin{array}{l}\text { near free } \\
\text { surface }\end{array}$ & 7.3 & 0.75 & 1.58 & $\begin{array}{l}23.6 \\
10.0 \\
29.1 \\
25.0 \\
21.6 \\
37.3 \\
27.3 \\
\end{array}$ & $\begin{array}{l}5.14 \\
2.17 \\
6.32 \\
5.44 \\
4.68 \\
8.10 \\
5.93 \\
\end{array}$ & 5.54 & $\begin{array}{c}10.0 \\
6.0 \\
12.5 \\
10.7 \\
7.0 \\
8.0 \\
12.0 \\
\end{array}$ & $\begin{array}{l}3.44 \\
1.01 \\
4.19 \\
3.61 \\
3.67 \\
7.39 \\
3.85 \\
\end{array}$ \\
\hline \multirow{6}{*}{$\begin{array}{l}\text { one-third } \\
\text { of depth }\end{array}$} & 4.6 & 1.0 & 8.59 & $\begin{array}{l}14.0 \\
21.0 \\
18.0 \\
18.0 \\
13.0 \\
\end{array}$ & $\begin{array}{l}3.04 \\
4.57 \\
3.91 \\
3.91 \\
2.83 \\
\end{array}$ & 12.55 & $\begin{array}{c}10.0 \\
7.5 \\
12.5 \\
14.0 \\
11.5 \\
\end{array}$ & $\begin{array}{l}1.01 \\
3.41 \\
1.39 \\
1.01 \\
0.38 \\
\end{array}$ \\
\hline & 13 & 1.0 & 8.59 & $\begin{array}{l}43.2 \\
49.2 \\
47.6 \\
57.3 \\
50.0 \\
\end{array}$ & $\begin{array}{c}9.40 \\
10.69 \\
10.34 \\
12.46 \\
10.87 \\
\end{array}$ & 12.55 & $\begin{array}{l}13.5 \\
17.2 \\
11.5 \\
13.7 \\
16.7 \\
\end{array}$ & $\begin{array}{c}7.51 \\
8.08 \\
9.10 \\
11.00 \\
8.39 \\
\end{array}$ \\
\hline & 2.8 & 2.0 & 8.59 & $\begin{array}{l}12.5 \\
16.5 \\
19.0 \\
18.0 \\
14.0\end{array}$ & $\begin{array}{l}2.72 \\
3.59 \\
4.13 \\
3.91 \\
3.04\end{array}$ & 12.55 & $\begin{array}{c}9.0 \\
10.0 \\
8.0 \\
8.5 \\
8.0\end{array}$ & $\begin{array}{l}0.88 \\
1.64 \\
2.78 \\
2.40 \\
1.51\end{array}$ \\
\hline & 8.4 & 2.0 & 8.59 & $\begin{array}{l}50.0 \\
46.0 \\
48.0 \\
50.0 \\
45.0 \\
\end{array}$ & $\begin{array}{c}10.87 \\
10.00 \\
10.43 \\
10.87 \\
9.78 \\
\end{array}$ & 12.55 & $\begin{array}{c}7.0 \\
10.0 \\
15.0 \\
16.0 \\
14.0 \\
\end{array}$ & $\begin{array}{c}10.85 \\
9.09 \\
8.33 \\
8.58 \\
7.82 \\
\end{array}$ \\
\hline & 5.5 & 3.0 & 8.59 & $\begin{array}{l}26.0 \\
29.0 \\
31.0 \\
28.0 \\
28.0\end{array}$ & $\begin{array}{l}5.65 \\
6.30 \\
6.74 \\
6.09 \\
6.09 \\
\end{array}$ & 12.55 & $\begin{array}{c}9.0 \\
9.0 \\
8.0 \\
10.0 \\
12.0 \\
\end{array}$ & $\begin{array}{l}4.29 \\
5.05 \\
5.80 \\
4.54 \\
4.04 \\
\end{array}$ \\
\hline & 4.3 & 4.0 & 8.59 & $\begin{array}{l}22.0 \\
18.0 \\
20.0 \\
17.0 \\
18.0\end{array}$ & $\begin{array}{l}4.78 \\
3.91 \\
4.35 \\
3.70 \\
3.91\end{array}$ & 12.55 & $\begin{array}{c}9.0 \\
8.0 \\
10.0 \\
9.0 \\
7.0\end{array}$ & $\begin{array}{l}3.28 \\
2.52 \\
2.52 \\
2.02 \\
2.78\end{array}$ \\
\hline
\end{tabular}




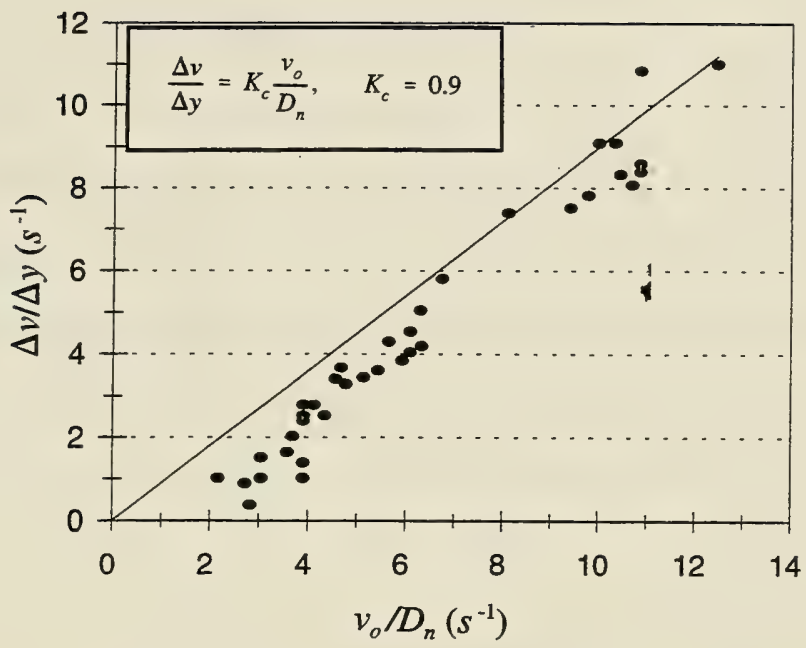

Figure 2.8. Vertical variation of vertical velocity under a steep wave front across the armor layer as a function of wave steepness

The drag and inertia coefficients can be more accurately defined if we assume spherical armor. Based on previous studies of forces on armor by Mizutani et al. (1992) and Torum (1994), reasonable estimates for drag and inertia coefficients are $C_{D}=0.8$ and $C_{m}=0.4$ yielding

$$
\begin{aligned}
& C_{D}^{\prime}=\frac{K_{A} C_{D}}{2} \approx 0.5 \quad\left(K_{A}=1.21\right) \\
& C_{m}^{\prime}=K_{c} C_{m} \approx 0.36 \quad\left(K_{c}=0.90\right)
\end{aligned}
$$

where $K_{A}=1.21$ corresponds to a sphere. The critical vertical velocity, $v_{c}$, for the incipient vertical armor movement reduces to 


$$
\frac{v_{c}^{2}}{D_{n} g\left(S_{r}-1\right)}=1.2
$$

where the critical vertical velocity, $v_{c}$, depends on the nominal diameter, $D_{n}$, and the specific gravity, $S_{r}$, only, for a loose armor unit. So, if the vertical velocity exceeds this critical velocity, motion of the sphere should occur. At the point of incipient motion, this critical condition can be expressed as

$$
v=v_{c}=\sqrt{1.2 D_{n} g\left(S_{r}-1\right)}
$$

Plan 4 in Table 2.1 was designed to test the above criterion. For Plan 4, the armor layer was constructed using silicon rubber spheres which were glued together and attached to an inflexible yet porous metal mat. The metal mat was placed directly on the underlayer and fixed to the flume walls. Several loose concrete spheres were placed in the armor layer along a line from above the still water level down to the toe. Each two loose spheres were separated by two glued spheres so that there was no interaction between loose spheres. The sphere layer of Plan 4 was constructed to have the minimum porosity of a sphere layer of 0.33 .

For Plan 4, the loose spheres would not move under any conditions unless they were slightly raised in the armor layer. This was accomplished by placing a 0.5 cm-thick spacer under each sphere. The primary effect of this was to raise the porosity 
surrounding the loose sphere, providing a path for water motion under the sphere. The only motion observed for the raised loose spheres was vertical motion under the steep wave front, following a slightly elliptical path, and landing back in their hole after the wave front passed. For tests with vertical velocities corresponding to the critical value, the spheres were just lifting off. For the larger vertical velocities, the spheres were lifting entirely out of their initial holes, but settling back into their holes. This sphere motion under the breaking wave is shown in the sequence of photographs in Figure 2.9. The sphere in motion is just left of the black rectangle on the right side of the photograph.

In the incipient motion experiment, spheres at a depth of one-third the toe depth were the most mobile while spheres at the still water level were somewhat less mobile. This movement corresponded to the variation of the vertical velocities in the water column as shown in Figure 2.6. Figure 2.10 shows the incipient motion criterion of Equation 2.16 versus wave steepness for Plan 4 using a few representative points from each motion category as summarized in Table 2.4. For this figure $v_{c}=61.8 \mathrm{~cm} / \mathrm{s}$ computed using Equation 2.16 with $D_{n}=3.03 \mathrm{~cm}, S_{r}=2.083$, and $\mathrm{g}=980.6 \mathrm{c} n / \mathrm{s}$. The dark horizontal line represents the theoretical incipient motion criteria while the velocity measurements are represented by the dark dots. Observed movement is noted for each data point. The vertical gaps between the lifting group of points and the stationary and rolling groups occurred because the vertical velocity increased dramatically under the steep breaking wave face. Therefore, it was difficult to get a continuous set of points 
over the entire range of $v / v_{c}$ ratios. For the drag and inertia coefficients selected, the incipient motion criteria agrees reasonably well with the observed movement.
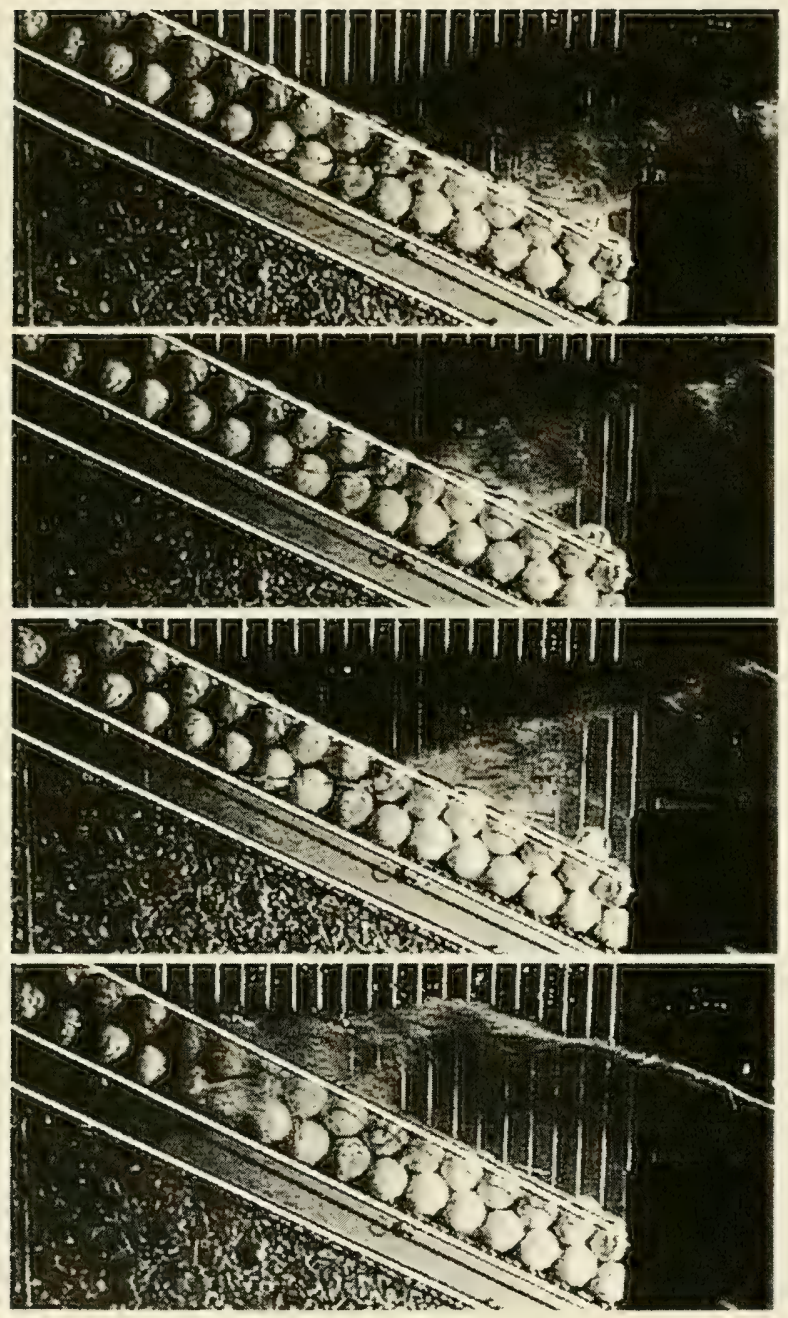

Figure 2.9. Photographs of sphere motion during a typical incipient motion experiment for Plan 4 


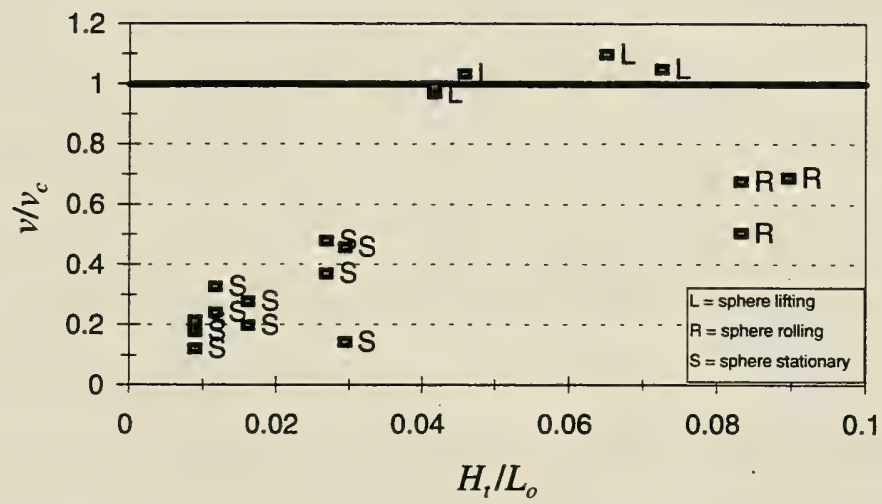

Figure 2.10. Incipient motion criterion (Equation 2.16 with $v_{c}=61.8 \mathrm{~cm} / \mathrm{s}$ ) versus wave steepness

\begin{tabular}{|c|c|c|c|c|c|}
\hline \multicolumn{6}{|c|}{$\begin{array}{l}\text { Table } 2.4 \\
\text { Summary of Incipient Motion Experimental Results }\end{array}$} \\
\hline $\begin{array}{c}\text { Sphere } \\
\text { depth } \\
\text { cm }\end{array}$ & $\begin{array}{c}\text { Wave } \\
\text { Height } \\
\mathrm{cm}\end{array}$ & $\begin{array}{c}\text { Wave } \\
\text { Period } \\
\mathbf{s} \\
\end{array}$ & $\begin{array}{c}\text { Wave } \\
\text { Steep- } \\
\text { ness } \\
H_{t} / L_{0} \\
\end{array}$ & $\begin{array}{c}\text { Velocity } \\
v \\
\mathrm{~cm} / \mathrm{s} \\
\end{array}$ & $v / v_{c}$ \\
\hline $\begin{array}{c}\text { near free } \\
\text { surface } \\
d_{i} / d_{t}=0.16\end{array}$ & $\begin{array}{c}4.6 \\
13.0 \\
2.8 \\
8.4 \\
5.5 \\
7.6 \\
14.0 \\
15.2 \\
17.0 \\
14.3 \\
13.0\end{array}$ & $\begin{array}{l}1.0 \\
1.0 \\
2.0 \\
2.0 \\
3.0 \\
3.0 \\
1.0 \\
1.5 \\
1.5 \\
2.0 \\
2.0 \\
\end{array}$ & $\begin{array}{l}0.029 \\
0.083 \\
0.009 \\
0.027 \\
0.012 \\
0.016 \\
0.090 \\
0.065 \\
0.073 \\
0.046 \\
0.042\end{array}$ & $\begin{array}{l}28.3 \\
41.8 \\
11.0 \\
29.6 \\
20.2 \\
17.2 \\
42.5 \\
67.8 \\
64.9 \\
63.8 \\
59.8 \\
\end{array}$ & $\begin{array}{l}0.46 \\
0.68 \\
0.18 \\
0.48 \\
0.33 \\
0.28 \\
0.69 \\
1.10 \\
1.05 \\
1.03 \\
0.97\end{array}$ \\
\hline $\begin{array}{l}\text { one-third of } \\
\text { depth } \\
d_{1} / d_{t}=0.38\end{array}$ & $\begin{array}{c}4.6 \\
13.0 \\
2.8 \\
8.4 \\
5.5 \\
7.6\end{array}$ & $\begin{array}{l}1.0 \\
1.0 \\
2.0 \\
2.0 \\
3.0 \\
3.0\end{array}$ & $\begin{array}{l}0.029 \\
0.083 \\
0.009 \\
0.027 \\
0.012 \\
0.016\end{array}$ & $\begin{array}{c}8.8 \\
31.3 \\
7.5 \\
22.9 \\
14.9 \\
12.3\end{array}$ & $\begin{array}{l}0.14 \\
0.51 \\
0.12 \\
0.37 \\
0.24 \\
0.20\end{array}$ \\
\hline
\end{tabular}




\subsection{Conclusions from Incipient Motion Study}

Experiments on incipient motion of breakwater armor showed several modes of displacement. One dominant mode was due to vertical wave forces which are shown to occur at the point of maximum vertical velocity under the steep wave front. A simple relation was derived assuming a Morison-like wave force balanced by the armor unit submerged weight. The wave force model was composed of drag, due to the maximum vertical velocities, and inertia, due to the vertical convective accelerations. The maximum vertical convective acceleration is shown to be roughly linearly related to the square of the velocity, which puts the inertial force term into the same form as the drag term. The resulting incipient motion stability relation is similar in form to the Shields sediment motion criteria. Further, when expressed as a traditional stability number, incipient motion is shown to be a function of the Froude number, $v /(g H)^{1 / 2}$. The incipient motion criterion shows promise in predicting the incipient motion of spheres for the conditions tested, but further experiments are required. This study provided some insight into how breaking waves can instigate armor motion and remove armor units from an intact armor layer. Further experiments were conducted using a highprecision force transducer to measure the forces on exposed spherical armor units. These measurements have not been analyzed completely and are not included herein. 


\section{Chapter 3}

\section{HISTORICAL DAMAGE MEASUREMENT AND DESCRIPTION}

\subsection{Damage Modeling Standards}

There is a substantial amount of literature concerning the measurement of damage on rubble-mound coastal structures. Hughes (1993) reviewed laboratory techniques for measuring damage. He noted three types of experiments for accumulated damage: (a) long-duration tests, (b) accumulated-storm-impacts tests, and (c) residualstability tests. There is overlap among these three and few standards appear to exist for these types of laboratory studies. Jensen (1984) noted that model storm duration should generally be specified to provide the equivalent of 8 to $10 \mathrm{hr}$ prototype. This is sufficient if equilibrium damage, where further waves cause no additional damage, occurs in this time; but if not, a subset of tests should be conducted to determine the ultimate damage level. Hughes stated that tests should be repeated at least two to four times to develop sufficient statistical certainty in the expected outcome with more extensive testing performed if the variance is large.

There are two dominant methods for damage measurement: (a) visual: counting the number of individual armor units that have been dislodged and moved more than one nominal diameter from their original location and (b) profile 
measurement: determining the eroded armor volume through profiling. A subset of the profiling method of characterizing damage, noted by Van der Meer (1988) for dynamic stability, is through description of the profile geometry. Torum et al. (1979) and Davies et al. (1994) described measurement of the minimum depth of cover, $d_{c}$ shown in Figure 3.1 , which is a reduction of the profile shape to a single parameter.

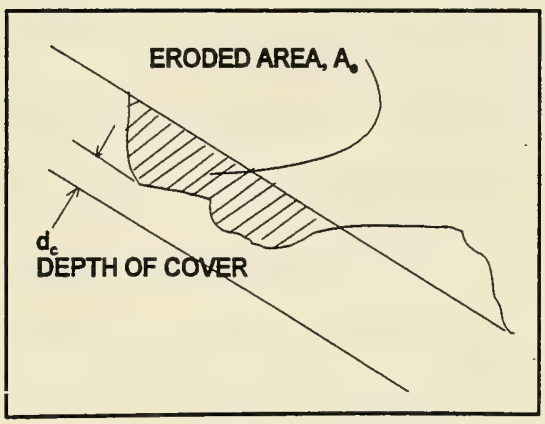

Figure 3.1. Sketch of breakwater profile with definition of eroded area and depth of cover

\subsection{Damage Measurement Methods}

\subsubsection{Eroded volume method}

The U.S. Army Engineer Waterways Experiment Station's (WES') historical method for characterizing damage utilized profiles to determine the percentage volume of stones eroded relative to the total volume of stones in the active armor layer. Hudson (1959) used this volume method. But the method apparently is 
not described in detail in any public references. As such, it will be described herein. In this volume method, the active armor layer was defined as extending from the middle of the breakwater crest to one zero-damage wave height below the still water level. The damage was determined through profiles using a sounding rod with a circular foot of diameter equal to $0.56 D_{n 50}$, where $D_{n 50}=\left(W_{50} / \gamma_{\mathrm{a}}\right)^{1 / 3}$ is the nominal diameter of the median stone weight, $W_{50}$, and $\gamma_{\mathrm{a}}$ is the specific weight of armor stone. The sounding disc size was determined so that the before-testing armor layer thickness, determined using the measured profile, coincided with the theoretical value. The soundings were generally obtained on a horizontal grid spaced evenly at $1.5 D_{n 50}$. A number of profiles along the breakwater length were averaged to determine an average profile. The average damaged profile was subtracted from the undamaged average profile to get an average eroded area over the active region. The eroded cross-sectional area is defined in Figure 3.1. This eroded area was divided by the total area of armor in the undamaged average profile to get a percent damage $D \%$. Hudson's (1959) zero-damage criteria corresponded to $D \% \leq 1$ percent. The zero-damage criteria given in the Shore Protection Manual (SPM 1984) corresponds to $D \% \leq 5$ percent by the eroded volume method or 2 percent by count. The justification for the less restrictive zero-damage criteria is not clear but evolved over many years.

The primary weakness of the WES eroded volume method is that, because the damage is only computed over the active region, the damage value will depend on 
the structure geometry. This method also provides no indication of the severity of damage as characterized by the profile shape.

Jackson (1968) gave damage due to regular waves in terms of the WES eroded volume definition of damage. Jackson's damage values, given in Table 7-9 in the SPM, have been widely used to predict damage but are limited to regular waves with damage starting from an undamaged structure. Also, the damage is not given as a function of time, which is critical for determining the reliability of a structure.

Broderick and Ahrens (1982) and Van der Meer (1988) defined a dimensionless damage index using profile data as

$$
S=\frac{A_{e}}{\left(\frac{M_{50}}{\rho_{a}}\right)^{2 / 3}}=\frac{A_{e}}{D_{n 50}^{2}}
$$

where

$$
\begin{aligned}
& A_{e} \quad=\text { eroded volume per unit length or cross-sectional eroded area } \\
& M_{50} \quad=\text { mass of median armor unit in mass distribution } \\
& \rho_{a} \quad=\text { armor unit density }
\end{aligned}
$$

where their variable nomenclature has been modified to avoid confusion. Broderick and Ahrens stated that $A_{e}$ was calculated from the profile data by determining the difference between before and after testing profiles. The difference in Broderick and Ahrens' method from the traditional eroded volume method was that they nondimensionalized 
by the square of the nominal stone diameter rather than the area in the undamaged armor profile.

If the eroded area over the entire structure is used to compute $S$ rather than just the active region, the ratio of damage by the eroded volume method to that of the damage index can be computed as per Cornett (1995)

$$
\frac{S}{D \%}=\frac{t_{a}\left(\frac{w_{c}}{2}+\frac{h_{c}-h_{t}+H}{\sin \theta}\right)}{100 D_{n S O}^{2}}, \quad H<h_{t}
$$

where

$$
\begin{aligned}
& t_{a}=\text { armor layer thickness } \\
& w_{c}=\text { crest width } \\
& h_{c}=\text { breakwater crest elevation above bottom } \\
& h_{t}=\text { water depth at toe } \\
& H=\text { design wave height } \\
& \theta=\text { seaside angle of armor slope relative to horizontal }
\end{aligned}
$$

Equation 3.2 assumes the wave height is less than the depth at the toe.

Cornett noted that the range of this ratio is 0.6 to 1.25 for typical rubble mounds. For $S / D \%=0.8$, he notes that the zero-damage criteria of $D=5 \%$ corresponds to $0<S<4$. This is quite a broad criterion. The damage index method appears to give a better 
representation of damage. Broderick and Ahrens and van der Meer noted a zerodamage level of $S=2$.

Thompson and Shuttler (1976) also used the eroded volume method. They used a profiler with a foot diameter of $D_{n 50} / 2$ with soundings spaced at $D_{n 50}$, which is similar to that used in the WES experiments. The structure was surveyed after each 1,000 waves. They computed the eroded volume $V_{e}$ using the trapezoidal rule and an average profile. A damage number $N_{\Delta}$ was calculated, assuming a spherical armor shape, as the number of stones eroded in a $9 D_{n 50}$ wide region of the breakwater section as follows

$$
N_{\Delta}=\frac{\rho_{a}^{B} V_{e}}{\rho_{a} \frac{\pi}{6} D_{n s 0}^{3}}
$$

which is equivalent to

$$
N_{\Delta}=\frac{54 \rho_{a}^{B}}{\pi \rho_{a}} \frac{A_{e}}{D_{n 50}^{2}}
$$

over a $9 D_{n 50}$ width of the structure, where

$$
\begin{aligned}
& \rho_{a}^{B}=\text { armor bulk density } \\
& V_{e}=\text { average eroded volume } \\
& \rho_{a}=\text { actual armor density }
\end{aligned}
$$

The difference between the method of Thompson and Shuttler and the damage index method is the $54 \rho^{B}{ }_{d} / \pi p_{a}$ in Equation 3.4. For Thompson and Shuttler's 
tests, the density ratio was $\rho_{d} / \rho^{B}{ }_{a}=1.81$. Therefore, the method of Thompson and Shuttler yielded a damage index approximately nine times that of Broderick and Ahrens, or the width of their structure in nominal diameters. Thompson and Shuttler also determined the minimum armor layer thickness at failure. They defined failure as the point at which an area of exposed underlayer of diameter $D_{n 50}$ occurred. Note that the minimum armor layer thickness will not be zero at failure because it is expressed as a spatial average of several profiles.

H. R. Wallingford, Ltd. (1990), showed that Equation 3.1 yielded very different results if a slightly different method was used to compute the average eroded area. The first method they used was that described for the WES eroded volume method, where an average profile was used to determine an average eroded area. The alternative method was to sum the eroded areas from all profiles in order to compute an average eroded area. The difference between the two methods ranged from 2 to 82 percent. In general, the difference decreased as the damage level increased. Note that most authors do not describe the method used to compute damage.

All damage methods discussed above share a common weakness, namely they compute the average damage, which may be concentrated in one pocket or spread out over several areas. Also, none of the methods give any indication of the profile shape, or more specifically, the maximum depth of erosion, which is certainly an important parameter for a multilayer structure. 


\subsubsection{Stone count method}

Hedar (1960), Owen and Allsop (1983), Hughes (1993), and Davies et al. (1994) describe measurement of damage through stone counts. Besides visual counting during the test, photo overlays and digital image processing software can be used to determine damage by stone counts; but these methods are relatively complex and time consuming. Stone count methods are useful for determining very low damage values but become inaccurate if more than a few stones begin to move or if movement is due to sliding rather than dislodgement of individual stones. Stone count suffers from the same weaknesses as the eroded volume method, namely that the spatial concentration of damage is generally not specified and the maximum depth of erosion is not computed. Stone count is also somewhat subjective.

\subsubsection{Recent damage measurement methods}

Davies et al. (1994) provided a review of laboratory techniques for measuring breakwater profiles and methods for characterizing damage. They described the WES damage D\% (SPM 1984) as a visual displaced stone count and made no reference to the WES eroded volume method. They introduced a technique to compare the stone count method of damage measurement with the damage index method of Broderick and Ahrens (1982). For damage measurement, they used a semiautomated profiler that measured profiles with a small spatial sampling interval by dragging a wheel over the structure face. During an experiment measuring damage on a riprap armor layer, they computed the damage index, apparently using an average profile, and 
they noted that stone counts were more accurate when only a few stones moved, but the volume method improved accuracy of the damage measurement for advanced damage. They also noted that the depth of cover $d_{c}$ was useful in describing the degree of damage. They noted that, for an armor layer thickness of approximately $2 D_{n 50}$, when $d_{c} \approx D_{n 50}$, the underlayer was visible through a hole $D_{n 50}$ in size, and when $d_{c} \approx 0$, significant damage to the underlayer had occurred.

\subsection{Damage Measurement Experiments}

Historically, breakwater design has been accomplished using an empirical stability equation, such as the Hudson equation (Hudson 1958, 1959) as shown in Equation 2.1. As described earlier, for this equation, $K_{D}$ is defined for a given level of performance, typically the no-damage condition represented by $D \%$ less than 2 percent by count or 5 percent by volume (SPM 1984). This technique assumed damage approached an equilibrium level of $D \%$, where further regular waves at the design condition induced no further damage. This is based on regular wave experiments where damage reaches an equilibrium level or failure occurs relatively quickly. Hudson (1958) and Van der Meer (1988) expressed Equation 2.1 as a stability number as shown in Equation 2.2 or

$$
N_{s}=\left(K_{D} \cot \theta\right)^{1 / 3}=\frac{H}{\Delta D_{n 50}}
$$

where $\Delta=S_{a}-1$. 
The Hudson equation was defined for regular waves but has been extended to irregular waves using irregular wave physical model experiments. The SPM suggests $H_{1 / 10}$, the average height of the highest $1 / 10$ waves, to replace the regular wave height in Equations 2.1 and 3.5, but the justification is unclear. Researchers attempted to relate regular and irregular wave effects on stability in the 1970s with no definite conclusions (e.g., Jensen (1984)). Recently, Vidal et al. (1991); Vidal et al. (1995); and Jensen et al. (1996) emphasized the need for characterization of the large waves in a random wave train. Vidal et al. (1995) noted that representation of the irregular time series by $H_{100}$, the average height of the highest 100 waves, provided a comparative level of damage to that produced by regular waves; but the equivalent statistic of the form $H_{1 / n}$ will depend on the number of waves. Medina and McDougal (1988) introduced an interesting, albeit not rigorous, method for interpreting Jackson's (1968) regular wave damage results using a Rayleigh wave height distribution. Their method incorporated storm duration into the equation. In summary, the regular wave stability and damage formulations given above are conservative for design; but a universal analytical technique for extending these relations using irregular waves and resulting damage development has not been completed.

Thompson and Shuttler (1976) performed both long-term deterioration and shorter single-storm damage tests using a riprap-armored embankment with an impermeable core. All of their tests were restricted to nonbreaking waves in front of the embankment, mostly deep water. The average run length was 5,000 waves, based on 
mean zero-upcrossing wave period $T_{m}$, with intermediate surveys every 1,000 waves.

They considered 5,000 waves to be a typical storm duration. Several of their significant conclusions concerning damage are paraphrased as follows:

1. The rate of erosion of a given riprap is, as expected, strongly dependent upon "the significant wave height" $H_{1 / 3}$.

2. The rate of erosion decreases with time and hence the damage history curves flatten out. At the lower wave heights, the curves can become nearly horizontal, giving an apparently stable riprap slope.

3. The very long preliminary tests give no certainty of the riprap eroding to a totally stable equilibrium state, even with low damage rates. Thus, it is not safe to assume, as is often done in regular wave tests, that a slope will erode to stability. All that can be said is that the erosion rate may become small enough to be ignored in practice.

4. The method of laying the riprap has a significant effect upon the damage history.

5. The wave energy spectral shape as specified by the width parameter, $\epsilon$, does not affect the ultimate erosion volume.

6. The failure criterion requiring a given area of exposed filter layer was easier to assess than that requiring the observation of the erosion of filter material and gave erosion volumes at failure which were independent of the filter grades used.

7. Experimental time limited the maximum value of $\bar{N}_{w}$, the average number of waves incident on the riprap, to 5000 , which is typical of a storm. In most cases this was too few waves to determine whether or not equilibrium damage was achieved or whether, at a given value of $H_{1 / 3}$, the slope protection would eventually fail. 
8. Even in the limiting case of waves with a small significant height incident for a very long time on relatively large riprap, there will be a few rare waves high enough to remove the smallest stones of the riprap pack and hence give damage.

9. The movement of the stone is greatest on the flatter slopes although the net erosion is small. This movement results in self-healing by the smaller stones.

These conclusions offer a somewhat different view of damage development than was accepted at that time based on regular wave experiments. The conclusion that an equilibrium level of damage may not occur provided motivation to include damage in a stability model.

Using Thompson and Shuttler's riprap stability data, Van der Meer (1988) stated that the damage rate should be linear up to 500 to 1,000 waves but "for large $N_{w}$ numbers a limit to the damage should be reached (equilibrium)." These criteria for the relation between damage and the number of waves were limited to tests where damage was larger than $S=3$ after 5,000 waves and where the filter layer was not visible after 5,000 waves. Van der Meer's discussion of damage progression is limited to widely graded armor, which may not deteriorate in a manner similar to uniformly sized stone armor. This will be discussed further in the next chapter.

\subsection{Damage Progression Prediction}

Table 7-9 in the SPM (1984), included herein as Table 3.1, provides a deterioration model for armor stability based on regular wave data from model studies 
discussed in Jackson (1968). The table gives damage as a function of wave height relative to the zero-damage wave height for several armor types. The tabulated values can be used to formulate an equation for armor stone damage. As an aside, note that the dolos damage progression in the table is limited to stability and does not include breakage. But because dolos movement causes breakage, this damage progression may not be conservative.

\begin{tabular}{|c|c|c|}
\hline \multicolumn{3}{|c|}{$\begin{array}{l}\text { Table } 3.1 \\
\text { Jackson (1968) Breakwater Damage from } \\
\text { Table } 7.9 \text { of SPM (1984) }\end{array}$} \\
\hline $\begin{array}{c}\text { Percent } \\
\text { Damage } \\
D \%\end{array}$ & $\begin{array}{l}\text { Rough } \\
\text { Stone } \\
H^{\prime} H_{d o}\end{array}$ & $\begin{array}{l}\text { Smooth } \\
\text { Stone } \\
H H_{d o}\end{array}$ \\
\hline 2 to 5 & 1.00 & 1.00 \\
\hline 5 to 10 & 1.08 & 1.08 \\
\hline 10 to 15 & 1.19 & 1.14 \\
\hline 15 to 20 & 1.27 & 1.20 \\
\hline 20 to 30 & 1.37 & 1.29 \\
\hline 30 to 40 & 1.47 & 1.41 \\
\hline 40 to 50 & 1.56 & 1.54 \\
\hline
\end{tabular}

A simple empirical model for the best fit line through the data points in the table for rough stone damage is given by

$$
D \%=f\left[\frac{H}{H_{d o}}\right]=2.79 \exp \left(2 \frac{H}{H_{d o}}\right)-18.08
$$


The experiments supporting Table 3.1 were conducted with regular waves, so measured damage approached an equilibrium after a relatively short duration. Therefore damage is not a function of storm duration in Equation 3.6. Figure 3.2 shows data from Table 3.1 and damage given by Equation 3.6. The relation utilizes $H$, the regular wave height, and $H_{d o}$, the no-damage regular wave height corresponding to 0 to 5 percent damage by the eroded volume method. This damage relation shows how damage varies with wave height but it assumes starting with an undamaged structure and damage approaching an equilibrium level.

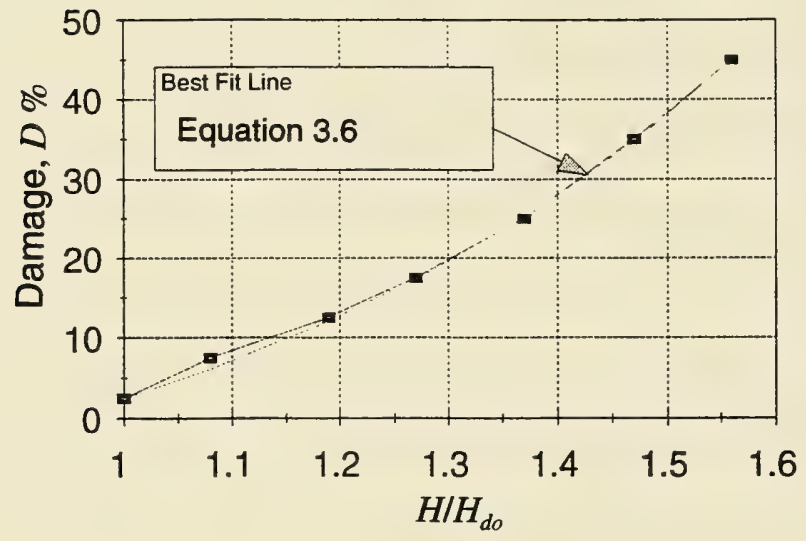

Figure 3.2. Damage, characterized as eroded volume, as a function of monochromatic wave height for angular stone (SPM 1984)

Van der Meer (1988) reanalyzed data from Thompson and Shuttler (1976) and conducted a number of additional experiments and found the damage index $S$ to be related to the number of waves $N_{w}$, the significant wave height $H_{1 / 3}$, and the mean wave 
period $T_{m}$. Van der Meer noted that $S=2$ in Equation 3.1 provides a good estimate of the initiation of damage and that failure occurred when $S=8$ for structure slopes of $1 \mathrm{~V}: 1.5 \mathrm{H}$ and $1 \mathrm{~V}: 2.0 \mathrm{H}$, where failure was defined as exposure of the underlayer through a hole $D_{n 50}$ in diameter. Van der Meer used test durations of 1,000 and 3,000 average wave periods. Virtually all of his tests were performed with nonbreaking waves. Van der Meer performed eight tests with depth limited waves and eight more where perhaps only the highest waves in the distribution were depth limited. Based on these data, he proposed breaking-wave-induced stability after $N_{w}$ waves could be determined by the following equations.

For plunging waves:

$$
\frac{H_{2 \%}}{\Delta D_{n 50}}=1.4(6.2) P^{0.18}\left(\frac{S}{\sqrt{N_{w}}}\right)^{0.2} \xi_{m}^{-0.5}
$$

and for surging waves:

$$
\frac{H_{2 \%}}{\Delta D_{n 50}}=1.4 P^{-0.13}\left(\frac{S}{\sqrt{N_{w}}}\right)^{0.2} \sqrt{\cot \theta} \xi_{m}^{P}
$$

where

$$
\begin{aligned}
& H_{2 \%}=\begin{array}{l}
\text { wave height exceeded by } 2 \text { percent of waves in wave height } \\
\text { probability distribution, where Van der Meer assumed } H_{2 \%}=1.4 H_{s} \\
\text { to obtain Equations } 3.7 \text { and } 3.8 \text { from his formulations for } \\
\text { nonbreaking waves at toe of structure }
\end{array} \\
& \Delta \quad=\quad\left(S_{a}-1\right) \text { with } S_{a}=\text { specific gravity of armor unit } \\
& P \quad=\quad \text { permeability coefficient } \\
& \theta \quad=\quad \text { structure slope angle }
\end{aligned}
$$




$$
\begin{aligned}
& \xi_{\mathrm{m}} \quad=\tan \theta /\left(H_{s} L_{o}\right)^{1 / 2}=\text { surf similarity or Iribarren parameter } \\
& H_{s} \quad=\text { significant wave height which is equal to } H_{1 / 3} \\
& L_{o} \quad=g T^{2}{ }_{m} /(2 \pi) \\
& T_{m} \quad=\text { mean wave period }
\end{aligned}
$$

Van der Meer's breaking wave tests were performed with a traditional multi-layer rubble mound where the notional permeability was $P=0.5$. This permeability is an empirical parameter without any regard to the flow throughout porous media. Using this value of $P$, Equations 3.7 and 3.8 suggest that $S$ is approximately proportional to $H_{s}^{5}$ and $N_{w}{ }^{0.5}$. Because the number of waves is defined as $N_{w}=t / T_{m}$, where $t_{r}$ is the total run time, these formulations indicate that damage increases with the square root of time. But because the Iribarren parameter is raised to a negative constant in Equation 3.7 but raised to a positive power of $\mathrm{P}$ in Equation 3.8, the effect of wave period is not clear. It is clear that damage progression is very sensitive to wave height.

Equations 3.7 and 3.8 are of limited practical use for depth-limited breaking waves primarily because the supporting breaking wave experiment was extremely limited in scope. These equations are essentially the same as Van der Meer's nonbreaking wave equations except the Rayleigh wave height distribution assumption of $H_{s}=H_{2 \%} / 1.4$ has been substituted. Van der Meer included the structure slope in the Iribarren or surf similarity parameter (Battjes 1974), but the beach slope is critical for depth-limited breaking waves. Van der Meer conducted experiments for only one beach slope and used a very narrow range of wave periods. Therefore, the effect of varying 
beach slope or breaker type was not determined. For breaking waves, as the beach slope steepens, the wave breaking becomes more vigorous (Battjes 1974) and the slamming forces increase dramatically as the waves start plunging to collapsing (Bruun 1985). Van der Meer's spilling breakers were not very severe with respect to stability relative to plunging or collapsing breakers.

Equations 3.7 and 3.8 do not indicate decreasing stability as the depth to wave length ratio decreases and the wave breaking becomes more severe. Carver and Wright (1991) showed that stability decreases dramatically with decreasing relative depth. The minimum stability condition occurs where the wave breaking is characterized by plunging to collapsing breakers at the toe of the structure. Figure 3.3 shows some of Carver and Wright's data replotted with Hudson stability coefficient, $K_{D}$ in Equation 2.1, as a function of relative depth. Here the water depth $h_{t}$ at the structure toe is normalized by the local wave length $L_{p}$ based on the peak spectral period computed using linear wave theory. It is clear that the Hudson stability coefficient decreases with decreasing relative depth. This is a reflection of the severity and location of the breaking wave and the resulting wave forces. As was shown in Chapter 2, the critical wave forcing for incipient motion was uplift occurring under the steep wave face for collapsing to plunging breakers. For depth-limited conditions, as the water depth decreases relative to the wave length, the wave face steepens, and vertical forces at the steep wave face are able to loosen and mobilize the stones. Therefore, for depth-limited 
waves, the critical condition for stability occurs for relatively long waves that plunge on the structure.

A minor difficulty with Equation 3.7 and 3.8 is a potential source of confusion because the stability number is given in terms of $H_{2 \%}$, but the Iribarren parameter is in terms of $H_{s}$. Finally, all of the previous damage empirical equations listed above are limited to constant incident wave conditions and water level as well as the initial condition of an undamaged structure. These equations are intended to predict damage for a single design storm. Therefore, they cannot be used to predict damage development over the life of a structure as is required in a life-cycle cost analysis.

\subsection{Variability in Stability Results}

Carver and Wright (1991) conducted irregular wave stability experiments primarily intended to determine random variations of damage initiation due to varying armor placement and due to variations in wave time series realizations with constant spectral parameters. Their tests progressed to low damage levels, varying up to 7.7 percent displacement, by count, of armor. The wave conditions were assumed to be constant for a given test. But they did vary the wave height and period between structure rebuilds if the damage had not progressed far enough. This testing strategy is not typical and their interpretation of the data assumed damage caused by one wave condition would be independent of the damage caused by the following wave condition. They made note of the uncertainty in stability of traditional stone-armored breakwaters. In Figure 3.3, for each value of relative depth, the stability coefficient is shown to 
scatter widely. They concluded that the uncertainty was due to differing construction techniques from test to test and different random number seeds being used to generate the spectra.

Font (1968) noted that the armor placement technique is important for determining when initiation of damage occurs, but is less relevant for advanced damage, which is similar to conclusions stated above by Thompson and Shuttler. It is anticipated that the scatter in damage will be large for advanced damage primarily because of the random nature of the interaction between irregularly shaped stones. Melby and Mlakar (1997) showed how Carver and Wright's data could be used to compute the reliability of a breakwater with respect to the zero-damage condition of armor stability and how Van der Meer's relation could be used to compute reliability of a damaged mound. But little work has been done on computing the reliability of a damaged rubble mound through simulated damage using historical storm data. 


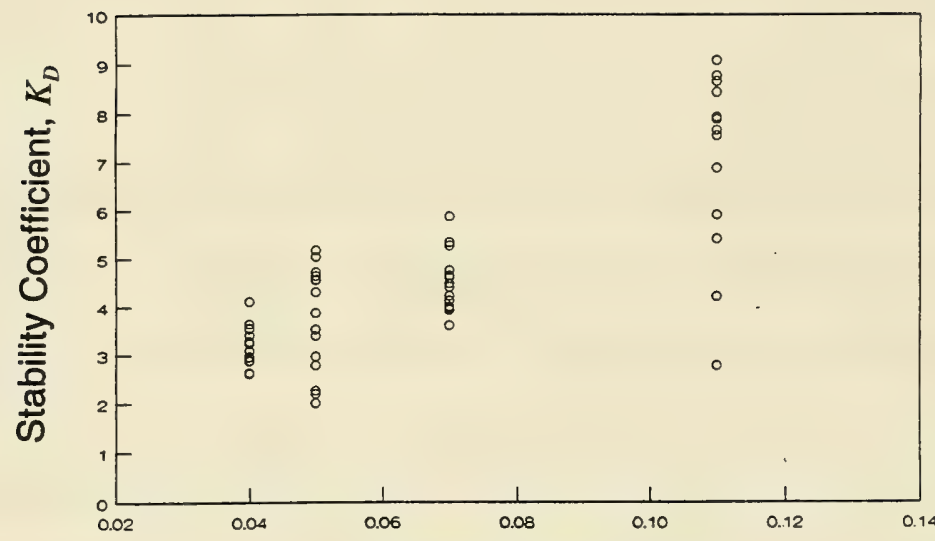

Relative Depth, $h_{t} / L_{p}$

Figure 3.3. Hudson stability coefficient versus relative depth for angular armor stone exposed to irregular waves (Carver and Wright 1991) 


\section{Chapter 4}

\section{DETERIORATION EXPERIMENT}

\subsection{Overview}

The deficiencies of previous damage experiments were noted in the preceding chapters. Because accurate quantification of damage is required for a risk analysis, a small-scale laboratory experiment was conducted to quantify breakwater deterioration. The initial experiment utilized a traditional trapezoidal multilayer rubblemound armored with uniform-sized stone which was exposed to depth-limited irregular waves. The objectives of the experiment were as follows:

a. Determine deterioration rates for the structure under long-term exposure to storm conditions.

b. Develop and evaluate methods for damage characterization.

c. Quantify development of damage with changing storm parameters, e.g., water level, wave height.

d. Quantify profile development as related to damage.

e. Quantify alongshore variability in damage.

f. Evaluate and standardize methods for breakwater profiling. 


\subsection{Experimental Setup}

\subsubsection{Flume and structure}

The experiment was accomplished using two identical side-by-side structures constructed in a flume measuring $61.1 \mathrm{~m}$ long, $1.52 \mathrm{~m}$ wide, and $2.0 \mathrm{~m}$ high (Figure 4.1). The structure cross sections are shown in Figures 4.2 and 4.3. Each 0.76$\mathrm{m}$-wide structure was constructed on a flat bottom. The offshore concrete beach slope was $1 \mathrm{~V}: 20 \mathrm{H}$. This steepness was selected to realistically produce severely breaking waves in the vicinity of the structure toe.

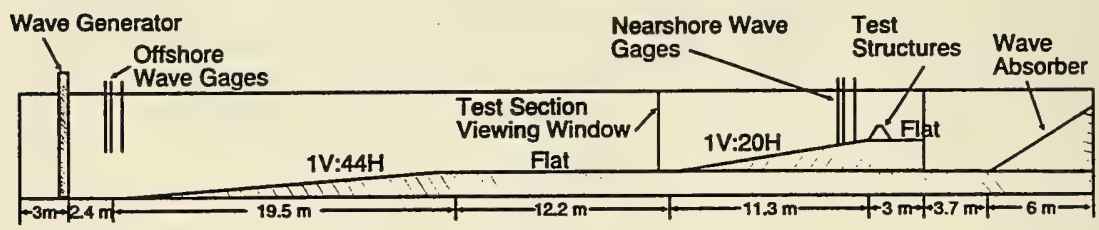

Figure 4.1 Flume profile for damage experiments

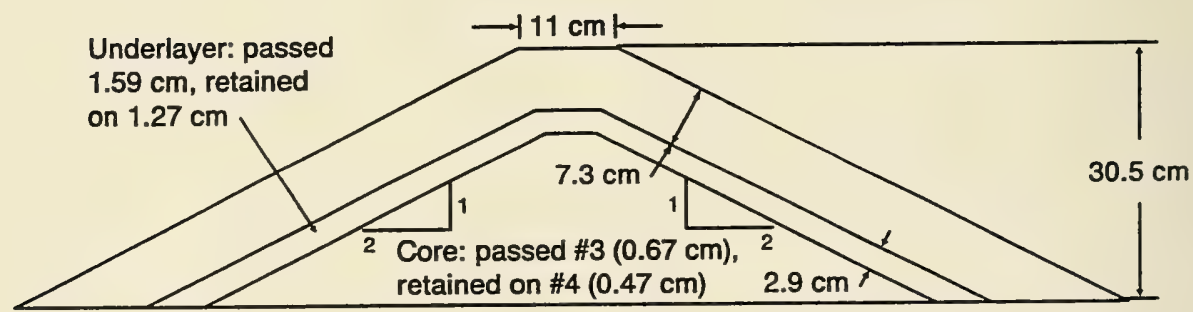

Figure 4.2 Model structure cross section for damage experiments 


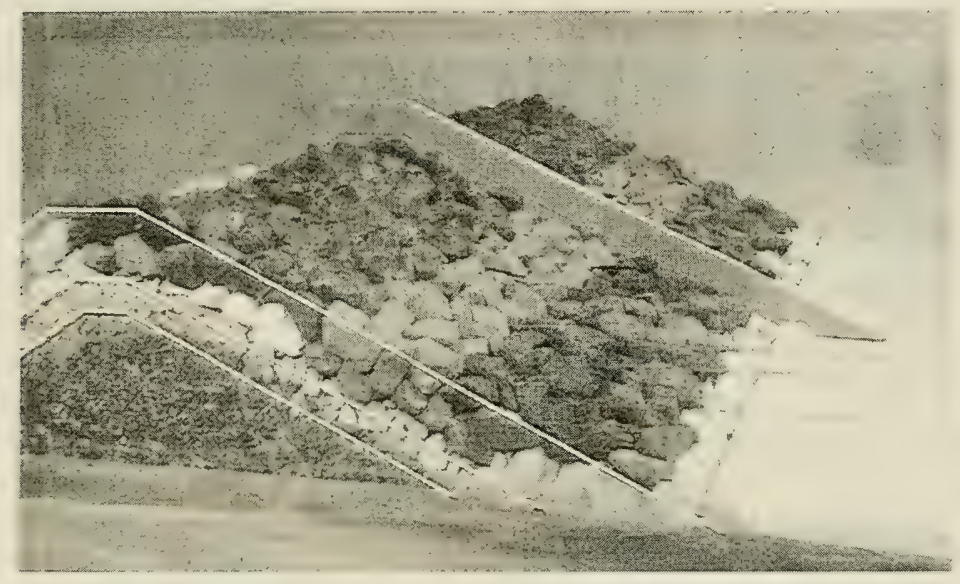

Figure 4.3. Photograph of model structures before testing

In armor stability experiments, breakwater crest heights are usually set high enough to prevent overtopping from influencing the stability, unless overtopping is the focus of the study or the breakwater is low crested. But the composite downslope weight of upslope armor units generally contributes to the stability of the armor layer and increases as the slope lengthens; although under some conditions, longer armor layers can have a tendency to buckle or slide. Just considering stone stability, for a given wave height, taller structures are typically more stable, with respect to main armor stability, than short structures. But, in the prototype, the cost of the breakwater is kept to a minimum by setting the breakwater crest height such that minor overtopping is allowed for a design wave condition. Thus, experimenting with non-overtopped structures that have high crest heights typically will not be conservative with respect to 
damage development. For the experiment discussed herein, the structure crest height above the toe of $30.5 \mathrm{~cm}$ corresponded to an elevation of approximately one significant wave height above the still water level for the larger wave conditions tested. This is typical of prototype structure crest heights. This crest height was specified so that results from this experiment could be used for analysis of prototype breakwaters with higher crest heights because the damage measured with the shorter structure should be relatively greater than that of a taller structure. The effect of wave overtopping on stability will be discussed in more detail later in this chapter.

\subsubsection{Experimental test conditions}

The test conditions for the initial study are summarized in Table 4.1. Note that wave period variation and armor gradation variation experiments are not listed in this table, but were added, and are discussed in Chapter 7. The waves had relatively long periods in this initial experiment, as this produces the lowest stability (Figure 3.3).

The depth-to-wavelength ratio $h_{t} / L_{p}$ at the structure toe was approximately 0.07 for this initial experiment, where $L_{p}$ was computed using linear wave theory and the spectral peak period. This shallow-water breaking wave is also typical of design conditions on United States coastlines.

\subsubsection{Armor layer and underlayer}

The mass distributions for armor and underlayers for the initial test series are shown in Figure 4.4. The armor layer consisted of uniformly hand-sized stones with 


\begin{tabular}{||l|l||}
\hline \hline \multicolumn{2}{|l|}{$\begin{array}{l}\text { Table } 4.1 \\
\text { Experimental Conditions for Initial Damage Experiment }\end{array}$} \\
\hline \hline Parameter & Range \\
\hline Water depth at toe, $h_{t}$ & $11.9-15.8 \mathrm{~cm}$ \\
\hline Wave height at toe & Variable \\
\hline Peak wave period, $T_{p}$ & $2.48-2.59 \mathrm{sec}$ \\
\hline Seaward beach slope, cot $\alpha$ & 20 \\
\hline Structure slope, cot $\theta$ & 2 \\
\hline Structure crest height above bottom, $h_{c}$ & $30.5 \mathrm{~cm}$ \\
\hline Nominal armor stone diameter, $D_{n 50}$ & $3.64 \mathrm{~cm}$ \\
\hline Median armor stone mass, $M_{50}$ & $128 \mathrm{~g}$ \\
\hline Stone density, $\rho_{z}$ & $2.66 \mathrm{~g} / \mathrm{cm}^{3}$ \\
\hline
\end{tabular}

$M_{50}=128 \mathrm{~g}$, while the underlayer was sieve sized passing $1.59-\mathrm{cm}$ and retained on

1.27- $\mathrm{cm}$ sieves. The ratio of armor median mass to underlayer median mass was

$\left(M_{50}\right)_{a} /\left(M_{50}\right)_{u}=25$, which was large relative to that typically used in the prototype. The gradation of the armor layer for this initial series was very narrow with $D_{85} / D_{15}=1.05$, where $D_{85}$ is the nominal diameter corresponding to the 85 -percent exceedance probability in stone mass and $D_{15}$ is the nominal stone diameter corresponding to the 15percent exceedance probability. The gradation of the underlayer was wider with $D_{85} / D_{15}=1.44$. The core material was sieve sized, passing No. $3(0.67-\mathrm{cm})$ and retained on No. $4(0.47-\mathrm{cm})$ sieves. While not impermeable, this core material was sized small enough to prevent strong flow within the core. Equations 3.7 and 3.8 indicate that lower porosity in the underlayer and core results in lower stability. Therefore, the underlayer 
and core were selected to be at the lower end of the range of material that is used in the prototype.

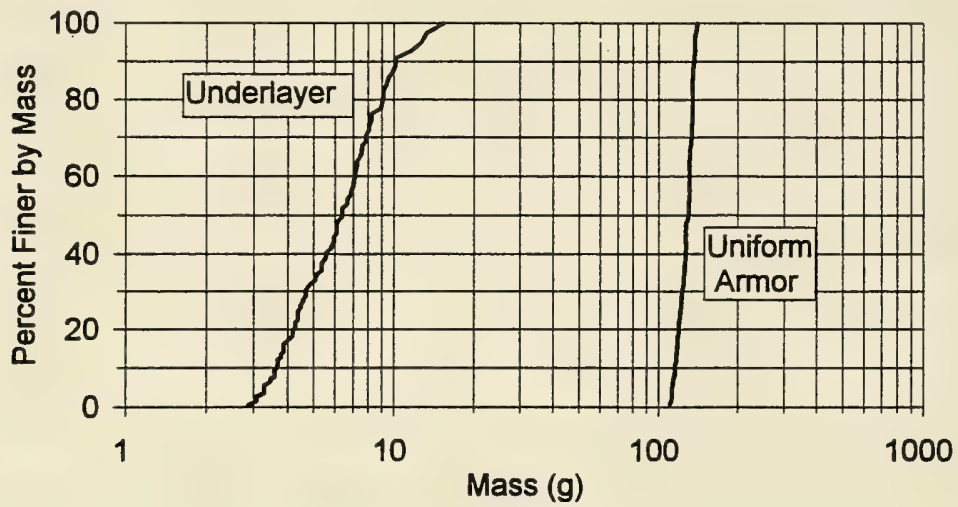

Figure 4.4. Armor and underlayer stone mass distributions for initial experiment

The amount of material in the armor layer is determined using the packing density equation, given in the SPM as

$$
\frac{N_{a}}{A}=n k_{\Delta}\left(1-P_{a} / 100\right)\left(\gamma_{a} / W_{50}\right)^{2 / 3}
$$

where

$$
\begin{aligned}
& N_{a}=\text { number of armor units } \\
& A=\text { unit area of breakwater slope to be armored } \\
& n=\text { number of armor layer thicknesses } \\
& k_{\Delta}=\text { layer coefficient } \\
& P_{a}=\text { armor layer porosity in percentage } \\
& W_{50}=\text { median armor weight }
\end{aligned}
$$


It will be convenient to refer to damage in terms of the nominal stone diameter, so the packing density equation can be rearranged to be compatible as

$$
\frac{N_{a}}{A}=\frac{\phi}{D_{n 50}^{2}}
$$

where $\phi$ is the packing density coefficient. The stone armor layer was placed in a traditional two-layer thickness at an average packing density coefficient of $\phi=1.2$, corresponding to $n=2, k_{\Delta}=1.0$, and $P_{a}=40$ percent as recommended in the SPM.

The core was placed by shovel, troweled to grade, and washed in place to naturally pack tight. This process simulates the natural washing action of waves during the construction sequence. Similarly, the underlayer was dumped onto the sloping core and lightly troweled to grade. Each armor stone was placed individually by hand, simulating crane placement as closely as possible. The armor stone placement during the experiment followed WES guidelines for random hand placement in the laboratory as follows:

a. Stones were lowered vertically into position.

b. Stones were placed on the slope rather than dropped.

c. Stones were placed so that they touched their neighbors.

$d$. Stones could not be pushed into a hole.

e. Particular orientation of stones or placement patterns were avoided. 


\subsubsection{Model-Prototype similitude}

Many authors have discussed similitude requirements for breakwater stability including Dai and Kamel (1969), Hudson et al. (1979), Sakakiyama and Kajima (1992), and Hughes (1993). As such, only a brief review will be provided herein. In order for damage measurements in the physical model to be scalable, similitude must be maintained, where the ratios of the dominant physical forces in the model are the same as they are in the prototype. Because there is no mathematical relationship that describes armor damage, dimensional and inspectional analysis and the resulting empirical relations are relied on to establish similitude requirements (Hudson et al. 1979, Hughes 1993).

The first requirement for similitude is that the model be geometrically and kinematically undistorted. Therefore, the size and shape of the breakwater, armor and underlayer stone, surface characteristics of the stone, and the height and length of the waves must all be undistorted. As described in Chapter 2, the wave forces on the armor units act to cause damage while the armor unit self-weight and inter-unit friction act to prevent armor movement. Also shown in Chapter 2, wave forces are typically decomposed into fluid drag, fluid inertia, and buoyancy. The two important force ratios that include these forces are the Froude number and the Reynolds number (e.g. Hudson et al. 1979). The Froude number is the square root of the ratio of the inertial and gravitational forces or $F r=u /(g l)^{1 / 2}$ where $u$ is the fluid velocity, $g$ is the gravitational acceleration, and $l$ is a characteristic dimension of an armor unit or wave height. Froude 
similitude demands that $F r_{m}=F r_{p}$, where $m$ and $p$ refer to model and prototype, respectively. The Reynolds number is the ratio of the inertial forces to viscous forces $R e=u l / v$, where $v$ is the fluid kinematic viscosity. So, in addition to geometric similitude, complete similarity in damage requires Froude and Reynolds similitude or

$$
\frac{F r_{p}}{F r_{m}}=1, \quad \frac{R e_{p}}{R e_{m}}=1
$$

In stability models, Froude and geometric similitude are typically maintained leading to the relationship between length and time scales of

$$
N_{T}=N_{u}=\sqrt{N_{L}}
$$

where $N_{T}, N_{u}$, and $N_{L}$ are the time, velocity, and length scales, respectively. Under Froude similitude, in order to achieve Reynolds similitude, the following relationship must be satisfied.

$$
N_{\mathrm{v}}=N_{L}^{1.5}
$$

where $\mathrm{N}_{\mathrm{v}}$ is the viscosity scale ratio. Therefore, it is not practically possible to attain both Reynolds and Froude similitude with the use of water in small-scale stability experiments. Water is always used in stability models, yielding some Reynolds scale effects. Thus the viscous forces are relatively stronger in the model than in the prototype. 
In order to maintain reasonably close similarity between model and prototype, armor stability models are usually constructed at a scale large enough to avoid significant Reynolds scale effects by ensuring that the flow around the armor remains turbulent. Dai and Kamel (1969) suggested that $R e=(g H)^{1 / 2} D_{n 50} / v \geq 3 \times 10^{4}$ will prevent Reynolds scale effects. Their results were based on large- and small-scale flume tests using regular waves. Van der Meer (1988) stated that the lower limit of Reynolds numbers should be in the range

$$
R e=\frac{\sqrt{g H_{s}} D_{n 50}}{v} \geq 1 \times 10^{4}-4 \times 10^{4}
$$

to prevent Reynolds scale effects. This guidance is presently accepted practice. In the experiment discussed herein, the Reynolds number range is $3.1 \times 10^{4}<\operatorname{Re}<4.0 \times 10^{4}$ which satisfies the requirements suggested by both Dai and Kamel and van der Meer.

\subsection{Wave Generation and Measurement in Initial Experiment}

\subsubsection{Wave generation}

Waves were generated based on the Texel, Marsen, and Arsloe (TMA) spectrum (Bouws et al. 1985). The deterministic spectral amplitude and random phase method was used to synthesize the time series that was used to drive the piston-type wave board. Long (1986) describes the computer program used to synthesize the time series. The software creates a variable spectral bandwidth $\Delta \omega_{n}$ by the method of Goda (1970), which allows closer spectral lines near the peak frequency. For this method, a 
sequence of random phases $\theta_{n}$ are specified over the interval from 0 to $2 \pi$. Then the Fourier amplitudes are found from the relation

$$
c_{n}=\sqrt{2 S_{\eta}\left(\omega_{n}\right) \Delta \omega_{n}}
$$

given a discrete target spectrum $S_{\eta}$ as a function of angular frequency $\omega_{n}$. The final step is to determine the discrete time series by inverse Fourier transforming the amplitudes and phases. This method provides a very close match with the target peak frequency and the spectral shape.

For these initial test series, two wave board drive signals were generated corresponding to two water depths. The design conditions for wave generation are listed in Table 4.2. Note that the gain is generator specific but provides a crude judge of the energy levels because gain is roughly linearly related to wave height.

\begin{tabular}{|c|c|c|c|}
\hline \multicolumn{4}{|c|}{$\begin{array}{l}\text { Table } 4.2 \\
\text { Wave Generation in Initial Damage } \\
\text { Experiment }\end{array}$} \\
\hline Wave & $\begin{array}{c}\text { Generator } \\
\text { Depth } \\
\text { cm }\end{array}$ & $\begin{array}{l}\text { Peak } \\
\text { Period } \\
T_{p} \\
\text { sec }\end{array}$ & $\begin{array}{l}\text { Gain } \\
\text { as percent of } \\
\text { maximum }\end{array}$ \\
\hline 1 & 112.7 & 2.50 & 50 \\
\hline 2 & 112.7 & 2.50 & 70 \\
\hline 3 & 112.7 & 2.50 & 90 \\
\hline 4 & 116.5 & 2.50 & 50 \\
\hline 5 & 116.5 & 2.50 & 70 \\
\hline 6 & 116.5 & 2.50 & 90 \\
\hline
\end{tabular}


The random number seed value for the random phase generation was different for the two depths. These two signals were scaled to achieve three wave heights for each water depth by adjusting the gain on the output amplifiers for the wave board command signal as indicated in Table 4.2. The resulting six time series of the command signals sent to the wave board are shown in Figure A.1 in Appendix A. Note that short segments at the beginning and end of each series have been cut off in the analysis. The spectra for these six signals are shown in Figures A.2 and A.3, for the two water depths. The wave board was commanded at a rate of $20 \mathrm{~Hz}$, and ramps of $5 \mathrm{sec}$ each were placed at the beginning and end of the command time series to gradually start and stop the wave generator.

\subsubsection{Wave measurement}

Waves were measured using capacitance-type wave gages. Two arrays of three gages, offshore and nearshore, were used as shown in Figure 4.1. Nearshore gage layout is shown in Figure 4.5. Considering the largest wave measured herein, this gage location approximately corresponds to the recommendation by Goda (1985) where the design breaking wave is determined $5 H_{s}$ seaward of the toe. This is the travel distance of large breaking waves. For the toe depth of $h_{t}=11.9 \mathrm{~cm}$, the depth at the most nearshore gage was $16.5 \mathrm{~cm}$, and the depth at the offshore array was $112.7 \mathrm{~cm}$. For $h_{t}=$ $15.8 \mathrm{~cm}$, the depth at the most nearshore gage was $20.4 \mathrm{~cm}$ and the depth at the offshore array was $116.5 \mathrm{~cm}$. 


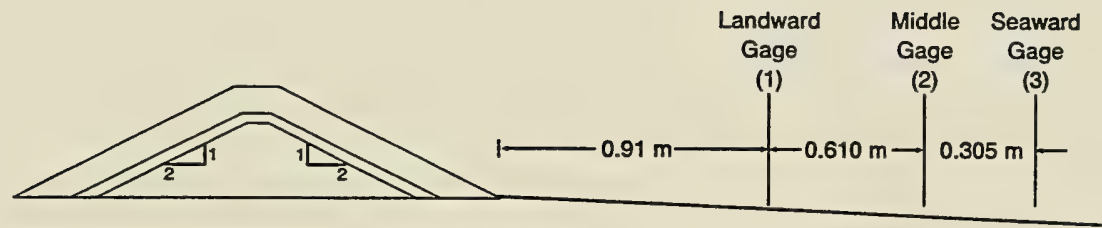

Figure 4.5. Flume profile near structure with nearshore wave gage layout

The gages were calibrated using the following automated technique. Each gage was attached to a Jordan servo-controller and motor. The wave gage data acquisition, control, and signal conditioning system consisted of a VAX PDP-11 microcomputer connected to 12-bit differential input analog-to-digital converters, digital-to-analog converters, and analog filters. A program on the PDP-11 sent signals to the Jordan controllers sending each through 10 calibration stops twice, covering a range of motion in excess of the largest wave expected in the irregular time series. At each stop, the voltage from each gage was recorded. For each gage, a calibration curve was automatically tested for fit through the calibration points using linear, quadratic, or cubic spline regression. The calibration program automatically chose the simplest technique with less than $0.25 \mathrm{~mm}$ deviation from the regression curve, which corresponds to approximately 0.1 -percent maximum deviation over the full calibration 
range. This was the maximum error allowed and the error varied because the calibration range was different for each gage.

Measured nearshore water surface oscillation time series are shown in Figures A.4 through A.6 for waves of three significant heights at $h_{t}=11.9 \mathrm{~cm}$. Figures A.7 through A.9 show wave gage time series for waves of three significant heights at $h_{t}$ $=15.8 \mathrm{~cm}$. Incident and reflected waves were resolved using these time series from the three-gage arrays using the technique of Goda and Suzuki (1976). The technique was modified as per Kobayshi, Cox, and Wuranto (1990) to determine the incident and reflected wave spectra and time series at the shallowest gage. Time series parameters were determined using the zero-upcrossing method. At frequencies containing little wave energy, the reflection analysis technique can yield poor estimates due to low signal-to-noise ratios. These regions are indicated by low coherency in the cross correlation between gage pairs. For this study, the cutoff frequencies were established to maintain the coherence above 0.3 in the cross correlation between gage pairs. The analysis technique was not sensitive to coherence cutoffs higher than 0.3 .

The resolved incident and reflected spectra for time series from the nearshore and offshore arrays are shown in Figures A.10 through A.12 for $h_{t}=11.9 \mathrm{~cm}$ and in Figures A.13 through A.15 for $h_{t}=15.8 \mathrm{~cm}$. Figures A.10 and A.13 show an increase in peak energy density due to wave shoaling between the offshore and nearshore gages and an increase in wave energy for low $(f<0.35 \mathrm{~Hz})$ and high $(f>1.0$ $\mathrm{Hz}$ ) frequencies. These figures show that wave energy is being transferred due to 
nonlinear wave interactions from the frequency band $0.35-1.0 \mathrm{~Hz}$ to frequency bands $f<0.35 \mathrm{~Hz}$ and $f>1.0 \mathrm{~Hz}$. Figures A.11, A.12, A.14, and A.15, for the larger wave heights, show a similar transfer of energy but also show a decrease in peak wave energy due to wave breaking. It is clear from these figures that the wave energy decrease due to wave breaking increased dramatically as the generated wave energy increased. It is also interesting that the measured reflected wave energy was much higher nearshore than offshore. This trend is primarily because wave breaking and bottom friction reduce the incident wave energy as waves progress shoreward while the reflected waves undergo little energy change as they progress offshore. This is consistent with the measured cross-shore variations of wave reflection from beaches (Baquerizo et al. 1997).

Tables 4.3 and 4.4 list nearshore incident-wave characteristics for the six wave trains, each of 15 -min duration, measured with the structure in place. Table 4.3 lists the spectral analysis parameters, and Table 4.4 lists the time series parameters, both at the location of the shallowest gage that was $0.91 \mathrm{~m}$ seaward of the toe. The values were computed using the analysis method discussed above with the three nearshore gages. In Table 4.3, the mean period $T_{m}$ is defined by the relation

$$
\frac{1}{T_{m}}=\frac{\int_{0}^{\infty} f S \eta(f) d f}{\int_{0}^{\infty} S_{\eta}(f) d f}
$$

where $S_{\eta}(f)$ is the energy spectral density of the incident wave and $f$ is the frequency. The spectral significant wave height is defined here as $H_{m o}=4 m_{o}{ }^{1 / 2}$ with $m_{o}=$ zero 
moment of the incident wave spectrum. The average reflection coefficient is defined as $R=\left[\left(m_{o}\right)_{r} / m_{o}\right]^{1 / 2}$ with $\left(m_{o}\right)_{r}=$ zero moment of the reflected wave spectrum. The change of wave reflection with damage measurement was negligible in this experiment. This is consistent with the reflection measurements made by Smith et al. (1992) on a horizontal bottom in deeper water in front of a $1 \mathrm{~V}: 3 \mathrm{H}$ slope. The local wave length $L_{m}$ and the deep water wave length $L_{o m}=g T_{m}{ }^{2} / 2 \pi$ were both computed using linear wave theory and the mean period. The Iribarren parameter in Table 4.3 is defined as $\xi_{o m}=\tan \alpha /\left(H_{m o} / L_{o m}\right)^{1 / 2}$ and in Table 4.4 as $\xi_{o m}=\tan \alpha /\left(H_{s} / L_{o m}\right)^{1 / 2}$ where $\tan \alpha=1 / 20$ is the nearshore beach slope and $H_{s}=H_{1 / 3}$ in Table 4.4 .

\begin{tabular}{|c|c|c|c|c|c|c|c|c|}
\hline \multicolumn{9}{|c|}{\begin{tabular}{|l} 
Table 4.3 \\
Nearshore Wave Statistics for Incident Spectra and Related \\
Parameters with Structure in Place \\
\end{tabular}} \\
\hline Wave & $\begin{array}{l}\text { Toe } \\
\text { Depth } \\
h_{t} \\
\text { cm }\end{array}$ & $\begin{array}{c}\text { Wave } \\
\text { Height } \\
H_{\text {mo }} \\
\text { cm }\end{array}$ & $\begin{array}{l}\text { Mean } \\
\text { Period } \\
T_{m} \\
\text { sec }\end{array}$ & $\begin{array}{c}\text { Peak } \\
\text { Period } \\
T_{p} \\
\text { sec }\end{array}$ & $\begin{array}{l}\text { Reflec- } \\
\text { tion } \\
\text { Coeff. } \\
R\end{array}$ & $\begin{array}{l}\text { Relative } \\
\text { Toe } \\
\text { Depth } \\
h_{t} L_{m}\end{array}$ & $\begin{array}{l}\text { Relative } \\
\text { Toe } \\
\text { Depth } \\
h_{t} \Omega_{\text {om }}\end{array}$ & $\begin{array}{c}\text { Spectral } \\
\text { Iribarren } \\
\text { Para- } \\
\text { meter } \\
\xi_{v m}\end{array}$ \\
\hline 1 & 11.9 & 9.78 & 1.72 & 2.48 & 0.59 & 0.066 & 0.026 & 0.34 \\
\hline 2 & 11.9 & 12.4 & 1.70 & 2.48 & 0.60 & 0.067 & 0.027 & 0.30 \\
\hline 3 & 11.9 & 14.2 & 1.72 & 2.48 & 0.60 & 0.066 & 0.026 & 029 \\
\hline 4 & 15.8 & 10.5 & 1.72 & 2.59 & 0.61 & 0.076 & 0.034 & 0.33 \\
\hline 5 & 15.8 & 13.6 & 1.69 & 2.59 & 0.62 & 0.077 & 0.035 & 0.29 \\
\hline 6 & 15.8 & 15.8 & 1.68 & 2.59 & 0.61 & 0.078 & 0.036 & 0.26 \\
\hline
\end{tabular}




\begin{tabular}{|c|c|c|c|c|c|c|c|c|c|c|}
\hline \multicolumn{11}{|c|}{$\begin{array}{l}\text { Table } 4.4 \\
\text { Nearshore Wave Statistics for Incident Time Series and Related } \\
\text { Parameters with Structure in Place }\end{array}$} \\
\hline Wave & $\begin{array}{c}\text { Toe } \\
\text { Depth } \\
h_{1} \\
\text { cm }\end{array}$ & $\begin{array}{c}\text { Wave } \\
\text { Height } \\
H_{1 / 3} \\
\mathrm{~cm}\end{array}$ & $\begin{array}{c}\text { Period } \\
T_{m} \\
\text { sec }\end{array}$ & $\begin{array}{l}\text { Stability } \\
\text { Number } \\
N_{8}=H_{8} / \Delta D\end{array}$ & \begin{tabular}{c|} 
Iribarren \\
Parameter \\
$\xi_{\text {om }}$
\end{tabular} & $\mid \begin{array}{c}\text { Period } \\
T_{1 / 3} \\
\text { sec }\end{array}$ & $\begin{array}{c}\text { Wave } \\
\text { Height } \\
H_{2 \%} \\
\text { cm }\end{array}$ & \begin{tabular}{|c} 
Period \\
$T_{1 M 0}$ \\
sec \\
\end{tabular} & $\begin{array}{l}\text { Wave } \\
\text { Height } \\
H_{1100} \\
\mathrm{~cm}\end{array}$ & $\begin{array}{c}\text { Stability } \\
\text { Coefficient } \\
K_{\bar{D}}=f\left(H_{1 / 10}\right)\end{array}$ \\
\hline 1 & 11.9 & 9.38 & 1.76 & 1.6 & 0.36 & 2.16 & 12.8 & 2.28 & 11.5 & 3.4 \\
\hline 2 & 11.9 & 11.6 & 1.69 & 1.9 & 0.31 & 2.13 & 15.4 & 2.40 & 13.8 & 6.0 \\
\hline 3 & 11.9 & 13.2 & 1.74 & 2.2 & 0.30 & 2.22 & 17.3 & 2.53 & 15.7 & 8.8 \\
\hline 4 & 15.8 & 10.1 & 1.73 & 1.7 & 0.34 & 2.15 & 14.3 & 2.31 & 12.7 & 4.7 \\
\hline 5 & 15.8 & 13.0 & 1.67 & 2.2 & 0.29 & 2.16 & 17.8 & 2.39 & 16.0 & 9.3 \\
\hline 6 & 15.8 & 14.9 & 1.66 & 2.5 & 0.27 & 2.20 & 19.3 & 2.47 & 18.0 & 13.2 \\
\hline
\end{tabular}

For a Rayleigh distribution of wave heights, $H_{1 / 10} / H_{s}=1.27$ and $H_{2 \%} / H_{s}=$ 1.40. Computing these ratios using the values from Table 4.4, $H_{1 / 10} / H_{s}=1.19-1.26$ and $H_{2 \sigma^{\prime}} / H_{s}=1.30-1.42$, indicating the slight reduction of wave heights due to wave breaking.

Traditionally, the incident waves are measured without the structure in place (Hughes 1993). For this study, the waves in the flume were measured both with and without the structure in place. For the condition with no structure in place, an array of three gages was placed with its centroid at the location of the structure toe for calibration purposes. The wave gage array was moved to the location shown in Figure 4.5 when the structure was in place: Wave heights measured without the structure in place were smaller than those measured with the structure in place, and the difference in $H_{m o}$ ranged from 6 to 24 percent. The difference between the two sets of measurements 
was due to the fact that the wave generation system did not allow absorption of reflected and re-reflected waves within the flume; so wave energy built up in the flume during testing. It should be noted that systems that absorb reflected energy are only partially effective, and so it is virtually impossible to prevent wave energy increase due to rereflected waves in stability tests.

The wave energy in this experiment reached an equilibrium state quickly during each run due to the relatively long wave period. A simple analysis was done to determine the rate of increase of wave energy. For this analysis, the wave time series were divided into eight segments, each of 4,096 points or $3.41 \mathrm{~min}$, except the first segment which was 2,048 points. Both the first and second segments started at the 400th data point or $t=20 \mathrm{~s}$ and the final segment ended at the 16,784 th data point or $t=$ 14.0 min. The segments overlapped by 2,048 data points, and each segment represented approximately 120 mean wave periods, except the first segment, which was about 60 wave periods long. For each segment, the incident $H_{m o}$ was calculated using the technique described above. Figures 4.6 and 4.7 show the wave height variation for $h_{t}=$ $11.9 \mathrm{~cm}$ and $h_{t}=15.8 \mathrm{~cm}$, respectively. In these figures, the ratio of the incident segment wave height $H_{m o}\left(t_{s d}\right)$ to the overall wave height $H_{m o}\left(t_{r}\right)$ is shown as a function of normalized duration $t_{s d} / t_{r}$ where $t_{s d}$ is the duration to the center of the segment and $t_{r}=$ $15 \mathrm{~min}$ is the total run duration. As can be seen from the figures, the wave height reached an equilibrium very early during each run. Based on these observations, the 
wave heights measured with the structure in place were used, as they were more accurate than those measured without the structure in place.

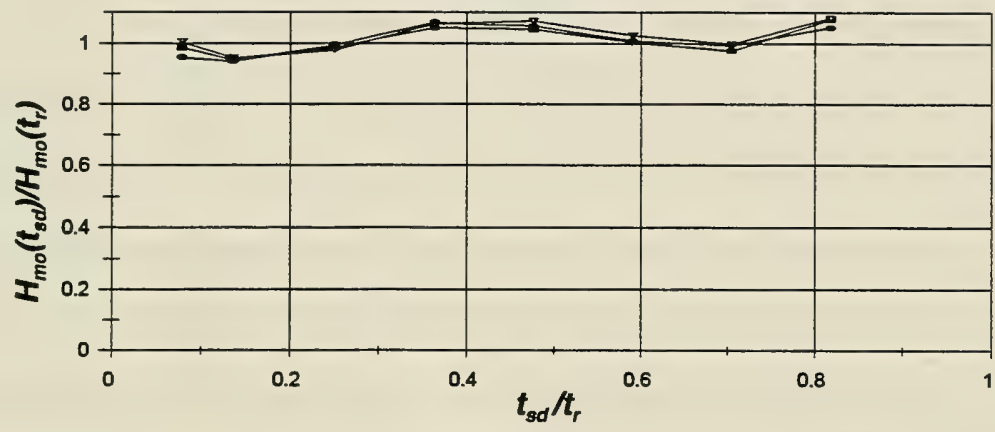

$\longrightarrow$ Wave $1 \longrightarrow$ Wave $2 \longrightarrow$ Wave 3

Figure 4.6. Wave height variation throughout Waves 1,2 , and 3 at $11.9 \mathrm{~cm}$ toe depth

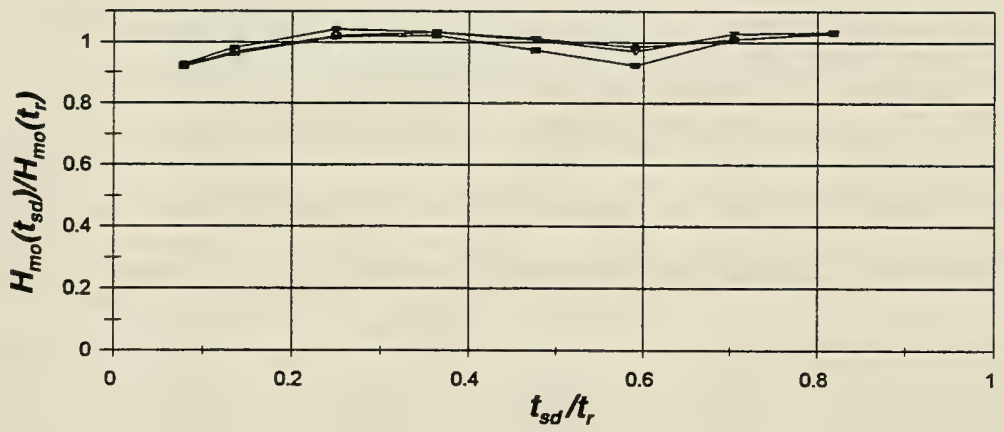

$\longrightarrow$ Wave $4 \longrightarrow$ Wave $5 \longrightarrow$ Wave 6

Figure 4.7. Wave height variation throughout Waves 4,5 , and 6 at $15.8 \mathrm{~cm}$ toe depth 
The wave reflection analysis as used assumed a flat sea bottom and that linear wave theory was valid. But the bottom of the flume sloped at $1 \mathrm{~V}: 20 \mathrm{H}$ and the waves were clearly nonlinear. An analysis was done to determine the sensitivity of the wave analysis method to selection of gage location and therefore beach slope. Using the depth at the center of the gage array in the reflection analysis, rather than the depth at Gage 1, resulted in no difference for $H_{m o}$, 2-percent difference for $H_{s}$, and 7-percent difference for $H_{2 \%}$. The difference in depths between Gage 1 and the array center was 12 percent. $H_{s}$ and $H_{m o}$ were more stable than $H_{2 \%}$ in this analysis. $H_{s}$ and $H_{m o}$ for Gage 1 closest to the toe were approximately the same for repeated tests. This is important, as the damage was shown to be approximately proportional to the fifth power of the wave height in the previous chapter, exaggerating any errors in wave height measurement. Therefore, the more stable values of $H_{s}$ and $H_{m o}$ are relied on in the analysis that follows. Comparison of measured wave heights with breaker index curves, such as Figure 7-2 of the SPM, showed that the maximum $H_{1 / 10}$ would just break at the mean period in the depth of the shallowest wave gage, approximately $1 \mathrm{~m}$ from the structure toe.

The Iribarren parameter or surf similarity parameter (Battjes 1974) is defined as

$$
\xi=\frac{\tan \theta}{\sqrt{\frac{H}{L_{o}}}}
$$


where $L_{o}=g T^{2} / 2 \pi$ and $\tan \theta$ is either the structure slope or the beach slope, depending on where the wave breaks. The wave height $H$ is usually either $H_{s}$ or $H_{m o}$, and the period is the mean period for armor stability (Van der Meer 1988). The Iribarren parameter can be used to characterize the type of wave breaking with $\xi<0.3$ corresponding to spilling waves, $0.3 \leq \xi \leq 2$ to plunging waves, $2 \leq \xi \leq 3$ to collapsing waves, and $\xi \gtrsim 3$ to surging waves. Van der Meer (1988) and others have used the structure slope in Equation 4.9. This is because they were primarily testing with nonbreaking waves on the beach. But for the experiment described herein, the wave heights were depth limited. So the beach slope was the critical parameter dictating the type of wave breaking near the structure and was therefore used to compute $\xi$. It is clear from Tables 4.3 and 4.4 that, for these tests, the most severe waves were primarily plunging. This corresponds to the design condition for most United States shoreline applications. The relative depths show that the wave condition selected is near the worst case for stability according to Figure 3.3.

The stability numbers shown in Table 4.4 were in the range $N_{\mathrm{s}}=1.6-2.5$. This is well within the range of $N_{\mathrm{s}}=1-4$ for conventional breakwaters suggested by Van der Meer (1988). On the other hand, stability coefficients in Table 4.4 based on $H_{1 / 10}$ are in the range 3.4-13.2 in comparison to $K_{D}=2.0$ recommended in the SPM for breaking waves on rough angular stone armor placed on a trunk. This indicates that the breakwaters in this experiment will incur some damage. 


\subsection{Effect of Overtopping on Stability}

The effect of wave overtopping on armor stability was investigated by Van der Meer and Daemen (1994). They gave a reduction factor for stable armor size as

$$
k_{o}=\frac{1}{1.25-4.8 R_{p}^{*}} \quad \text { for } 0<R_{p}^{*}<0.052
$$

with

$$
R_{p}^{*}=\frac{R_{c}}{H_{s}} \sqrt{\frac{S_{o p}}{2 \pi}} \quad S_{o p}=\frac{2 \pi H_{m o}}{g T_{p}^{2}}
$$

where $R_{c}$ is the freeboard or structure crest height above the still water level. There is an odd mix of wave height statistics in Equation 4.11. Substituting the conditions in the experiment discussed herein yields $R_{p}{ }^{*}$ of $0.063-0.076$ for the toe depth of $h_{t}=11.9 \mathrm{~cm}$ and $0.047-0.058$ for $h_{t}=15.8 \mathrm{~cm}$. Therefore, the 11.9-cm depth is outside the range of applicability of Equations 4.10 and 4.11. Actually, wave overtopping was negligible in the shallow depth of $h_{t}=11.9 \mathrm{~cm}$. For $h_{t}=15.8 \mathrm{~cm}$, the range of stable armor size reduction coefficients is $0.98 \leq k_{o} \leq 1.0$. Therefore, wave overtopping had negligible effect on stability of the armor layer.

\subsection{Armor Profiler and Profile Measuring Technique}

A structure profiler similar in concept to that used by Davies et al. (1994) was constructed. The profiler design and construction are described in detail in Winkelman (1998), who participated in the planning and setup of the project. The profiler, shown in Figures 4.8 and 4.9, consisted of eight aluminum profiling arms, 
laterally spaced at $5 \mathrm{~cm}$, which pivoted about a point on a sliding carriage. A rotating spheroid with diameter approximately $D_{n 50}$ at the end of each profiling arm followed the structure surface as the carriage passed over the structure, from just landward of the crest to just past the seaward toe.
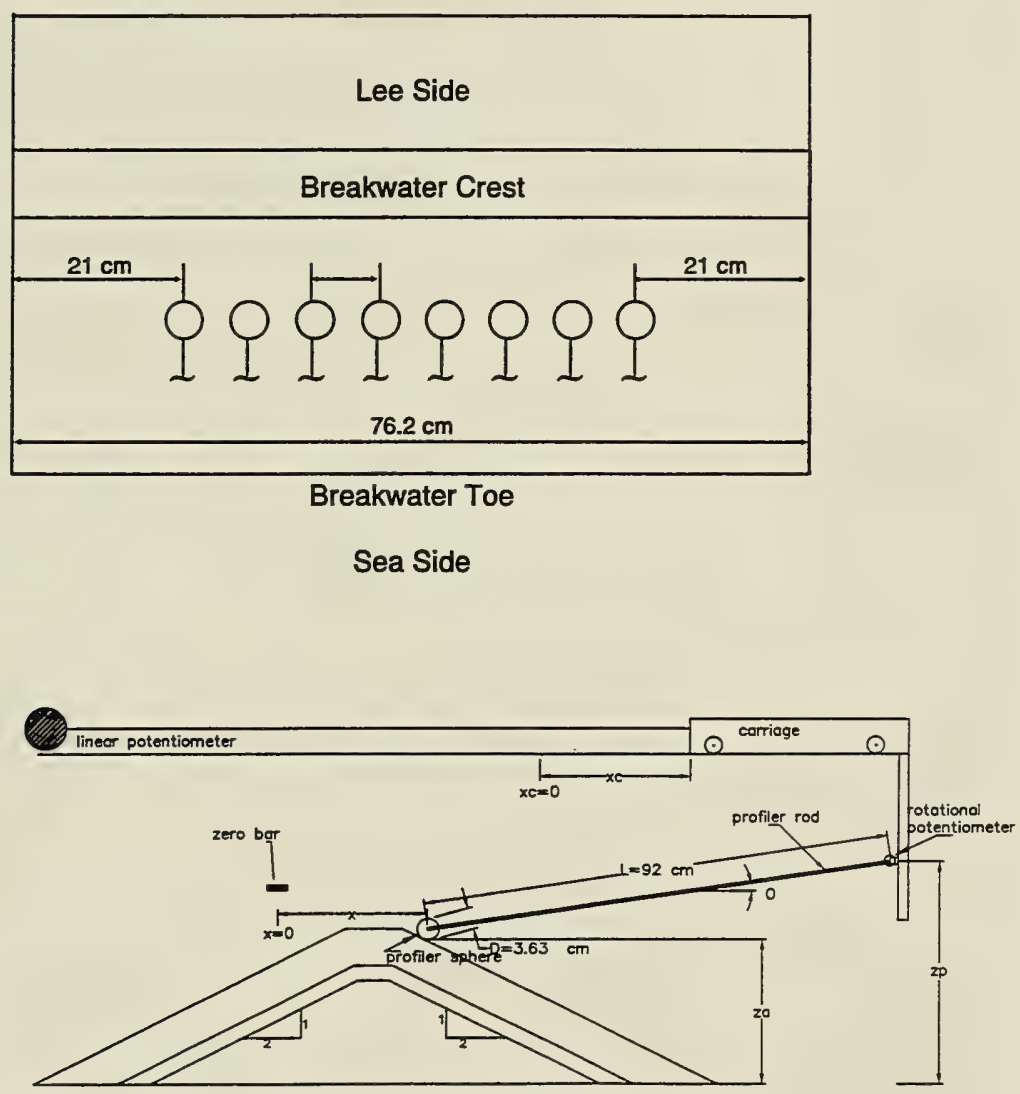

Figure 4.8. Plan (top) and profile (bottom) views of breakwater profiler 


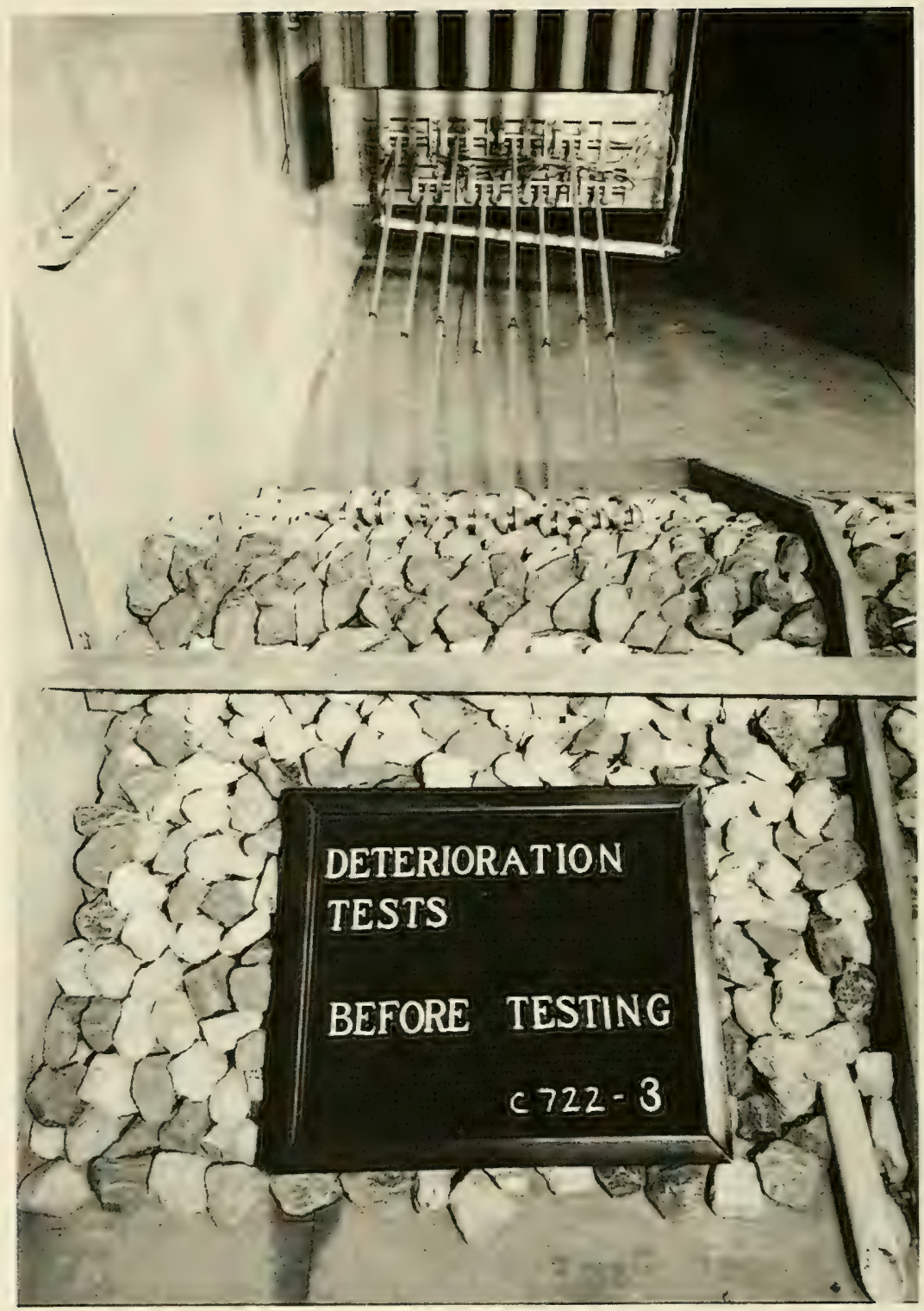

Figure 4.9. Photograph of breakwater profiler 
Note that acoustic and laser profiling instruments were available as alternatives to the mechanical system used, but the signal returns off the irregular stone surfaces were poor resulting in unacceptably high data analysis requirements and low accuracy. Also, these backscatter-type sensors were generally an order of magnitude more costly. The spheroid diameter was chosen to coincide with that of Davies et al. (1994) so that results could be compared and was nearly twice the diameter of the sounding disc in the WES eroded volume method. In the present case, the sphere provides varying resolution of voids depending on the depth of penetration between stones and so corresponds to a range of sounding disc sizes. No attempt is made herein to relate the sphere size to the WES sounding disc size since there exist no damage progression data from the historical records that are directly comparable with data obtained for the present study. The profiler arm pivot point was at a fixed elevation just above the crest of the structure with the profiler arms extending back toward the structure. The angle of an arm at any point during the profiling process was determined through recorded voltages from rotational potentiometers attached to the pivot on the carriage. The location of the carriage was determined using a linear potentiometer fixed to the flume wall.

It was required that the profiler arms be just heavy enough to continuously follow the structure without plowing, or moving stones. Another requirement was that the structure be profiled without lowering the water level between runs. Therefore, the hinge point, rod length, rod and ball weight, and counter weight were chosen to provide 
an optimal balance over the length of the slope, where the profiling rods were out of water at the crest and partially submerged at the toe.

The power input to, and analog output from, each of the potentiometers was controlled by a personal computer (PC)-based data acquisition system. Analog-todigital data conversion and signal conditioning and recording were performed using an Optim MEGADAC 5000. The MEGADAC had 4 MB of internal memory and could sample up to $250 \mathrm{kHz}$ from 20 channels. The heart of the MEGADAC consisted of AD682SH modules that included 12-bit differential input analog-to-digital converters and programmable Bessel filters. The MEGADAC also included power amplifiers to provide power to the potentiometers. The digital voltages were recorded to a hard disk within the PC at $20 \mathrm{~Hz}$. The speed of the carriage over the structure varied, so this sampling rate produced a variable spatial sampling resolution. But, in general, the horizontal cross-shore sampling resolution was approximately one sample per millimeter. Optim, Inc. TCS software was utilized to control data acquisition.

Prior to each day's tests, the profiler was calibrated by first recording the rotational potentiometer voltages with the rods positioned horizontally on a jig that was set using high-resolution tiltometers. Then the rods were swung through a known angle and the voltage differences recorded. The resulting voltage-to-angle ratios provided a daily specific calibration coefficient for each potentiometer. Prior to each profile, the output voltage for each potentiometer was set to zero on the fixed bar just above the breakwater crest. 
The elevations of each sphere bottom above the toe, $z_{a}$, and horizontal distances from an arbitrary starting point, $x_{a}$, were determined using the potentiometer measurements. The profiler sphere horizontal coordinate was computed as $x_{a}=x_{c}+$ $L(1-\cos \phi)$, relative to $x_{a}=0$ with $\phi=0$, and the profiler sphere vertical elevation above bottom was computed as $z_{a}=z_{p}-L \sin \phi-D / 2$, where $L=$ length of the profiler arm from pivot point to center of sphere, $\phi=$ angle of the arm from horizontal, $D=$ sphere diameter, $x_{c}=$ transverse distance the carriage moved, and $z_{p}=$ elevation of the arm pivot point. Figure 4.8 shows a definition sketch for this transformation, where the initial carriage position $x_{c}=0$ corresponds to the initial sphere position $x_{a}=0$ with $\phi=$ 0 . The measured sphere elevations were averaged over a $0.5-\mathrm{cm}$ interval in the crossshore direction to remove small variations in elevations resulting from minor stone settlements that occurred during the tests. This is an essential step as this "noise" will cause a bias in the eroded area calculation.

For each arm, the eroded area was calculated using a Simpson's Rule numerical integration of the damaged profile below the undamaged profile. The eroded depth was determined as the maximum slope-normal distance between undamaged and damaged profiles. This slope-normal distance was calculated using a numerical technique beginning at each point on the eroded profile and stepping along a line normal to the slope of $\cot \theta=2$ until the undamaged profile was crossed. Then the point at which the crossing occurred was interpolated to obtain the slope-normal distance. The slope-normal minimum depth of cover at a given time $t$ was calculated as the minimum 
vertical difference between eroded profile and underlayer multiplied by the cosine of the structure slope angle or

$$
d_{c}(t)=\min \left[z_{a}(x, t)-z_{u}(x, t=0)\right] \cos \theta
$$

where min indicates the minimum value with respect to $x, z_{a}(x, t)$ is the damaged profile elevation at location $x$ and time $t$, and $z_{u}(x, t=0)$ is the underlayer elevation at $x$ before testing began. The numerical interpolation technique used to compute the eroded depth was not required for the depth of cover as the underlayer was smooth relative to the profiler probe size in comparison to the undamaged armor profile. 


\section{Chapter 5}

\section{DAMAGE MEASUREMENTS}

\subsection{Overview}

In all, five test series were conducted with two structures in the flume within this initial experiment. The first test was not repeated. The other four series included two originals and two repeats; so three unique series were conducted and will be described in Chapters 5 and 6: Series $A^{\prime}, B^{\prime}$, and $C^{\prime}$. As noted earlier, additional test series were added to investigate wave period and armor gradation and they are discussed in Chapter 7. Table 5.1 describes the test sequences for Series $A^{\prime}, B^{\prime}$, and $C^{\prime}$. Tables B1 through B3 in Appendix B provide a more detailed summary of the Series $A^{\prime}, B^{\prime}$, and $C^{\prime}$.

\begin{tabular}{||c|c|c|c|c||}
\hline \multicolumn{4}{||c||}{$\begin{array}{l}\text { Table 5.1 } \\
\text { Summary of Test Series for Initial Damage Experiment }\end{array}$} \\
\hline \hline $\begin{array}{c}\text { Test } \\
\text { Series }\end{array}$ & $\begin{array}{c}\text { Test } \\
\text { Type }\end{array}$ & $\begin{array}{c}\text { Order of Wave } \\
\text { Conditions } \\
\text { (Tables 2 and 3) }\end{array}$ & $\begin{array}{c}\text { Water-Level } \\
\text { Order }\end{array}$ & $\begin{array}{c}\text { Test Duration, } \\
\text { hr }\end{array}$ \\
\hline \hline$A^{\prime}$ & $\begin{array}{c}\text { Deterioration to } \\
\text { failure }\end{array}$ & $1,2,3,4,5,6$ & Low - High & 28.5 \\
\hline$B^{\prime}$ & Storm ordering & $1,2,3,5,6$ & Low - High & 8.5 \\
\hline$C^{\prime}$ & Storm ordering & $4,5,6,2,3$ & High - Low & 9.0 \\
\hline
\end{tabular}


For Series $A^{\prime}$, lasting $28.5 \mathrm{hr}$, the general experimental strategy was designed to provide an indication of the long-term deterioration of a structure. The structure was exposed to waves until failure, where the underlayer was visible through a hole in the armor layer at least $D_{n 50}$ in diameter. For this series, the experiment began at the lower water depth and progressed through each of the three wave heights listed in Tables 4.3 and 4.4, reaching an apparent equilibrium (visually observed) at each. Then the water level was raised, and each of the three wave conditions at the greater depth was run until an apparent equilibrium was achieved. The structures were exposed to a total of approximately 60,000 waves for Series $A^{\prime}$. This is equivalent to 100 to $250 \mathrm{hr}$ of accumulated prototype storms for mean wave periods ranging from 7 to $15 \mathrm{sec}$. The number of waves was computed by dividing the run length by the mean period of the incident wave time series.

For Series $B^{\prime}$ and $C^{\prime}$, the testing strategy was intended to simulate damage from a sequence of individual storms. So for $B^{\prime}$ and $C^{\prime}$, each wave-water level condition was run for approximately 4,200 waves, representing roughly10-hr prototype storms. For $B^{\prime}$ and $C^{\prime}$, each sequence was run twice. And because there were two structures in the flume, this testing provided an original and three repeats to determine statistical variabilities. The total run length for $B^{\prime}$ and $C^{\prime}$ was 8.5 and $9 \mathrm{hr}$ or approximately 18,000 waves. Damage did not progress to failure for Series $B^{\prime}$ and $C^{\prime}$. In Series $B^{\prime}$, the three wave heights at the low water level were run first (Waves $1,2,3$ ), followed by the two highest wave heights at the high water level (Waves 5,6). Series $C^{\prime}$ was similar 
except the high-water condition was run first followed by the low-water condition

(Waves 4, 5, 6, 2, 3). Throughout the experiment, the waves were run in 15 min bursts, with the water completely settling between wave bursts. Profiles were measured after each two of these bursts, every $30 \mathrm{~min}$ of waves.

\subsection{Damage and Eroded Profile Parameters}

In Chapter 3, damage was characterized by the nondimensional eroded area $S$ defined by Equation 3.1, and this parameter is used to describe damage herein. For a damage analysis, the shape of the eroded portion of the slope may be characterized by three parameters of primary engineering interest shown in Figure 5.1: cover depth $d_{c}$, eroded depth $d_{e}$, and eroded length $l_{e}$. The cover depth, the minimum remaining depth of the cover layer along a profile, was shown by Torum et al. (1979) and Davies et al. (1994) to be a useful parameter to characterize the reserve capacity of the armor layer. For this experiment, the nondimensional cover depth was computed as the minimum depth of armor layer remaining for each measured profile after each 30 min of waves and normalized by the nominal stone diameter as

$$
C=\frac{d_{c}}{D_{n s 0}}
$$

where $d_{c}$ was computed using Equation 4.12 and $C$ is the normalized minimum cover depth. 


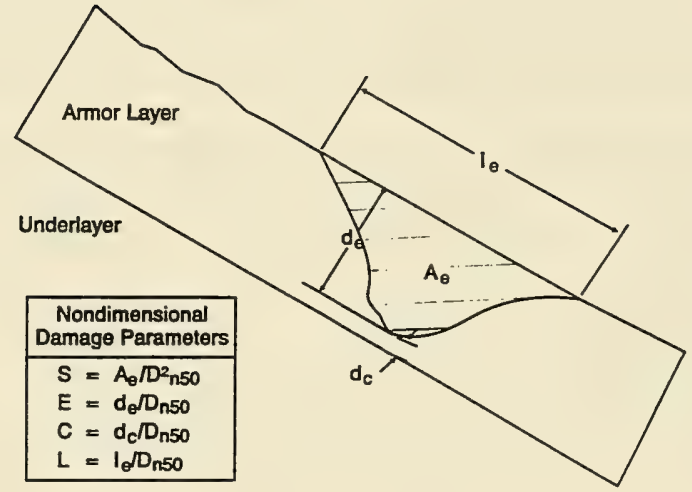

Figure 5.1. Sketch of breakwater profile with definition of damage parameters

In this study, eroded depth and eroded length are introduced to describe the shape of the eroded area. They are parameters of primary engineering interest, providing a description of extent of damage normal to and along the slope, respectively. The eroded depth is defined as the maximum difference between undamaged and damaged profiles measured normal to the slope and is normalized as

$$
E=\frac{d_{e}}{D_{n 50}}
$$

The eroded depth is useful because it gives an indication of progress toward failure, particularly if failure is defined by exposure of the underlayer. The sum of eroded depth and cover depth is approximately equal to the initial cover layer thickness $t_{a}$

$$
t_{a} \approx(E+C) D_{n 50}
$$


which is only approximate because the maximum $d_{e}$ and the minimum $d_{c}$ may not occur at the same location due to variability in the original layer thickness.

The eroded length $l_{e}$ is defined herein as

$$
l_{e}=\frac{2 A_{e}}{d_{e}}
$$

and the normalized eroded length is given by

$$
L=\frac{l_{e}}{D_{n 50}}=\frac{2 A_{e} / D_{n 50}^{2}}{d_{e} / D_{n 50}}=\frac{2 S}{E}
$$

Here the dimensional eroded length $l_{e}$ is not measured directly, but is a derived value. It is roughly equivalent to the surface length of the eroded region along a profile. As seen in Figure 5.1, the eroded length characterizes the along-profile length of the roughly triangular eroded area and describes the along-slope extent of damage.

\subsection{Probability Density Functions of Damage, Eroded Depth, and Cover Depth}

The number of damage profiles measured at a given time during damage progression is denoted by $N_{p}$ in the following, where $N_{p}=16$ for Series $A^{\prime}$ and $N_{p}=32$ for Series $B^{\prime}$ and $C^{\prime}$. The $N_{p}$ values for $S, E$, and $C$ are analyzed statistically to reduce the number of measured values and separate the variability along the structure from the temporal variation associated with damage progression. First, the mean and standard deviation of the $N_{p}$ values of $S, E$, and $C$ are calculated. The standard deviations $\sigma_{S} \sigma_{E}$. 
and $\sigma_{C}$ of $S, E$, and $C$ indicate the variability of $S, E$, and $C$ among the $N_{p}$ profiles. The means and standard deviations of $S, E$, and $C$ vary with damage progression.

The $N_{p}$ values of $S, E$, and $C$ are normalized as

$$
S^{*}=\frac{S-\bar{S}}{\sigma_{S}} ; \quad E^{*}=\frac{E-\bar{E}}{\sigma_{E}} ; \quad C^{*}=\frac{C-\bar{C}}{\sigma_{C}}
$$

where the means, indicated by overbars, and the standard deviations, $\sigma$, of $S^{*}, E^{*}$, and $C^{*}$ are zero and unity, respectively. As an example, the mean and the standard deviation for Series $A^{\prime}$ after each $30 \mathrm{~min}$ of waves were computed as

$$
\begin{gathered}
\bar{S}=\frac{1}{N_{p}} \sum_{n=1}^{N_{p}} S_{n}, \quad N_{p}=16 \\
\sigma_{S}=\sqrt{\frac{1}{N_{p}} \sum_{n=1}^{N_{p}}\left(S_{n}-\bar{S}\right)^{2}}, \quad N_{p}=16
\end{gathered}
$$

where $S_{n}$ is the individual measured value of $S$. The probability density functions $P\left(S^{*}\right)$, $P\left(E^{*}\right)$, and $P\left(C^{*}\right)$ are calculated using the $N_{p}$ values of $S^{*}, E^{*}$, and $C^{*}$, respectively, where the range between the maximum and minimum values is divided into eight bins of constant spacing. Admittedly, eight bins do not yield a fine resolution, but the number of data points for this estimation is limited to $N_{p}=16$ or 32 .

In summary, the $N_{p}$ damaged profiles measured every $0.5 \mathrm{hr}$ yield one data set consisting of means and standard deviations of $S, E$, and $C$ and the probability 
density functions of $S^{*}, E^{*}$, and $C^{*}$. The number of data sets is 57 for Series $A^{\prime}$ lasting $28.5 \mathrm{hr}, 17$ for Series $B^{\prime}$ lasting $8.5 \mathrm{hr}$, and 18 for Series $C^{\prime}$ lasting $9.0 \mathrm{hr}$. For the undamaged profile at the beginning of each test series, $S=0$ and $E=0$, which yield $\bar{S}_{0}=0, \sigma_{S_{0}}=0, \bar{E}_{0}=0$, and $\sigma_{E_{0}}=0$, where the subscript zero indicates initial values. For an undamaged structure, the probability density functions of $S$ and $E$ are the delta functions with a spike at $S=0$ and $E=0$, but $S^{*}$ and $E^{*}$ defined in Equation 5.6 cannot be computed because $\sigma_{S_{0}}=0$ and $\sigma_{E_{0}}=0$. On the other hand, the normalized cover depth $C$ for the undamaged profile is a statistical variable related to the placement of the armor layer. The $N_{p}$ undamaged profiles are analyzed in the same way to obtain the mean $\bar{C}_{0}$, the standard deviation $\sigma_{C_{0}}$, and the probability density function $P\left(C^{*}\right)$ at the beginning of each test series.

The probability density functions of $S^{*}, E^{*}$, and $C^{*}$ exhibit large scatters but do not indicate any specific variations with damage progression and among the three test series. All 92 data sets of $P\left(S^{*}\right)$ and $P\left(E^{*}\right)$ are plotted together in Figures 5.2 and 5.3, respectively, whereas all 95 data sets of $P\left(C^{*}\right)$ are plotted in Figure 5.4. The standard normal distribution given by

$$
P(y)=\exp \left(-0.5 y^{2}\right) / \sqrt{2 \pi}
$$

with $y=S^{*}, E^{*}$, or $C^{*}$ is also shown in each figure for reference. Note that a fit to the distribution was not attempted because each data set consisted of too few points to determine the fit error. The data points in these figures scatter about the normal 
distribution. The approximate ranges of the data points in these figures may be chosen as

$$
-2.7<S^{*}<3 ; \quad-2.7<E^{*}<2.7 ; \quad-2.7<C^{*}<2.8
$$

which are in the range from -3 to 3 . The corresponding ranges of $S, E$, and $C$ can be found using Equations 5.6 and 5.10. This approximate procedure allows one to estimate the lower and upper limits of $S, E$, and $C$ in terms of their means and standard deviations, which vary with damage progression.

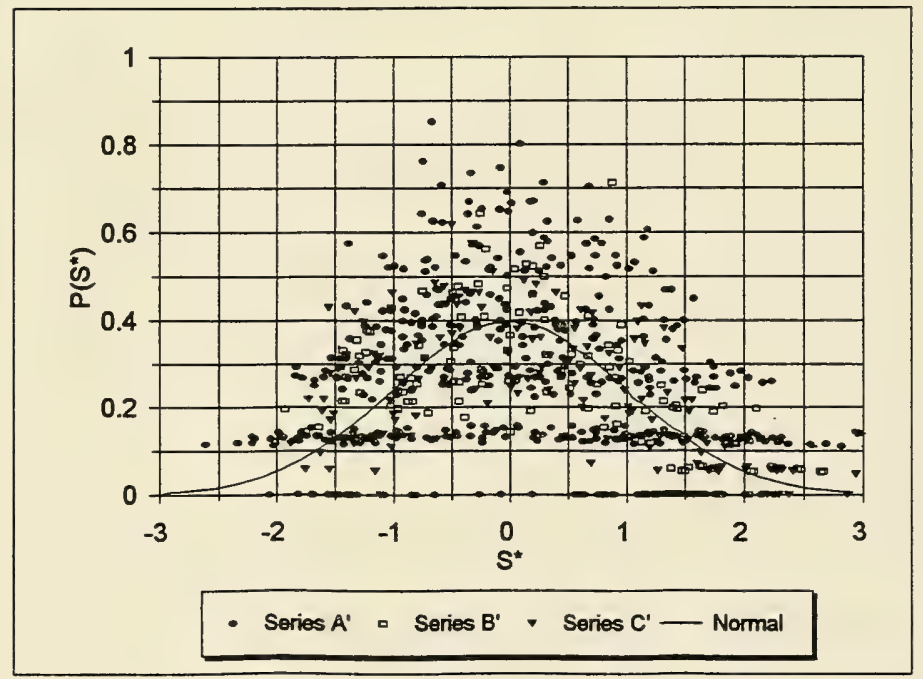

Figure 5.2. Probability density function for normalized damage $S^{*}$ for Series $A^{\prime}, B^{\prime}$, and $C^{\prime}$ 


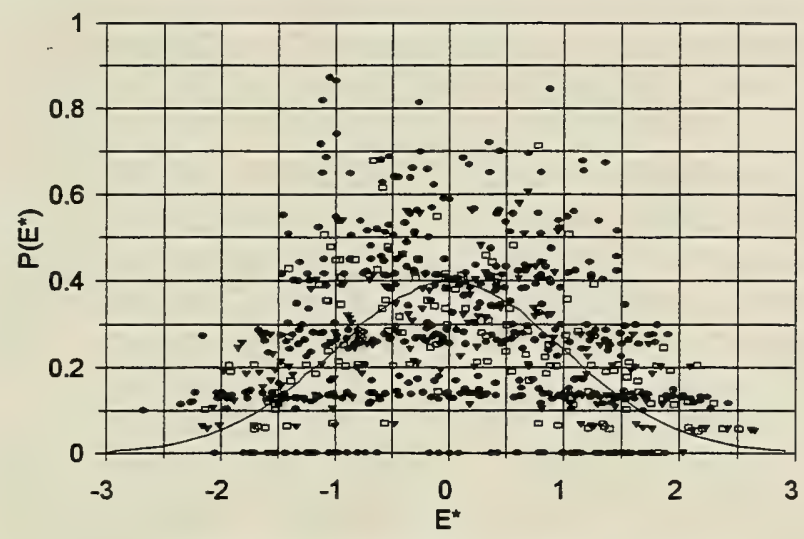

- Series $A^{\prime}$ a Series B' - Series $C^{\prime}$ - Normal

Figure 5.3. Probability density function for normalized eroded depth $E^{*}$ for Series $A^{\prime}$, $B^{\prime}$, and $C^{\prime}$

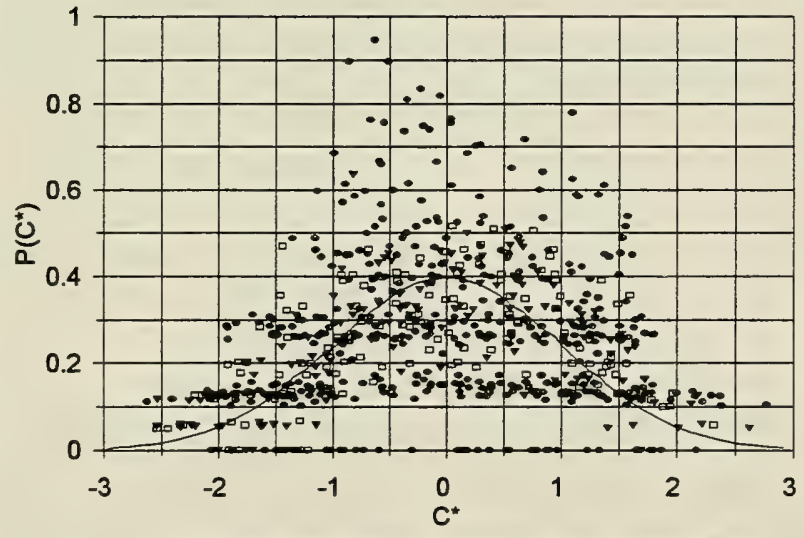

- Series $A^{\prime}$ - Series $B^{\prime}$ - Series $C^{\prime} \longrightarrow$ Normal

Figure 5.4. Probability density function for normalized cover depth $C^{*}$ for Series $A^{\prime}, B^{\prime}$, and $C^{\prime}$ 


\subsection{Temporal Damage Development}

The means and standard deviations of $S, E$, and $C$ are used hereafter to examine damage progression. Figure 5.5 shows the structures prior to Series $A^{\prime}$. Figures 5.6 through 5.8 show the measured profiles at the beginning, midway through, and at the end of Series $A^{\prime}$. In Figure 5.6, one profile and the average of all eight profiles on one of the structures at the beginning of Series $A^{\prime}$ are shown. In Figure 5.7, the average profile is shown along with a photo of the structures at the midway point of the series. This figure corresponds to an average damage level of $\bar{S}=6.5$. It may be seen from the photo that the top stones in the cover layer have been eroded sporadically over a wide region near the still water level. Figure 5.8 shows one profile and the average profile at the end of Series $A^{\prime}$, where the underlayer is exposed through a hole of $D_{n 50}$ diameter. Figure 5.9 shows photos of the structures following Series $A^{\prime}$. It is clear that most of the armor layer has been mobilized. 

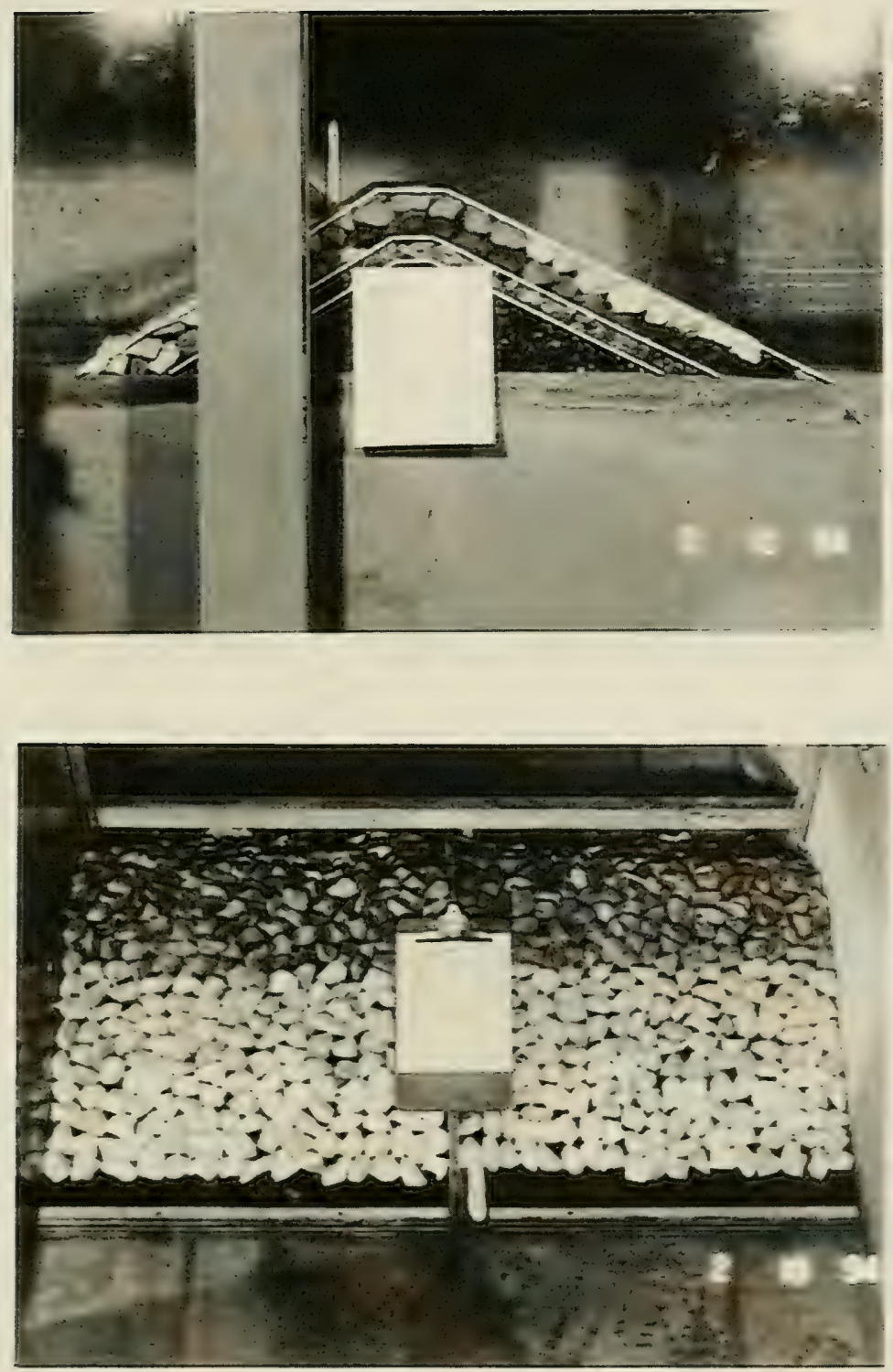

Figure 5.5. Photographs of undamaged structures prior to Series $A^{\prime}$ 

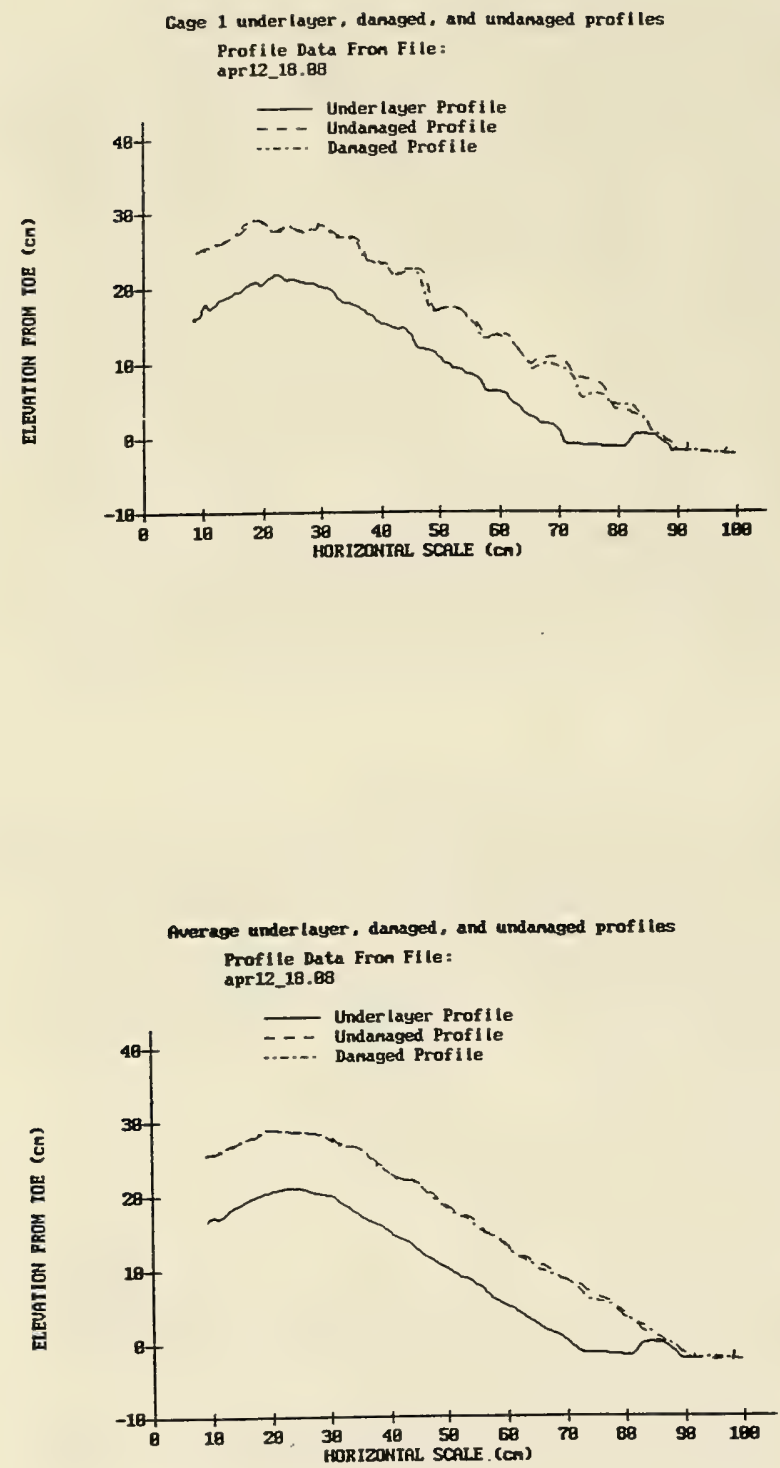

Figure 5.6. Profiles at beginning of Series $A^{\prime}$, damage level of $\bar{S} \approx 0$ 

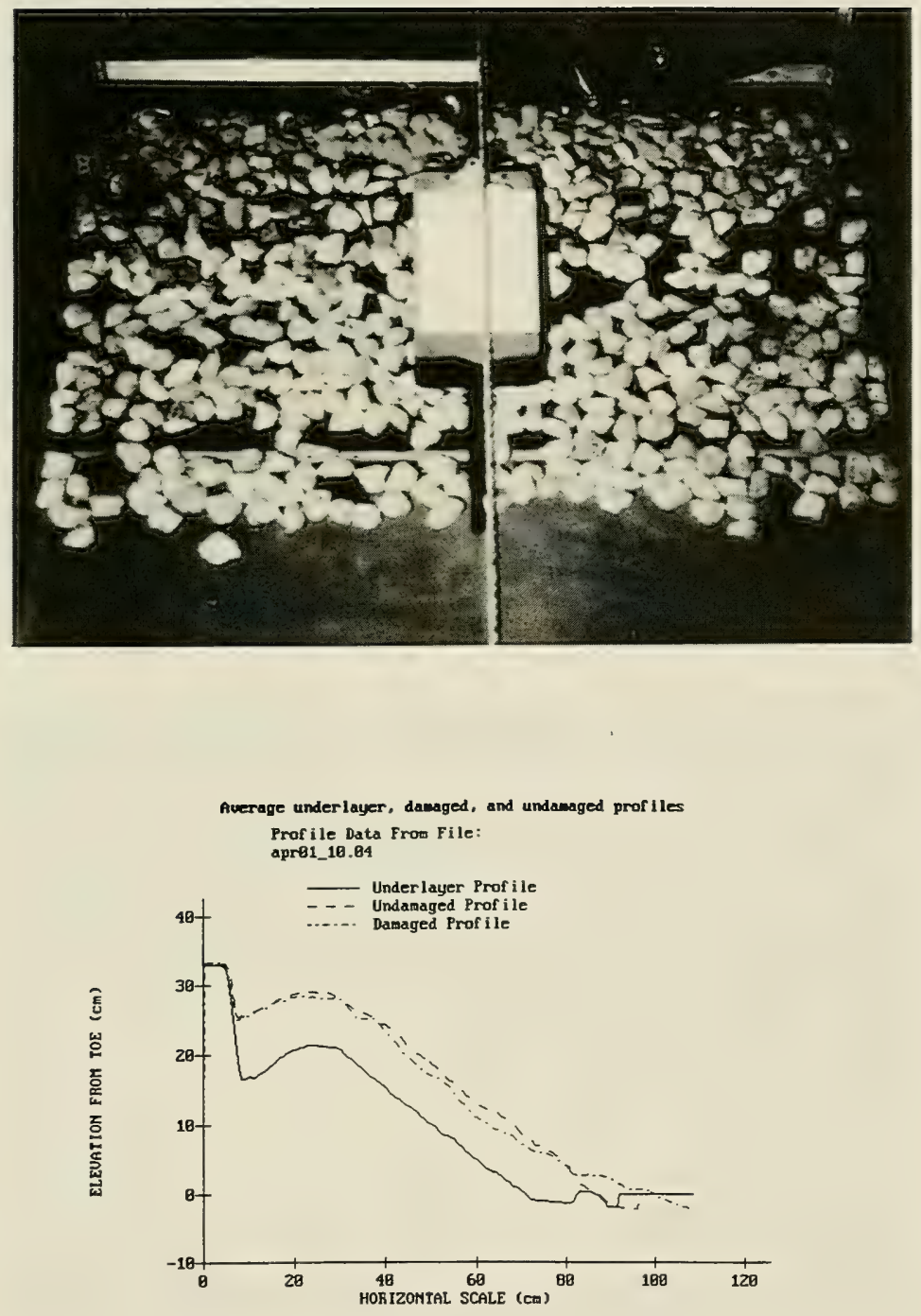

Figure 5.7. Profiles midway through Series $A^{\prime}$, damage level of $\bar{S}=6.5$ 
Gage 1 underlayer, damaged, and undamaged profiles Profile Data From File: apro1_31.13

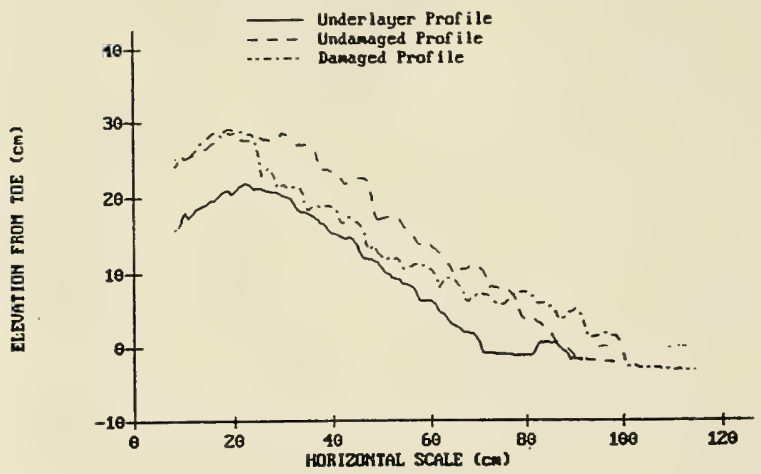

Average underlayer, dasaged, and undanaged profiles Proflle Data Fron File:

apre1_31.13

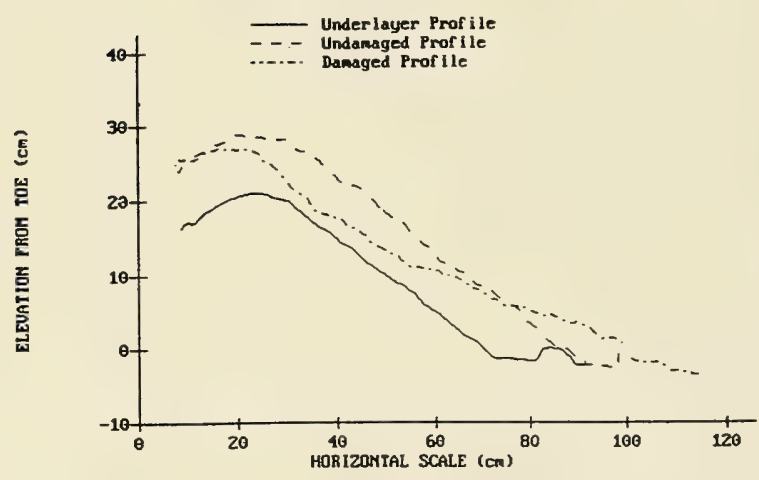

Figure 5.8. Profiles following completion of Series $A^{\prime}$, damage level of $\bar{S}=12.8$ 

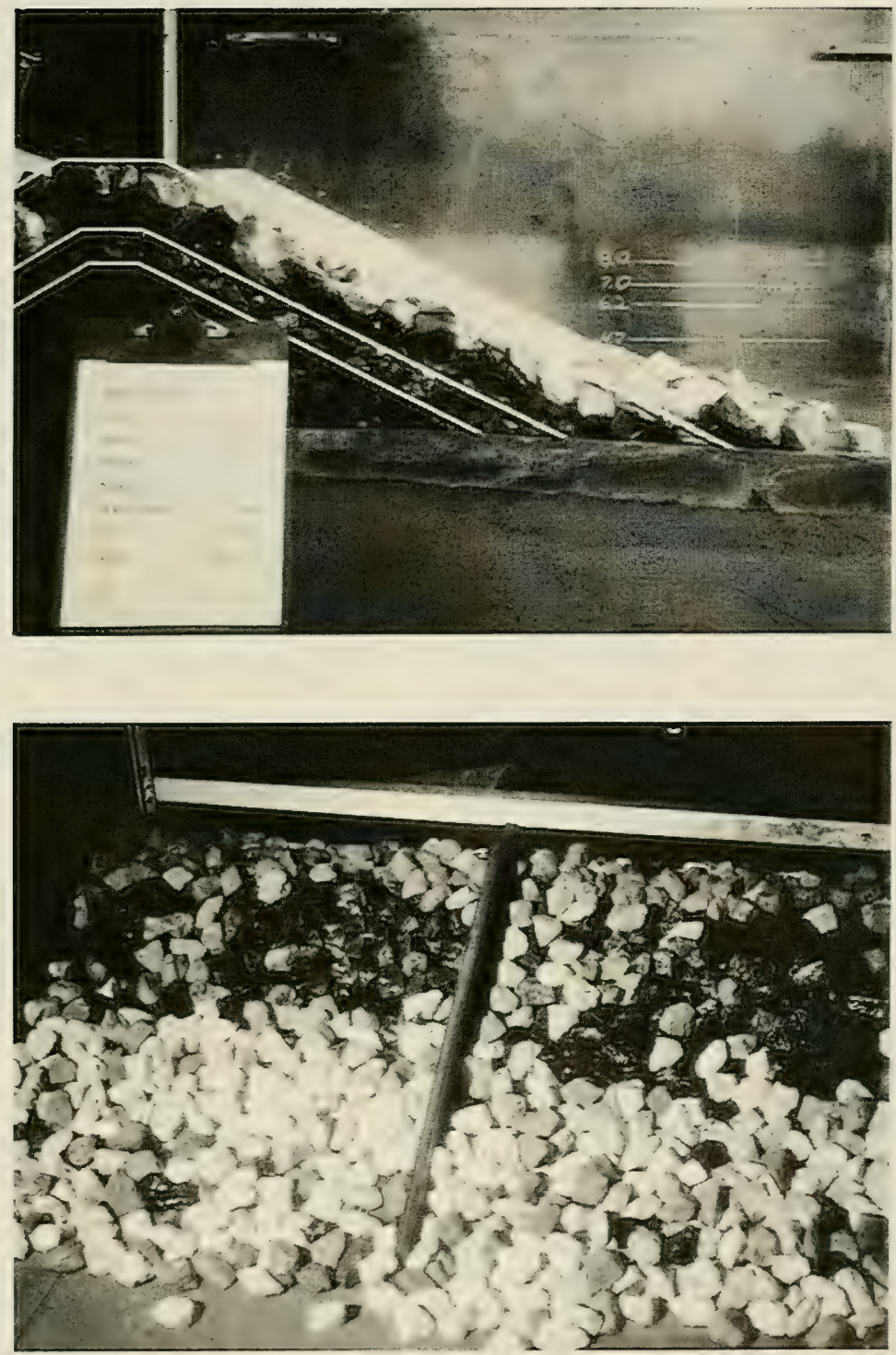

Figure 5.9. Photographs of structures following completion of Series $A^{\prime}$, damage level of $\vec{S}=12.8$ 
Figure 5.10 shows the number of waves $N_{w}$ versus the measured average damage $\bar{S}$ for Series $A^{\prime}$ for $N_{p}=16$. Here, the cumulative number of waves $N_{w}$ is obtained using the mean wave period $T_{m}$ from Table 4.4 and duration of Waves 1-6 listed in Table B1 in Appendix B. Also shown are the alongshore variability of damage as one standard deviation above and below $\bar{S}$. For Series $A^{\prime}$, waves were run at the initial depth until the structure appeared to stabilize, which occurred after approximately 22,000 waves. At that point, the water depth was raised. As noted in Table 4.4, the stability number ranged from 1.6 to 2.2 for the shallower depth and from 1.7 to 2.5 for the deeper depth. In this figure, the significant wave heights $H_{s}$ and associated stability numbers $N_{s}$ are listed across the top of the figure, while the water depths at the toe are listed across the bottom of the figure.

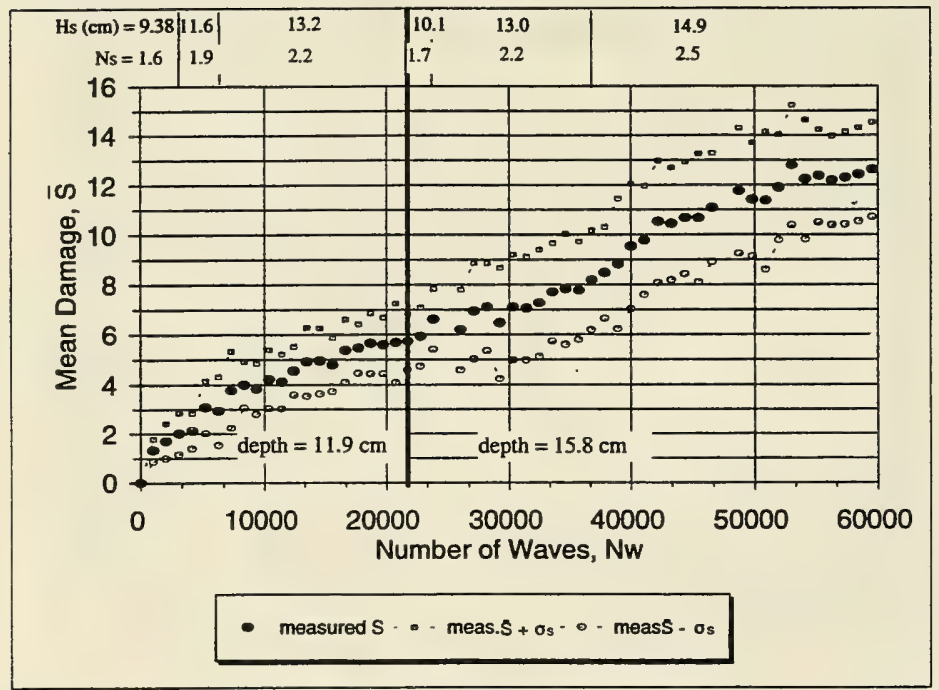

Figure 5.10. Number of waves versus mean damage \pm one standard deviation for Series $A^{\prime}$ 
Figure 5.10 shows that the rate of damage increased with wave height, and damage became more scattered as the damage increased. Although the wave heights were reduced when the depth was increased approximately midway through the run, the damage continued to increase. This was due to the fact that, when the depth was increased, several stones higher on the structure (at the new still water level) were displaced down into the damage area, which was centered at the lower still water level. This can be seen in Figure 5.10 as small jumps in eroded area after the depth change. These small increments of damage approximately correspond to one stone displaced.

Although the structure visually appeared to stabilize at various times during Series $A^{\prime}$, Figure 5.10 indicates that the structure never really stabilized or reached equilibrium, where further waves produced no additional damage. Thompson and Shuttler (1976) noted this for their riprap tests. It is also clear that an extraordinarily large number of waves was required to induce failure. For Series $A^{\prime}$, approximately 60,000 waves at significant wave heights appreciably greater than the no-damage wave height were required to fail the structure. Again, failure was defined as exposure of the underlayer through a hole at least $D_{n 50}$ in diameter. A higher mean damage value at failure was recorded for Series $A^{\prime}$ than was noted by Van der Meer (1988). Van der Meer quoted a failure damage value of $\bar{S}=8$, whereas $\bar{S}=13$ at failure for Series $A^{\prime}$. It was noted during the series that the waves had a difficult time moving the second layer of stones. This led to high damage values at failure, with most of the first layer of stones moved before the second layer began moving. Most other recent damage testing 
has been done with riprap, which consists of stone having a wide mass distribution (Thompson and Shuttler 1976; Davies et al. 1994). Riprap may not exhibit this secondary armoring because the small stones in the mass distribution are continuously moving. Deterioration of a riprap layer is examined in Chapter 7.

The sawtooth nature of the damage curves was caused by partial selfhealing. If a stone moved out of its location and started downslope, the next profile would show a hole and relatively increased damage. But during the following wave burst, the hole would fill in through adjustment of surrounding stone so that the next profile would show a partially healed structure. This healing process can be clearly seen in Figure 5.10 just after the water level was raised. Over time, the structure became more and more loosened, to the point that it could no longer heal itself because the surrounding stones were also displaced.

Series $B^{\prime}$ and $C^{\prime}$ were similar to Series $A^{\prime}$ in that the wave and water level sequences were similar; but the durations and ordering of the storms were different for $B^{\prime}$ and $C^{\prime}$. The results of Series $B^{\prime}$ and $C^{\prime}$ are tabulated in Appendix B. Mean damage versus number of waves for the storm sequences of Series $B^{\prime}$ and $C^{\prime}$ are shown in Figures 5.11 and 5.12. Also shown are the variability as a standard deviation above and below the mean. For these series, the 32 profiles were used to compute each data point, corresponding to the four repeats with eight profiles each. The characteristics of armor deterioration for Series $B^{\prime}$ were similar to Series $A^{\prime}$ because the order of the storms was the same for both series. But for Series $C^{\prime}$, Waves 4-6 at the high-water level increased 


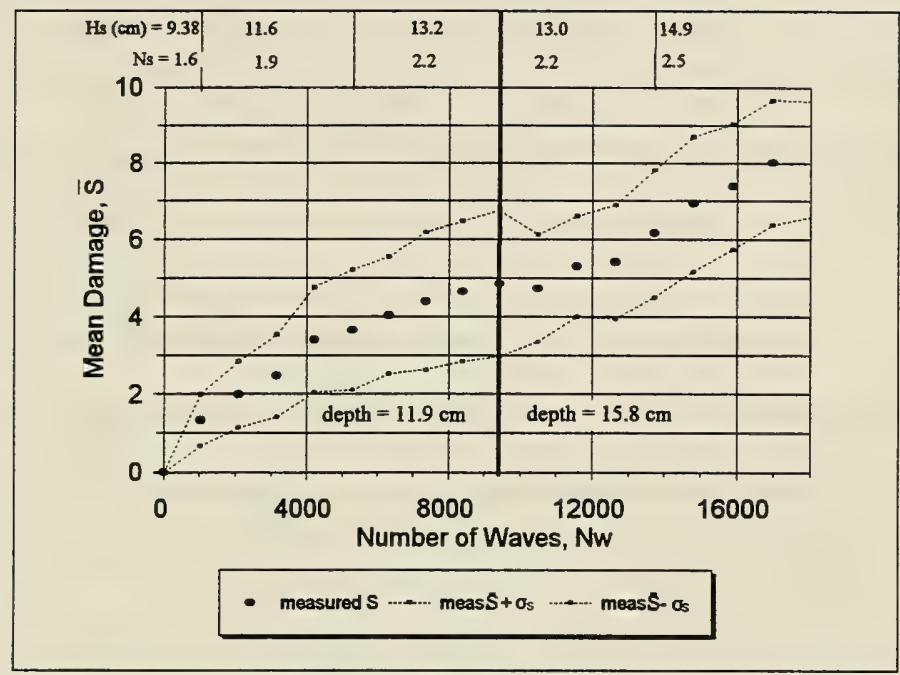

Figure 5.11. Number of waves versus mean damage \pm one standard deviation for Series $B^{\prime}$

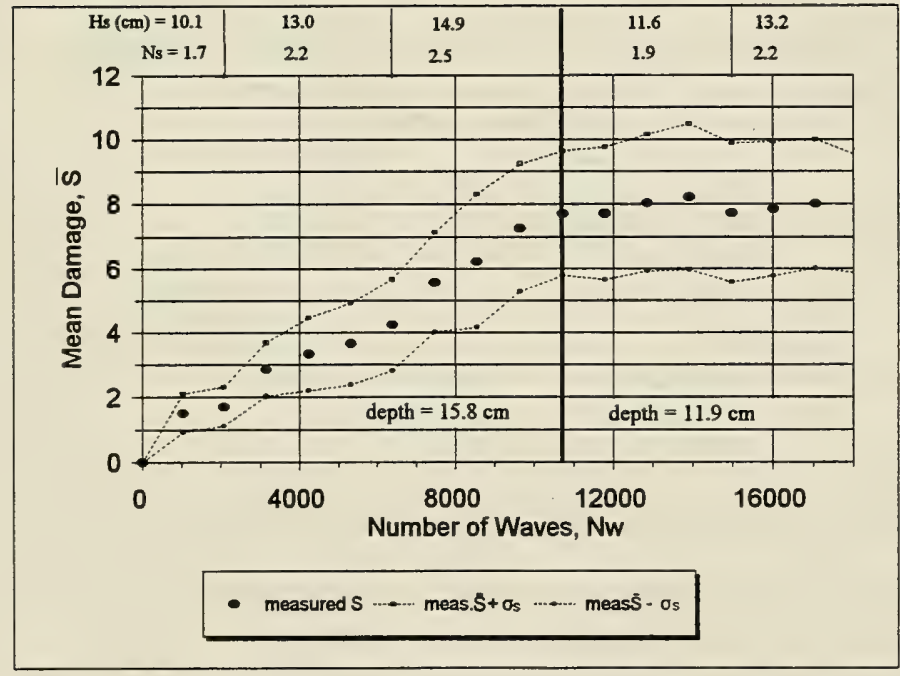

Figure 5.12. Number of waves versus mean damage \pm one standard deviation for Series $C^{\prime}$ 
damage initially. Waves 2 and 3 at the lower water followed but caused little additional damage to the segment of the armor layer damaged by Waves 4-6. This suggests that the damaged armor layer can withstand subsequent wave action at a lower intensity if the wave action is confined to the damaged area.

As one would expect, the damage rates differed for the different storm ordering. But the ultimate damage at the end of the storm sequence was surprisingly consistent. Both the mean damage and the standard deviation for the four repeats were consistent. At the end of Series $B^{\prime}$ and $C^{\prime}$ after approximately 18,000 waves, $\bar{S}=8$ and $\sigma_{s}=2$ for both series. Although the testing was by no means comprehensive, it suggests that damage and variability are similar after being exposed to similar cumulative wave action with different sequences. This is useful in determining the reliability of a structure because the cumulative damage may be assumed to be the sum of damages caused by individual storms.

\subsection{Characteristics of Profile Erosion}

For Series $A^{\prime}$, the mean minimum cover depth was computed as the average of the minima from the 16 profiles, while the mean eroded depth was computed as the mean of the maxima from the 16 profiles. Figure 5.13 shows the mean eroded depth versus number of waves, and Figure 5.14 shows the mean cover depth versus number of waves, both for Series $A^{\prime}$. These figures clearly show the periodic healing process as a jagged sawtooth shape to the curves. They also show that the armor layer thickness decayed to an equilibrium level, with an asymptote at $C=0$. Figure 5.15 shows that the 
eroded length jumps to a level of $\bar{L} \approx 7$ initially and then increases with the number of waves in a manner similar to damage, as one would expect. The initially large value of $\bar{L}$ computed from a small value of $\bar{E}$ illustrates that there was quite a lot of stone settlement but not displacement as damage was initiated.

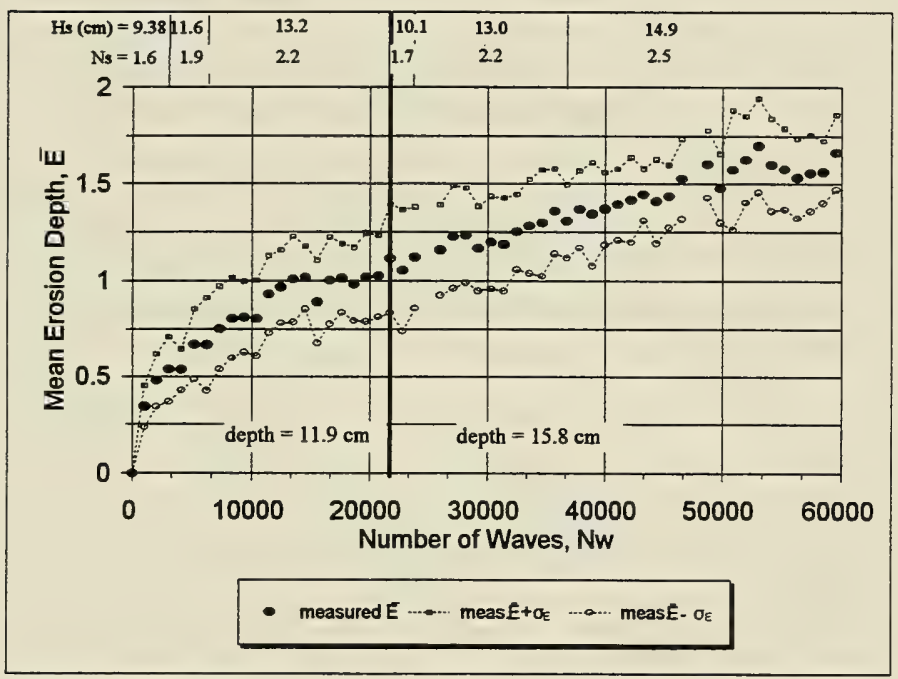

Figure 5.13. Number of waves versus mean maximum eroded depth \pm one standard deviation for Series $A^{\prime}$ 


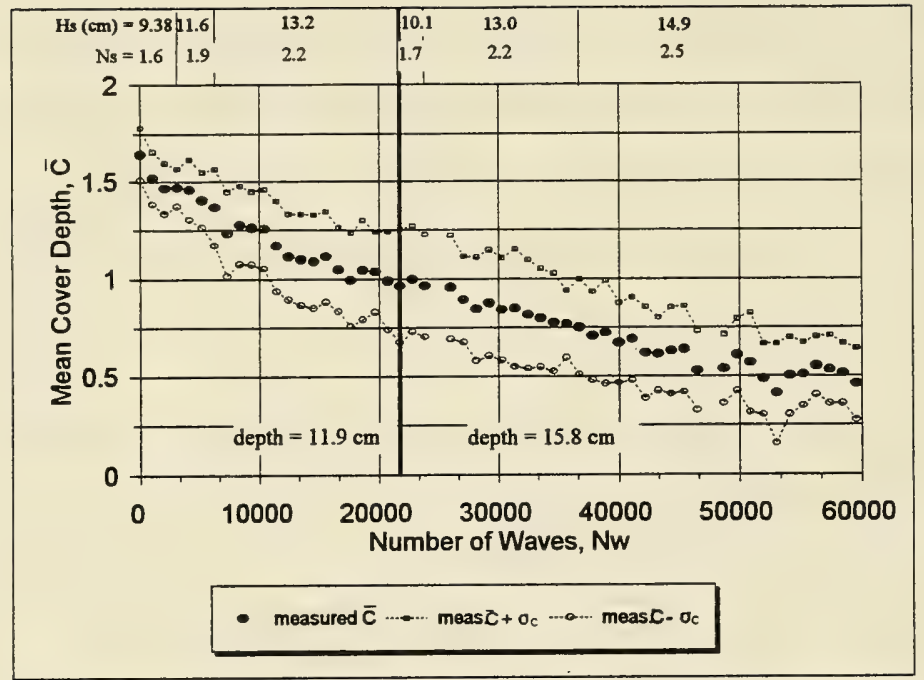

Figure 5.14. Number of waves versus mean minimum cover depth \pm one standard deviation for Series $A^{\prime}$

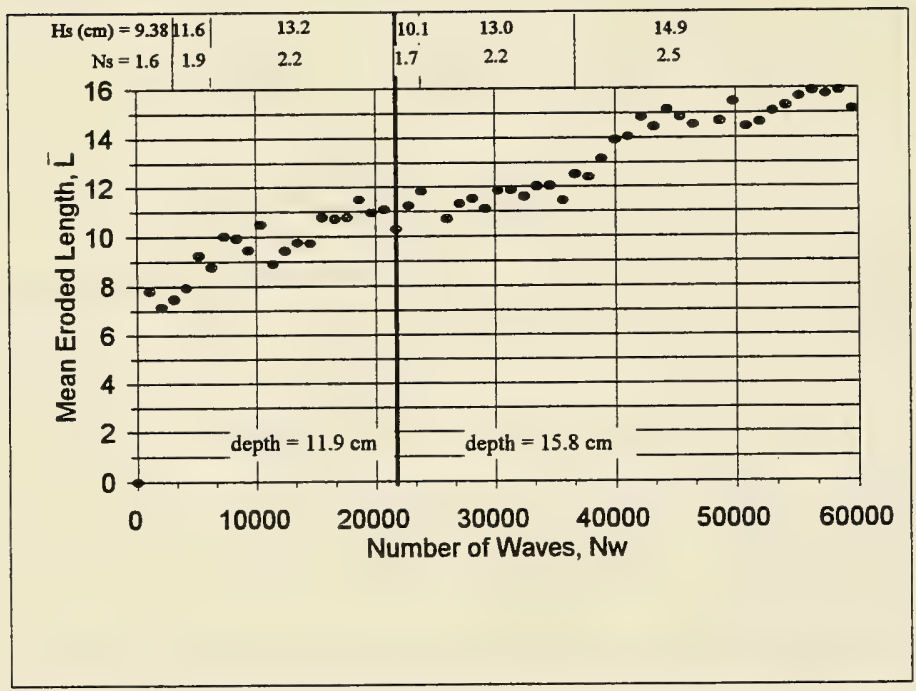

Figure 5.15. Number of waves versus mean maximum eroded length for Series $A^{\prime}$ 
Figure 5.16 shows mean eroded depth and mean cover depth versus mean damage for Series $A^{\prime}$. As one would expect, cover depth is inversely related to damage, while eroded depth is directly related to damage. Eroded depth and cover depth are clearly inversely related. Similarly, Figure 5.17 shows that mean eroded length and mean damage are directly related.

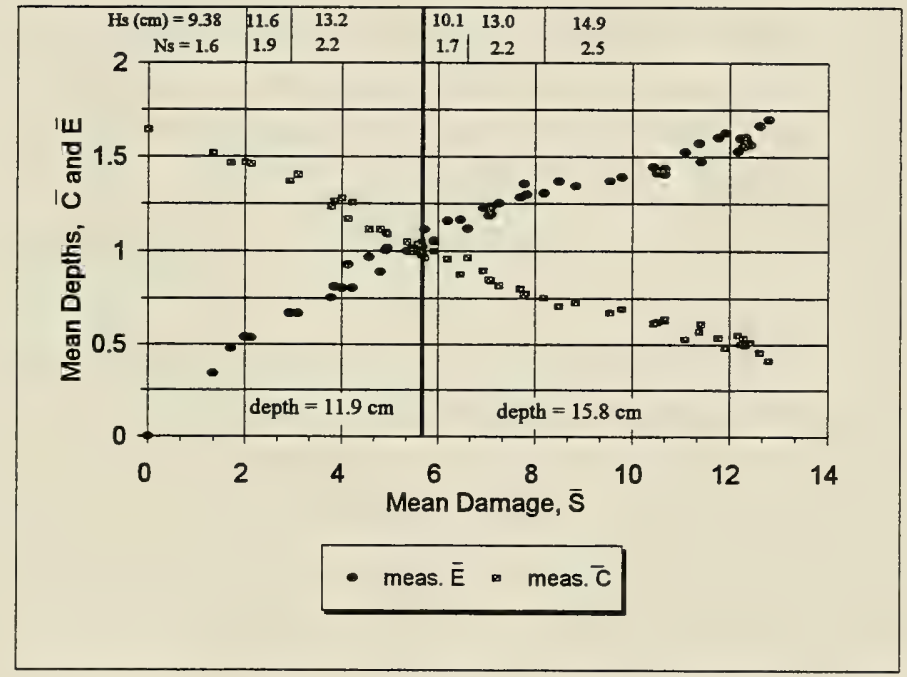

Figure 5.16. Mean damage versus mean maximum eroded depth and mean minimum cover depth for Series $A^{\prime}$ 


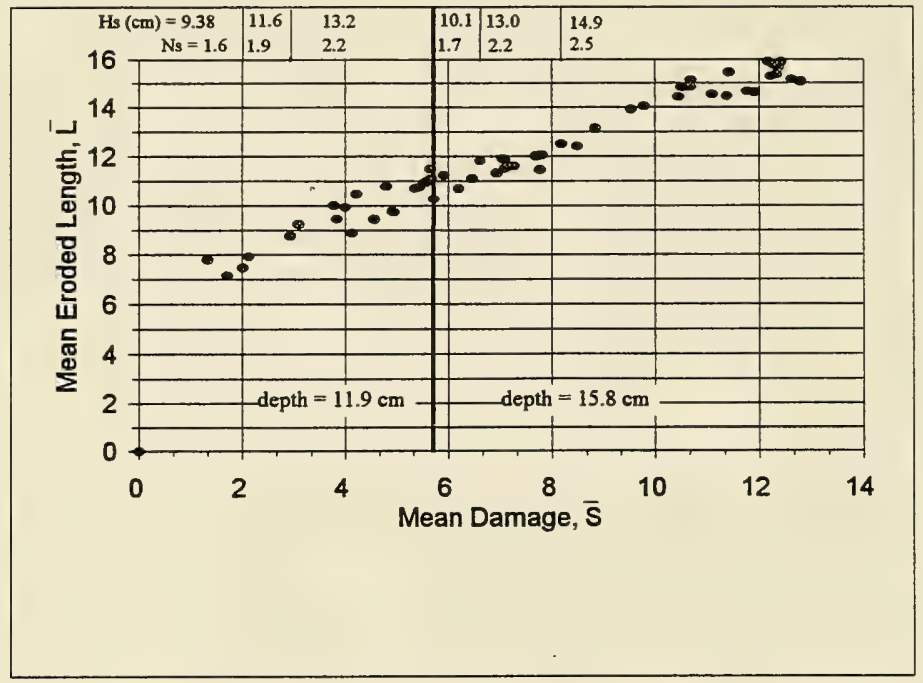

Figure 5.17. Mean damage versus mean maximum eroded length for Series $A^{\prime}$

Figures 5.18 through 5.23 show that the profile development characteristics for Series $B^{\prime}$ and $C^{\prime}$ are similar to those of Series $A^{\prime}$ discussed above. Figures 5.24 through 5.27 show means of the three profile parameters versus mean damage for Series $B^{\prime}$ and $C^{\prime}$. It is clear that profile development is related to mean damage. This will be investigated in the following chapter. 


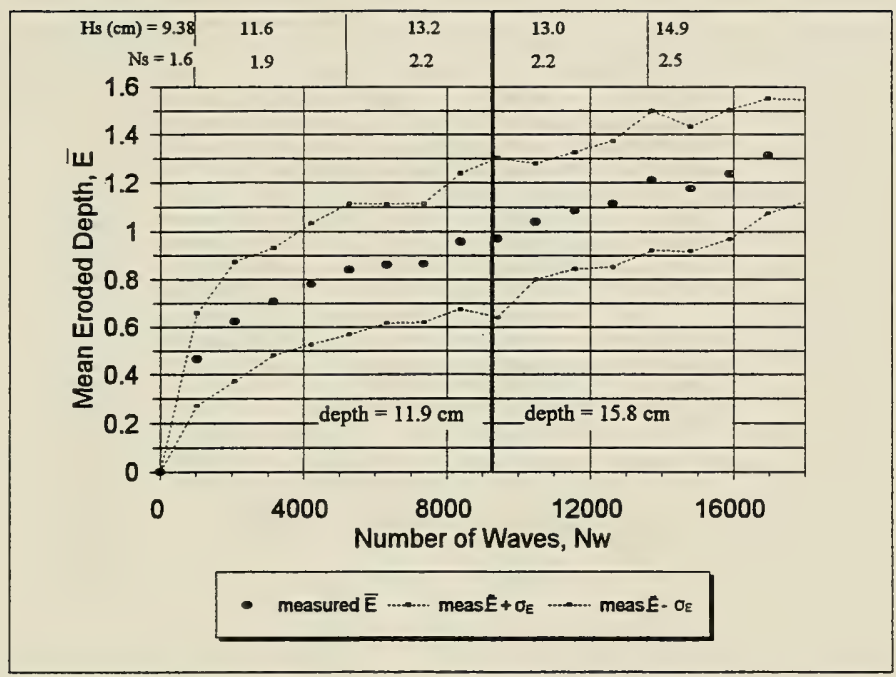

Figure 5.18. Number of waves versus mean maximum eroded depth \pm one standard deviation for Series $B^{\prime}$

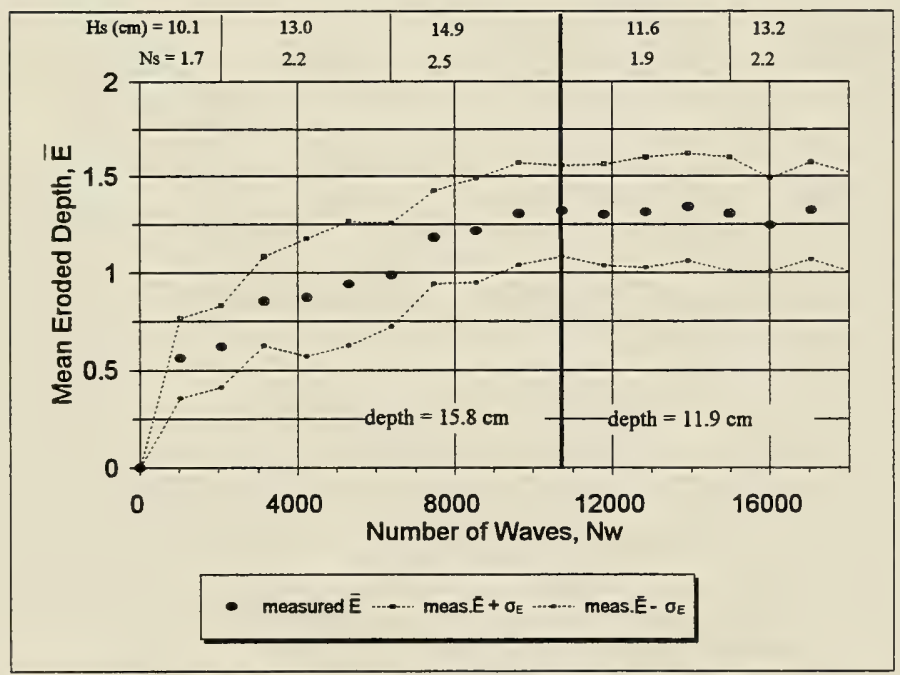

Figure 5.19. Number of waves versus mean maximum eroded depth \pm one standard deviation for Series $C^{\prime}$ 


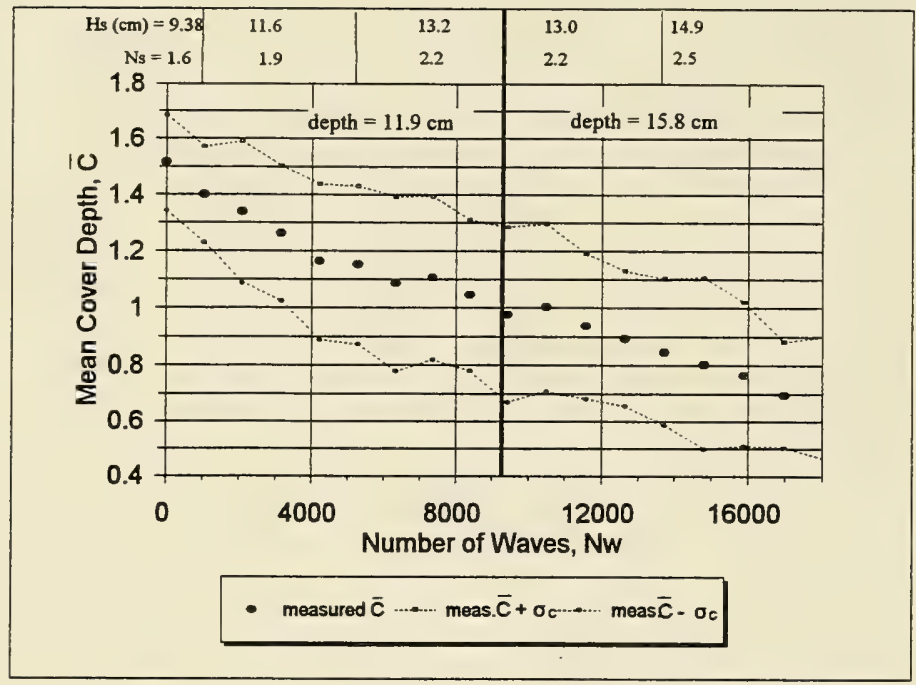

Figure 5.20. Number of waves versus mean minimum cover depth \pm one standard deviation for Series $B^{\prime}$

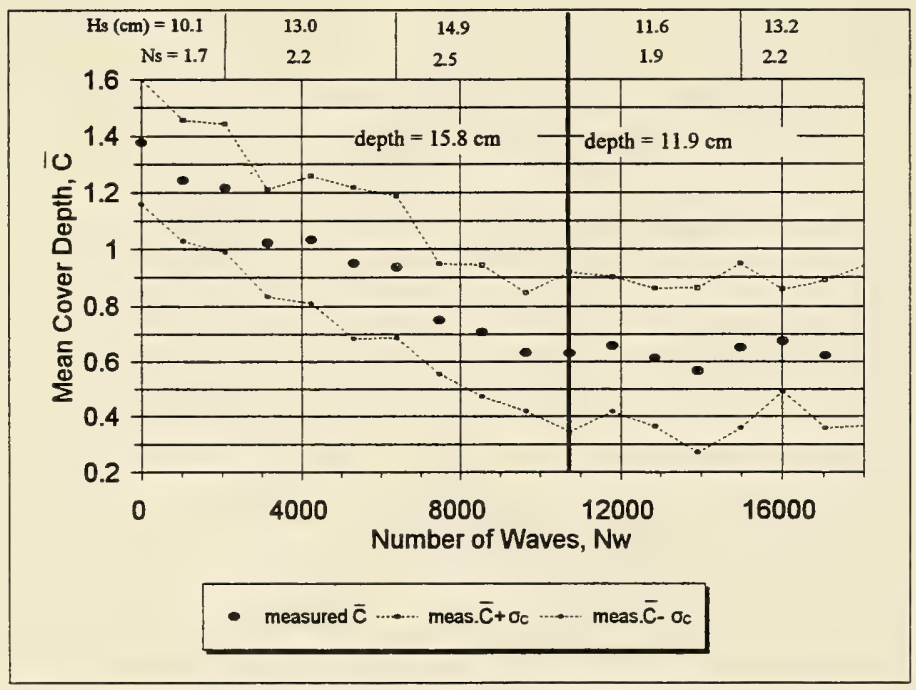

Figure 5.21. Number of waves versus mean minimum cover depth \pm one standard deviation for Series $C^{\prime}$ 


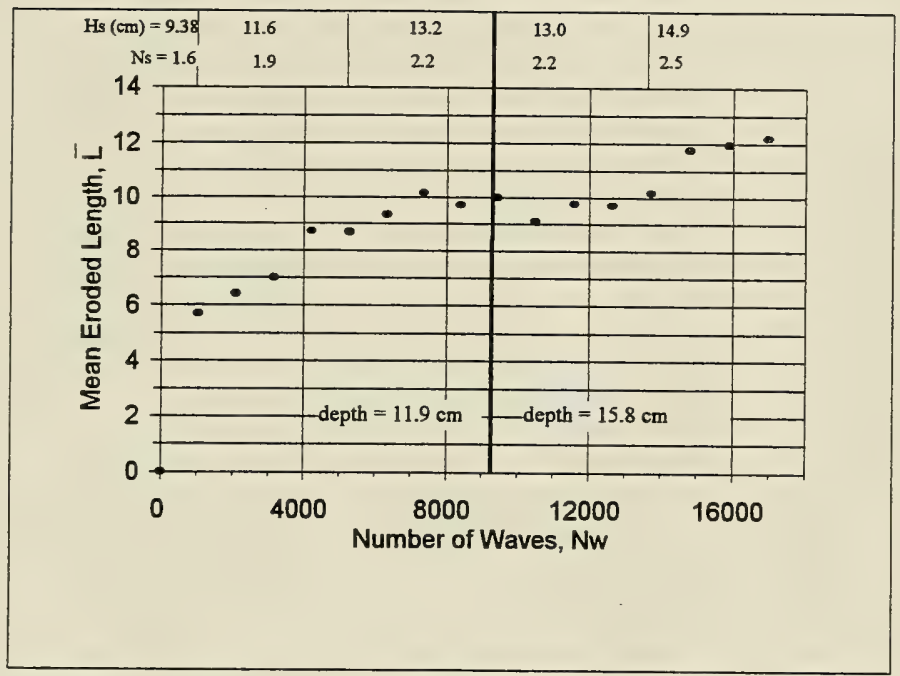

Figure 5.22. Number of waves versus mean maximum eroded length for Series $B^{\prime}$

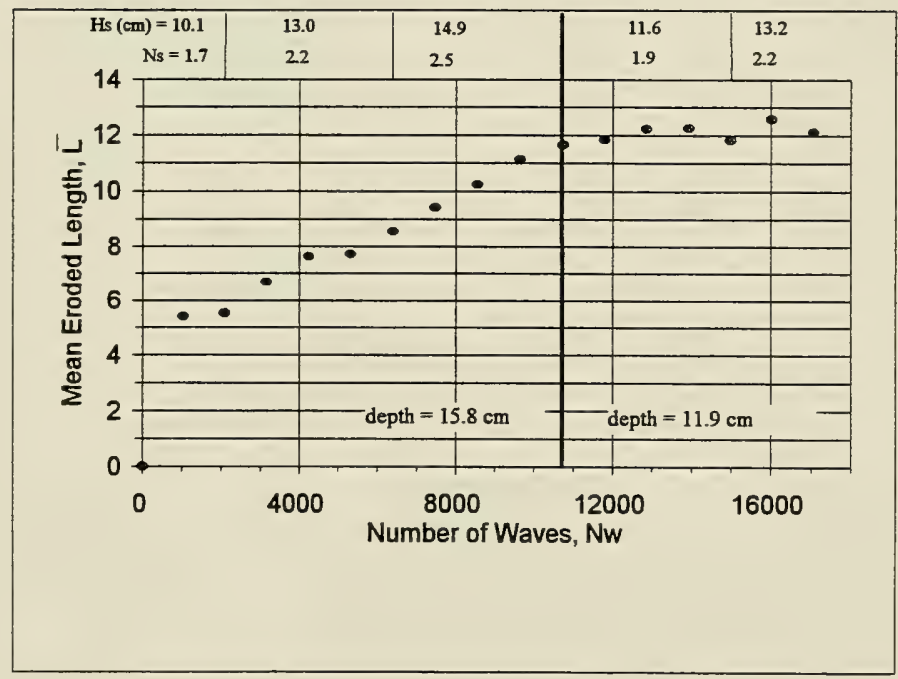

Figure 5.23. Number of waves versus mean maximum eroded length for Series $C^{\prime}$ 


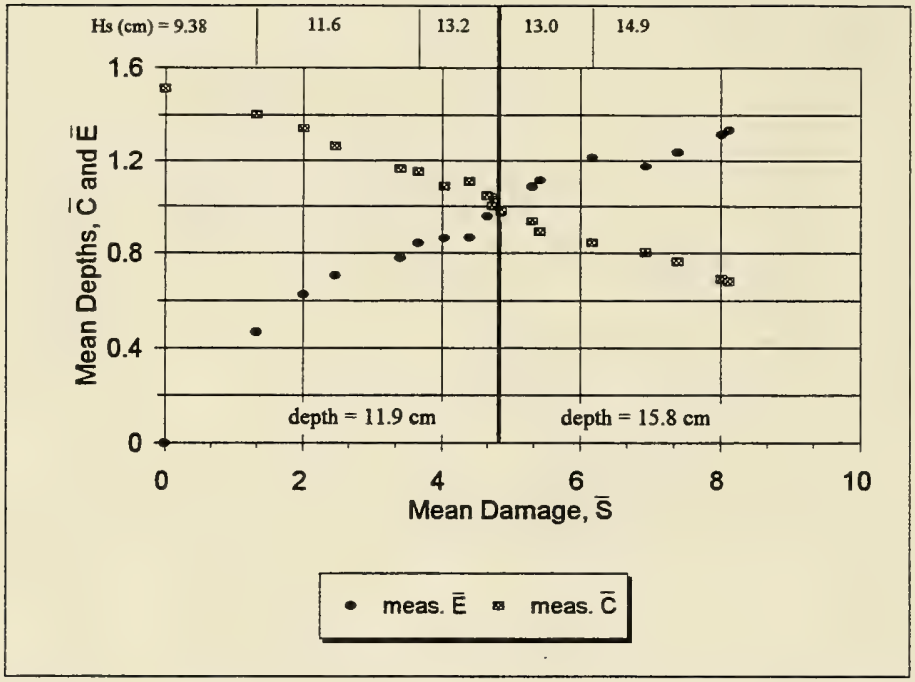

Figure 5.24. Mean damage versus mean maximum eroded depth and mean minimum cover depth for Series $B^{\prime}$

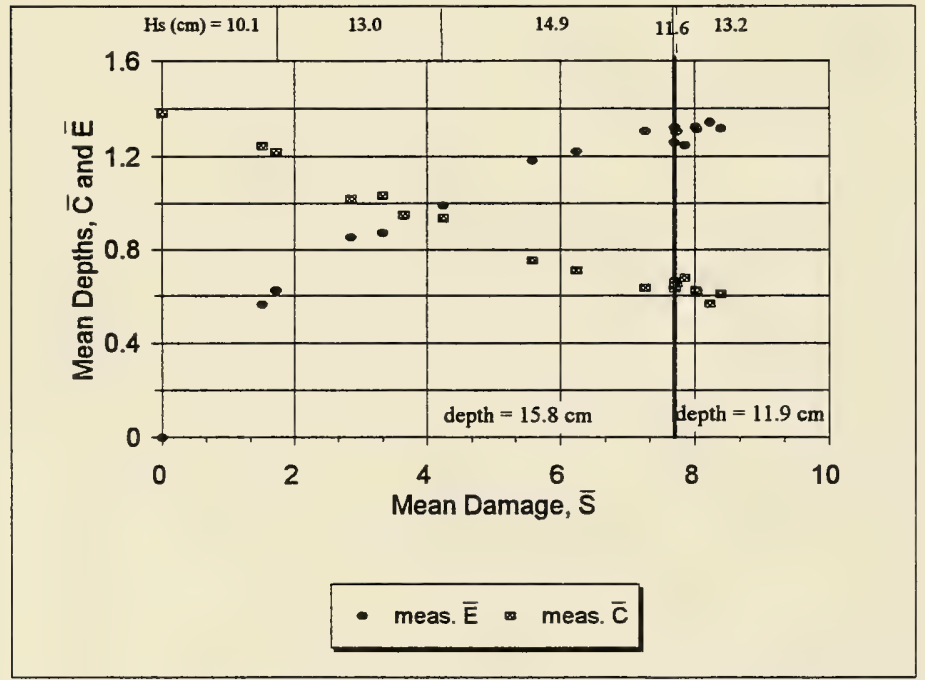

Figure 5.25. Mean damage versus mean maximum eroded depth and mean minimum cover depth for Series $C^{\prime}$ 


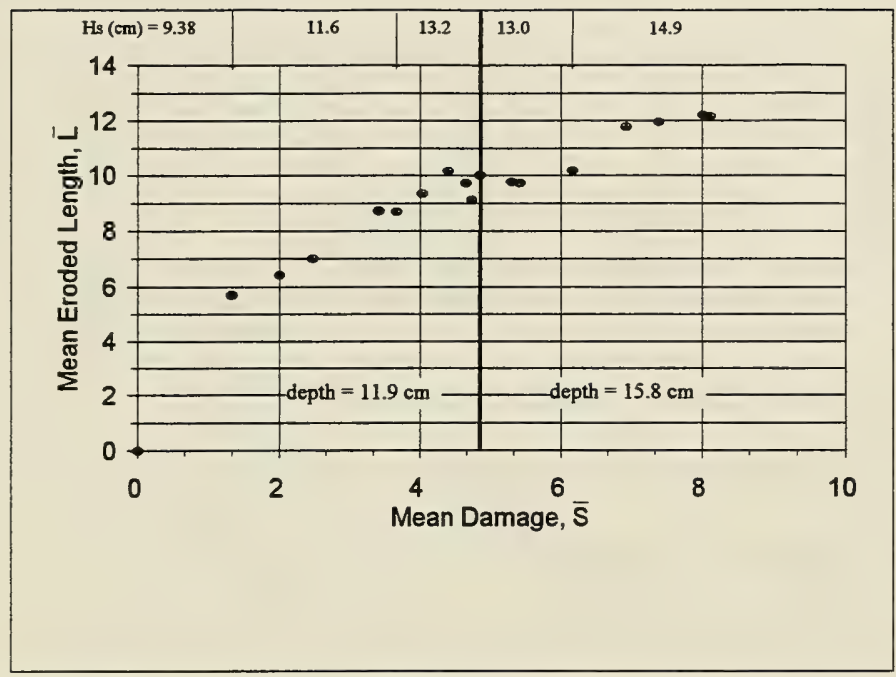

Figure 5.26. Mean damage versus mean maximum eroded length for Series $B^{\prime}$

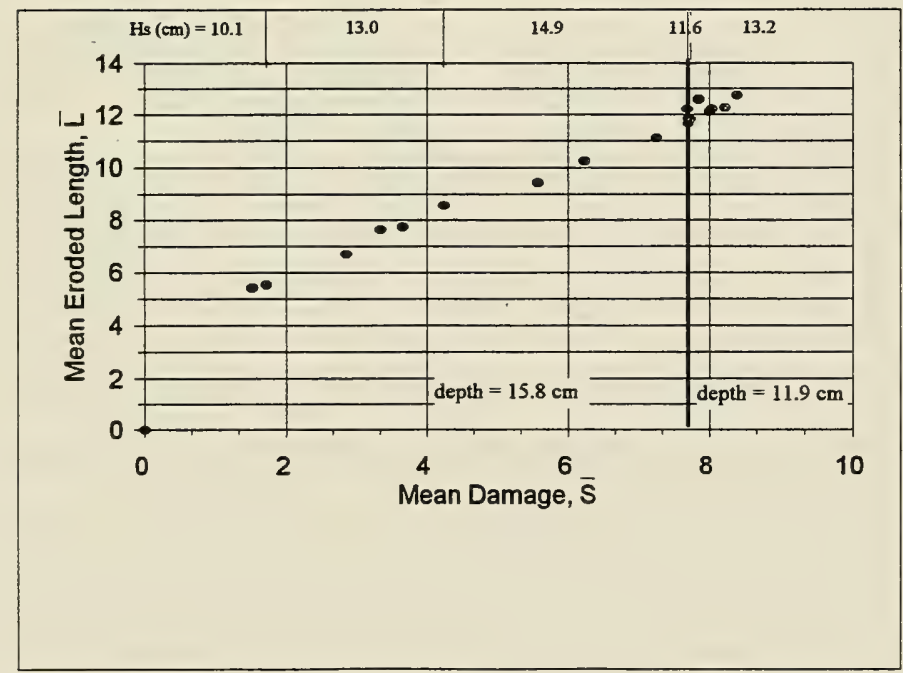

Figure 5.27. Mean damage versus mean maximum eroded length for Series $C^{\prime}$ 


\section{Chapter 6}

\section{DAMAGE AND ERODED PROFILE PREDICTION}

\subsection{Damage Variability}

Figures $5.10-5.12$ indicated that the standard deviation of damage $S$ varying along the structure increases with mean damage $\bar{S}$. Figure 6.1 shows the relationship between $\sigma_{S}$ and $\bar{S}$ for all data in the three series plotted in Figures 5.10 5.12. The scattered data points for the three series may be represented by the relation

$$
\sigma_{s}=0.5 \bar{S}^{0.65}
$$

which is the solid curve shown in Figure 6.1. This relation implies that damage variability along the structure increases with the mean damage. On the other hand, relative variability defined as the coefficient of variation $V_{s}=\sigma_{S} / \bar{S}$ decreases with increasing $\tilde{S}$. This implies that higher damage levels may be estimated with smaller relative errors. The correlation coefficients for the three series for Equation 6.1 were all $r=0.99$. An example of the use of Equation 6.1 is illustrated for $\bar{S} \approx 13$ at failure of

Series $A^{\prime}$. Substituting $\bar{S}=13$ into Equation 6.1 yields $\sigma_{S}=2.65$. The approximate range of $-2.7<S^{*}<3$ in Equation 5.10 corresponds to $6<S<21$, indicating damage variability of a factor of 3.5 along the structure. 


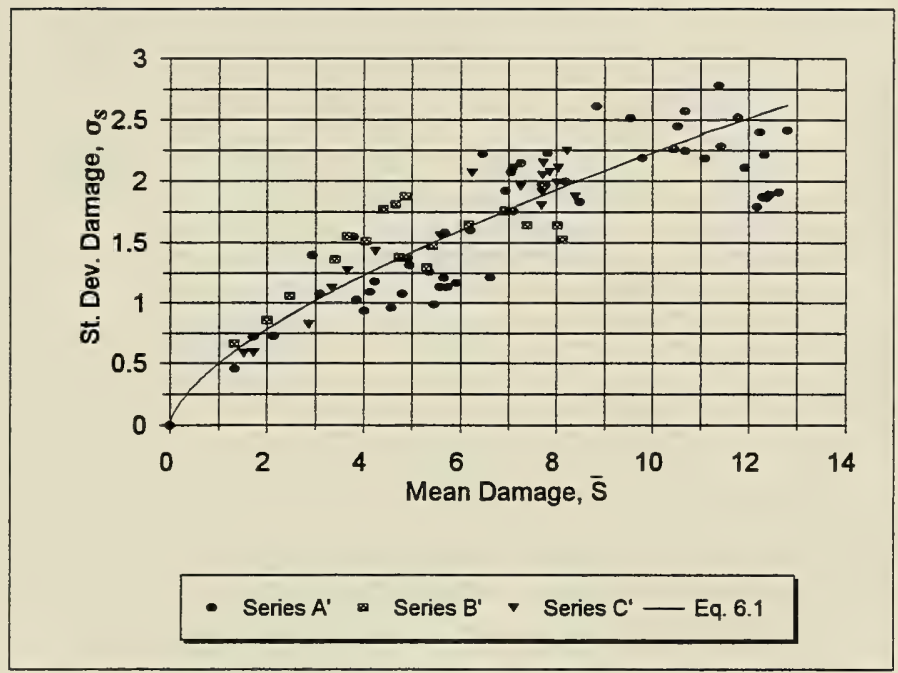

Figure 6.1. Prediction of damage variability, characterized by the standard deviation, as a function of mean damage for Series $A^{\prime}, B^{\prime}$, and $C^{\prime}$

\subsection{Eroded Profile Prediction}

It is useful to express the normalized eroded depth $\bar{E}$ and the variability of eroded depth, $\sigma_{E}$, as a function of mean damage also. The measured values of $\bar{E}$ and $\bar{E} \pm$ $\boldsymbol{\sigma}_{E}$ were shown as a function of cumulative number of waves for Series $A^{\prime}$ in Figure

5.13. The trends for Series $B^{\prime}$ and $C^{\prime}$ were shown to be similar in Figures 5.18 and 5.19. Figures 6.2 and 6.3 show $\bar{E}$ and $\sigma_{E}$ as a function of $\bar{S}$ for all data points of the three series. These figures indicate the following empirical relationships

$$
\begin{gathered}
\bar{E}=0.46 \sqrt{\bar{S}} \\
\sigma_{E}=0.26-0.00007(\bar{S}-7.8)^{4}
\end{gathered}
$$




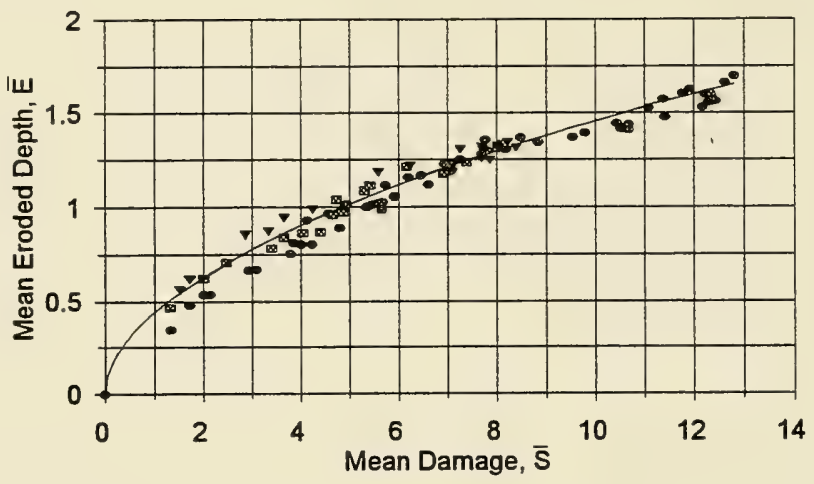

- Series $A^{\prime}$ \Series $B^{\prime} \quad$ - Series $C^{\prime}$ - Eq. 6.2

Figure 6.2. Prediction of mean maximum eroded depth as a function of mean damage for Series $A^{\prime}, B^{\prime}$, and $C^{\prime}$

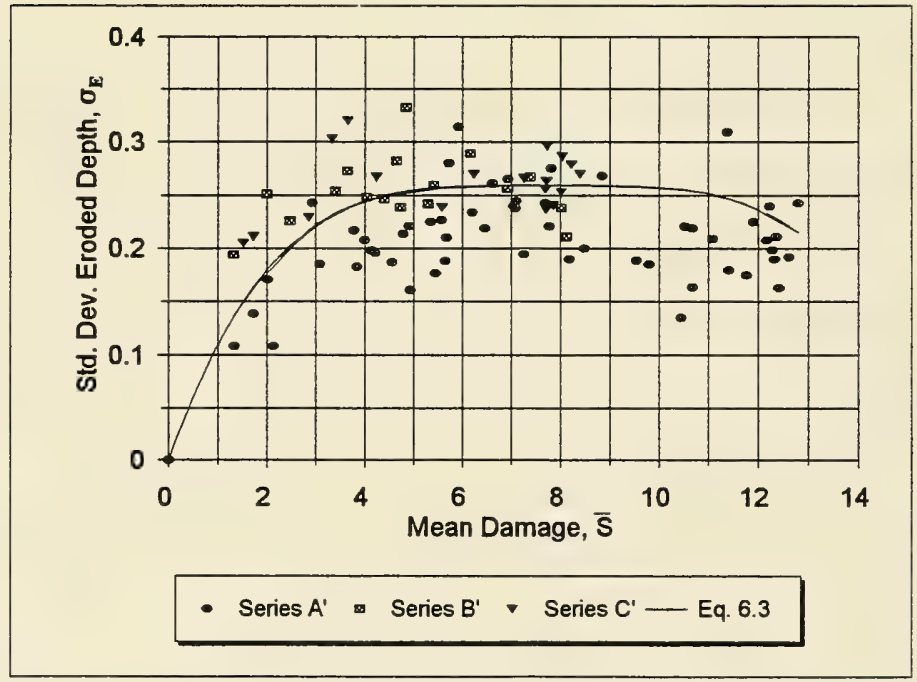

Figure 6.3. Prediction of standard deviation of maximum eroded depth as a function of mean damage for Series $A^{\prime}, B^{\prime}$, and $C^{\prime}$ 
The correlation coefficients for Equation 6.2 were $r=0.99$ for all three series. Equation 6.2 indicates $\tilde{E} / \bar{S}^{0.5}$ is approximately constant. This implies that the average shape of the eroded area remains approximately constant during damage progression. Figure 6.3 and Equation 6.3 suggest that the variability of eroded depth increases rapidly with damage and becomes approximately constant at $\bar{S} \approx 4$. The variability in eroded depth decreases somewhat as the damage approaches the failure level of the armor layer.

The eroded length $L$ along the slope depicted in Figures 5.15, 5.17, 5.22, $5.23,5.26$, and 5.27 is analyzed in the following. The mean eroded length $\bar{I}_{e}$ is simply defined as $\bar{I}_{e}=2 \bar{A}_{e} / \bar{d}_{e}$, corresponding to a triangular shape. The normalized eroded length $\bar{L}=I_{e} / D_{n 50}$ is then given by $\bar{L}=2 \bar{S} / \bar{E}$, as shown in Equation 5.5. From the measured values of $\bar{S}$ and $\bar{E}$, the corresponding values of $\bar{L}$ are calculated to examine the variation of $\bar{L}$ during damage progression. Figure 6.4 shows all calculated values of $\bar{L}$ for the three series against the corresponding values of $\bar{S}$. Figure 6.4 also shows the following relationship derived from Equations 6.2 and 5.5

$$
\bar{L}=4.4 \sqrt{\bar{S}}
$$

The correlation coefficients for Equation 6.4 were $r=0.98$ for Series $A^{\prime}$ and $r=0.99$ for Series $B^{\prime}$ and $C^{\prime}$. As an example of the use of Equation 6.4 , for $\bar{S} \approx 13$ at failure for Series $A^{\prime}$, Equations 6.2 and 6.4 yield $\bar{E} \approx 1.7$ and $\bar{L} \approx 16$, implying the average damaged profile at failure extends 16 stone diameters along the slope. For the model structure with $D_{n 50}=3.64 \mathrm{~cm}$ shown in Figures 4.2 and 4.3 , this damage extent 
corresponds to most of the seaward slope and crest of the structure as shown in Figures 5.8 and 5.9 .

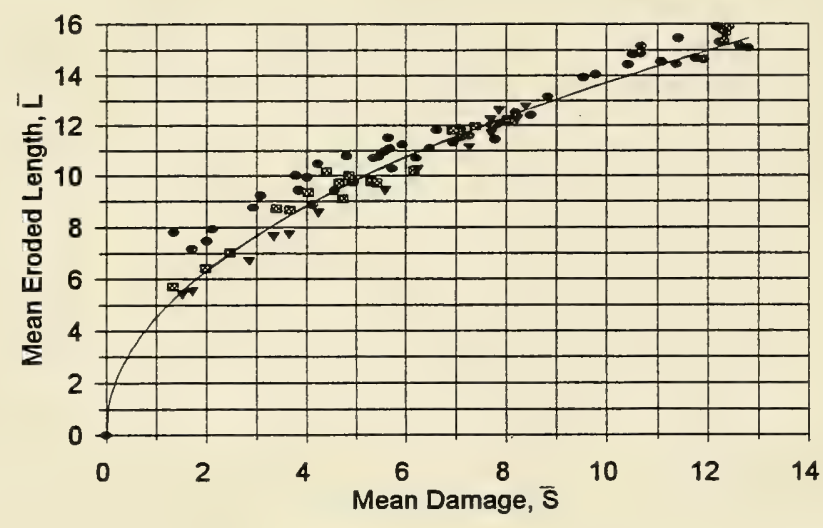

- Series $A^{\prime}$ × Series $B^{\prime}$ - Series $C^{\prime}$ - Eq. 6.4

Figure 6.4. Prediction of mean eroded length as a function of mean damage for Series $A^{\prime}, B^{\prime}$, and $C^{\prime}$

Finally, the normalized minimum cover depth $C$ is analyzed to examine the decrease of protection with damage progression. The measured values of $\bar{C}$ and $\bar{C} \pm \sigma_{C}$ were plotted as a function of cumulative number of waves in Figures 5.14, 5.20, and 5.21 for Series $A^{\prime}, B^{\prime}$, and $C^{\prime}$, respectively. These relations are similar to the corresponding results for damage and eroded depth except that $\bar{C}$ decreases with $N_{w}$ and $\sigma_{C}$ is positive at $N_{w}=0$. The initial values of $\bar{C}$ at $N_{w}=0$ were $\bar{C}_{0}=1.65,1.52$, and 1.38 for Series $A^{\prime}, B^{\prime}$, and $C^{\prime}$, respectively, and the initial value of $\sigma_{C}$ at $N_{w}=0$ was $\sigma_{C o}=$ $0.14,0.17$, and 0.22 for Series $A^{\prime}, B^{\prime}$, and $C^{\prime}$, respectively. To account for the 
differences of $\bar{C}_{0}$ and $\sigma_{C_{0}},\left(\bar{C}_{0}-\bar{C}\right)$ and $\left(\sigma_{C}-\sigma_{C_{0}}\right)$ are plotted against $\bar{S}$ for all the data points of the three series in Figures 6.5 and 6.6, respectively. The empirical relationships shown in these figures are given by

$$
\begin{gathered}
\bar{C}=\bar{C}_{0}-0.1 \bar{S} \\
\sigma_{C}=\sigma_{C_{0}}+0.098-0.002(\bar{S}-7)^{2}
\end{gathered}
$$

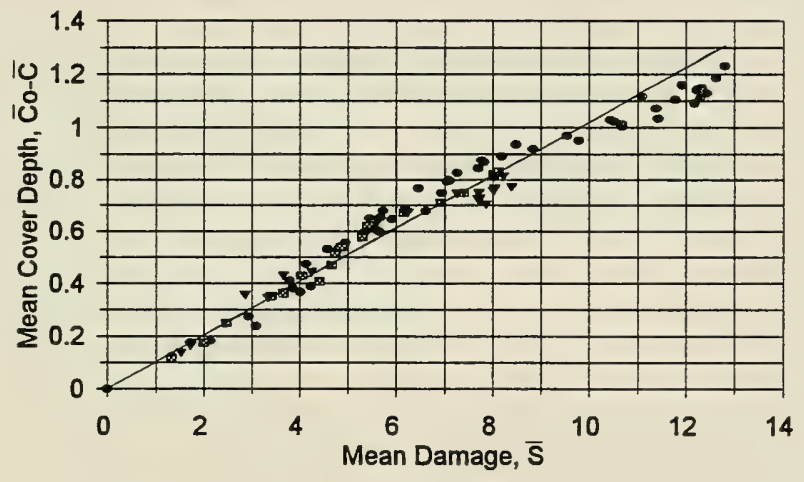

- Series $A^{\prime} \otimes$ Series $B^{\prime} \quad$ Series $C^{\prime} \longrightarrow$ Eq. 6.5

Figure 6.5. Prediction of mean minimum cover depth as a function of mean damage for Series $A^{\prime}, B^{\prime}$, and $C^{\prime}$ 


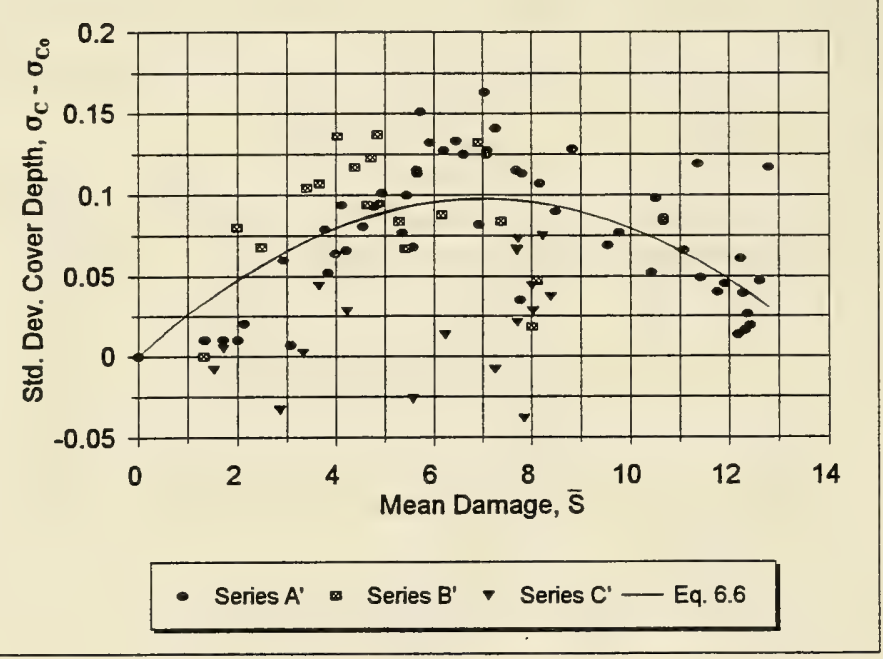

Figure 6.6. Prediction of standard deviation of minimum cover depth as a function of mean damage for Series $A^{\prime}, B^{\prime}$, and $C^{\prime}$

For Equation 6.5, the correlation coefficients were $r=0.99$ for all three series. Figure 6.5 and Equation 6.5 indicate that the mean cover depth decreases approximately linearly with mean damage increase. The scattered values of $\left(\sigma_{C}-\sigma_{C_{0}}\right)$ plotted in Figure 6.6 are of the same order of magnitude as the initial value $\sigma_{C_{0}}$ listed above. Figure 6.6 and Equation 6.6 indicate that the standard deviation $\sigma_{C}$ representing the variability of cover depth along the structure increases somewhat with damage progression and then decreases as the cover depth approaches zero. It is noted that Equation 6.6 overestimates $\sigma_{C}$ somewhat for Series $C^{\prime}$ as can be seen in Figure 6.6.

A failure criterion based on the normalized minimum cover depth $C$ is explored in the following. Using the lower limit of $C^{*}=(C-\bar{C}) / \sigma_{C}$ in Equation 5.10, 
the lower limit of $C$ may be estimated as $\left(\bar{C}-2.7 \sigma_{C}\right)$. The failure may be assumed to initiate when this lower limit becomes zero. This criterion with Equations 6.5 and 6.6 yields the following equation for the mean damage at failure initiation

$$
0.1 \bar{S}+2.7\left[0.098-0.002(\bar{S}-7)^{2}\right]=\overline{C_{0}}-2.7 \sigma_{C_{0}}
$$

This criterion accounts for the initial minimum cover depth and its variability along the structure where $\left(\bar{C}_{0}-2.7 \sigma_{C_{0}}\right)=1.27,1.06$, and 0.79 for Series $A^{\prime}, B^{\prime}$, and $C^{\prime}$. Solving Equation 6.7 for mean damage for Series $A^{\prime}$ yields $\bar{S}=10.9$ at failure initiation, compared with $\bar{S} \approx 13$ measured. The failure initiation criterion of Equation 6.7 based on the lower limit of $C^{*}$ of all data points plotted in Figure 5.4 yields the lower limit of the mean damage at failure. The upper limit of mean damage at failure may simply be estimated by $\bar{C}=0$ in Equation 6.5. This upper limit is $\bar{S}=16.5$ for Series $A^{\prime}$.

\subsection{Temporal Damage Development}

If the mean damage can be predicted, then Equations $6.1-6.6$ yield $\sigma_{s}, \bar{E}$, $\sigma_{E}, \bar{L}, \bar{C}$, and $\sigma_{C}$. These relationships have been obtained by analyzing the measured profiles of the armor layer and underlayer without regard to the incident waves and water level. This statistical analysis indicates that the damaged profile statistics can be

represented by the mean damage $\bar{S}$. The next step is to predict the temporal variation of $\bar{S}$ on the rubble-mound breakwater exposed to depth-limited breaking waves in sequences of storms with varying wave conditions and water levels. 
The empirical formulas of Van der Meer (1988) indicate that breakwater damage due to depth-limited waves is a function of $N_{s}, T_{m}$, and time $t$. In addition, it is likely that damage is a function of structure slope, structure permeability, armor gradation, armor porosity, armor stone shape, and method of armor placement. None of these latter parameters except armor gradation were varied in this study. Gradation is discussed in Chapter 7. The remainder of the parameters will be investigated in future studies.

In the following, the depth-limited breaking-wave stability data of Van der Meer (1988) will be used to develop relations for damage progression. His depthlimited wave and measured damage data are shown in Table 6.1. The particular data set shown in Table 6.1 corresponded to a structure slope of $1 \mathrm{~V}: 2 \mathrm{H}$, a beach slope of $1 \mathrm{~V}: 30 \mathrm{H}$, and the stone armor characterized by $D_{85} / D_{15}=1.25, D_{n 50}=3.60 \mathrm{~cm}$, and $\Delta=1.615$. The table shows that, for toe depth $h_{t}=0.4 \mathrm{~m}$, the waves were only marginally depth limited because $H_{s} / h_{t}$ was in the range $0.26-0.31$. Therefore, Van der Meer's data provide only eight tests where the waves were clearly depth limited $\left(h_{t}=\right.$ $0.2 \mathrm{~m}$ ). The temporal development of damage cannot be deduced from these data because the damage was only given after 1,000 waves and 3,000 waves.

From Van der Meer's data, it can be seen that the surf similarity parameter with respect to the beach slope for the eight breaking wave tests 9-16 ranged from 0.20 to 0.25 . This suggests that all were spilling breakers, which is not the worst case for armor stability. As explained in the previous chapters, plunging breakers expose the 
armor units to the highest vertical forces at the steep front of a plunging wave, which is the worst case for armor stability.

\begin{tabular}{|c|c|c|c|c|c|c|c|c|c|}
\hline \multicolumn{10}{|c|}{$\begin{array}{l}\text { Table } 6.1 \\
\text { Depth-Limited Wave Damage Data from Van der Meer (1988) }\end{array}$} \\
\hline Test & \begin{tabular}{|l} 
Toe \\
Depth \\
$h_{n}$ \\
$\mathrm{~m}$ \\
\end{tabular} & \begin{tabular}{|l} 
Wave \\
Height \\
$H_{s}$ \\
m \\
\end{tabular} & \begin{tabular}{|l|} 
Mean \\
Per- \\
iod \\
$T_{m m}$ \\
sec \\
\end{tabular} & $H_{g} / h_{t}$ & $N_{s}$ & $\begin{array}{l}\xi_{m} \text { for } \\
\text { Beach } \\
\text { Slope }\end{array}$ & $\begin{array}{l}\xi_{m} \text { for } \\
\text { Struc- } \\
\text { ture } \\
\text { Slope }\end{array}$ & $\begin{array}{l}S \text { for } \\
N_{w}= \\
1,000\end{array}$ & $\begin{array}{l}S \text { for } \\
N_{\mathrm{w}}= \\
3,000\end{array}$ \\
\hline 1 & 0.4 & 0.1253 & 1.68 & 0.31 & 2.16 & 0.198 & 2.97 & 8.51 & 12.69 \\
\hline 2 & 0.4 & 0.0900 & 1.69 & 0.23 & 1.55 & 0.235 & 3.52 & 0.86 & 1.56 \\
\hline 3 & 0.4 & 0.1088 & 1.68 & 0.27 & \begin{tabular}{|l|}
1.87 \\
\end{tabular} & 0.212 & 3.18 & 2.85 & 4.05 \\
\hline 4 & 0.4 & 0.1359 & 1.67 & 0.34 & 2.34 & 0.189 & 2.83 & 10.15 & 18.15 \\
\hline 5 & 0.4 & 0.1286 & 2.19 & 0.32 & 2.21 & 0.255 & 3.82 & 6.04 & 9.85 \\
\hline 6 & 0.4 & 0.1052 & 2.19 & 0.26 & 1.81 & 0.281 & 4.22 & 1.16 & 2.15 \\
\hline 7 & 0.4 & 0.1555 & 2.18 & 0.39 & 2.67 & 0.231 & 3.46 & 8.78 & 20.04 \\
\hline 8 & 0.4 & 0.1215 & 2.20 & 0.30 & 2.09 & 0.263 & 3.94 & 4.78 & 7.19 \\
\hline 9 & 0.2 & 0.1345 & 2.18 & 0.67 & 2.31 & 0.248 & 3.72 & 4.50 & 6.29 \\
\hline 10 & 0.2 & 0.1275 & 2.17 & 0.64 & 2.19 & 0.253 & 3.80 & 3.05 & 3.00 \\
\hline 11 & 0.2 & 0.1415 & 2.17 & 0.71 & 2.43 & 0.241 & 3.61 & 5.13 & 6.43 \\
\hline 12 & 0.2 & 0.1445 & 2.18 & 0.72 & 2.49 & 0.239 & 3.58 & 6.52 & 12.45 \\
\hline 13 & 0.2 & 0.1270 & 1.70 & 0.64 & 2.18 & 0.199 & 2.98 & 2.27 & 3.63 \\
\hline 14 & 0.2 & 0.1320 & 1.73 & 0.66 & 2.27 & 0.199 & 2.98 & 4.97 & 7.97 \\
\hline 15 & 0.2 & 0.1350 & 1.74 & 0.68 & 2.32 & 0.197 & 2.96 & 6.65 & 11.03 \\
\hline 16 & 0.2 & 0.1350 & 1.77 & 0.68 & 2.32 & 0.201 & 3.01 & 8.65 & 11.38 \\
\hline
\end{tabular}

Consider Equations 3.7 and 3.8, which are Van der Meer's equations for stability that include damage as a parameter. The stability number was a minimum at the transition between plunging and surging waves occurring at 


$$
\xi_{m c}=\left[6.2 P^{0.31} \sqrt{\tan \theta}\right]^{Q}
$$

where $Q=(P+0.5)^{-1}$ and $P=$ permeability coefficient varying in the range $0.1-0.6$. Keep in mind that $\theta$ in Equation 6.8 is the structure slope measured from horizontal. Later in this chapter, this requirement will be abandoned. Using Equations 3.7 and 6.8, the minimum stability number can be expressed as

$$
N_{s}=C_{N} 6.2^{P Q} P^{Q(0.18 P-0.065)}(\cot \theta)^{0.25 Q}\left(\frac{\bar{S}}{\sqrt{N_{w}}}\right)^{0.2}
$$

where

$$
\begin{aligned}
& N_{s}=H_{s} / \Delta D_{n 50}=\text { stability number based on the significant wave height } \\
& C_{N}=\text { empirical coefficient introduced here } \\
& N_{w} \quad=\begin{array}{l}
\text { number of waves associated with the damage } \bar{S} \text { starting from zero } \\
\text { damage }
\end{array}
\end{aligned}
$$

For depth-limited breaking waves on a sloping beach in front of the structure, Van der Meer (1988) proposed the use of $H_{2 \%}$ and rewrote his equation for relatively deep water using $H_{2 \%}=1.4 H_{s}$ based on the Rayleigh distribution of wave heights where $\xi_{m}$ based on $H_{s}$ was not changed. Note that the values of $H_{2 \%}$ were not tabulated in his report, so it is difficult to evaluate this shallow-water extension of his stability equations. In the present experiment, incident irregular wave breakers were spilling and plunging on the 1:20 beach slope and collapsing and surging on the 1:2 structure slope. However, plunging waves on the beach were also observed to hit the 
structure directly. Consequently, although it is likely that the beach slope was most influential on the breaking process, an appropriate slope for $\xi_{m}$ is uncertain and Equation 6.9 is simply adopted, although the relation does not contain $\xi_{m}$. The stability number $N_{s}$ in Equation 6.9 based on $H_{s}$ is used here because it will be easier to predict $H_{s}$ than $H_{2 \%}$ using time-averaged surf zone models such as Battjes and Stive (1985) and Dally (1992) that will need to be modified to account for reflected waves (Baquerizo et al. 1997). The empirical coefficient $C_{N}$ is calibrated using the 16 tests in Table 6.1. For eight tests with toe depth $h_{t}=0.4 \mathrm{~m}$ and $H_{s} / h_{t}=0.23-0.39, C_{N}=0.97-1.21$ for $N_{w}=$ 1,000 and $C_{N}=0.99-1.19$ for $N_{w}=3,000$. For eight tests with $h_{t}=0.2 \mathrm{~m}$ and $H_{s} / h_{t}=$ 0.64-0.72, $C_{N}=1.03-1.27$ for $N_{w}=1,000$ and $C_{N}=1.09-1.34$ for $N_{w}=3,000$. The present experiment with $H_{s} / h_{t}=0.64-1.11$ using Table 4.4 is more similar to the eight tests in Table 6.1 with $h_{t}=0.2 \mathrm{~m}$. So $C_{N}=1.2$ is tentatively assumed in Equation 6.9 .

Equation 6.9 is rewritten as two damage formulas in the following to facilitate the representation of incident random waves in time series and spectra. The first damage model, based on wave time series statistics, has the form

$$
S=a_{s} N_{s}^{5}\left(\frac{t}{T_{m}}\right)^{b}
$$

where $t=T_{m} N_{w}$ is the test duration for constant wave conditions. The empirical coefficient $a_{s}$ is related to $\cot \theta, P$, and $C_{N}$, and $b$ in Equation 6.10 is introduced for long duration tests, where $b=0.5$ in Equation 6.9. The second model is based on the wave frequency domain statistics and has the form 


$$
S=a_{p} N_{m o}^{5}\left(\frac{t}{T_{p}}\right)^{b}
$$

In Equation 6.11, $N_{m o}=H_{m o} / \Delta D_{n 50}$ is the stability number based on the zeroth moment wave height, the test duration $t$ for constant wave conditions is normalized by the peak period, and $a_{p}$ and $b$ are again empirical coefficients that will be obtained from data. It is noted that Equations 6.10 and 6.11 assume $S=0$ at $t=0$ and constant wave conditions.

The expression for $a_{s}$ in Equation 6.10 can be found from Equation 6.9 where $P=0.4$ for conventional rubble-mound breakwaters. For $C_{N}=1.2, P=0.4$, and $\cot \theta=2, a_{s}=0.003$ for Equation 6.10 if $b=0.5$ is applicable to the present long duration tests. Van der Meer (1988) analyzed the five long duration tests with $N_{w}$ up to 15,000 conducted by Thompson and Shuttler (1976) and obtained the term $\bar{S} / N_{w}{ }^{0.5}$ in Equation 6.9 for $N_{w}=1,000-8,500$. His data analysis indicated $b<0.5$ for $N_{w}>8,500$. In the following, the values of $a_{s}$ and $b$ are calibrated for this experiment where $N_{w}=$ 60,000 for Series $A^{\prime}$ and $N_{w}=18,000$ for Series $B^{\prime}$ and $C^{\prime}$.

The empirical relationship in Equation 6.10 is limited to damage due to incident irregular waves with constant $H_{s}$ and $T_{m}$ starting from $\bar{S}=0$ at $t=0$. As a result, these formulas and other existing formulas are intended for prediction of damage during the peak of a design storm. In order to develop an empirical procedure for more 
realistic conditions of $H_{s}$ and $T_{m}$ varying with time, the rate of damage increase $d \bar{S} / d t$ is obtained from Equation 6.10 as

$$
\frac{d \bar{S}}{d t}=a_{s} b N_{s}^{5} T_{m}^{-b} t^{b-1}
$$

which is assumed to be valid at arbitrary time $t$. To apply Equation 6.12 for $H_{s}$ and $T_{m}$ varying with time $t$, the relation must be integrated numerically with an arbitrary initial value of $\bar{S}$. For practical applications, the values of $H_{s}$ and $T_{m}$ may be assumed to be constant for a short duration. Integration of Equation 6.12 for the duration of constant $H_{s}$ and $T_{m}$ lasting $t=t_{n}$ to $t=t_{n+1}$ yields the mean damage at arbitrary time $t$

$$
\bar{S}(t)=\bar{S}\left(t_{n}\right)+a_{s} N_{s}^{5} T_{m}^{-b}\left(t^{b}-t_{n}^{b}\right) \quad \text { for } t_{n} \leq t \leq t_{n+1}
$$

where $\bar{S}\left(t_{n}\right)=$ known damage at $t=t_{n}$. Use of Equation 6.13 for each interval of constant $H_{s}$ and $T_{m}$ in sequence allows one to compute $\bar{S}\left(t_{n}\right)$ for incident wave conditions represented by $H_{s}$ and $T_{m}$ varying with time. Alternatively, representing the irregular waves at the toe of the slope using spectral parameters as shown in Equation 6.11 yields the equation

$$
\bar{S}(t)=\bar{S}\left(t_{n}\right)+a_{p} N_{m o}^{5} T_{p}^{-b}\left(t^{b}-t_{n}^{b}\right) \quad \text { for } t_{n} \leq t \leq t_{n+1}
$$

Equations 6.13 and 6.14 are valid for an undamaged structure $(S=0$ at $t=0)$ or damaged structure, $S\left(t_{0}\right)=S_{i}$ at $t=t_{0}$. Using the coefficients predicted by Van der Meer's data, $a_{s}=0.003$ and $b=0.5$, Equation 6.13 follows the general trend of the data 
but underpredicts damage up to $N_{w} \approx 5000$. For a greater number of waves, this equation overpredicts damage.

The empirical coefficients in Equations 6.13 and 6.14 are recalculated in the following using the present experimental data, which were obtained from tests much longer in duration than those listed in Table 6.1. The wave heights and periods for the present experiment were listed in Tables 4.3 and 4.4 and the experimental data are summarized in Appendix B. In order to get a more gradual increase in $S(t)$ it was necessary to raise $a$ and lower $b$. The final coefficients were $a_{s}=0.025$ and $b=0.25$ for Equation 6.13 and $a_{p}=0.022$ and $b=0.25$ for Equation 6.14 yielding the general predictive relations for mean damage progression due to breaking waves for time and frequency wave statistics, respectively, as

$$
\begin{aligned}
& \bar{S}(t)=\bar{S}\left(t_{n}\right)+0.025\left(N_{s}\right)^{5} T_{m}^{-0.25}\left(t^{0.25}-t_{n}^{0.25}\right) \quad \text { for } t_{n} \leq t \leq t_{n+1} \\
& \bar{S}(t)=\bar{S}\left(t_{n}\right)+0.022\left(N_{m o}\right)^{5} T_{p}^{-0.25}\left(t^{0.25}-t_{n}^{0.25}\right) \quad \text { for } t_{n} \leq t \leq t_{n+1}
\end{aligned}
$$

Figure 6.7 shows Equation 6.15 (dashed line) and Equation 6.16 (solid line) plotted against the damage data of Figure 5.10 for Series $A^{\prime}$. The mean damage is well predicted by Equations 6.15 and 6.16 with a correlation coefficient of $r=0.99$ for both equations for this series. Similarly, Figures 6.8 and 6.9 show that the equations predict damage well for Series $B^{\prime}$ and $C^{\prime}$, with correlation coefficients of $r=0.99$ for both. Equations 6.15 and 6.16 are therefore generalized for Series $A^{\prime}, B^{\prime}$, and $C^{\prime}$. The 
agreement for Equations 6.15 and 6.16 is good for the three series except that the formulas do not predict damage stabilization adequately. This deficiency becomes much worse for $b=0.5$. The calibrated value of $b=0.25$ indicates that damage varies less with time $t$ in the long duration experiments using uniform-sized stone armor. The calibrated values of $a_{s}=0.025$ and $a_{p}=0.022$ for $b=0.25$ are much larger than $a_{s}=$ 0.003 for $b=0.5$ estimated using data from Table 6.1 . This difference is mainly caused by the different value of $b$. As an example, for $t / T_{m}=10,000,\left(t / T_{m}\right)^{b}=10$ or 100 for $b=0.25$ or 0.5 . Consequently, the values of $a_{s}$ and $a_{p}$ are coupled with the calibrated value of $b$.

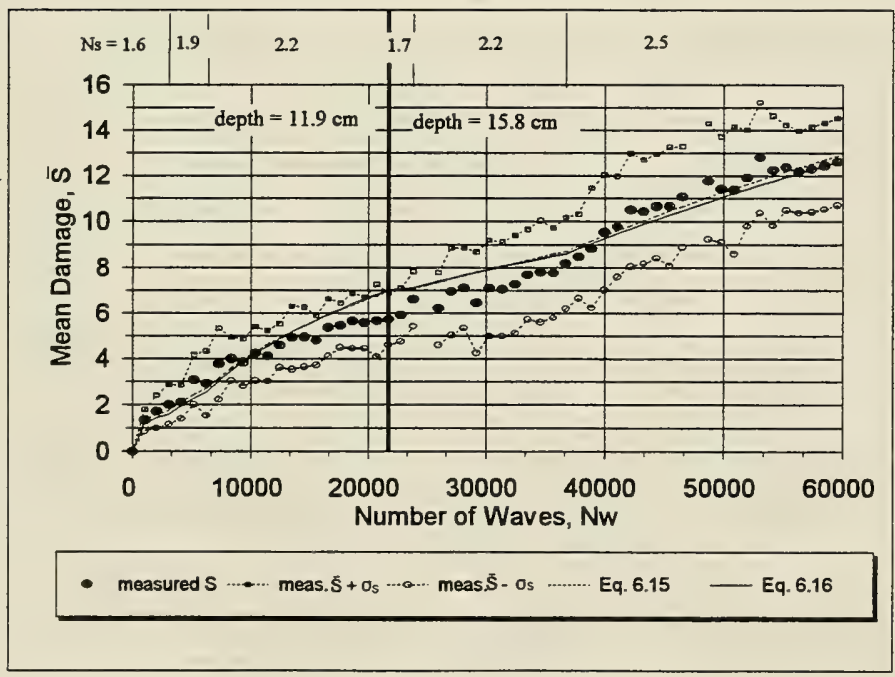

Figure 6.7. Damage prediction relations compared to data for Series $A^{\prime}$ 


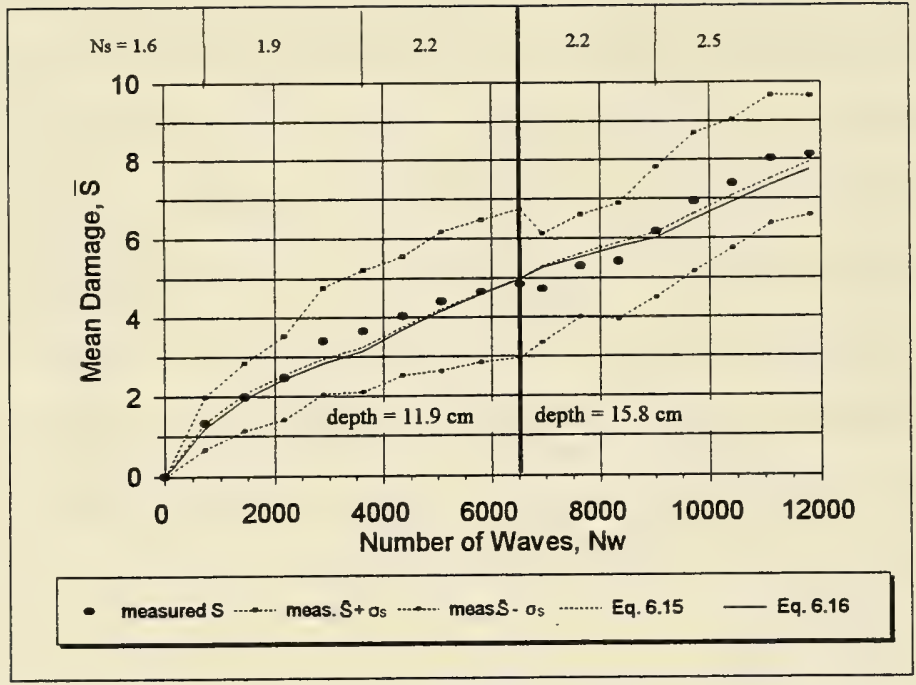

Figure 6.8. Damage prediction relations compared to data for Series $B^{\prime}$

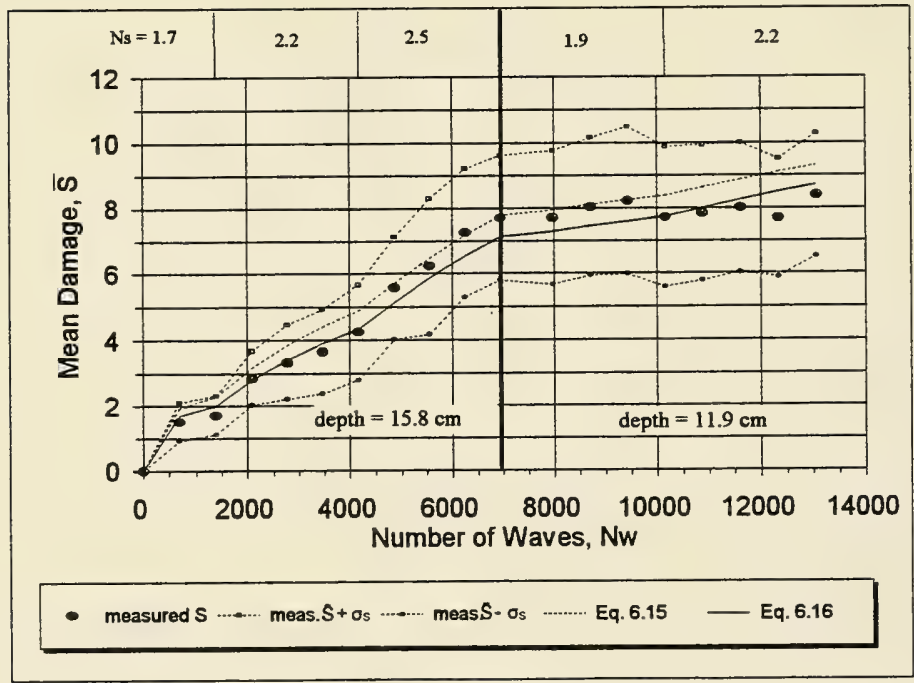

Figure 6.9. Damage prediction relations compared to data for Series $C^{\prime}$ 


\section{Chapter 7}

\section{EFFECT OF WAVE PERIOD AND ARMOR GRADATION ON DAMAGE PROGRESSION}

\subsection{Experimental Setup and Test Conditions}

It is expected that the empirical coefficients in Equations 6.15 and 6.16 are, to some extent, a function of wave period. In addition, only uniform sized armor was utilized in Series $A^{\prime}, B^{\prime}$, and $C^{\prime}$. Therefore, four test series $\left(D^{\prime}, E^{\prime}, F^{\prime}\right.$, and $\left.G^{\prime}\right)$ were added to address the effect of wave period and stone gradation on damage progression. These additional test series are summarized in Table 7.1 along with Series $A^{\prime}, B^{\prime}$, and $C^{\prime}$ for comparison. The spectral and time series incident wave parameters for all series are listed in Table 7.2. Damage measurements are summarized for Series $D^{\prime}, E^{\prime}, F^{\prime}$, and $G^{\prime}$ in Tables B4 through B7 in Appendix B.

\begin{tabular}{|c|c|c|c|c|}
\hline \multicolumn{5}{|c|}{$\begin{array}{l}\text { Table } 7.1 \\
\text { Summary of Test Series for Damage Experiments }\end{array}$} \\
\hline $\begin{array}{l}\text { Test } \\
\text { Series }\end{array}$ & $\begin{array}{l}\text { Test } \\
\text { Type }\end{array}$ & $\begin{array}{l}\text { Armor } \\
\text { Type }\end{array}$ & $\begin{array}{c}\text { Water Level } \\
\text { Order }\end{array}$ & $\begin{array}{l}\text { Test Duration } \\
\text { (hr) }\end{array}$ \\
\hline$\overline{A^{\prime}}$ & Deterioration to Failure & Uniform & Low - High & 28.5 \\
\hline$B^{\prime}$ & Storm Ordering & Uniform & Low - High & 8.5 \\
\hline$C^{\prime}$ & Storm Ordering & Uniform & High - Low & 9.0 \\
\hline$D^{\prime}$ & Wave Period & Uniform & Low-High & 8.5 \\
\hline$E^{\prime}$ & Wave Period & Uniform & Low-High & 8.5 \\
\hline$F^{\prime}$ & Gradation & Riprap & Low-High & 8.5 \\
\hline$G^{\prime}$ & Gradation & Riprap & Low-High & 8.5 \\
\hline
\end{tabular}




\begin{tabular}{|c|c|c|c|c|c|c|c|c|c|c|}
\hline \multicolumn{11}{|c|}{$\begin{array}{l}\text { Table } 7.2 \\
\text { Summary }\end{array}$} \\
\hline Serie & Wave & $\begin{array}{l}\text { Dura- } \\
\text { tion } \\
\mathrm{hr}\end{array}$ & $\begin{array}{l}h_{t} \\
\mathrm{~cm}\end{array}$ & $\begin{array}{l}T_{p} \\
\text { sec }\end{array}$ & $\begin{array}{l}H_{m o} \\
\mathrm{~cm}\end{array}$ & $R$ & $\begin{array}{l}T_{m} \\
\text { sec }\end{array}$ & $\begin{array}{l}H_{s} \\
\mathrm{~cm}\end{array}$ & $\begin{array}{l}H_{1 / 10} \\
\mathrm{~cm}\end{array}$ & $\begin{array}{l}\mathrm{H}_{2 \%} \\
\mathrm{~cm}\end{array}$ \\
\hline \multirow[t]{6}{*}{$A^{\prime}$} & 1 & 1.5 & 11.9 & 2.48 & 9.78 & 0.46 & 1.76 & 9.38 & 11.50 & 12.80 \\
\hline & 2 & 1.5 & 11.9 & 2.48 & 12.40 & 0.47 & 1.69 & 11.60 & 13.80 & 15.37 \\
\hline & 3 & 7.5 & 11.9 & 2.48 & 14.20 & 0.48 & 1.74 & 13.20 & 15.70 & 17.30 \\
\hline & 4 & 1.0 & 15.8 & 2.59 & 10.50 & 0.52 & 1.73 & 10.10 & 12.72 & 14.30 \\
\hline & 5 & 6.0 & 15.8 & 2.59 & 13.60 & 0.51 & 1.67 & 13.00 & 15.97 & 17.80 \\
\hline & 6 & 11.0 & 15.8 & 2.59 & 15.80 & 0.51 & 1.66 & 14.90 & 18.00 & 19.30 \\
\hline \multirow[t]{5}{*}{$B^{\prime}$} & 1 & 0.5 & 11.9 & 2.48 & 9.78 & 0.46 & 1.76 & 9.38 & 11.50 & 12.80 \\
\hline & 2 & 2.0 & 11.9 & 2.48 & 12.40 & 0.47 & 1.69 & 11.60 & 13.80 & 15.37 \\
\hline & 3 & 2.0 & 11.9 & 2.48 & 14.20 & 0.48 & 1.74 & 13.20 & 15.70 & 17.30 \\
\hline & 5 & 2.0 & 15.8 & 2.59 & 13.60 & 0.51 & 1.67 & 13.00 & 15.97 & 17.80 \\
\hline & 6 & 2.0 & 15.8 & 2.59 & 15.80 & 0.51 & 1.66 & 14.90 & 18.00 & 19.30 \\
\hline \multirow[t]{5}{*}{$C^{\prime}$} & 4 & 1.0 & 15.8 & 2.59 & 10.50 & 0.52 & 1.73 & 10.10 & 12.72 & 14.30 \\
\hline & 5 & 2.0 & 15.8 & 2.59 & 13.60 & 0.51 & 1.67 & 13.00 & 15.97 & 17.80 \\
\hline & 6 & 2.0 & 15.8 & 2.59 & 15.80 & 0.51 & 1.66 & 14.90 & 18.00 & 19.30 \\
\hline & 2 & 2.0 & 11.9 & 2.48 & 12.40 & 0.47 & 1.69 & 11.60 & 13.80 & 15.37 \\
\hline & 3 & 2.0 & 11.9 & 2.48 & 14.20 & 0.48 & 1.74 & 13.20 & 15.70 & 17.30 \\
\hline \multirow[t]{5}{*}{$D^{\prime}$} & 7 & 0.5 & 11.9 & 1.97 & 6.13 & 0.44 & 1.64 & 6.05 & 7.62 & 8.36 \\
\hline & 8 & 2.0 & 11.9 & 1.97 & 9.88 & 0.38 & 1.54 & 9.88 & 12.48 & 13.59 \\
\hline & 9 & 2.0 & 11.9 & 1.97 & 13.11 & 0.33 & 1.44 & 13.18 & 16.14 & 17.11 \\
\hline & 10 & 2.0 & 15.8 & 2.02 & 9.62 & 0.38 & 1.61 & 9.74 & 12.48 & 14.00 \\
\hline & 11 & 2.0 & 15.8 & 2.02 & 12.83 & 0.34 & 1.55 & 13.21 & 16.80 & 17.87 \\
\hline \multirow[t]{5}{*}{$E^{\prime}$} & 12 & 0.5 & 11.9 & 1.53 & 5.05 & 0.38 & 1.29 & 5.05 & 6.72 & 7.75 \\
\hline & 13 & 2.0 & 11.9 & 1.53 & 7.13 & 0.35 & 1.29 & 7.26 & 9.70 & 11.11 \\
\hline & 14 & 2.0 & 11.9 & 1.53 & 9.93 & 0.31 & 1.23 & 10.19 & 13.38 & 14.90 \\
\hline & 15 & 2.0 & 15.8 & 1.48 & 6.60 & 0.34 & 1.30 & 6.58 & 8.15 & 8.78 \\
\hline & 16 & 2.0 & 15.8 & 1.48 & 9.41 & 0.32 & 1.26 & 9.53 & 12.03 & 13.34 \\
\hline \multirow[t]{5}{*}{$F^{\prime}$} & 17 & 0.5 & 11.9 & 2.48 & 7.21 & 0.49 & 1.72 & 6.96 & 8.68 & 9.61 \\
\hline & 18 & 2.0 & 11.9 & 2.48 & 11.68 & 0.42 & 1.56 & 11.51 & 14.39 & 15.63 \\
\hline & 19 & 2.0 & 11.9 & 2.48 & 15.33 & 0.37 & 1.39 & 14.95 & 18.09 & 19.39 \\
\hline & 20 & 2.0 & 15.8 & 2.59 & 6.43 & 0.47 & 1.80 & 6.18 & 7.78 & 8.58 \\
\hline & 21 & 2.0 & 15.8 & 2.59 & 8.82 & 0.44 & 1.72 & 8.54 & 10.95 & 12.45 \\
\hline \multirow[t]{5}{*}{$G^{\prime}$} & 22 & 0.5 & 11.9 & 1.97 & 7.62 & 0.42 & 1.50 & 7.53 & 9.53 & 10.62 \\
\hline & 23 & 2.0 & 11.9 & 1.97 & 12.07 & 0.37 & 1.36 & 11.99 & 14.93 & 16.22 \\
\hline & 24 & 2.0 & 11.9 & 1.97 & 15.42 & 0.35 & 1.30 & 15.21 & 17.95 & 18.99 \\
\hline & 25 & 2.0 & 15.8 & 2.02 & 11.92 & 0.37 & 1.44 & 11.98 & 15.06 & 16.67 \\
\hline & 26 & 2.0 & 15.8 & 2.02 & 15.34 & 0.35 & 1.34 & 15.36 & 18.64 & 20.03 \\
\hline
\end{tabular}


Series $D^{\prime}$ and $E^{\prime}$ were similar to Series $B^{\prime}$ except with different target peak periods. The different spectra also produced different characteristic wave heights at the toe of the structure. Series $F^{\prime}$ and $G^{\prime}$ were similar to Series $B^{\prime}$ and $D^{\prime}$ except that riprap was used as armoring. Series $F^{\prime}$ had the same wave peak periods as Series $B^{\prime}$ while Series $G^{\prime}$ had the same wave peak periods as Series $D^{\prime}$. Therefore, Series $B^{\prime}, D^{\prime}, E^{\prime}, F^{\prime}$, and $G^{\prime}$ provide comparative damage measurements with systematic variation of armor gradation and wave period.

As shown in Table 7.1, the order of water levels, individual storm durations, and series durations for Series $D^{\prime}, E^{\prime}, F^{\prime}$, and $G^{\prime}$ were identical to Series $B^{\prime}$. Four storms were run within each test series following $30 \mathrm{~min}$ of shakedown waves, with the lowwater-level storms run first followed by the high-water-level ones. The duration of each of 4 storms was 2 hours yielding 8.5 hours of waves for each series. Wave heights were incrementally raised at each water level to simulate increasing storm severity. The waves were run in $15 \mathrm{~min}$ bursts, with the water completely settling between bursts. As was done for Series $A^{\prime}, B^{\prime}$, and $C^{\prime}$, the 2 structures were profiled every 30 min using eight profile rods across the center portion of each structure. Each storm series was repeated to yield 32 profiles alongshore for the undamaged underlayer and armor layer and after every $30 \mathrm{~min}$ of waves. As discussed in Chapter 5, the mean and standard deviation of $E, C, L$, and $S$ for these 32 profiles were computed.

The armor stone for Series $F^{\prime}$ and $G^{\prime}$ was widely graded riprap with a median mass $M_{50}=256 \mathrm{~g}$, nominal diameter $D_{n 50}=\left(M_{50} / \rho_{a}\right)^{1 / 3}=4.58 \mathrm{~cm}$, stone density 
$\rho_{a}=2.66 \mathrm{~g} / \mathrm{cm}^{3}$, and $D_{85} / D_{15}=1.53$. The mass distribution, plotted as percent finer by mass, is shown in Figure 7.1. The median mass was computed from a 200 stone sample as the value where half the total mass in the sample was greater. For comparison, the median mass by count for a 200 stone sample was $M_{50 \mathrm{c}}=128 \mathrm{~g}$ (i.e. half the stones weighed less). This latter value was not used in this thesis, although it is sometimes used in the field. The riprap followed the widest recommendation of the SPM (1984) of approximately $0.125 M_{50}<M<4 M_{50}$. For all series, the underlayer or filter layer had a gradation of $D_{85} / D_{15}=1.32$ and was sized such that $\left(M_{50}\right)_{a m o r} /\left(M_{50}\right)_{\text {filter }}=25$ and $\left(D_{50}\right)_{a m o r} /\left(D_{50}\right)_{\text {filter }}=2.9$.

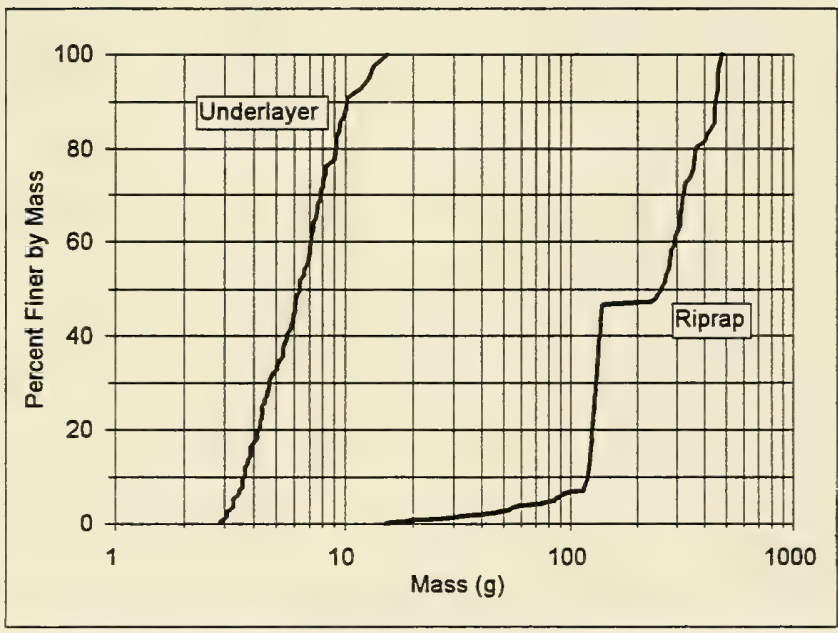

Figure 7.1. Stone mass distributions for riprap and underlayer 


\subsection{Probability Density Functions of Damage, Eroded Depth, and Cover Depth}

The probability density functions of $S^{*}, E^{*}$, and $C^{*}$ are shown in Figures

$7.2,7.3$, and 7.4, respectively, with Series $D^{\prime}, E^{\prime}, F^{\prime}$ and $G^{\prime}$ combined onto each figure. These figures can be compared to Figures 5.2, 5.3, and 5.4 for Series $A^{\prime}, B^{\prime}$, and $C^{\prime}$, respectively. The figures indicate that the variability of the eroded profile and eroded area for the new series are similar to those of Series $A^{\prime}, B^{\prime}$, and $C^{\prime}$. The limits of variability remain as prescribed by Equation 5.10 or approximately in the range from -3.0 to 3.0 . It is noted that the damage and eroded depth distributions are negatively skewed while the cover depth is positively skewed. This indicates that more cross sections have less normalized damage and larger normalized cover layer thickness. Relatedly, the negative tails of the damage and eroded depth distributions are less populated for Series $D^{\prime}, E^{\prime}, F^{\prime}$ and $G^{\prime}$ than for Series $A^{\prime}, B^{\prime}$, and $C^{\prime}$, particularly below normalized values of -2 . As will be described in the following sections, wave energy and therefore damage levels were lower for the new series than for Series $A^{\prime}, B^{\prime}$, and $C^{\prime}$. The damage increased rapidly at low damage levels, $\bar{S}=0-1$, resulting in few damage measurements at these low damage levels. 


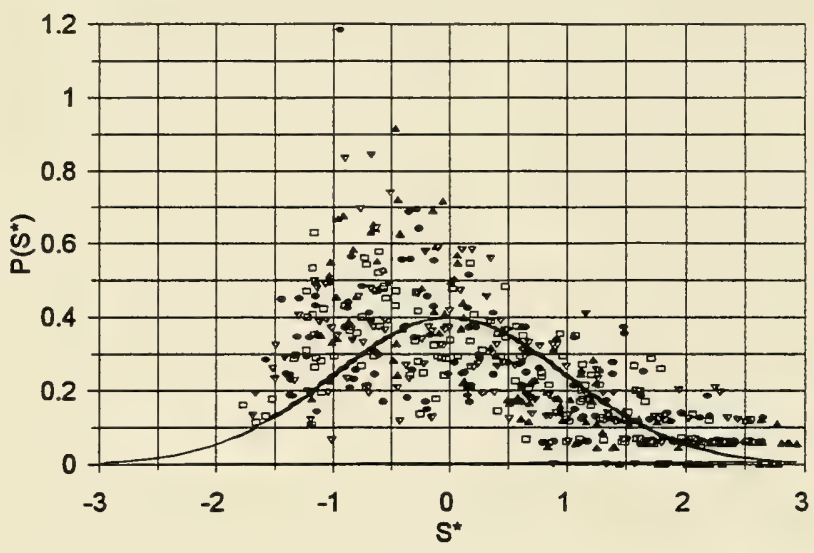

- Series D' - Series E' \ Series F' • Series G' — Normal

Figure 7.2. Probability density function for normalized damage $S^{*}$ for Series $D^{\prime}, E^{\prime}, F^{\prime}$ and $G^{\prime}$

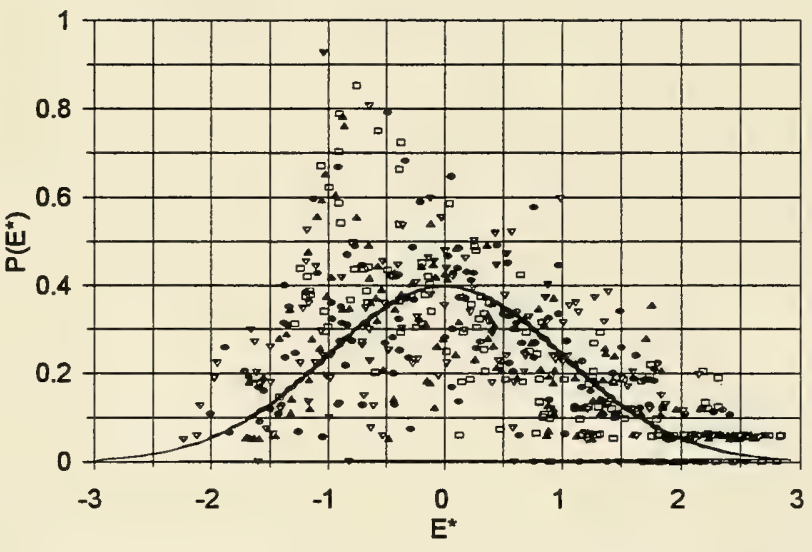

\section{- Series $D^{\prime}$ - Series E' ^ Series $F^{\prime}$ Series $G^{\prime}$ — Normal}

Figure 7.3. Probability density function for normalized eroded depth $E^{*}$ for Series $D^{\prime}$, $E^{\prime}, F^{\prime}$ and $G^{\prime}$ 


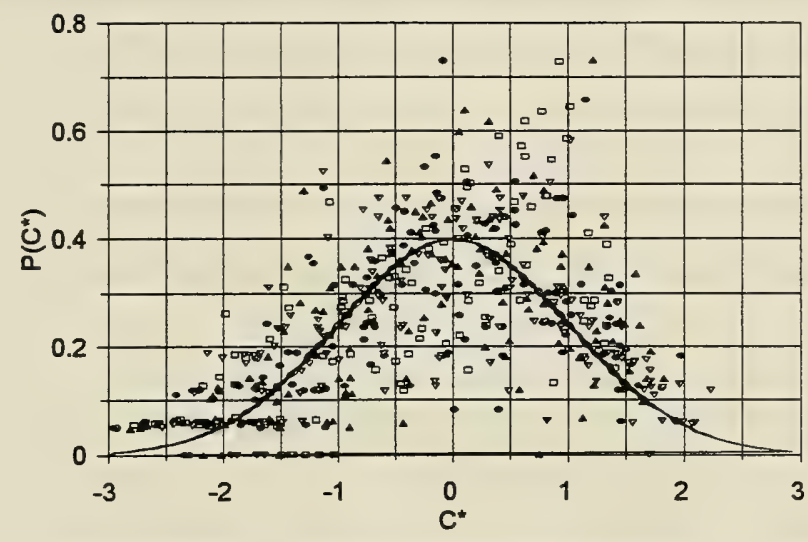

- Series $D^{\prime}$ o Series $E^{\prime} \triangle$ Series $F^{\prime}$ - Series $G^{\prime}$ - Normal

Figure 7.4. Probability density function for normalized cover depth $C^{*}$ for Series $D^{\prime}, E^{\prime}$, $F^{\prime}$ and $G^{\prime}$

\subsection{Damage Variability}

Figure 7.5 shows $\sigma_{s}$ as a function of mean damage $\bar{S}$ for Series $D^{\prime}, E^{\prime}, F^{\prime}$, and $G^{\prime}$ along with Equation 6.1. Series $B^{\prime}$ is included for comparison. This figure indicates that Equation 6.1 underpredicts damage variability for the new series in the range $\bar{S}=1-4$. But above and below this range the results are inconclusive. The greater variability in damage for the wider gradation (Series $F^{\prime}$ and $G$ ) is expected; but the reason for the greater damage variability for shorter wave periods is not clear. It appears there are insufficient data to make a definitive modification to Equation 6.1. Even though the data are slightly underpredicted by Equation 6.1, Equations 5.10 and 6.1 
provide a description of the alongshore variability of damage that is reasonable for experimental results described herein.

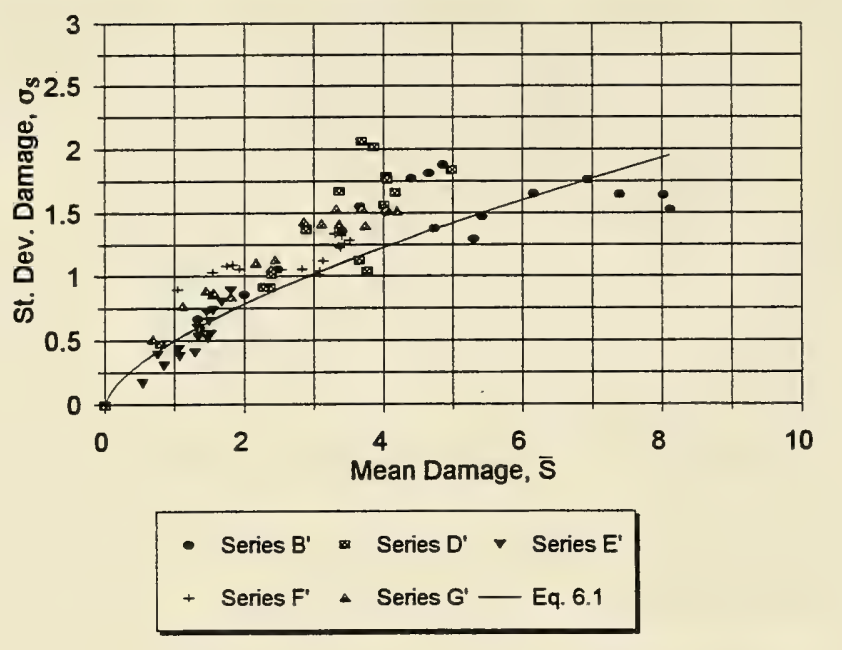

Figure 7.5. Prediction of damage variability, characterized by the standard deviation, as a function of mean damage for Series $B^{\prime}, D^{\prime}, E^{\prime}, F^{\prime}$, and $G^{\prime}$

\subsection{Eroded Profile Prediction}

Figure 7.6 shows the mean eroded depth $\bar{E}$ for the four new series as a function of $\bar{S}$ along with Series $B^{\prime}$. Equation 6.2, for prediction of $\bar{E}$ based on Series $A^{\prime}$, $B^{\prime}$, and $C^{\prime}$, is also plotted in Figure 7.6. It is clear that this equation describes the new data well without modification. The standard deviation for eroded depth $\sigma_{E}$ as a function of $\bar{S}$ is shown in Figure 7.7 for the four new series and $B^{\prime}$. Equation 6.3 for $\sigma_{E}$ as a function of $\bar{S}$, also plotted in Figure 7.7, underestimates the variability of eroded 
depth in the new data sets. This reinforces the fact that damage variability was greater in Series $D^{\prime}, E^{\prime}, F^{\prime}$, and $G^{\prime}$ than in Series $A^{\prime}, B^{\prime}$, and $C^{\prime}$. Also, Series $D^{\prime}$ produced more outlying points in this Figure than the other series. This is consistent with previous figures and indicates that further testing is required to better quantify the coefficient of variation of the damage and profile parameters, particularly for low damage levels. The mean normalized eroded length $\bar{L}$ is plotted as a function of $\bar{S}$ for data from the four new series in Figure 7.8. Equation 6.4 for $\bar{L}$ as a function of $\bar{S}$ is shown to provide an excellent fit to the new data.

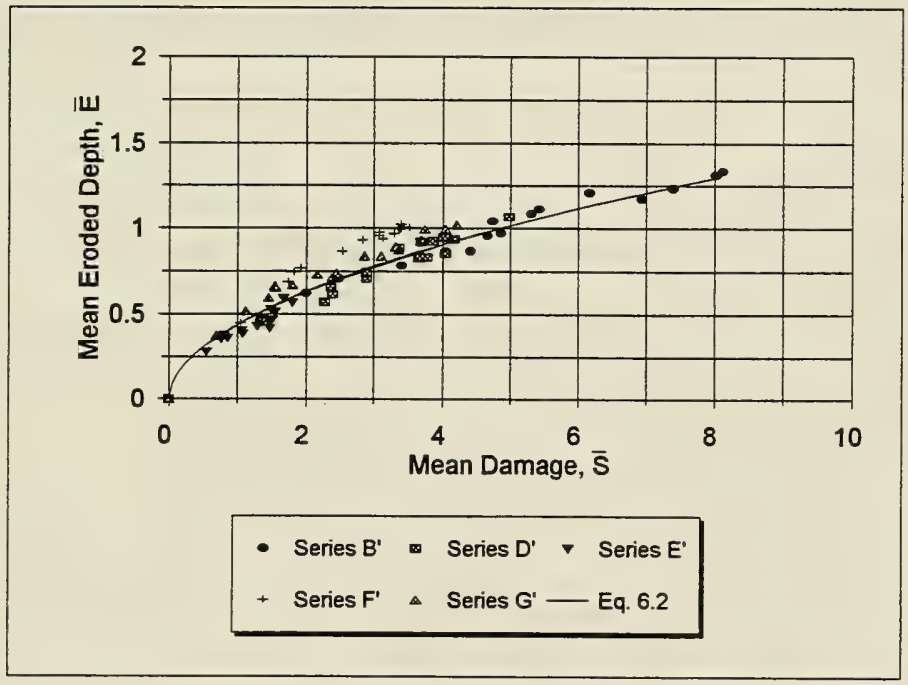

Figure 7.6. Prediction of mean maximum eroded depth as a function of mean damage for Series $B^{\prime}, D^{\prime}, E^{\prime}, F^{\prime}$, and $G^{\prime}$ 


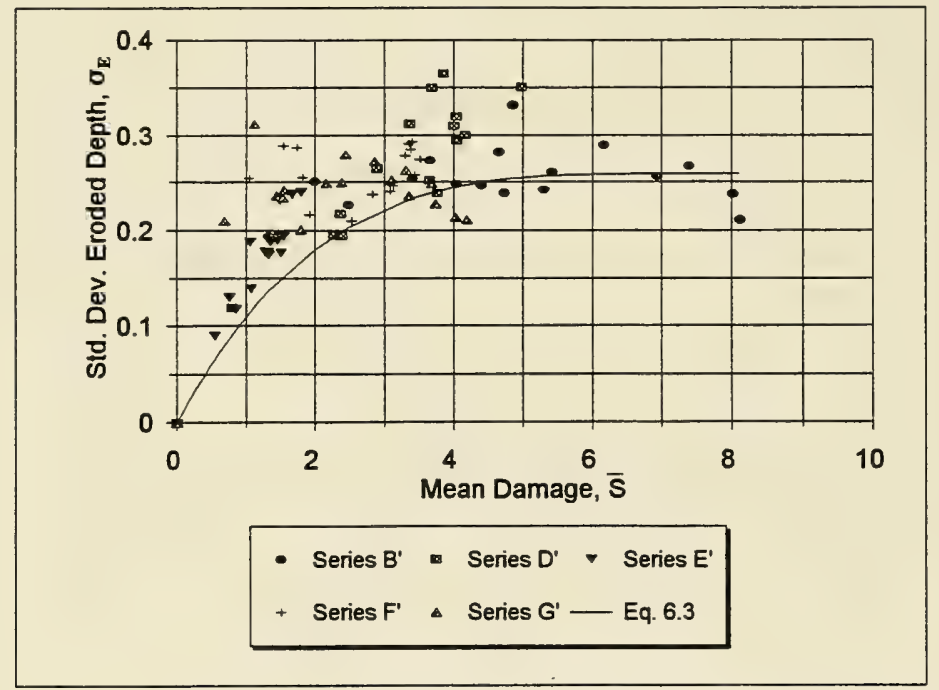

Figure 7.7. Prediction of standard deviation of maximum eroded depth as a function of mean damage for Series $B^{\prime}, D^{\prime}, E^{\prime}, F^{\prime}$, and $G^{\prime}$

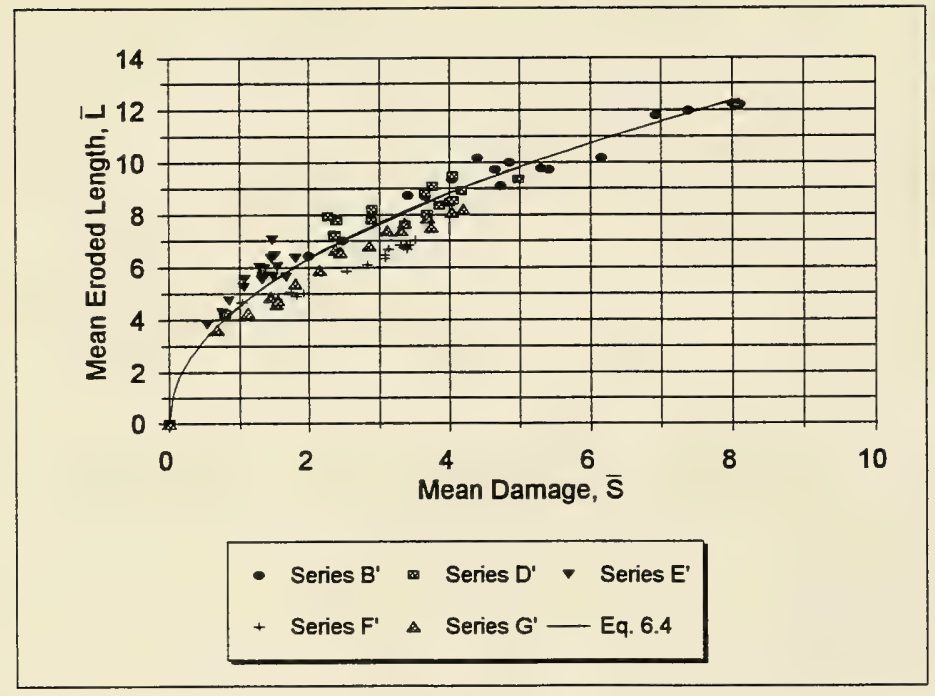

Figure 7.8. Prediction of mean maximum eroded length as a function of mean damage for Series $B^{\prime}, D^{\prime}, E^{\prime}, F^{\prime}$, and $G^{\prime}$ 
The mean cover depth as a function of $\bar{S}$ was shown to be described by Equation 6.5. This relation, rearranged to be eroded cover depth, also provides a good fit to the new data, as shown in Figure 7.9. In addition, the standard deviation of minimum cover depth $\sigma_{c}$ was shown to be described by Equation 6.6. This equation, along with the new data, are shown in Figure 7.10. Equation 6.6 underpredicts the variability in cover depth, as expected. Again, Series $D^{\prime}$ produced most of the outlying points. Data from the other series are reasonably well predicted by Equation 6.6 .

The profile and variability relationships given by Equations 5.10 and 6.1 through 6.6, derived from Series $A^{\prime}, B^{\prime}$, and $C^{\prime}$ data, fit the new data remarkably well, considering the ranges of stone grading and peak wave period in this experiment. Equation 6.3 and 6.6 underpredict the variability and will likely require modification as more data are acquired. It appears that the coefficient of variation is more scattered for low damage levels. The relations given above allow prediction of profile shape and alongshore variability of the profile. The above relations were developed using only profile data without regard to incident wave conditions or water levels. 


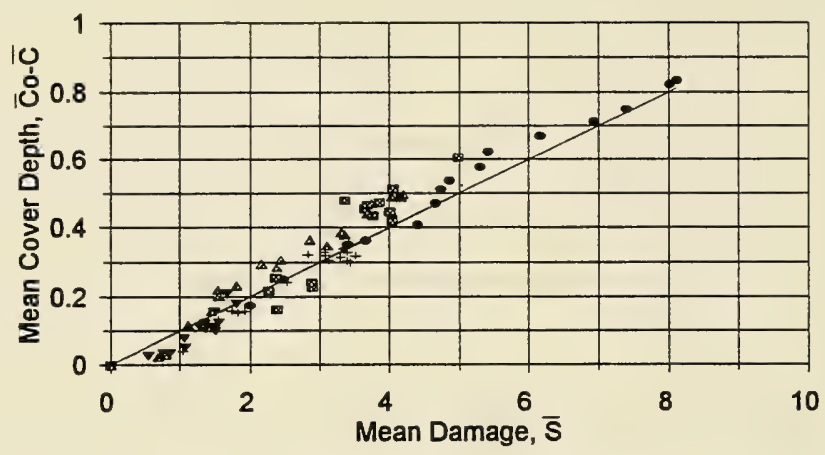

- Series $B^{\prime}$ Series $D^{\prime} \quad$ Series $E^{\prime}$

+ Series $F^{\prime} \Delta$ Series G' Eq. 6.5

Figure 7.9. Prediction of mean minimum cover depth as a function of mean damage for Series $B^{\prime}, D^{\prime}, E^{\prime}, F^{\prime}$, and $G^{\prime}$

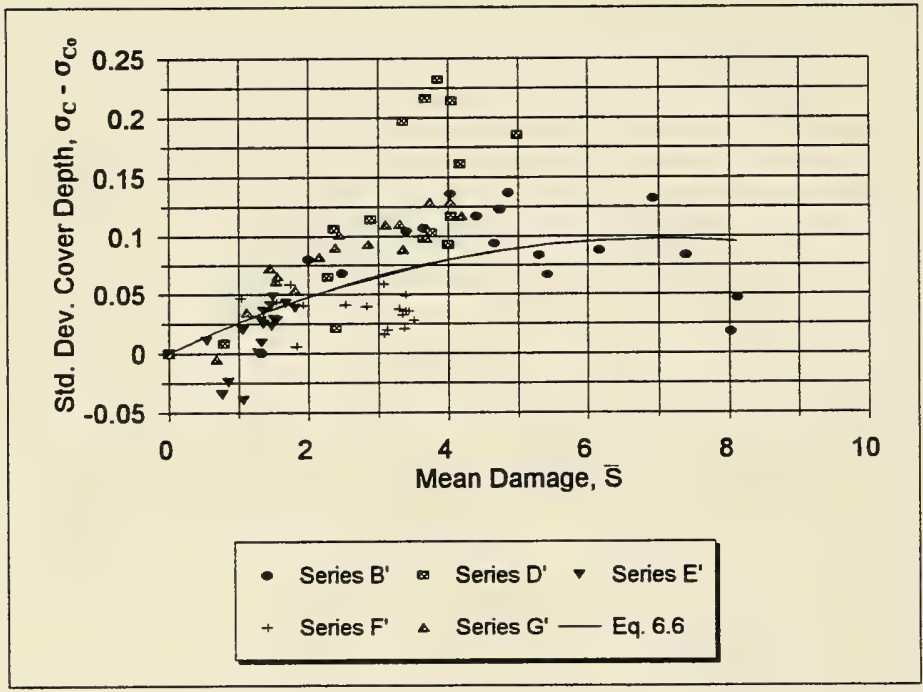

Figure 7.10. Prediction of standard deviation of minimum cover depth as a function of mean damage for Series $B^{\prime}, D^{\prime}, E^{\prime}, F^{\prime}$, and $G^{\prime}$ 


\subsection{Temporal Damage Development}

In Chapter 6, the generalized Equations 6.15 and 6.16 for predicting damage progression were highly correlated with damage data from Series $A^{\prime}, B^{\prime}$, and $C^{\prime}$. Figures 7.11 through 7.14 show Equations 6.15 and 6.16 plotted against data from Series $D^{\prime}, E^{\prime}$, $F^{\prime}$, and $G^{\prime}$. To recap, Series $D^{\prime}$ and $E^{\prime}$ were nearly identical to Series $B^{\prime}$ except that the peak wave period was changed for the three series. Series $F^{\prime}$ and $G^{\prime}$ were again similar except that the uniform armor was replaced with riprap. Two different peak wave periods were tested in Series $F^{\prime}$ and $G^{\prime}$. It can be seen that the damage progression equations predict the overall trend of damage progression for Series $D^{\prime}$ through $G^{\prime}$ using $a_{s}=0.025, a_{p}=0.022$, and $b=0.25$, although there are noted discrepancies. For example, it can be seen that damage initiation is underpredicted in all series. Equations 6.15 and 6.16 significantly underpredict damage initiation, if only 1 or 2 stones are displaced at the beginning of each test series. This underprediction appears to be produced by the variability in damage initiation. Figures 7.15 through 7.18 show Equation 6.15 starting from two different points: from $N_{w}=0$ and from the first measured damage point past $N_{w}=1000$. As can be seen, the prediction is much better when the damage is predicted after initial profile adjustment. Figures 7.11 through 7.18 indicate that the empirical coefficients in Equations 6.15 and 6.16 may vary somewhat with wave period and stone gradation for the range of experimental conditions described herein. The initial profile adjustment may need to be accounted for in test series with relatively small cumulative damage. 


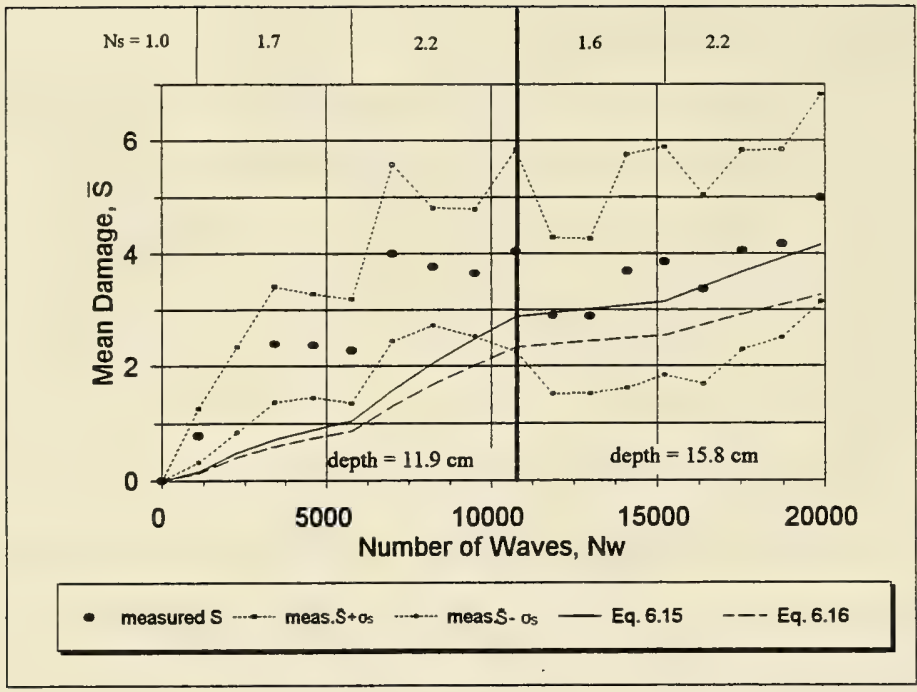

Figure 7.11. Damage prediction relations compared to data for Series $D^{\prime}$

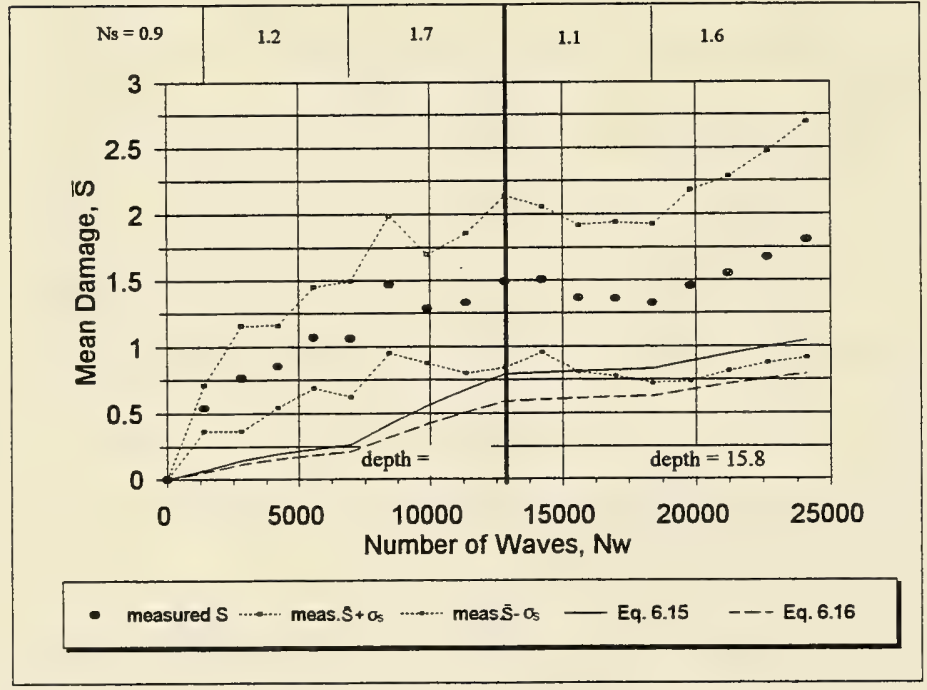

Figure 7.12. Damage prediction relations compared to data for Series $E^{\prime}$ 


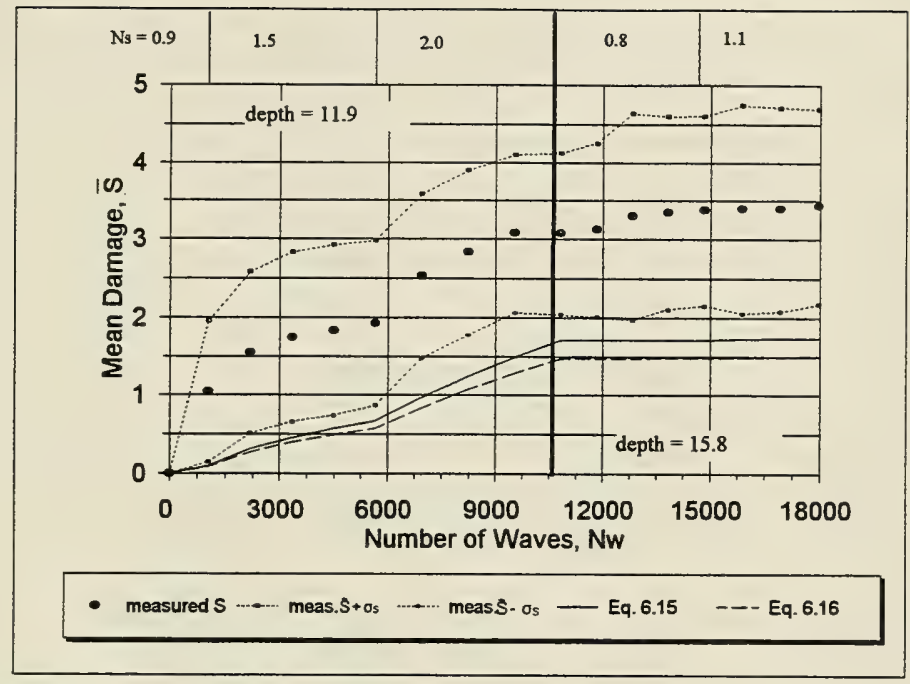

Figure 7.13. Damage prediction relations compared to data for Series $F^{\prime}$

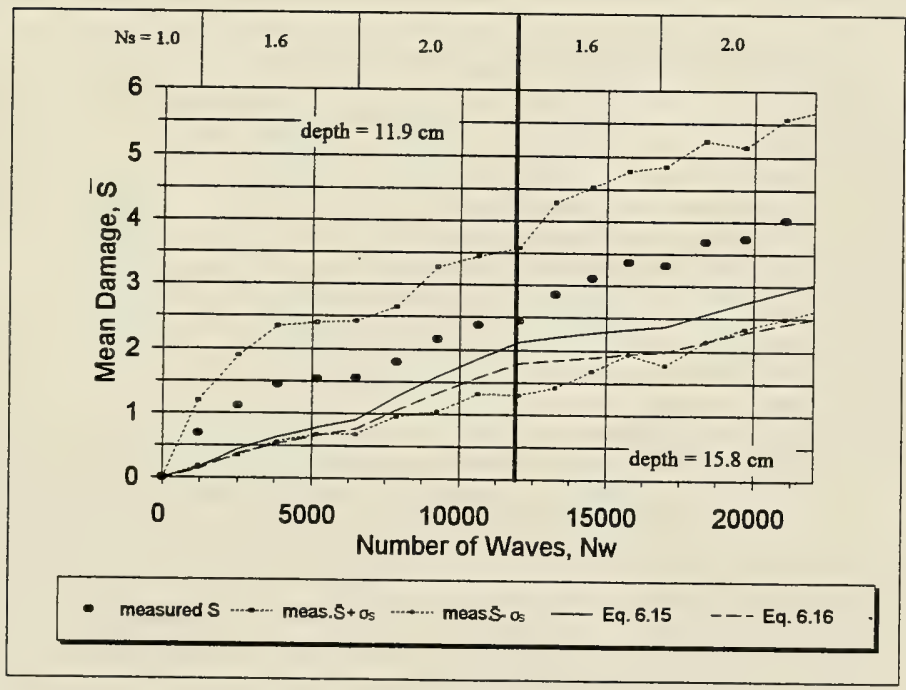

Figure 7.14. Damage prediction relations compared to data for Series $G^{\prime}$ 


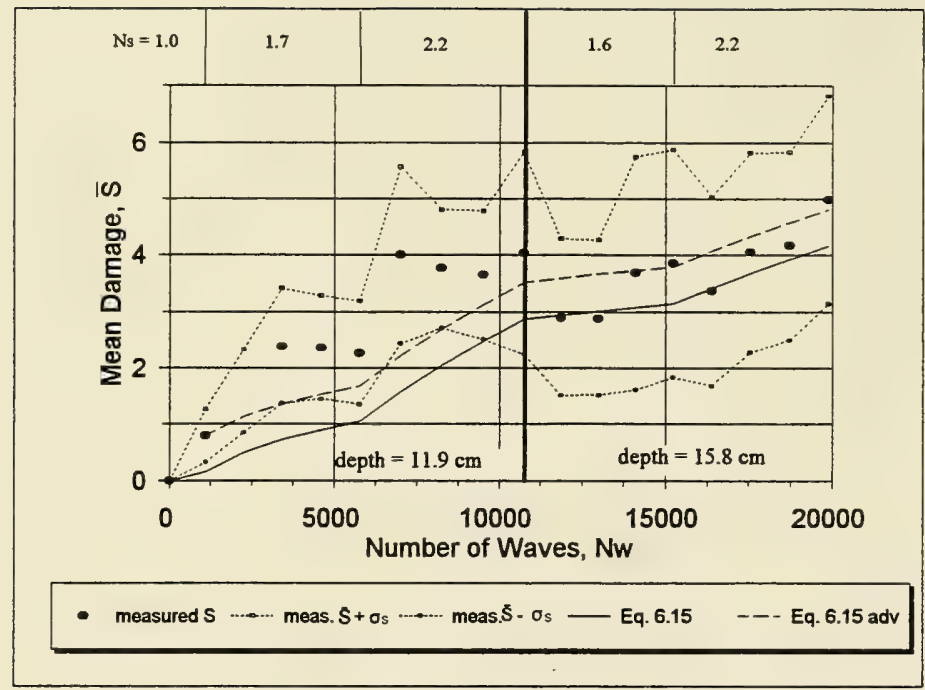

Figure 7.15. Damage prediction relations compared to data for Series $D^{\prime}$ including damage initiation adjustment

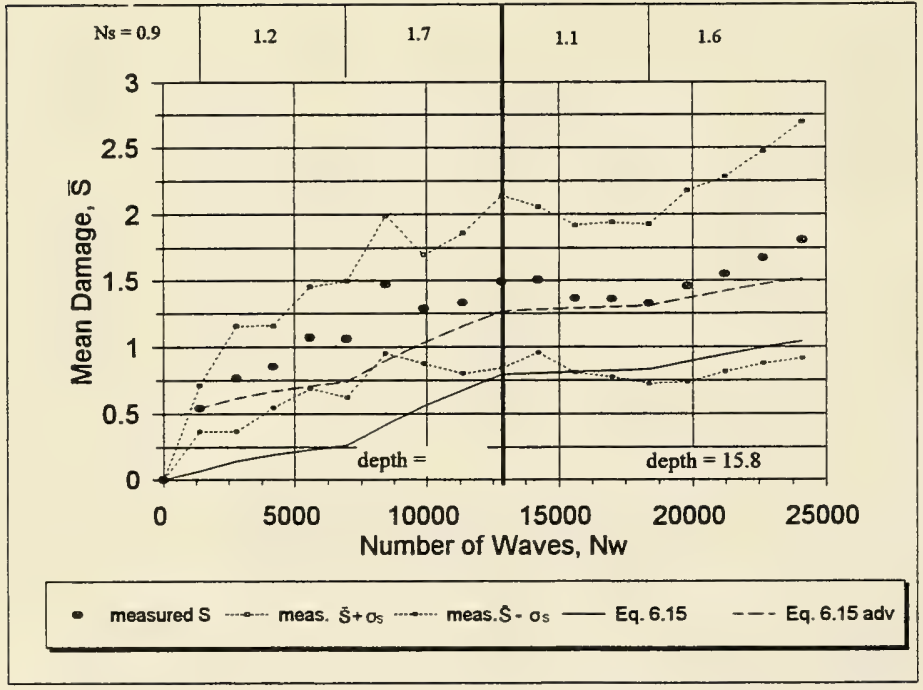

Figure 7.16. Damage prediction relations compared to data for Series $E^{\prime}$ including damage initiation adjustment 


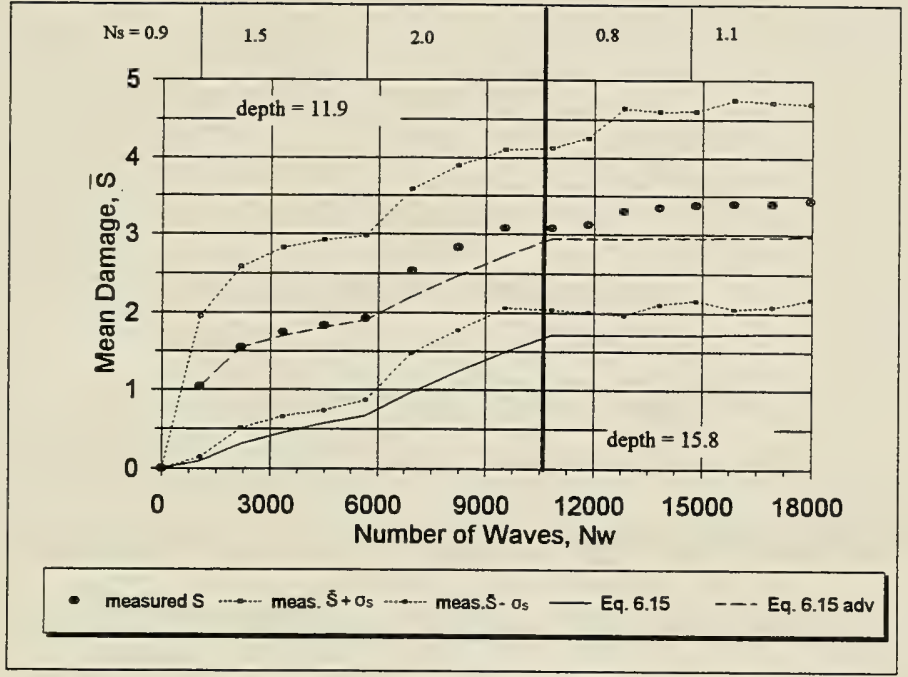

Figure 7.17. Damage prediction relations compared to data for Series $F^{\prime}$ including damage initiation adjustment

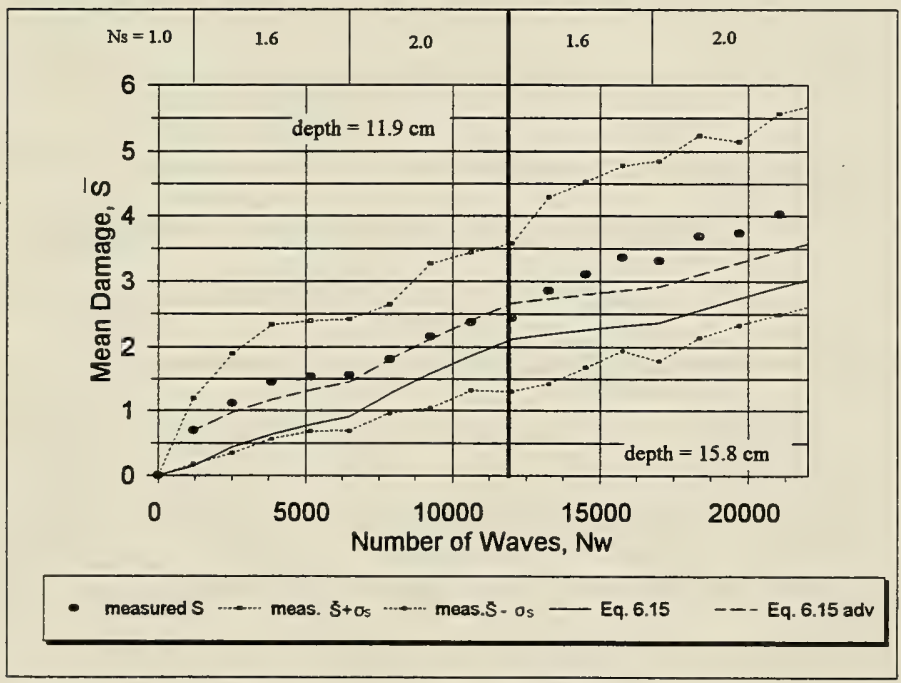

Figure 7.18. Damage prediction relations compared to data for Series $G^{\prime}$ including damage initiation adjustment 


\section{Chapter 8}

\section{SUMMARY AND CONCLUSIONS}

This thesis addresses depth-limited breaking wave damage on rubble mound breakwaters. Chapters 1-3 are introductory. Chapter 1 introduces the topic of rubble mound structures and their failure modes. It is noted that deterioration models are required for risk and reliability analyses as part of rehabilitation studies for these structures.

Chapter 2 discusses a new experiment conducted to investigate incipient motion of stone armor units in depth-limited breaking waves. Observations were made of incipient motion on both stone and sphere armor layers. Velocity measurements were made during these experiments both inside and just outside the armor layer using a laser Doppler velocimeter. It is shown that the maximum vertical convective acceleration across the armor layer is proportional to the square of the maximum vertical velocity. Equation 2.11, an incipient motion criterion similar to the Shields criterion for sediment motion, is derived based on Morison forcing for the dominant mode of motion: vertical lift under the steep breaking-wave face. Equation 2.11 is restated in terms of the stability number as Equation 2.12 as follows 


$$
N_{s}=\frac{H_{c}}{D_{n}\left(S_{r}-1\right)}=\frac{g H_{c}}{v_{c}^{2}}\left(C_{D}^{\prime}+C_{m}^{\prime}\right)^{-1}
$$

The experimental observations and measurements are used to validate this incipient motion criterion for breakwater armor.

In Chapter 3, historical damage experimental techniques, measurements, and models are described for rubble mound breakwaters. It is noted that there are inconsistencies in both historical and recent modeling techniques which have a large effect on the conclusions drawn. In particular, different methods of computing eroded area or volume produce results that differ by nearly a factor of 2 . Several authors have made note of the fact that irregular wave experiments may not produce an equilibrium profile prior to failure. This conclusion was verified within this study. Many breakwater stability experiments have been conducted; but nearly all tests were conducted with nonbreaking waves, started with an undamaged structure, and progressed to relatively low levels of damage.

Chapters 4-7 discuss a new experiment to investigate damage development on a breakwater exposed to a series of depth limited storms of varying wave energy and in varying water levels. It is noted that this study was motivated by the fact that no general irregular-breaking-wave damage progression experiments have been conducted. Therefore, no generally applicable relations exist that would permit prediction of damage progression in breaking waves. A methodology is developed for measuring 
damage in a small-scale physical model. The methodology uses damage defined by Equation 3.1 as the eroded area normalized by the square of the nominal stone diameter

$$
S=\frac{A_{e}}{D_{n S 0}^{2}}
$$

In addition, three profile descriptors of engineering interest are suggested as follows. The minimum cover depth (Equation 5.1), maximum eroded depth (Equation 5.2), and maximum eroded length (Equation 5.5) along the profile are normalized as

$$
\begin{gathered}
C=\frac{d_{c}}{D_{n 50}} \\
E=\frac{d_{e}}{D_{n 50}} \\
L=\frac{l_{e}}{D_{n 50}}=\frac{2 S}{E}
\end{gathered}
$$

Data were obtained from an automated profiler on a traditional rubble mound breakwater section. The profiler is shown to provide improved damage measurements, as the cross-shore spatial sampling interval was less than $1 \mathrm{~mm}$, which is considerably smaller than traditional sounding measurements. In addition, the profiler was automated making profiling very efficient. Because profiling did not require draining the wave 
flume between tests, more tests could be accomplished and with more frequent profiling.

In the experiment, damage development was measured on two identical breakwaters with seaward slopes of 1:2 exposed to depth-limited breaking waves on a 1:20 beach slope. The armor was limited to a traditional two-layer thickness of uniformly sized stone and a widely graded riprap. The waves were run as sequences of storms with varying irregular wave conditions and water levels. Seven unique longterm damage test series were conducted. The first, Series $A^{\prime}$, was a long duration test with varying water level and wave height. In this first series, the water level was increased midway through the test. The wave heights were increased in five increments. Damage was allowed to reach an observed apparent equilibrium level before the wave height or water level was changed. The second and third series $\left(B^{\prime}\right.$ and $\left.C^{\prime}\right)$ were designed to yield insight into damage progression for variations in storm ordering. During Series $B^{\prime}$, the water level was increased midway through the test, while for Series $C^{\prime}$ the water level was decreased midway through. For Series $B^{\prime}$ and $C^{\prime}$, wave heights were increased in four increments, each after about 4,200 waves or approximately 8 to $10 \mathrm{hr}$ of prototype storm. Series $D^{\prime}$ and $E^{\prime}$ were similar to Series $B^{\prime}$ except with different peak wave periods. Series $F^{\prime}$ and $G^{\prime}$ were similar to Series $B^{\prime}$ and $D^{\prime}$ except that riprap was used as armoring.

It was observed during the series that the damage never really stabilized or reached an equilibrium. Also, Series $B^{\prime}$ and $C^{\prime}$ indicated that the final damage was 
similar for both series consisting of different sequences of storms of similar cumulative wave action. The damage data showed partial healing during damage progression, where eroded pockets from displaced stones were filled in by minor shifting of surrounding stones.

The probability density functions of damage, eroded depth, and cover depth were analyzed in Chapter 5. For each series, at each point in time, the probability density functions of normalized values, given by Equation 5.6 as

$$
S^{*}=\frac{S-\bar{S}}{\sigma_{S}} ; \quad E^{*}=\frac{E-\bar{E}}{\sigma_{E}} ; \quad C^{*}=\frac{C-\bar{C}}{\sigma_{C}}
$$

are shown to have ranges given by Equation 5.10 as

$$
-2.7<S^{*}<3 ; \quad-2.7<E^{*}<2.7 ; \quad-2.7<C^{*}<2.8
$$

All normalized variables are in the range from -3 to 3 . It is shown that series with lower overall damage levels had negatively skewed distributions with fewer points in the negative tail in the range $-3<S^{*}<-2$ due to the fact that there were few measurements at very low damage in the range $\bar{S}=0-1$.

Equation 6.1 was obtained through statistical analysis of the profile data to describe the alongshore variability of damage as

$$
\sigma_{s}=0.5 \bar{S}^{0.65}
$$


This equation, along with Equation 5.10, can be used to predict the range of damage for a given level of mean damage. These relations indicated that alongshore damage variability was greater than previously suspected and could be significant in a life-cycle cost analysis.

The damaged profile shape, as characterized by the mean eroded depth $\bar{E}$ and mean cover depth $\bar{C}$, was shown to be well described in terms of the mean damage by Equations 6.2 and 6.5

$$
\begin{gathered}
\bar{E}=0.46 \sqrt{\bar{S}} \\
\bar{C}=\overline{C_{0}}-0.1 \bar{S}
\end{gathered}
$$

where $\bar{C}_{0}$ is the mean cover depth when $\bar{S}=0$. The mean eroded length was shown to be described in terms of the mean damage by Equation 6.4 as

$$
\bar{L}=4.4 \sqrt{S}
$$

The variability of eroded depth and cover depth was shown to be described by Equations 6.3 and 6.6 , respectively, as

$$
\begin{gathered}
\sigma_{E}=0.26-0.00007(\bar{S}-7.8)^{4} \\
\sigma_{C}=\sigma_{C_{0}}+0.098-0.002(\bar{S}-7)^{2}
\end{gathered}
$$


where $\sigma_{C_{0}}$ is the value of $\sigma_{C}$ when $\bar{S}=0$. It is noted that Equations 6.1, 6.3, and 6.6 underpredict variability of erosion somewhat, but more data are required to better quantify these relations. Equations 5.10 and 6.1 through 6.6 define the damage profile shape and alongshore variability as a function of mean damage without regard to wave conditions.

The temporal variation of mean damage is given by Equations 6.15 and 6.16

$$
\begin{array}{cc}
\bar{S}(t)=\bar{S}\left(t_{n}\right)+0.025\left(N_{s}\right)^{5} T_{m}^{-0.25}\left(t^{0.25}-t_{n}^{0.25}\right) & \text { for } t_{n} \leq t \leq t_{n+1} \\
\bar{S}(t)=\bar{S}\left(t_{n}\right)+0.022\left(N_{m o}\right)^{5}\left(T_{p}\right)^{-0.25}\left(t^{0.25}-t_{n}^{0.25}\right) & \text { for } t_{n} \leq t \leq t_{n+1}
\end{array}
$$

for time domain and frequency domain wave statistics, respectively. These formulas can be used for predicting mean damage $\bar{S}$, where the wave height and period vary in steps. The formulas fit the data well for Series $A^{\prime}, B^{\prime}$, and $C^{\prime}$, with systematic variations of water depth and wave height. The equations are shown to fit the trends of damage progression well for Series $D^{\prime}, E^{\prime}, F^{\prime}$, and $G^{\prime}$, where the peak wave period and stone gradation were varied. Damage initiation, where only 1 or 2 stones moved, was consistently underpredicted by more than a standard deviation for Series $D^{\prime}$ through $G^{\prime}$. This appears to be due to the variability in damage initiation. It is shown that the prediction is significantly improved if the damage progression is begun immediately after the initial profile adjustment or 1000 waves. The initial profile adjustment may need to be accounted for in test series with relatively small cumulative damage. Also, 
the empirical parameters in these equations may need to be varied somewhat with wave period and armor gradation.

The relations given in this thesis for eroded area and damaged profile prediction can be used to predict the future performance of a new or damaged structure. They can be used to predict damage for a single design event or in a simulation to predict the life-cycle costs. Further, because the variability in damage is given, these equations can be used to predict the reliability of a given design or of a damaged structure. The equations described above are valid for the range of wave, water level, and structure conditions within this experiment. Employment of a critical stability number for measurable damage may be necessary to reduce the number of storms required in a life-cycle analysis. These relations should be conservative because the structures were relatively impermeable, relatively low crested, and exposed to severe breaking waves. But they may not be conservative for more highly grouped wave conditions and other structure slopes. Therefore, care should be taken in extending these relations for conditions not tested herein. Additional experiments are being conducted to evaluate the generality of these equations. 
APPENDIX A

SUMMARY OF WAVE MEASUREMENTS 

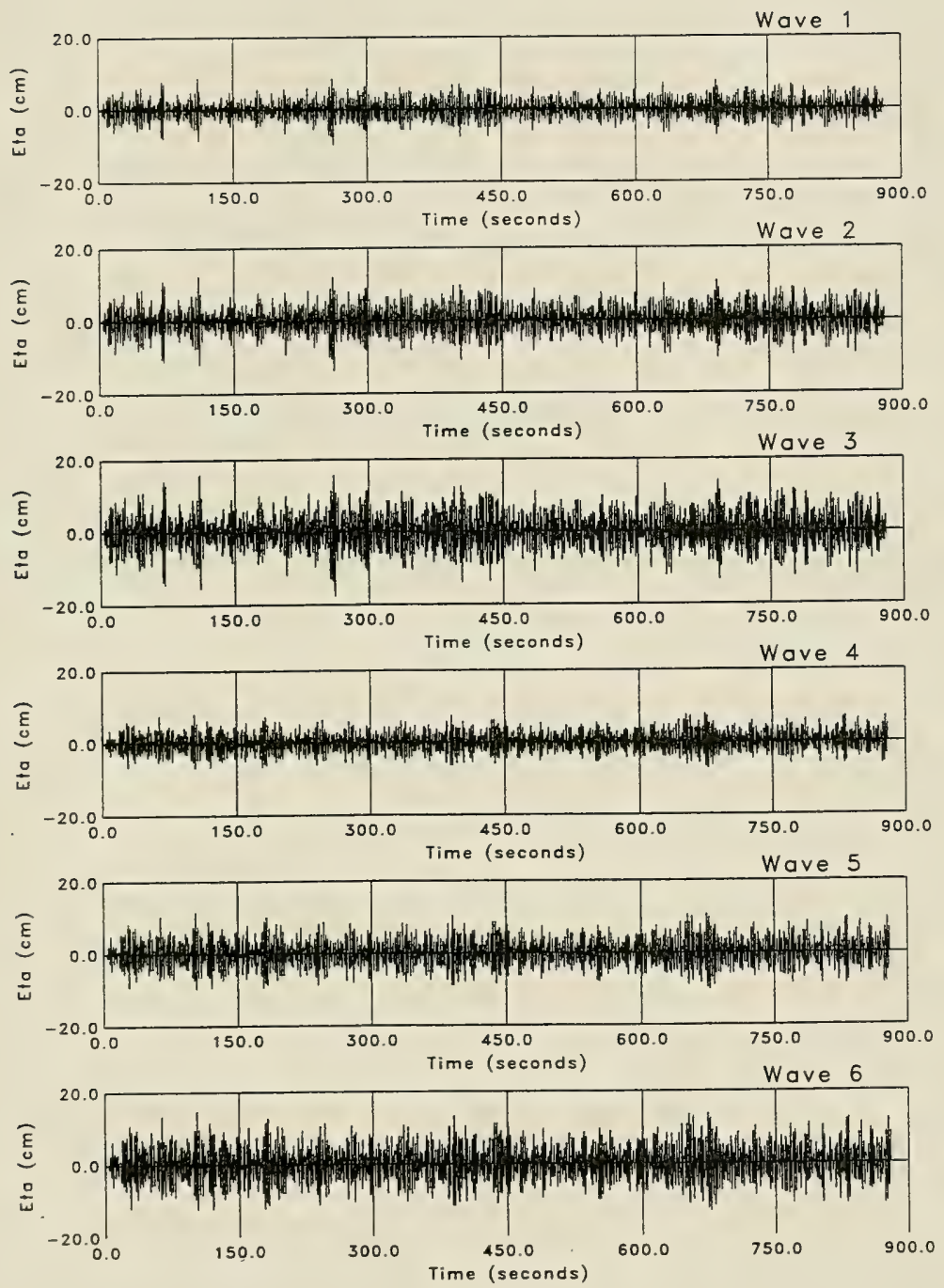

Figure A.1. Wave generator command signals for six wave cases of initial experiment 


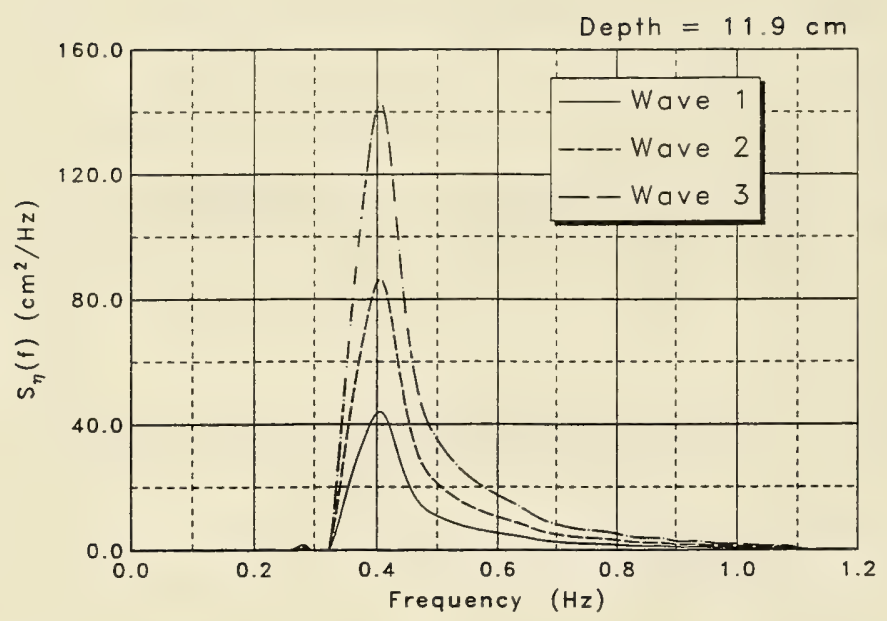

Figure A.2. Spectra of wave generator command signals for Waves 1,2 , and 3 for 11.9 cm toe depth

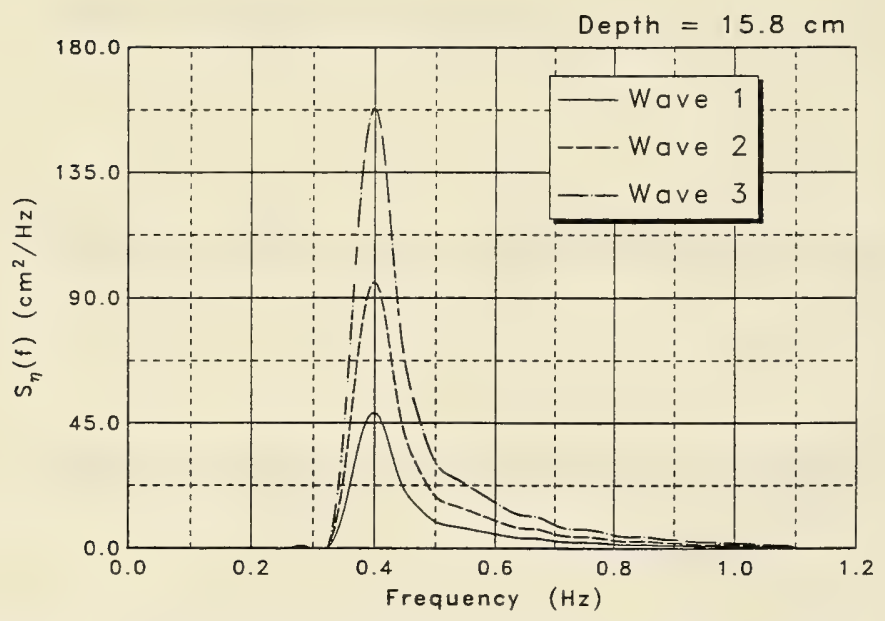

Figure A.3. Spectra of wave generator command signals for Waves 4, 5, and 6 for 15.7 $\mathrm{cm}$ toe depth 

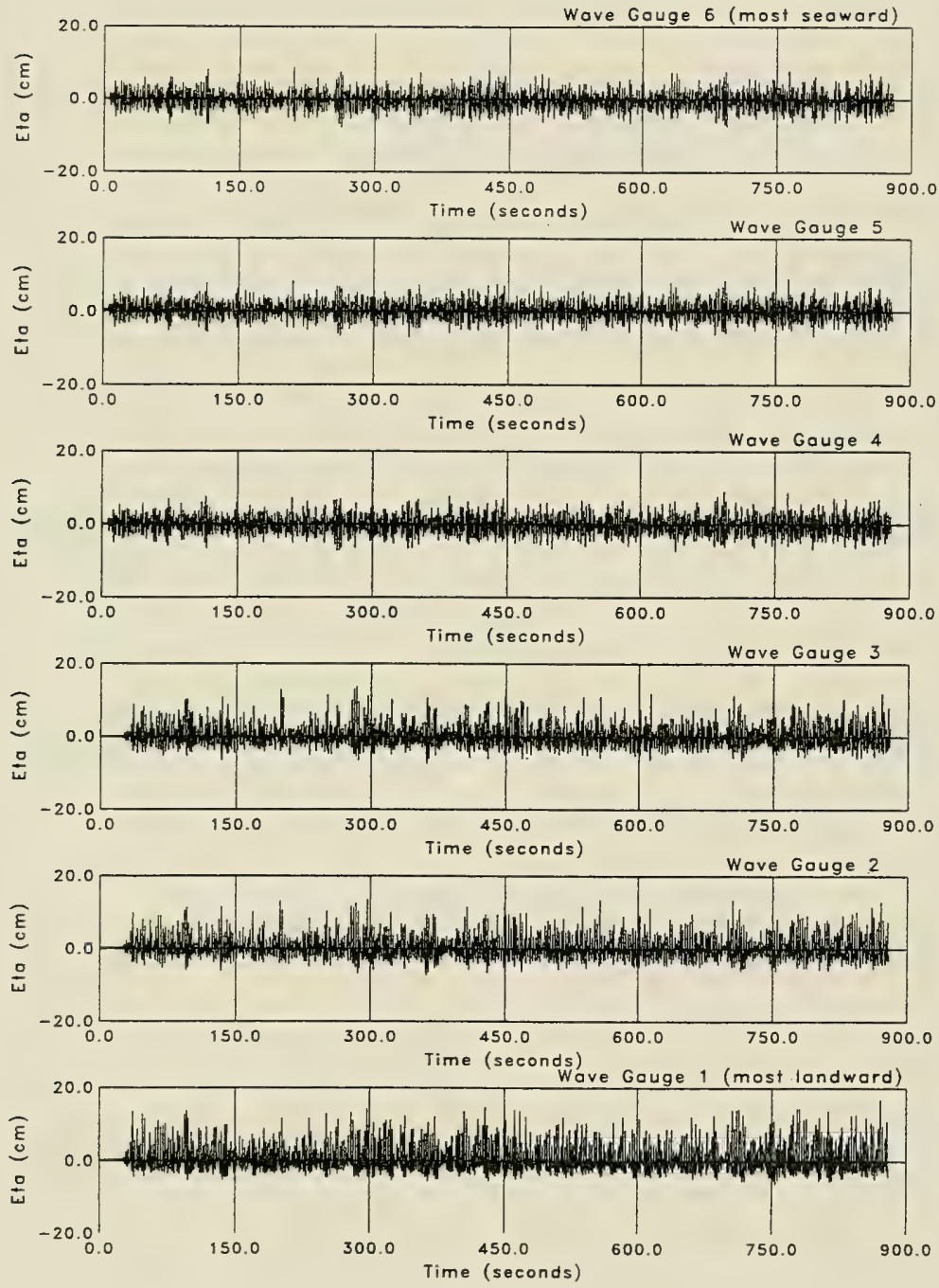

Figure A.4. Wave 1 measured time series from wave gages 

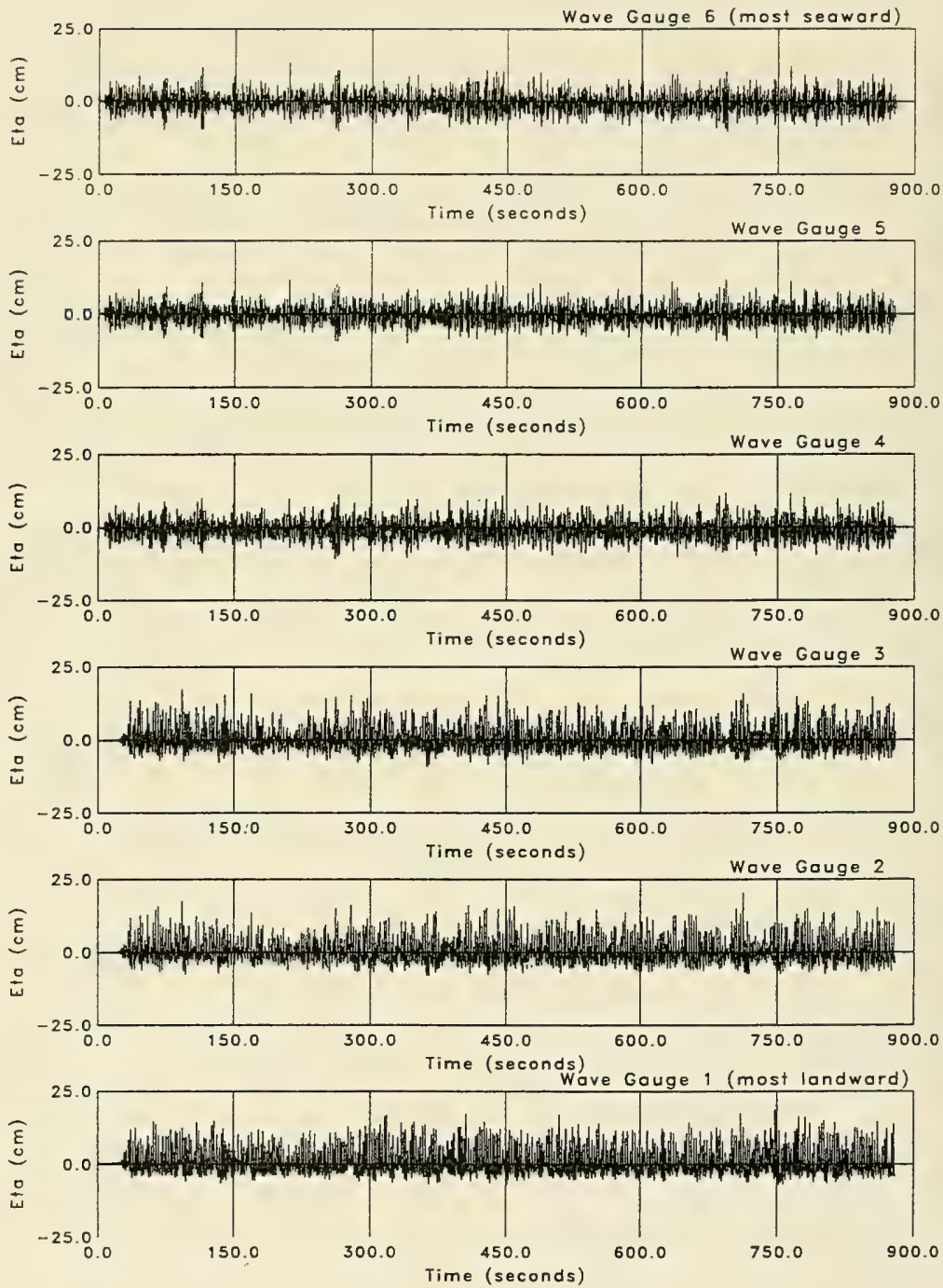

Figure A.5. Wave 2 measured time series from wave gages 

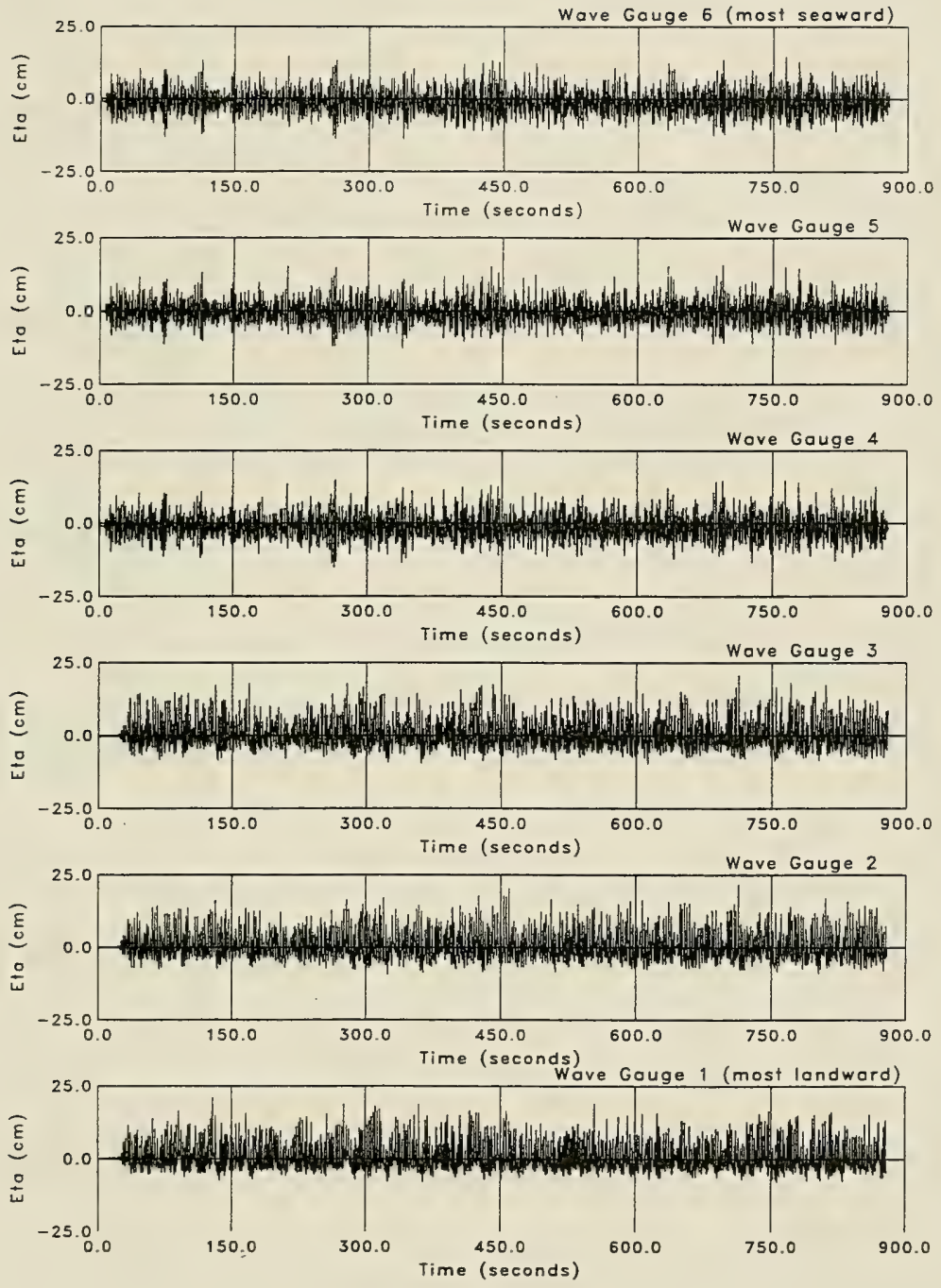

Figure A.6. Wave 3 measured time series from wave gages 

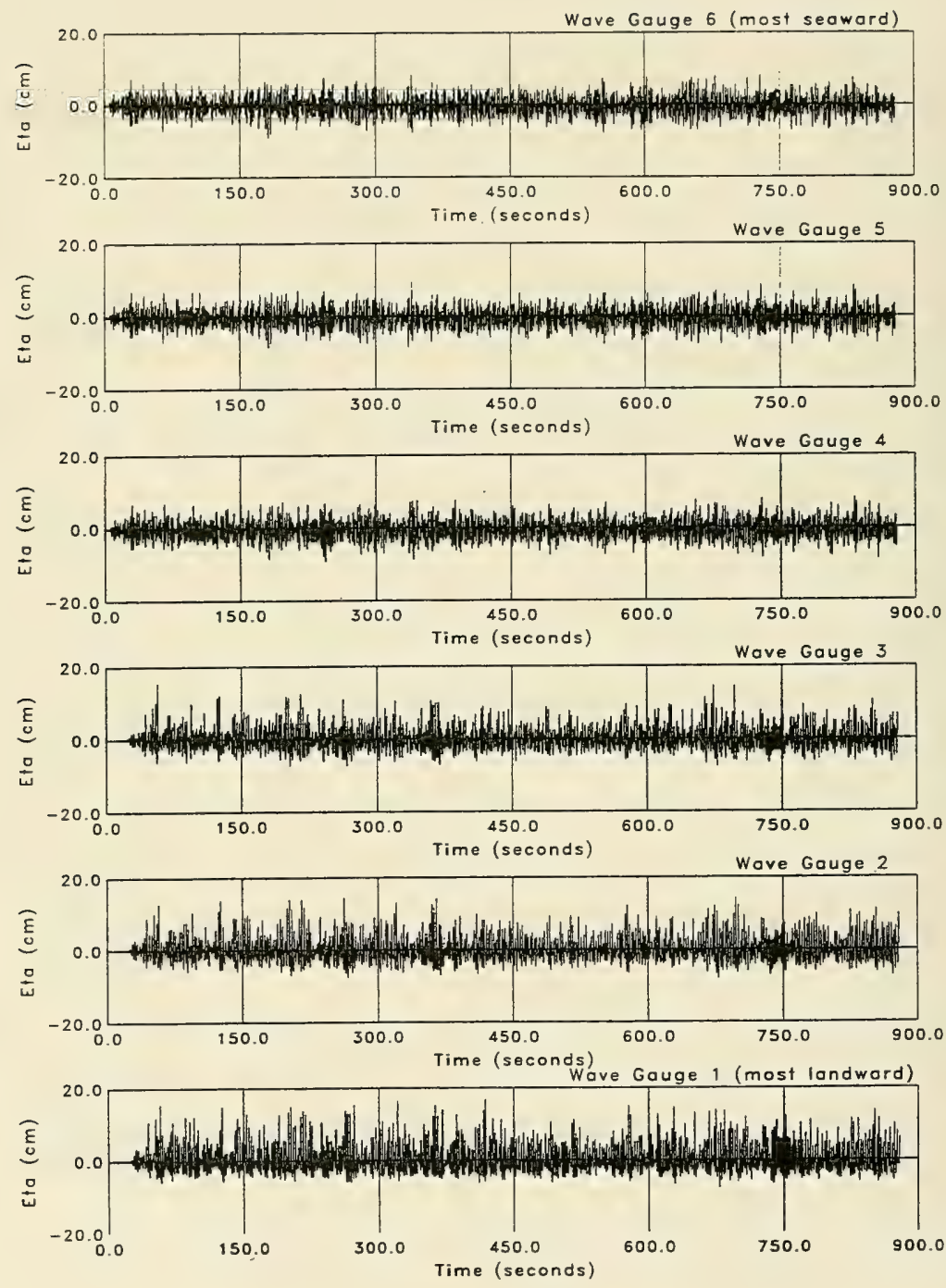

Figure A.7. Wave 4 measured time series from wave gages 

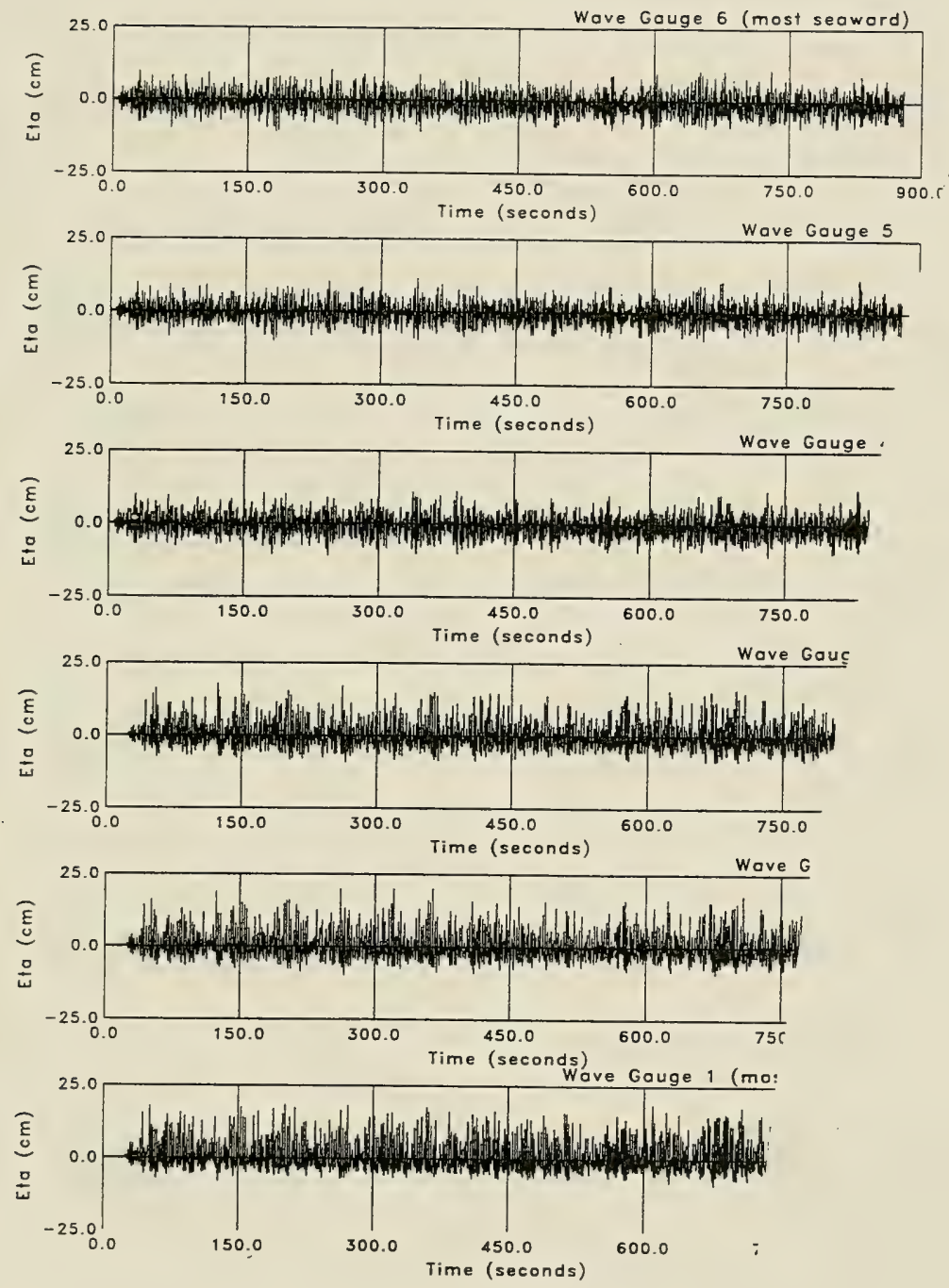

Figure A.8. Wave 5 measured time series from wave gages 

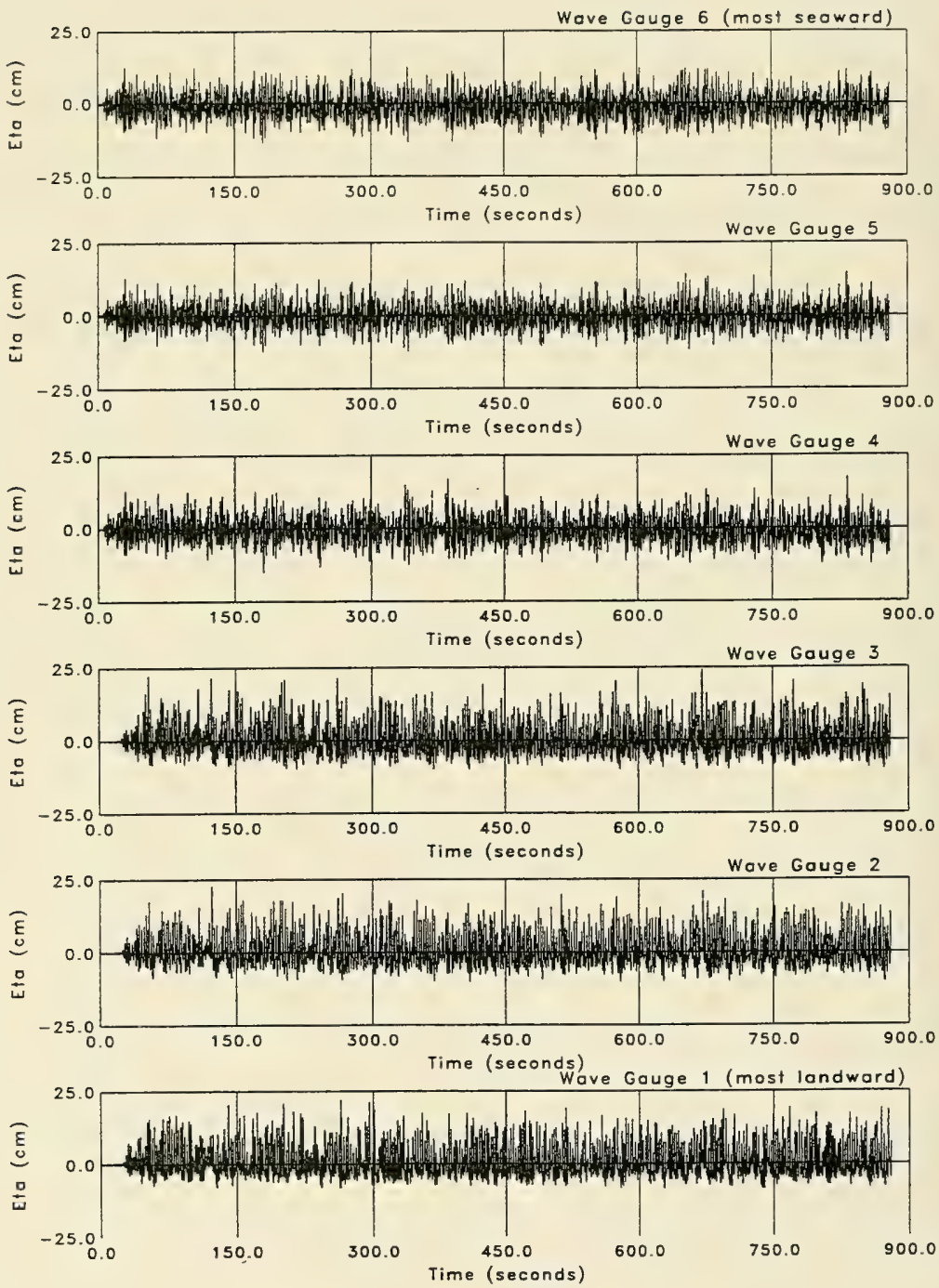

Figure A.9. Wave 6 measured time series from wave gages 



Figure A.10. Wave 1 incident and reflected spectra from wave gages 

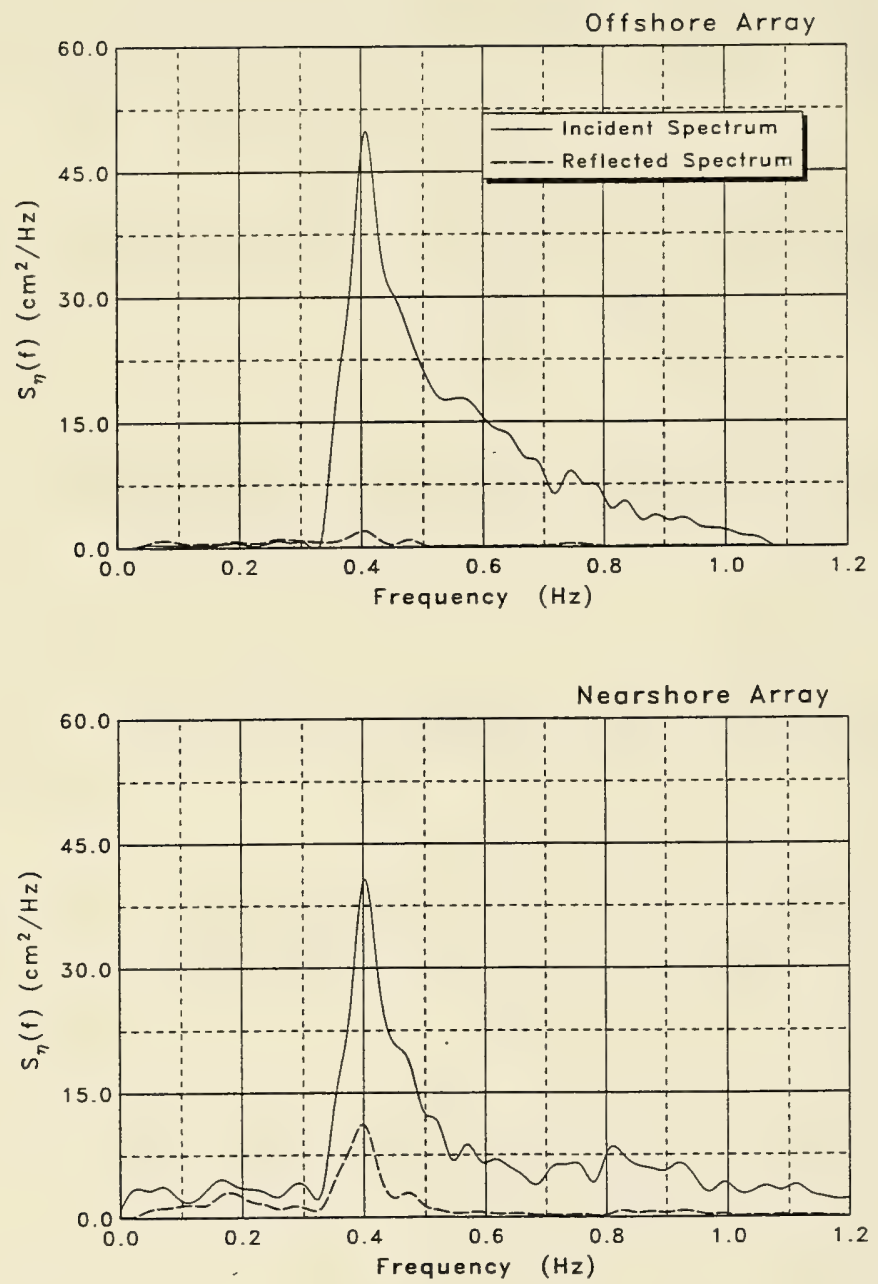

Figure A.11. Wave 2 incident and reflected spectra from wave gages 

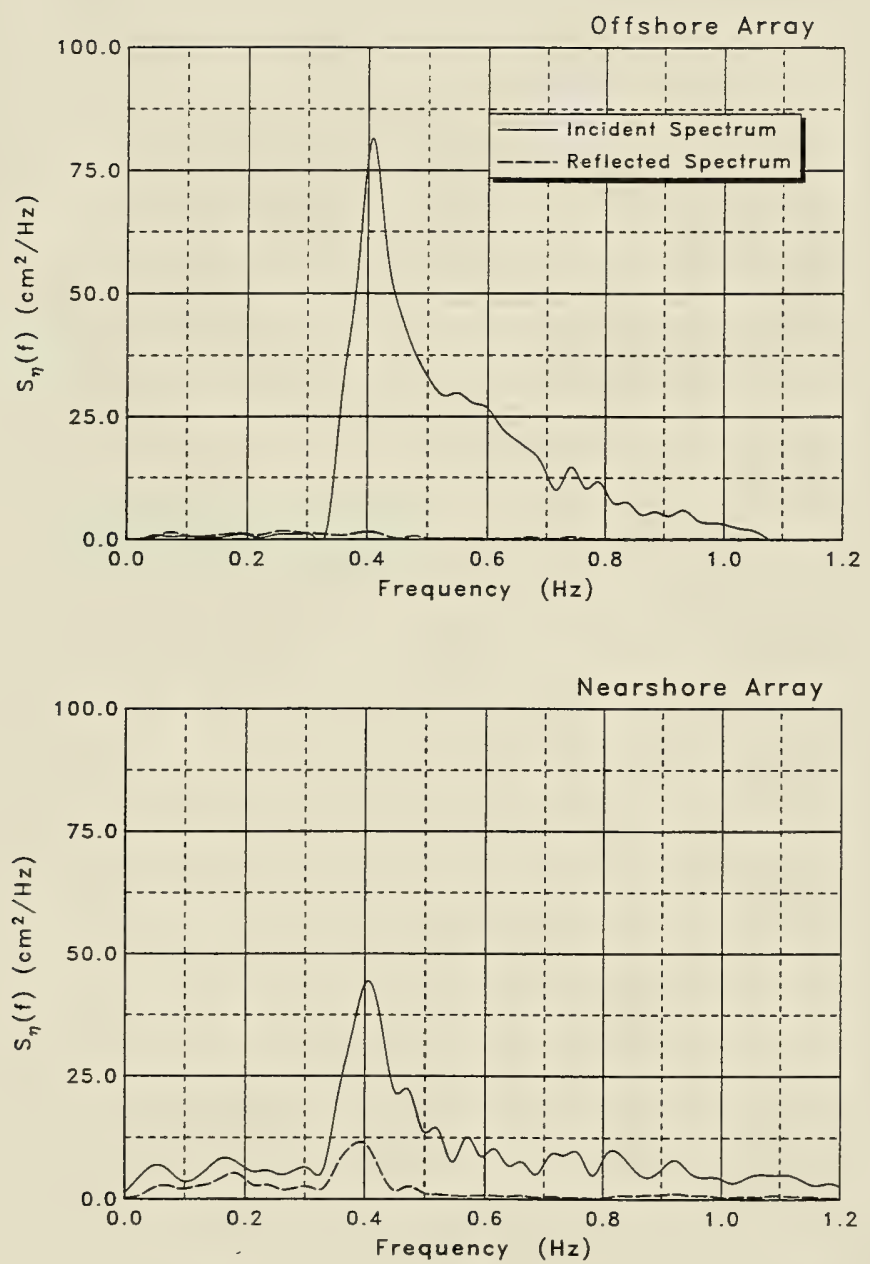

Figure A.12. Wave 3 incident and reflected spectra from wave gages 

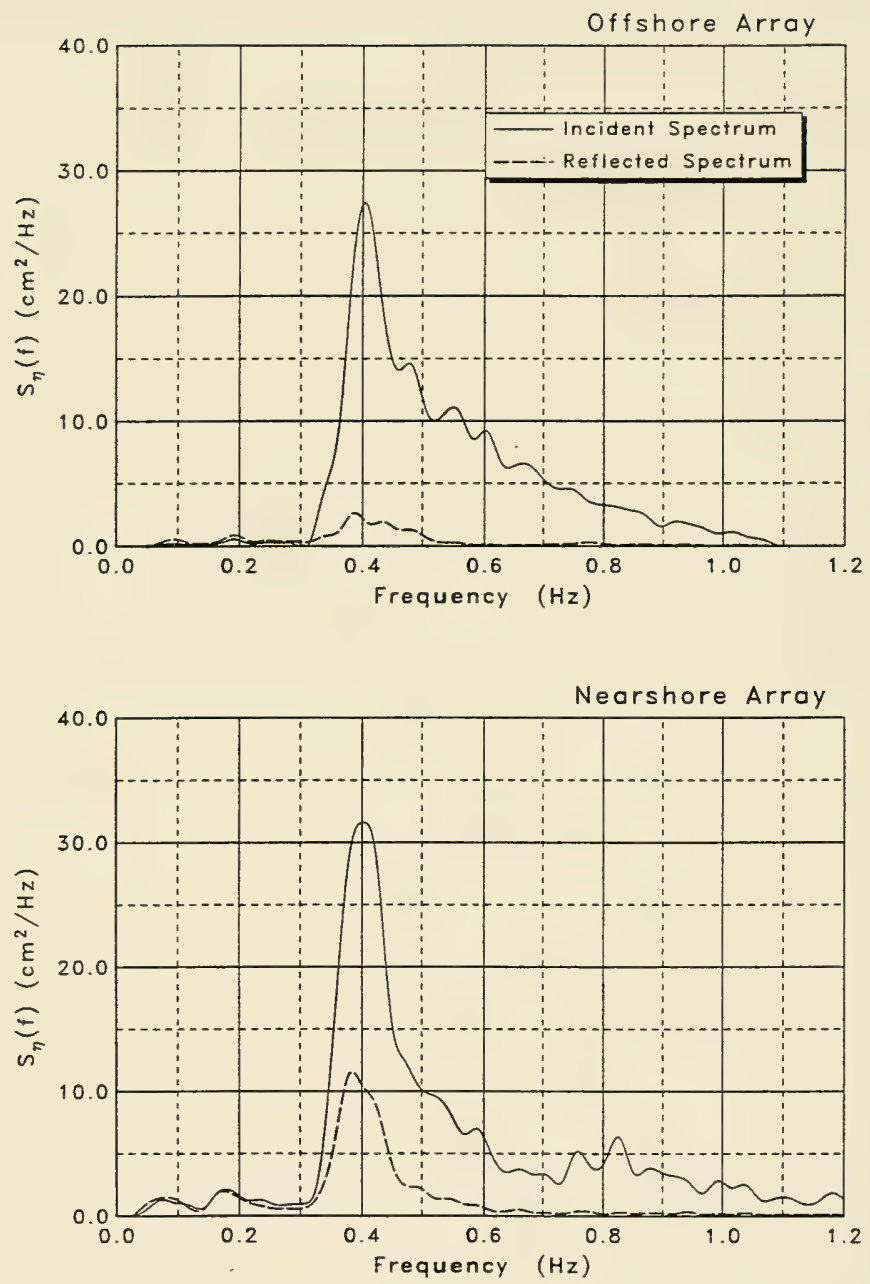

Figure A.13. Wave 4 incident and reflected spectra from wave gages 

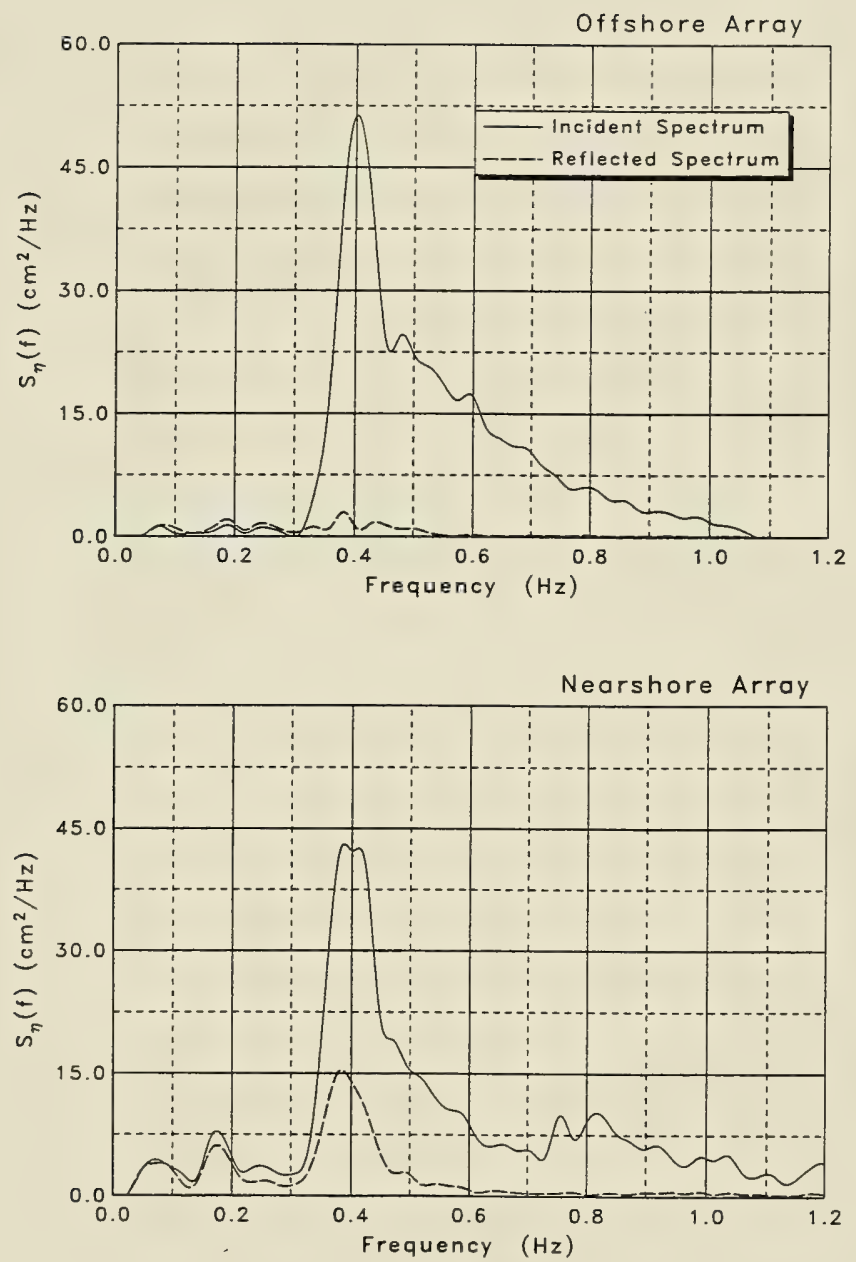

Figure A.14. Wave 5 incident and reflected spectra from wave gages 

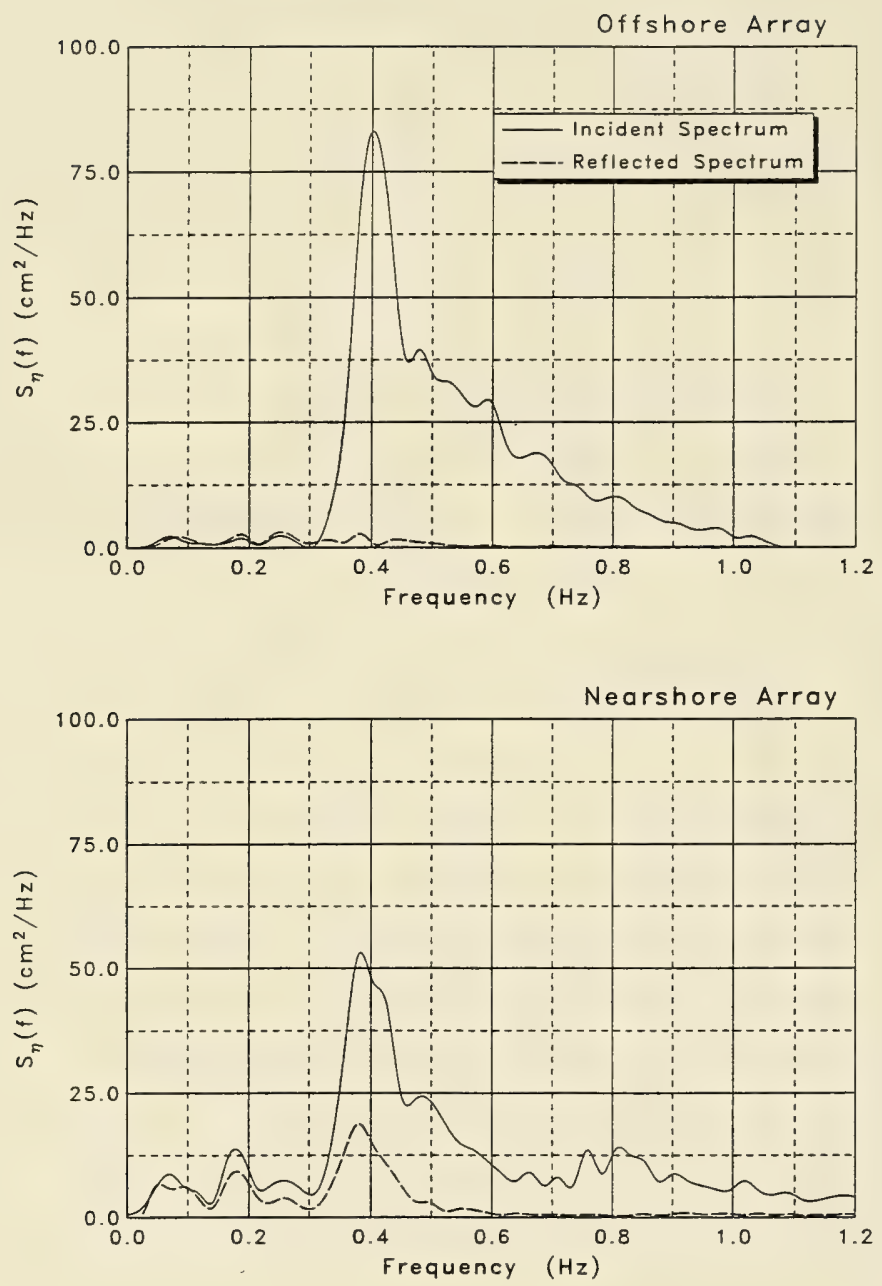

Figure A.15. Wave 6 incident and reflected spectra from wave gages 

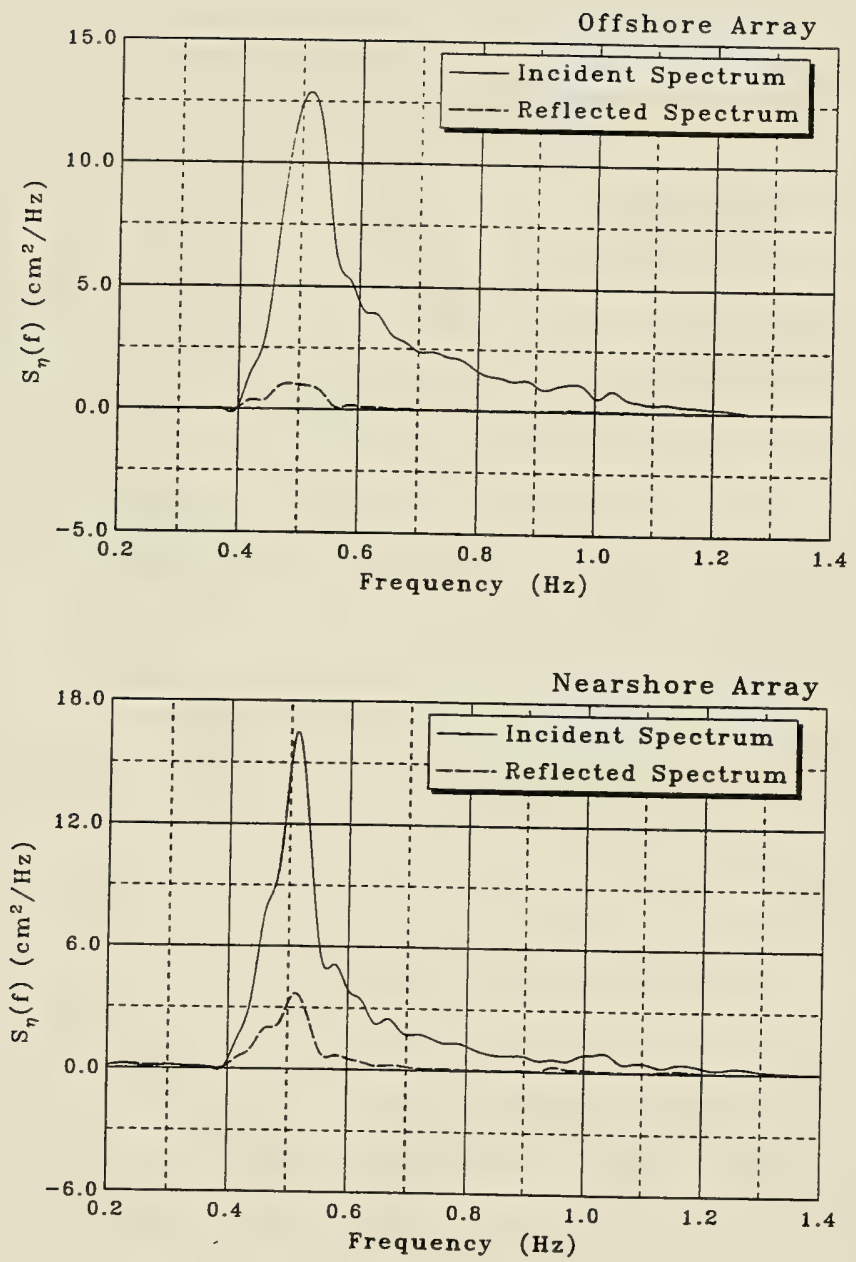

Figure A.16. Wave 7 incident and reflected spectra from wave gages 

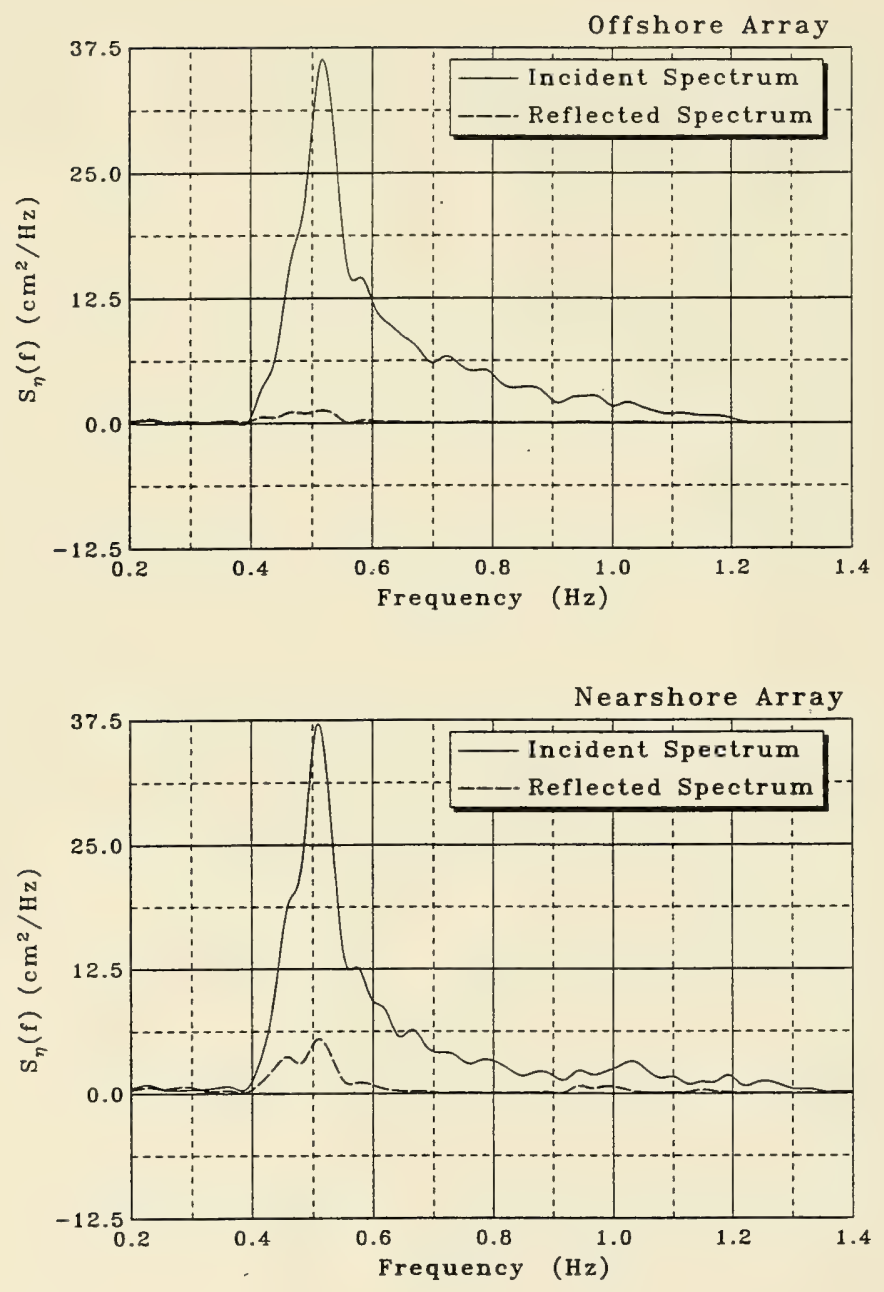

Figure A.17. Wave 8 incident and reflected spectra from wave gages 

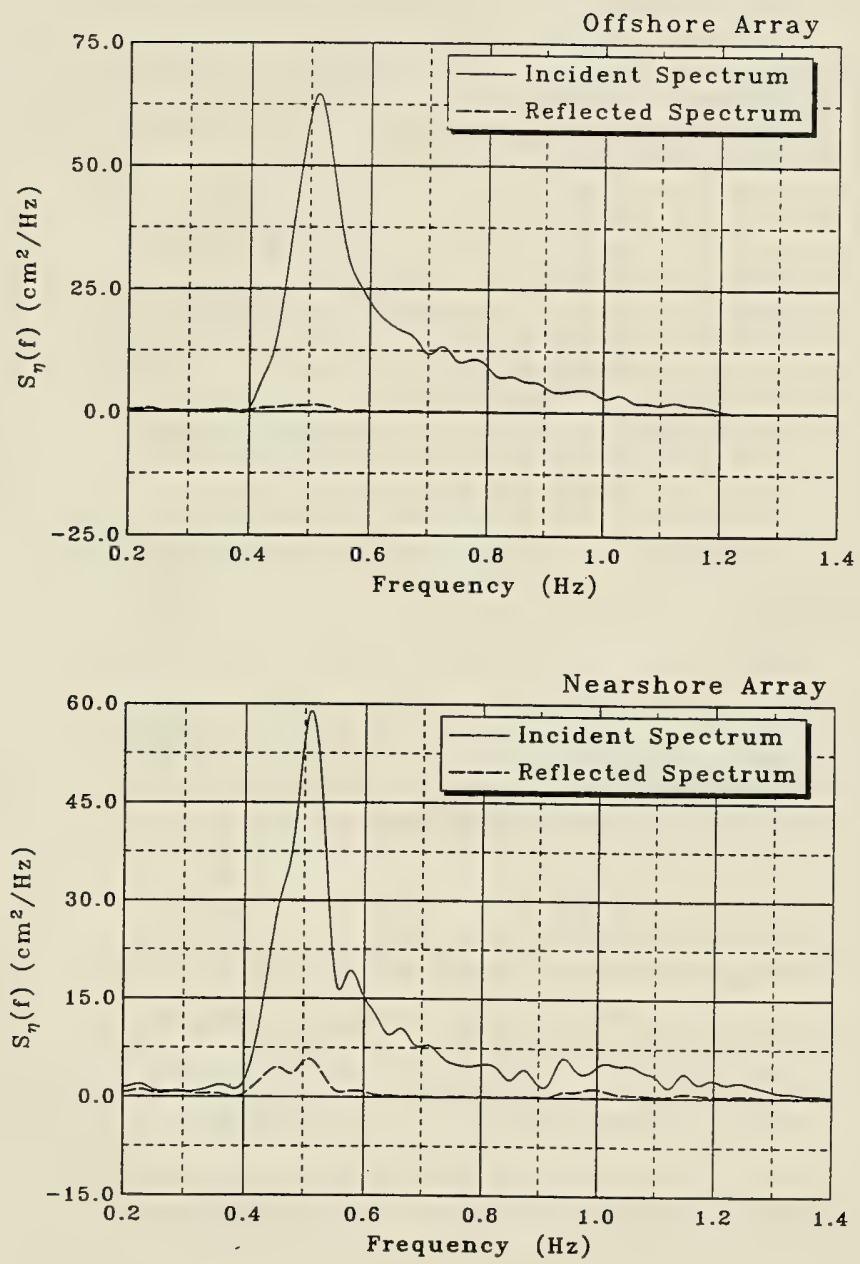

Figure A.18. Wave 9 incident and reflected spectra from wave gages 

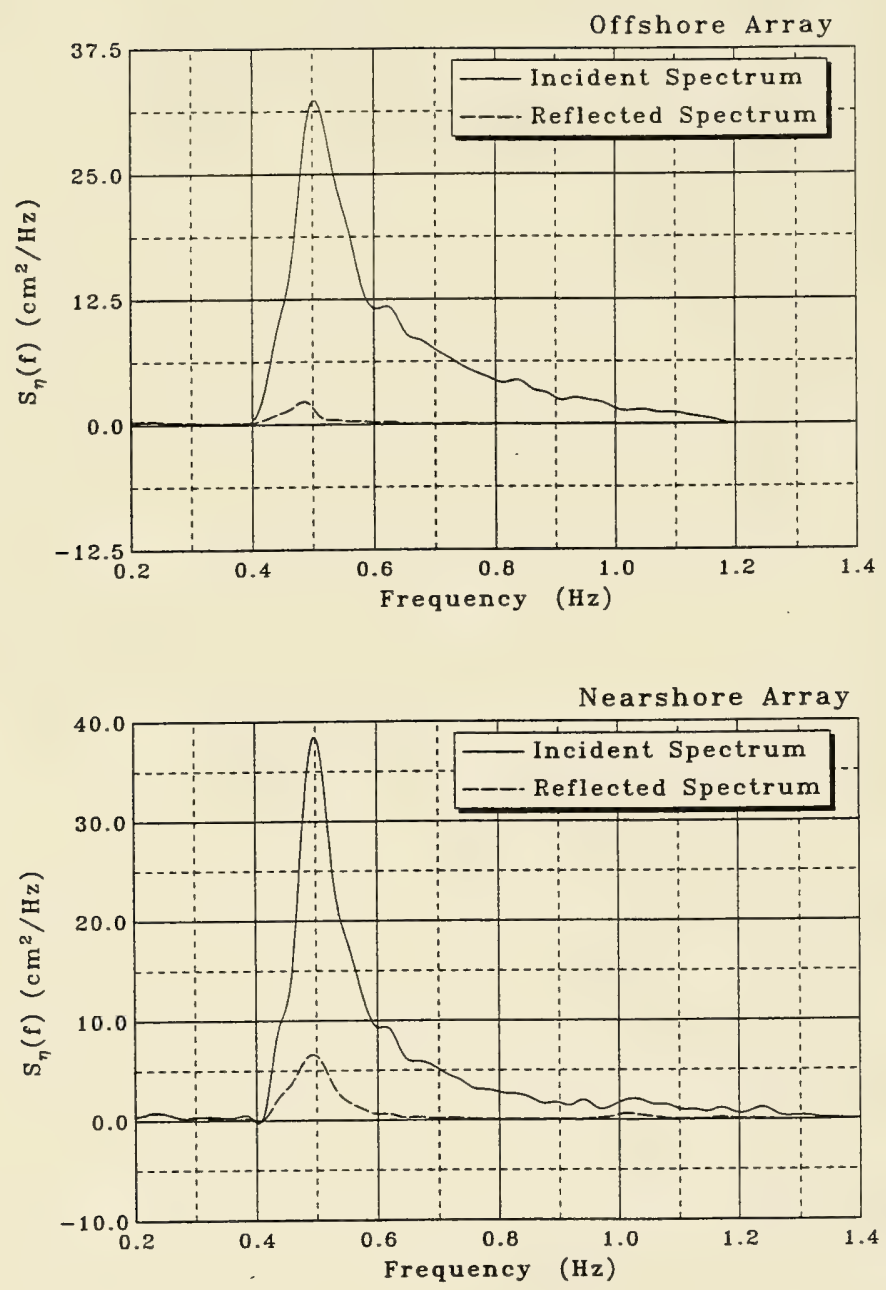

Figure A.19. Wave 10 incident and reflected spectra from wave gages 

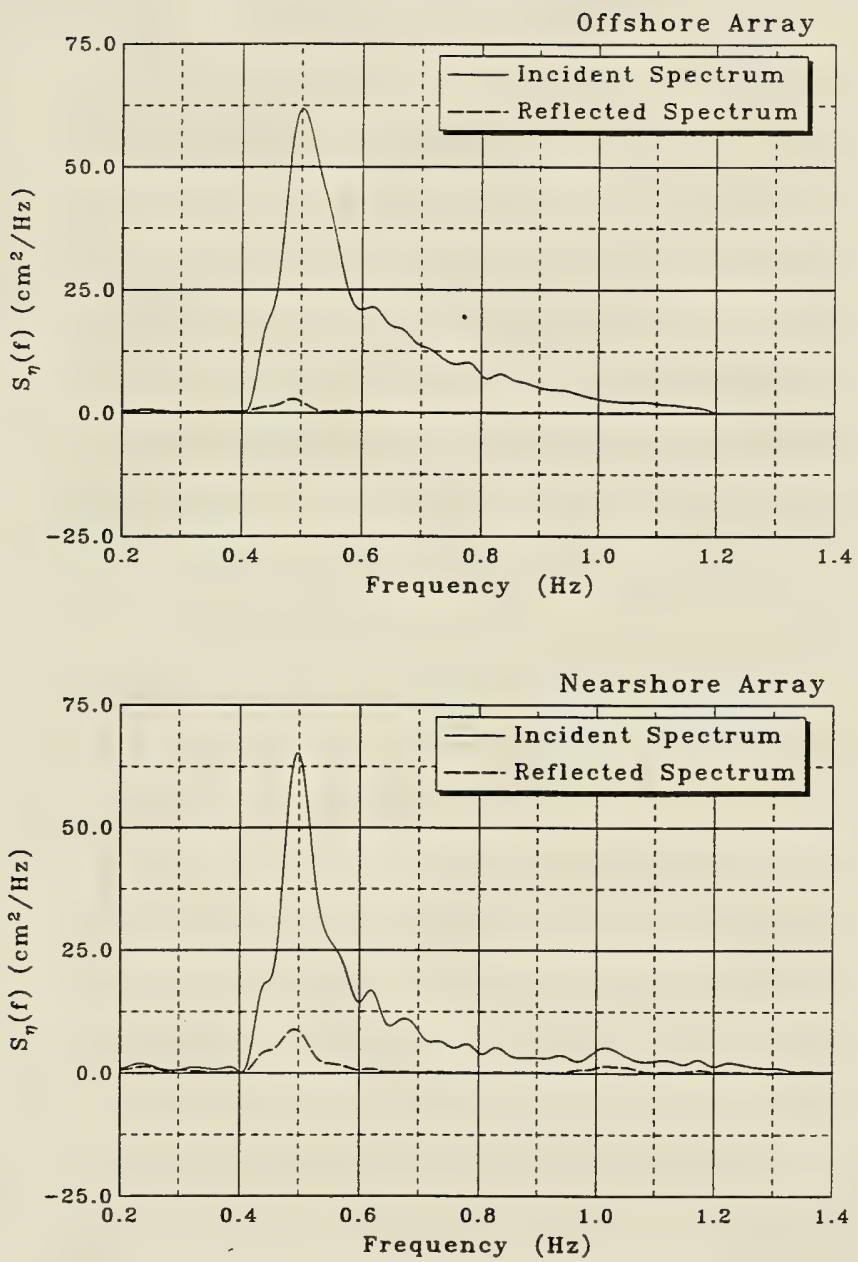

Figure A.20. Wave 11 incident and reflected spectra from wave gages 

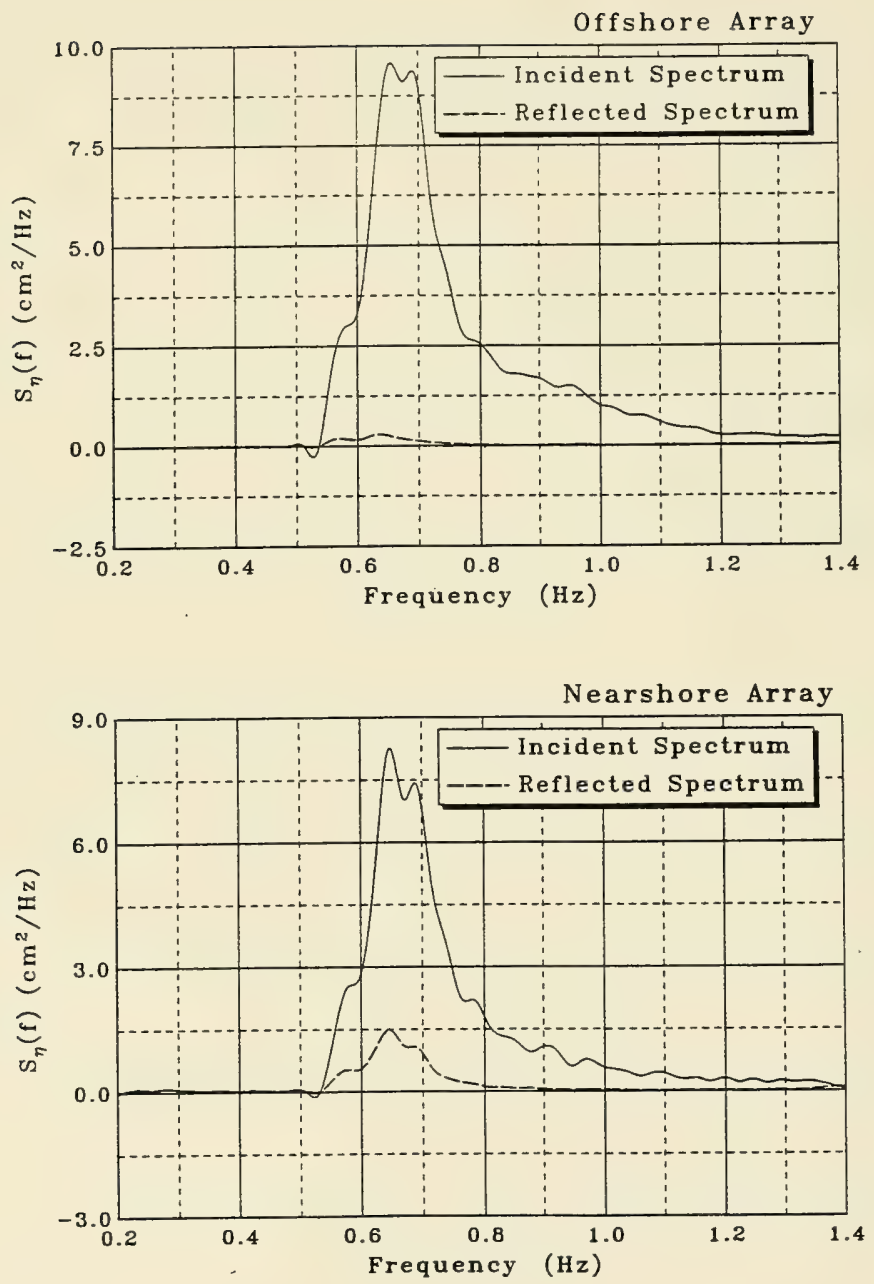

Figure A.21. Wave 12 incident and reflected spectra from wave gages 

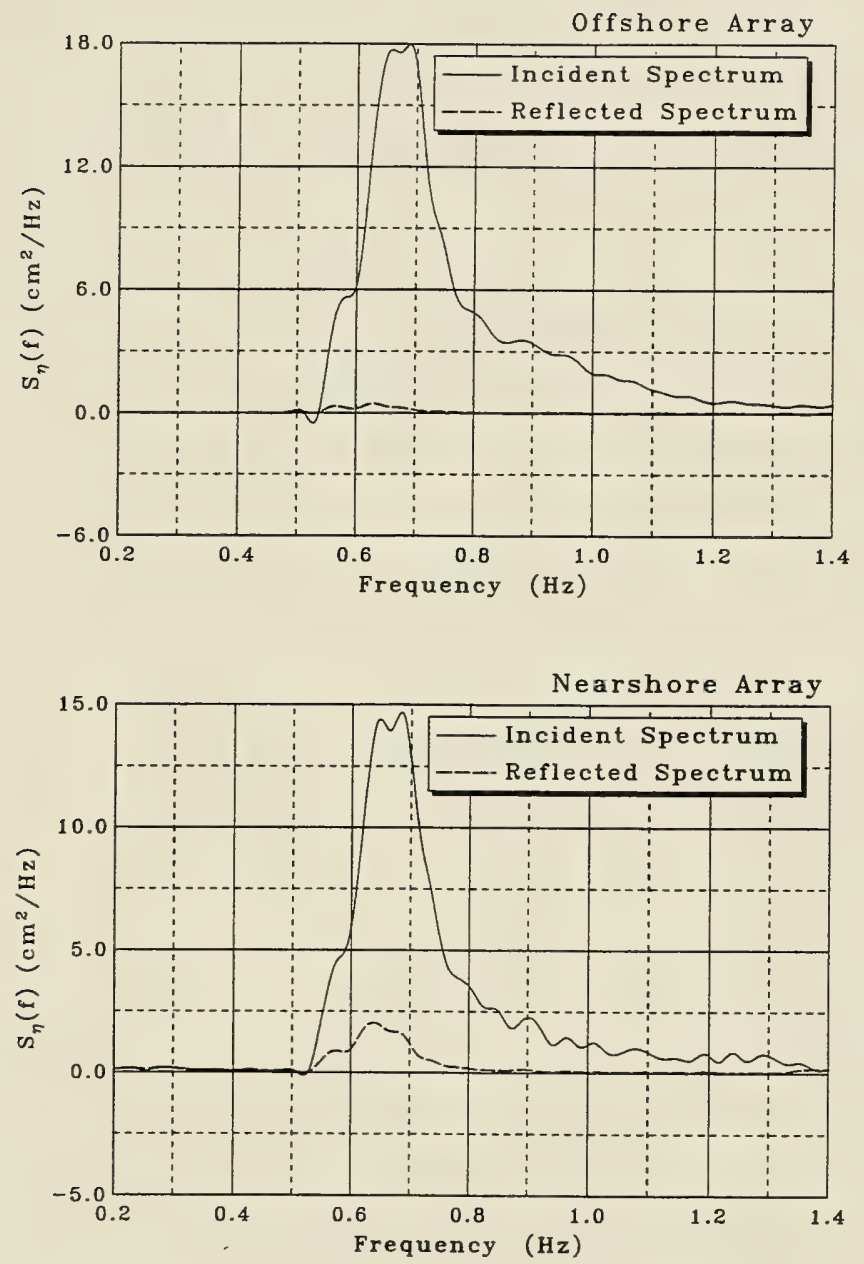

Figure A.22. Wave 13 incident and reflected spectra from wave gages 

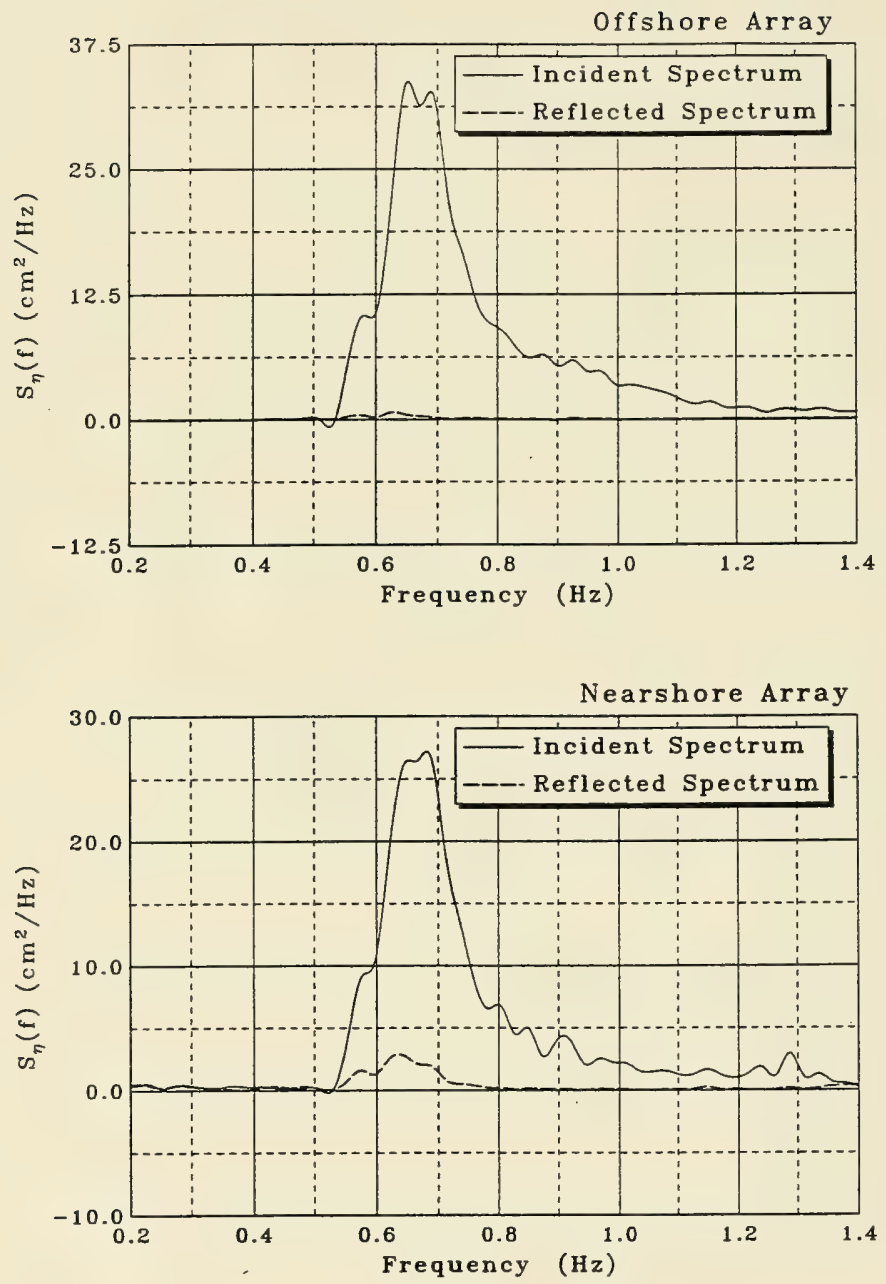

Figure A.23. Wave 14 incident and reflected spectra from wave gages 

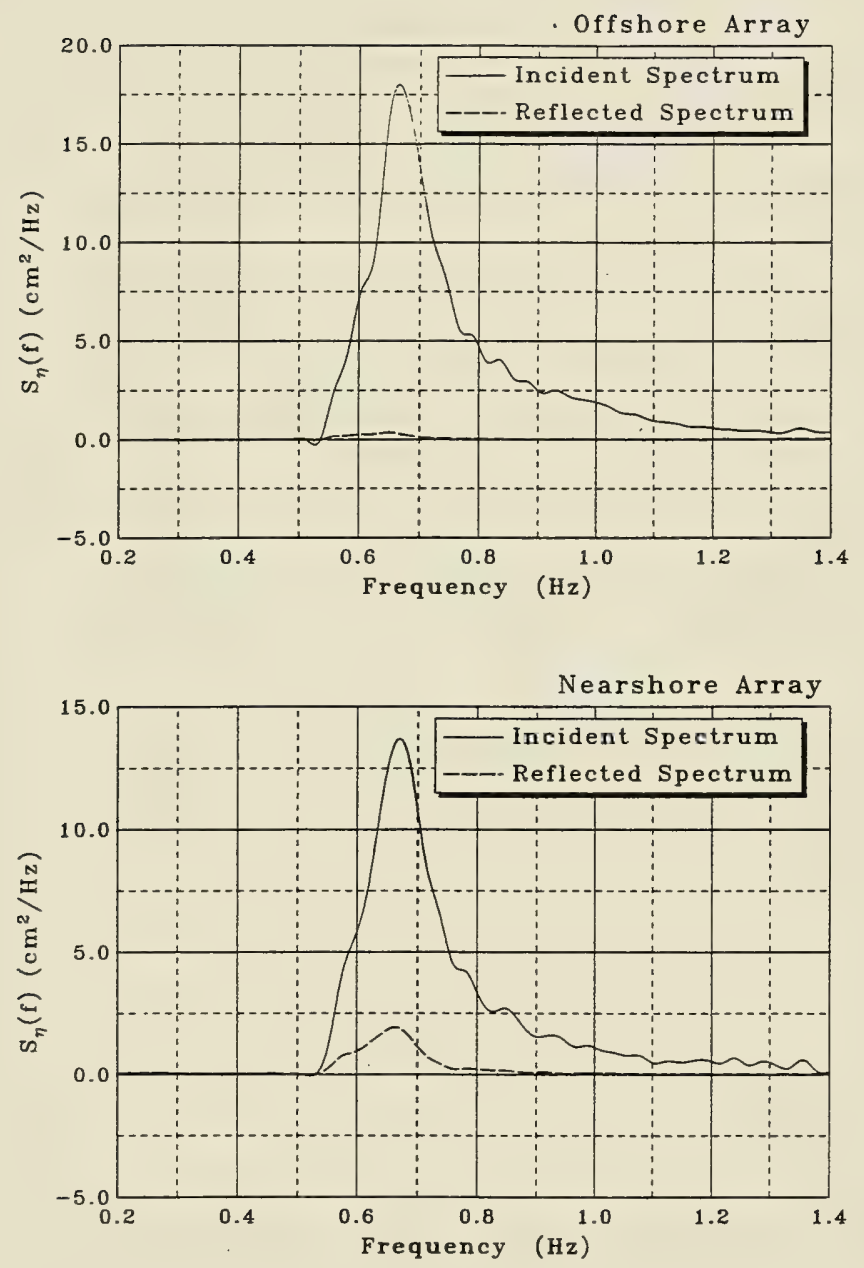

Figure A.24. Wave 15 incident and reflected spectra from wave gages 

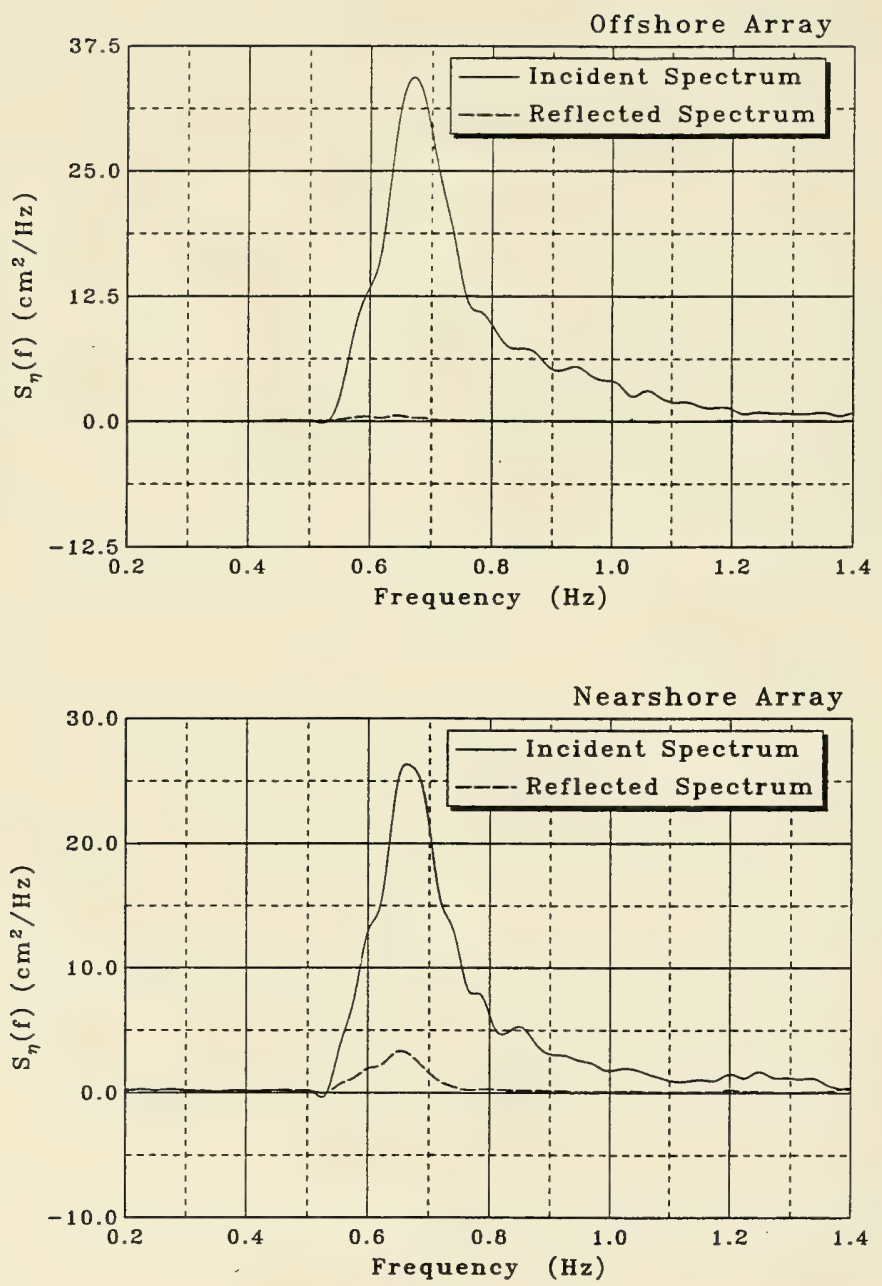

Figure A.25. Wave 16 incident and reflected spectra from wave gages 

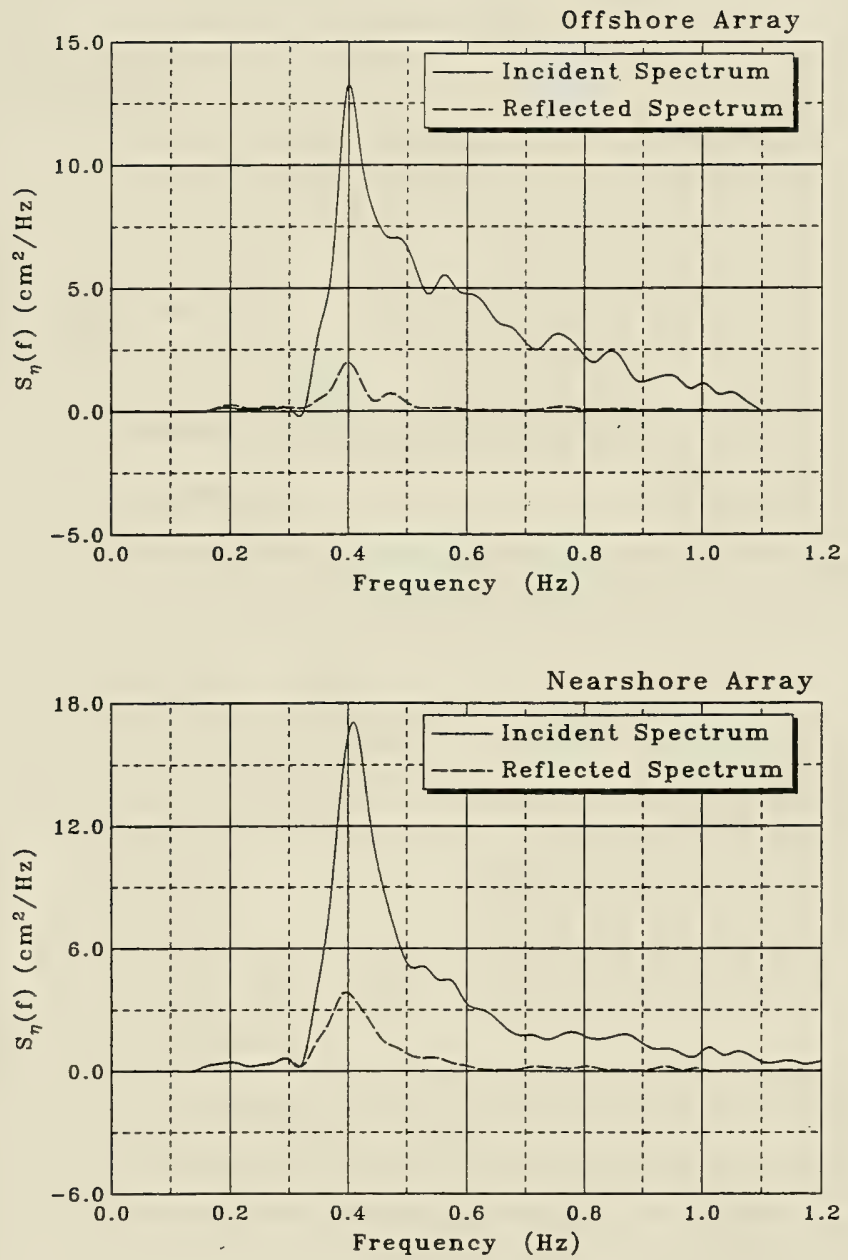

Figure A.26. Wave 17 incident and reflected spectra from wave gages 

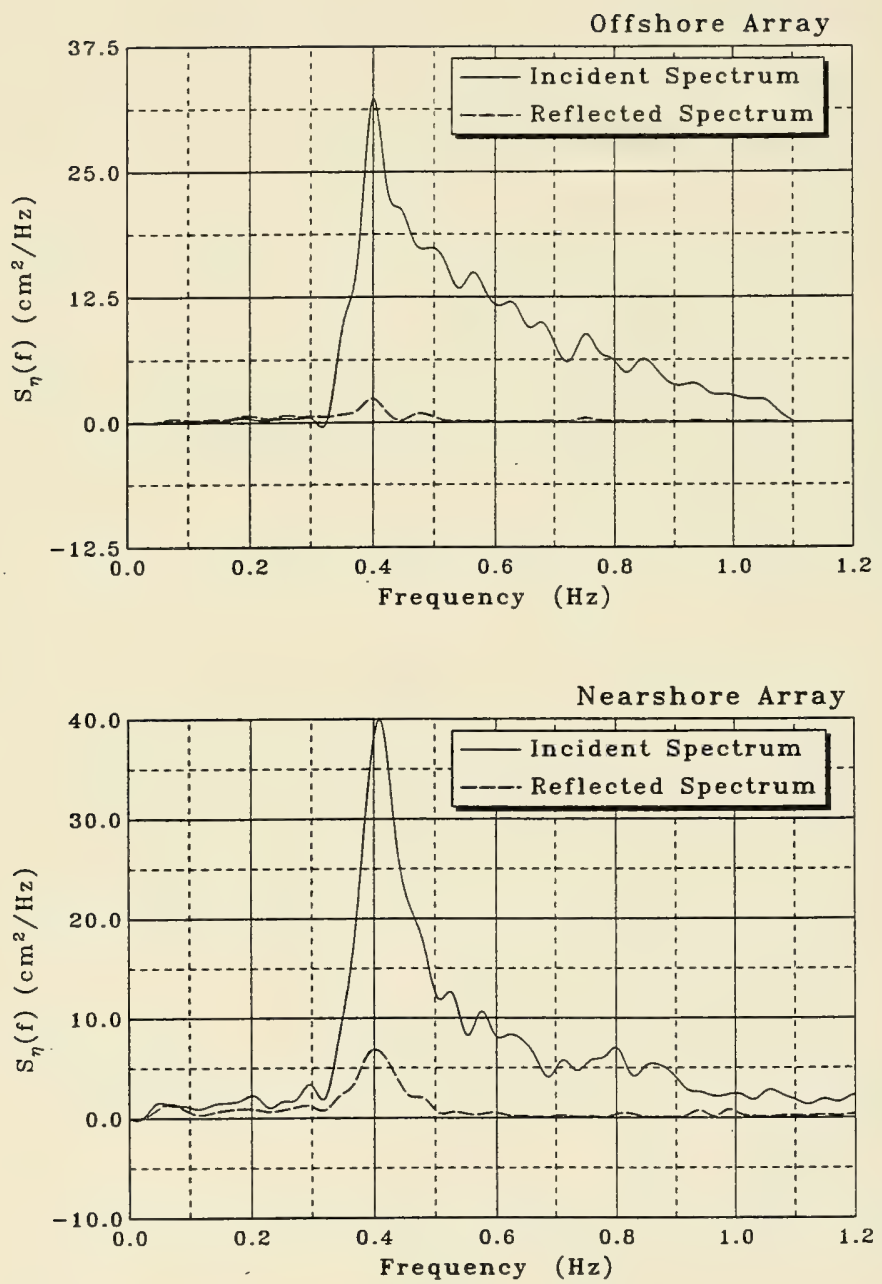

Figure A.27. Wave 18 incident and reflected spectra from wave gages 

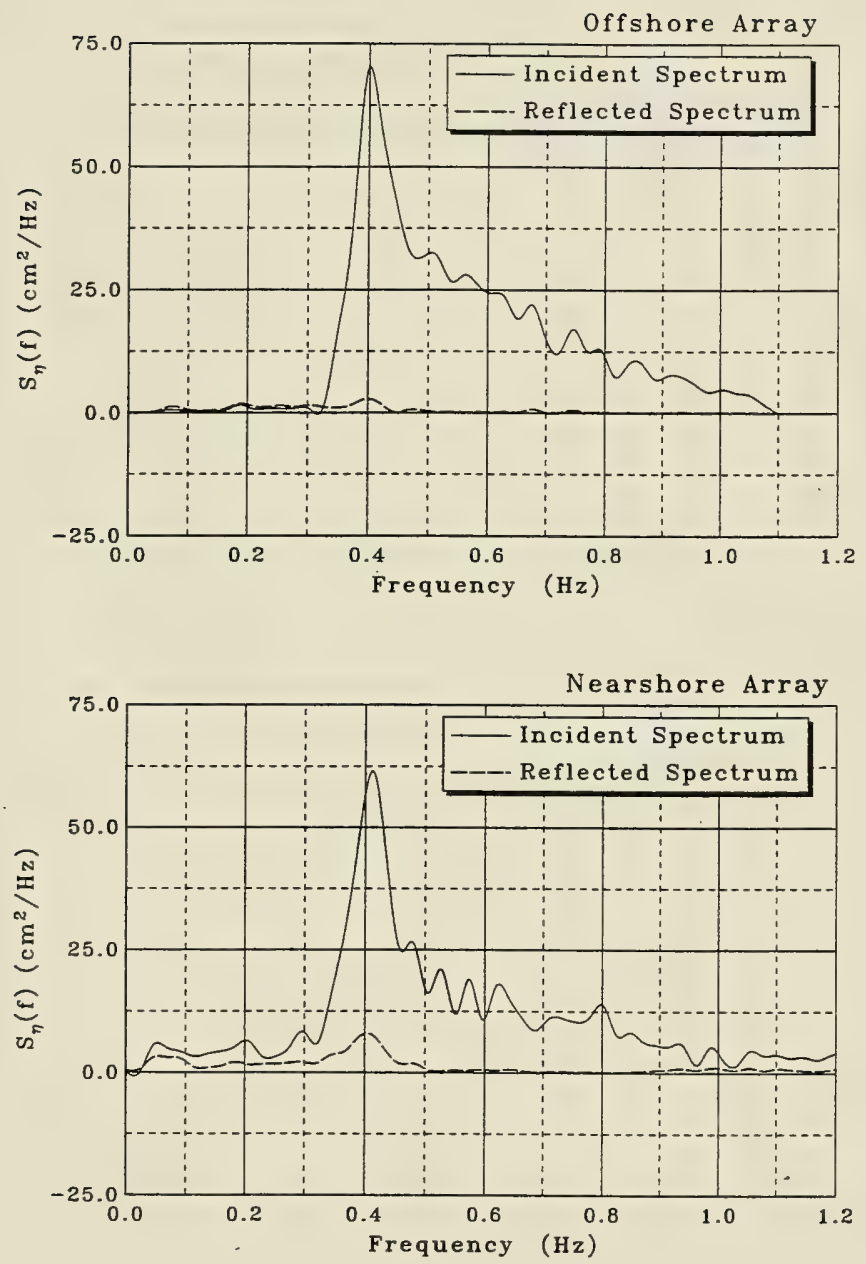

Figure A.28. Wave 19 incident and reflected spectra from wave gages 

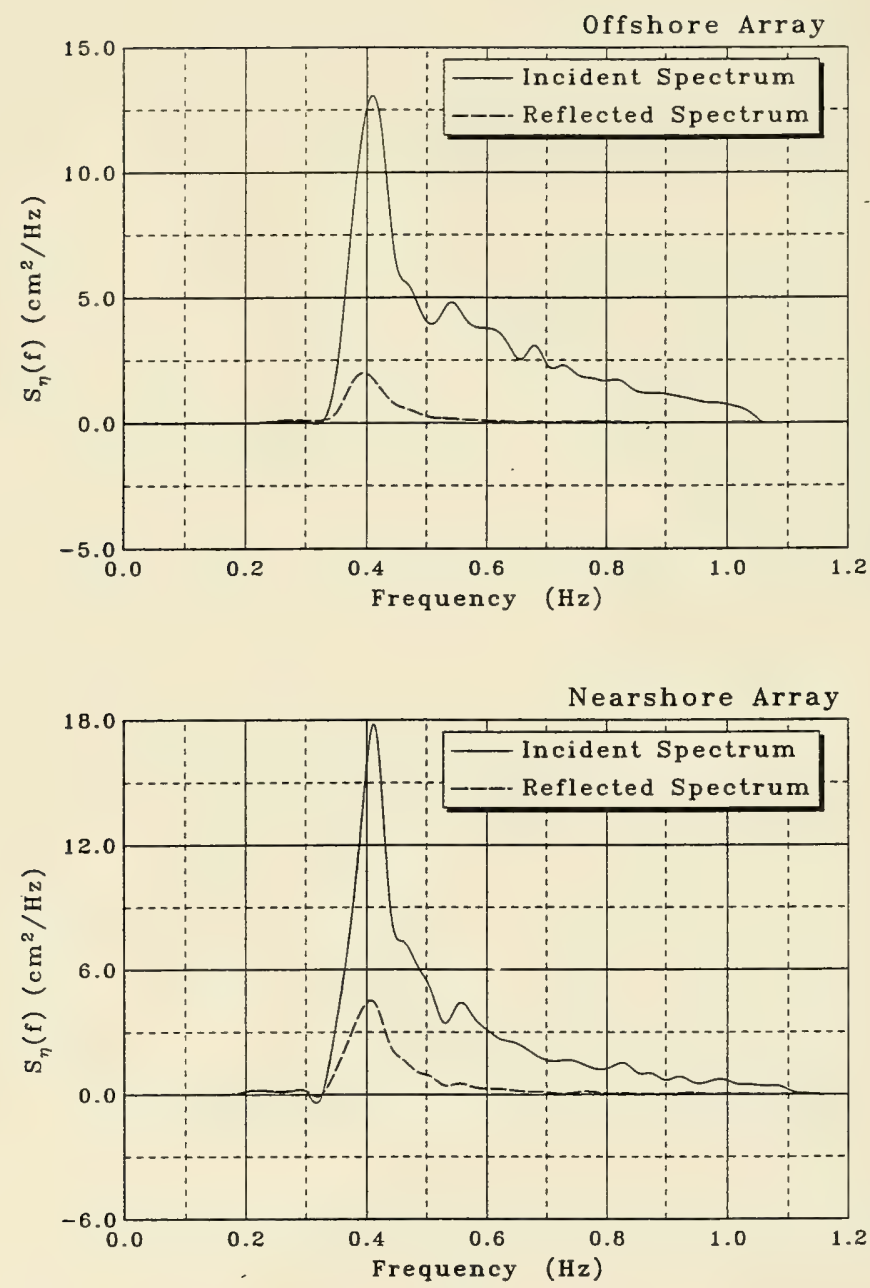

Figure A.29. Wave 20 incident and reflected spectra from wave gages 

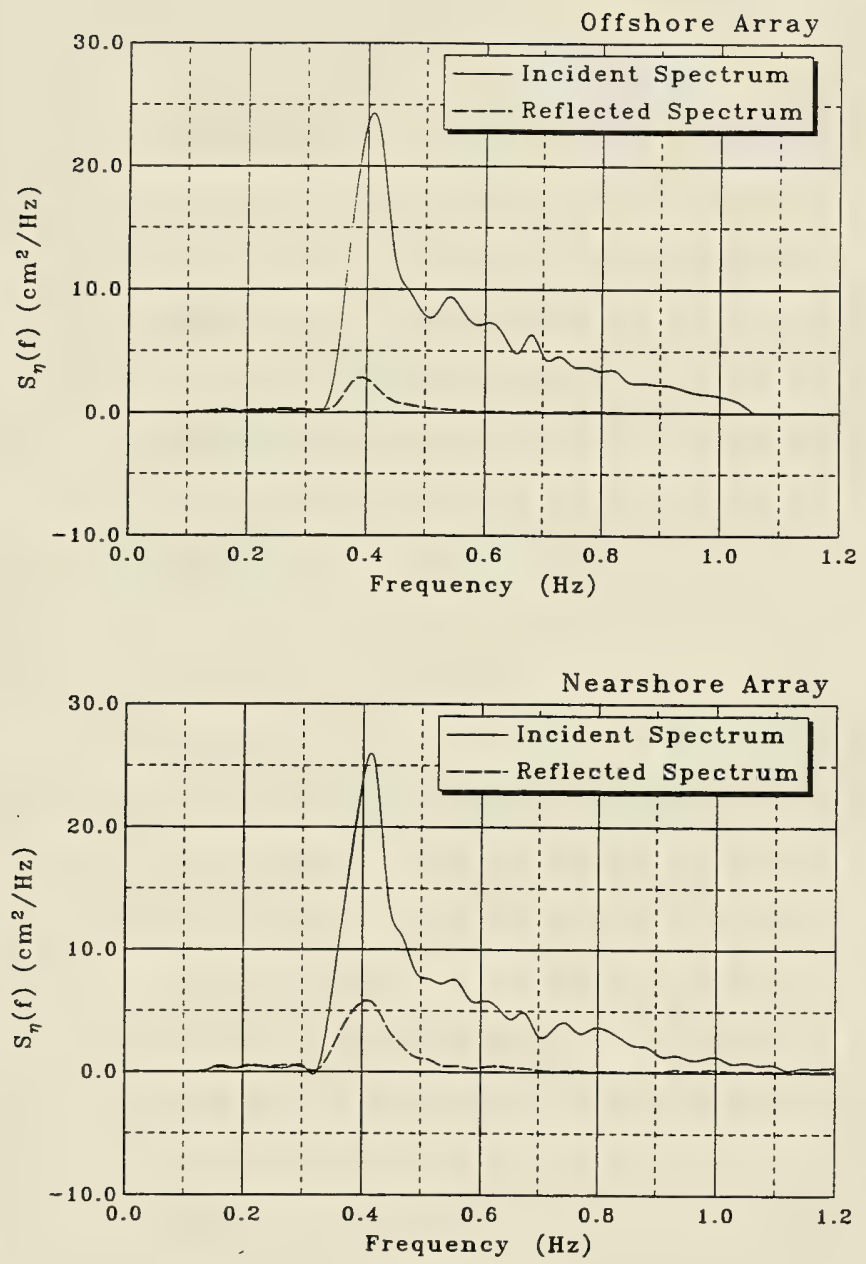

Figure A.30. Wave 21 incident and reflected spectra from wave gages 

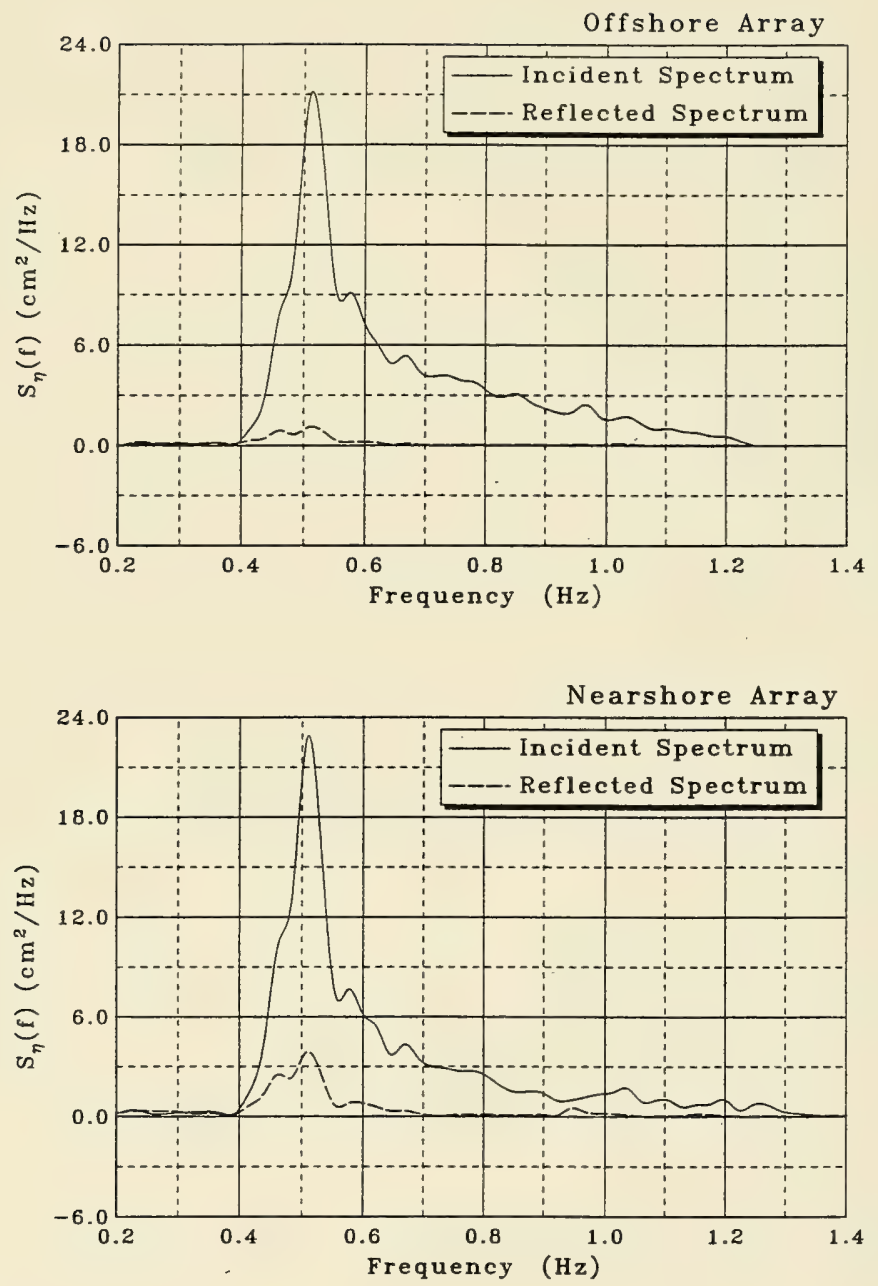

Figure A.31. Wave 22 incident and reflected spectra from wave gages 

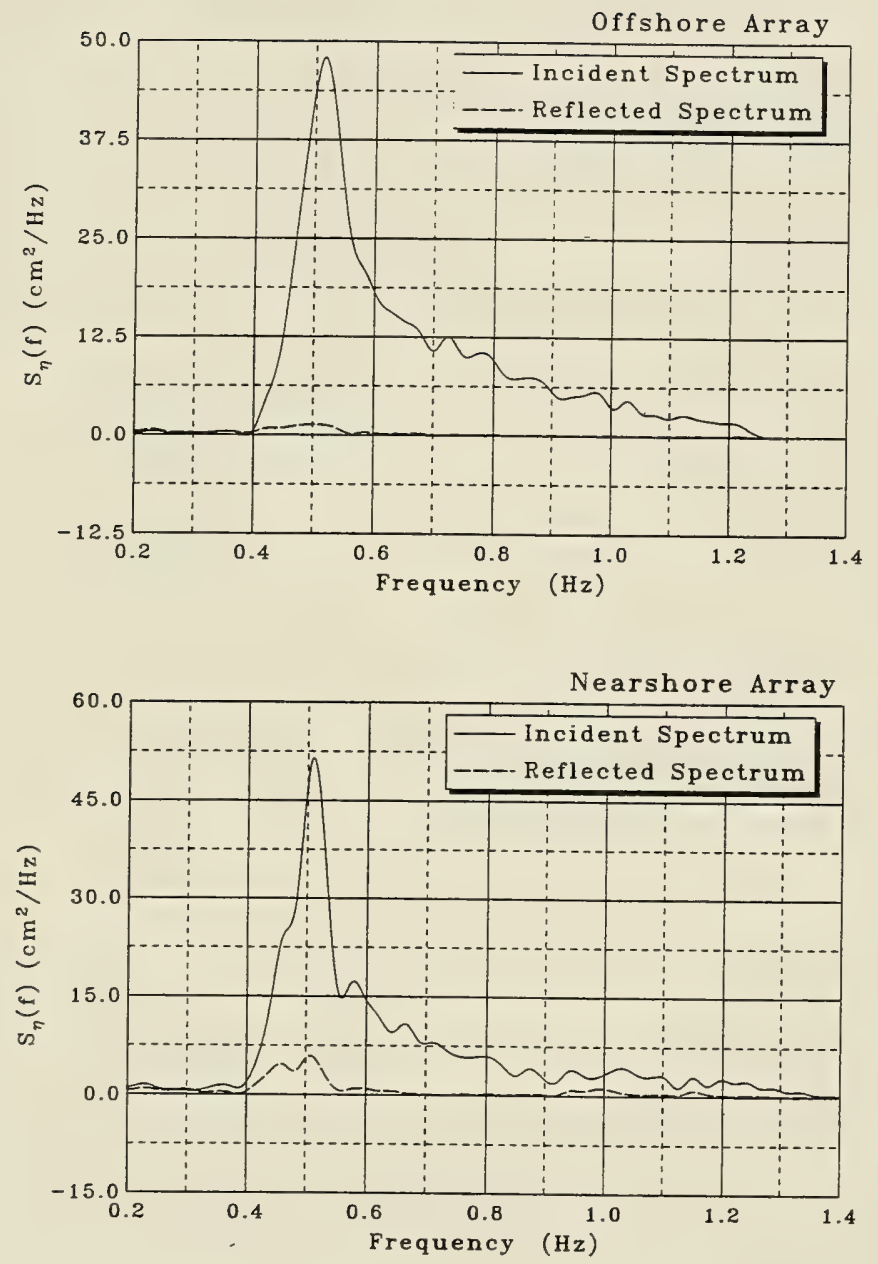

Figure A.32. Wave 23 incident and reflected spectra from wave gages 

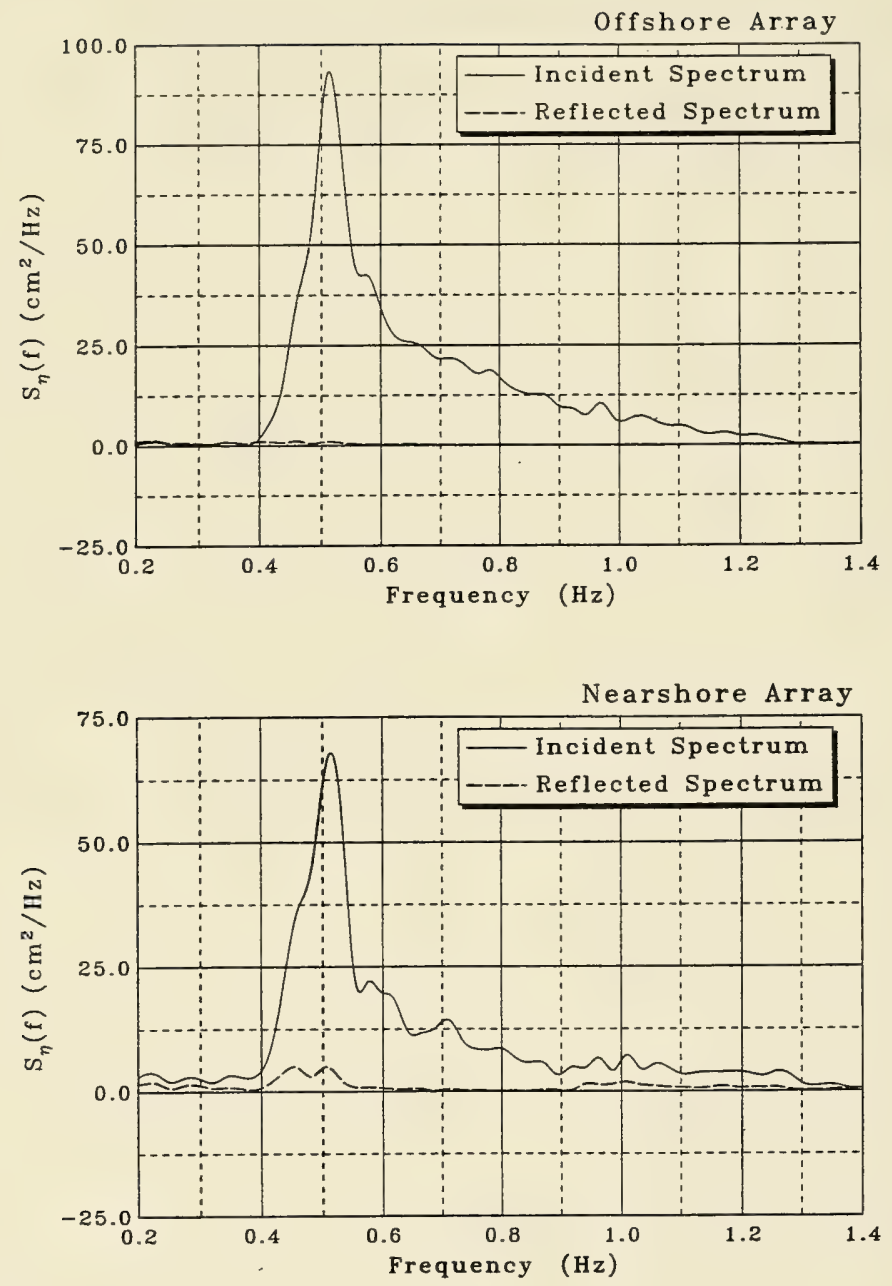

Figure A.33. Wave 24 incident and reflected spectra from wave gages 

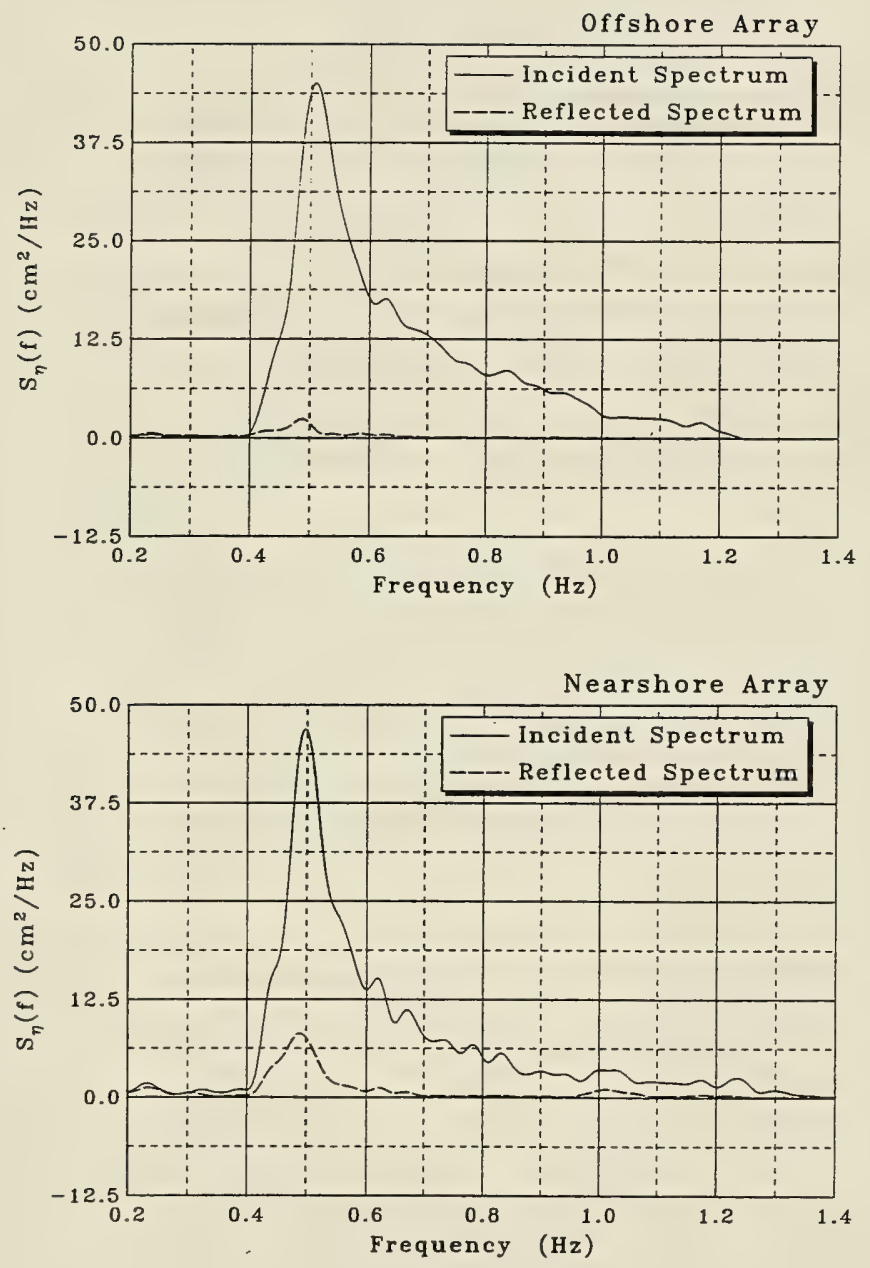

Figure A.34. Wave 25 incident and reflected spectra from wave gages 

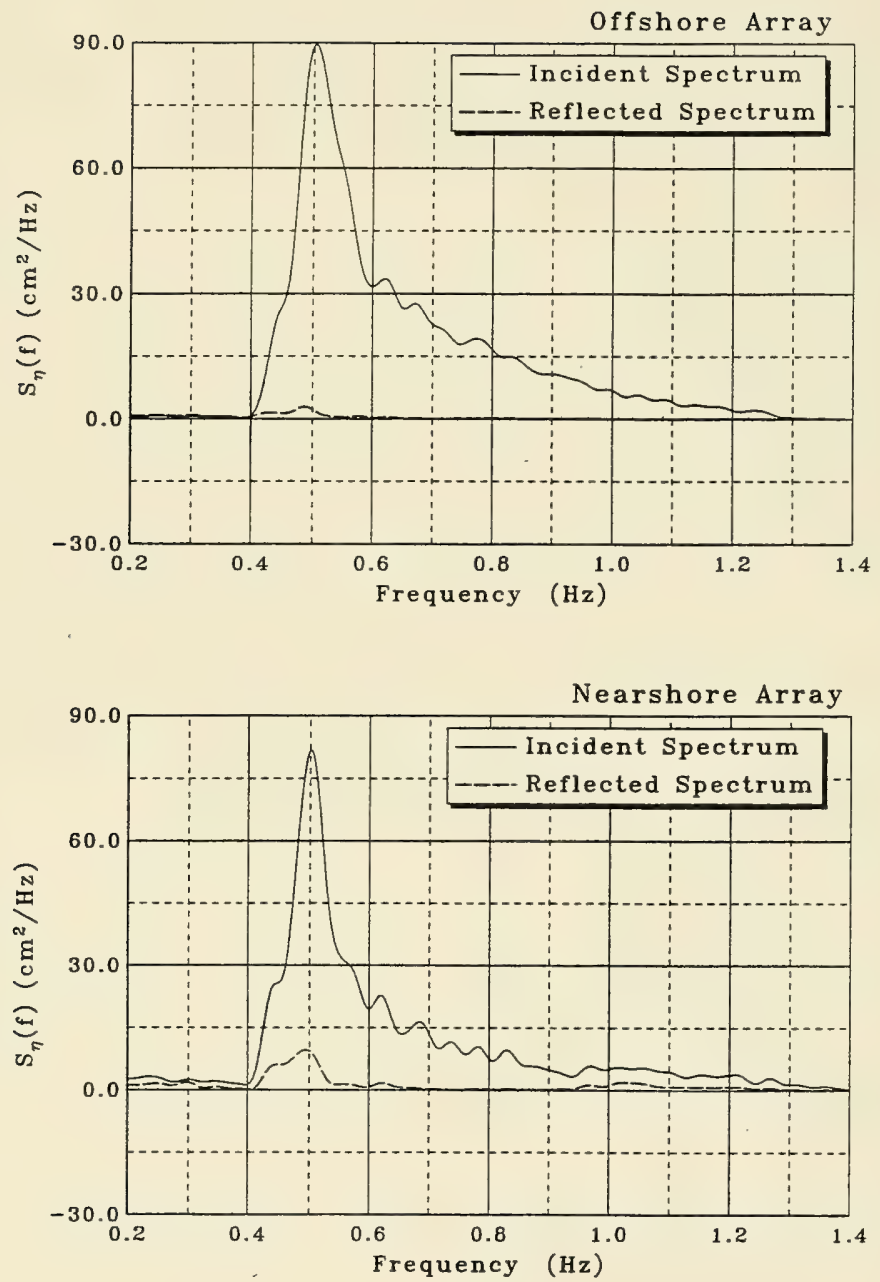

Figure A.35. Wave 26 incident and reflected spectra from wave gages 
APPENDIX B

SUMMARY OF DAMAGE AND PROFILE MEASUREMENTS 


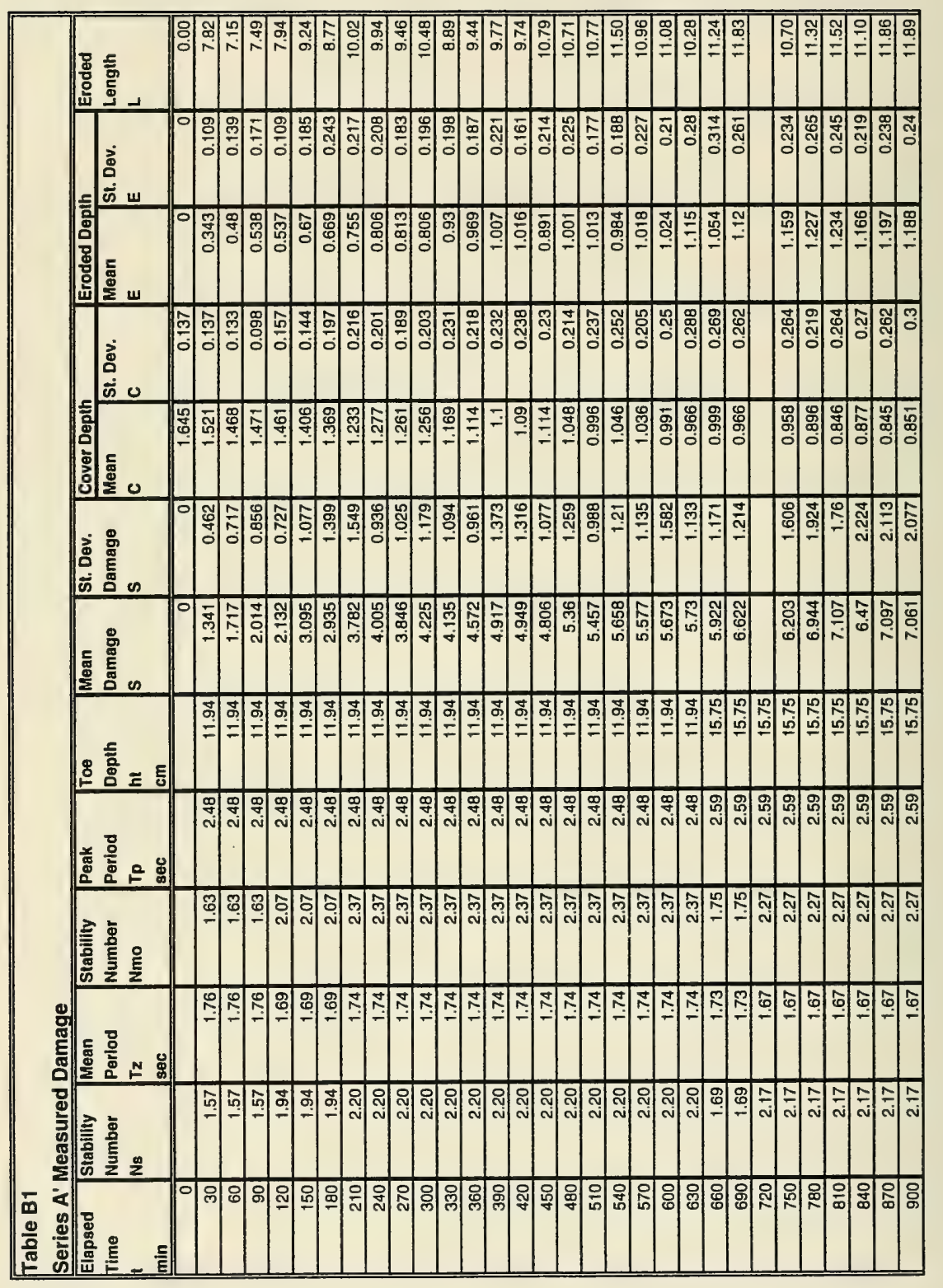




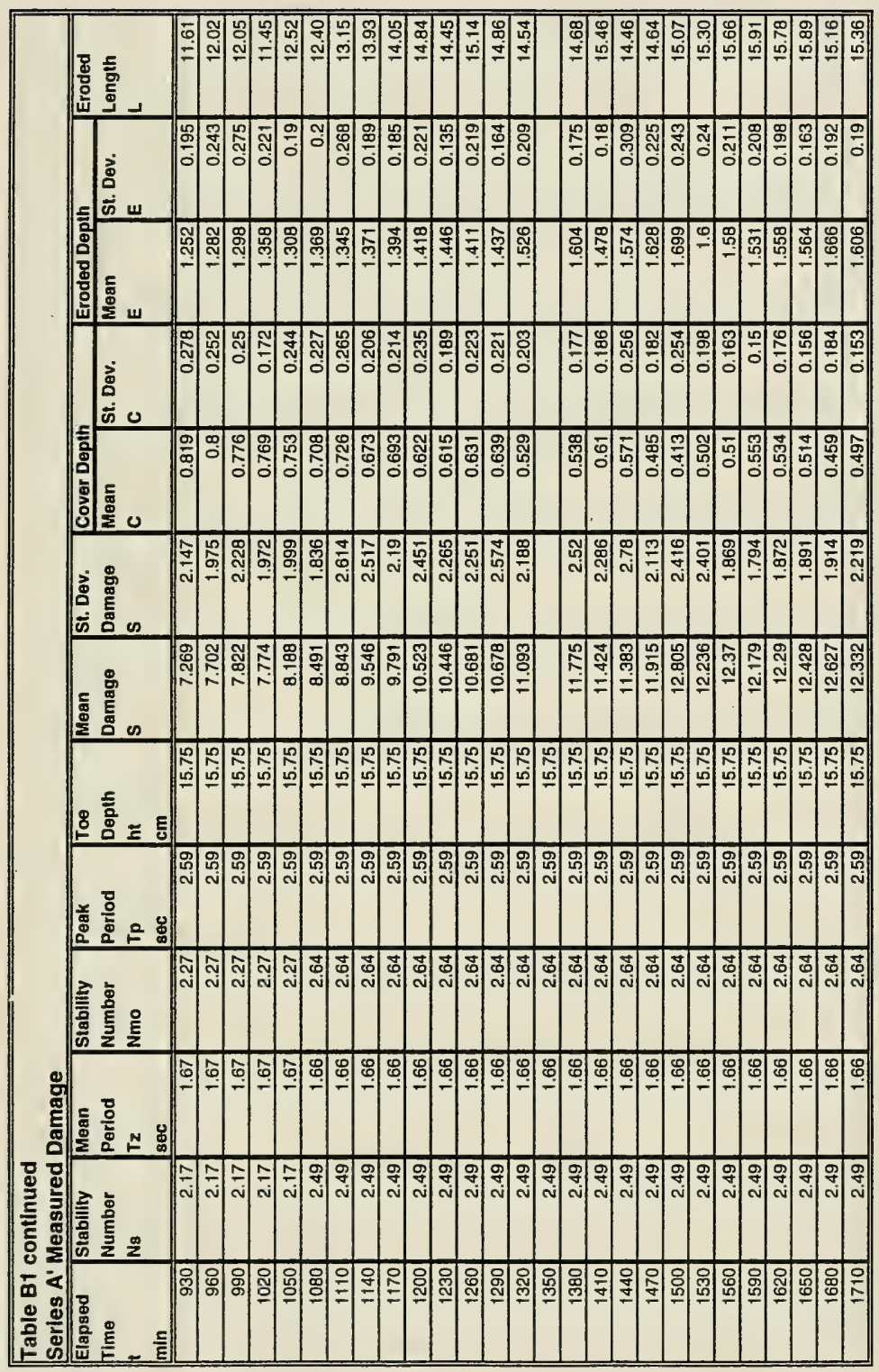




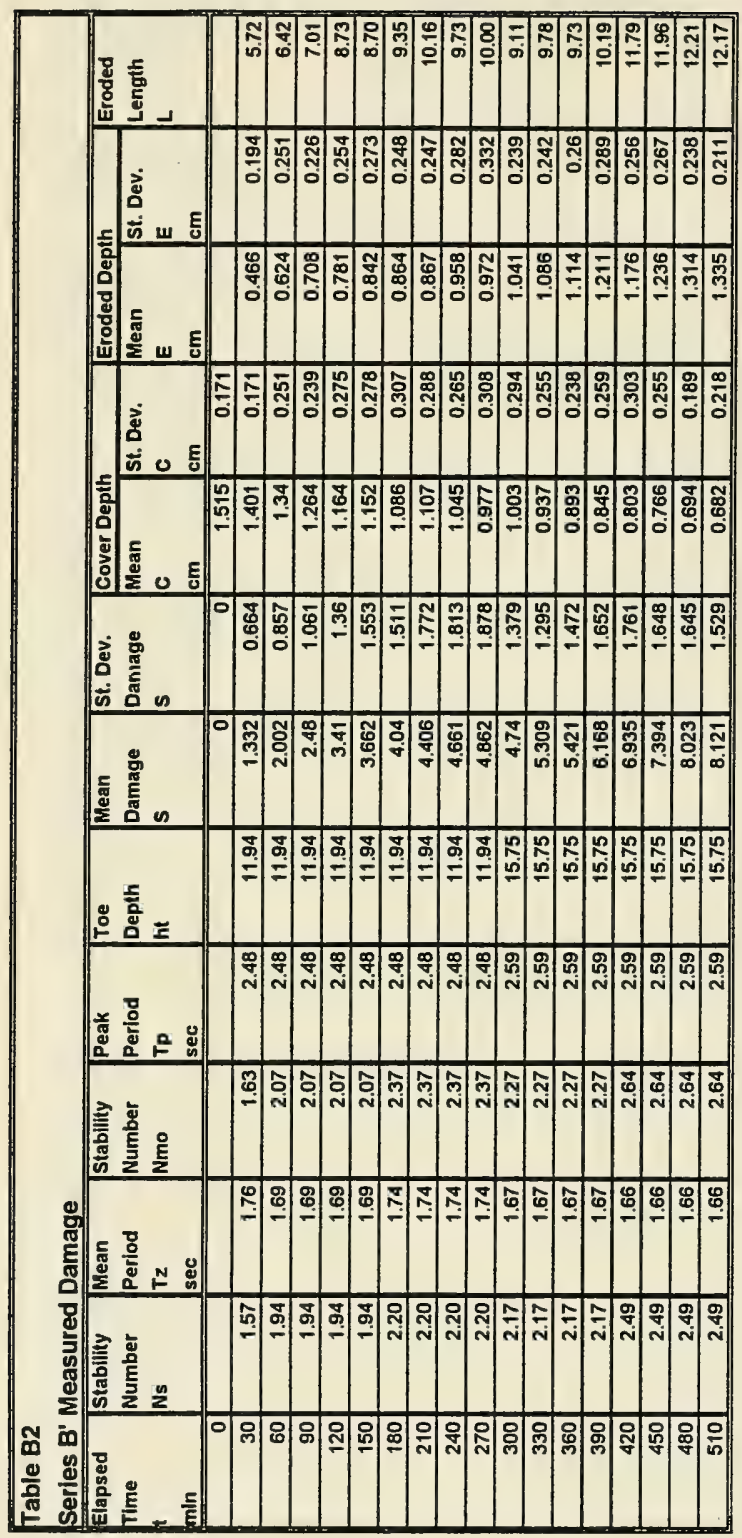




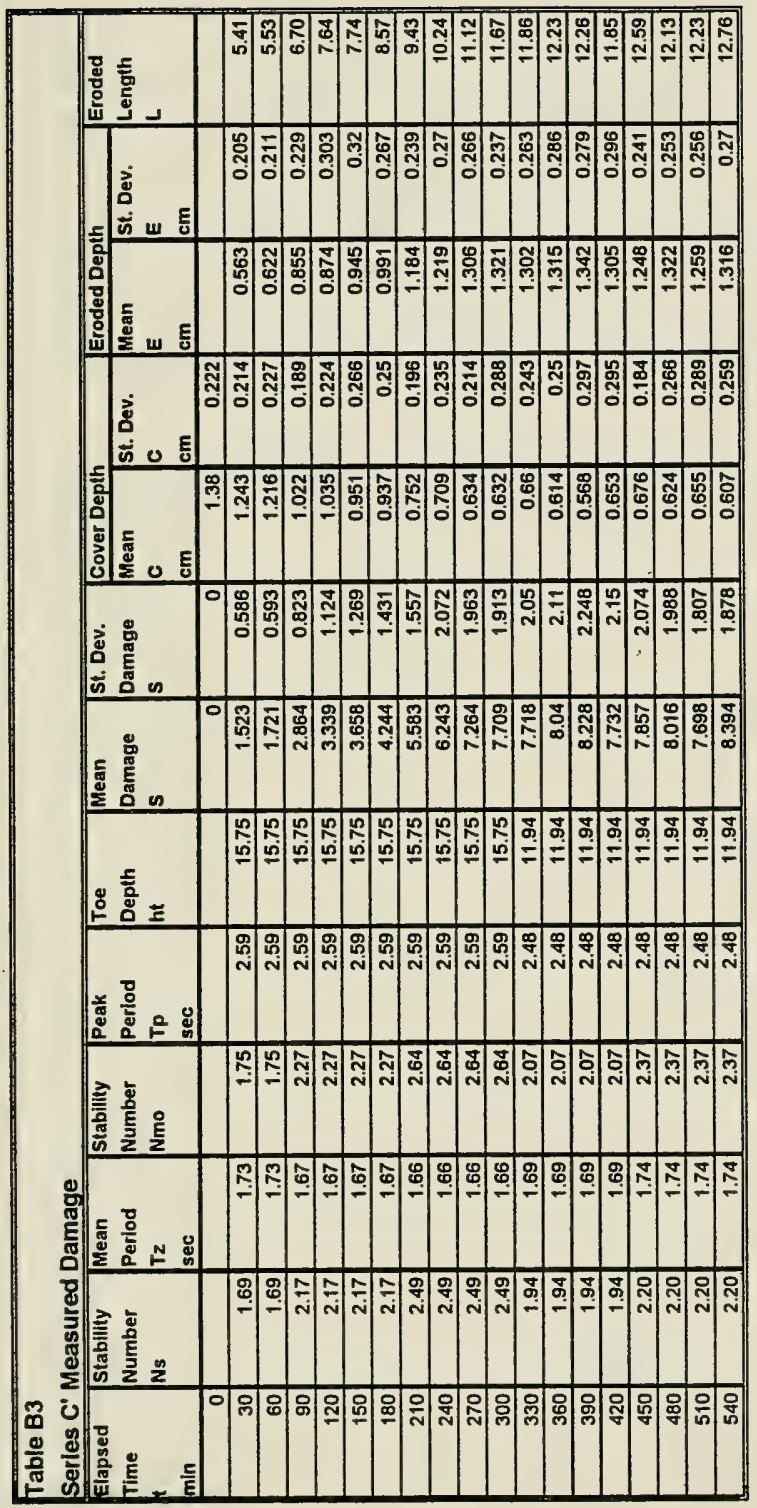




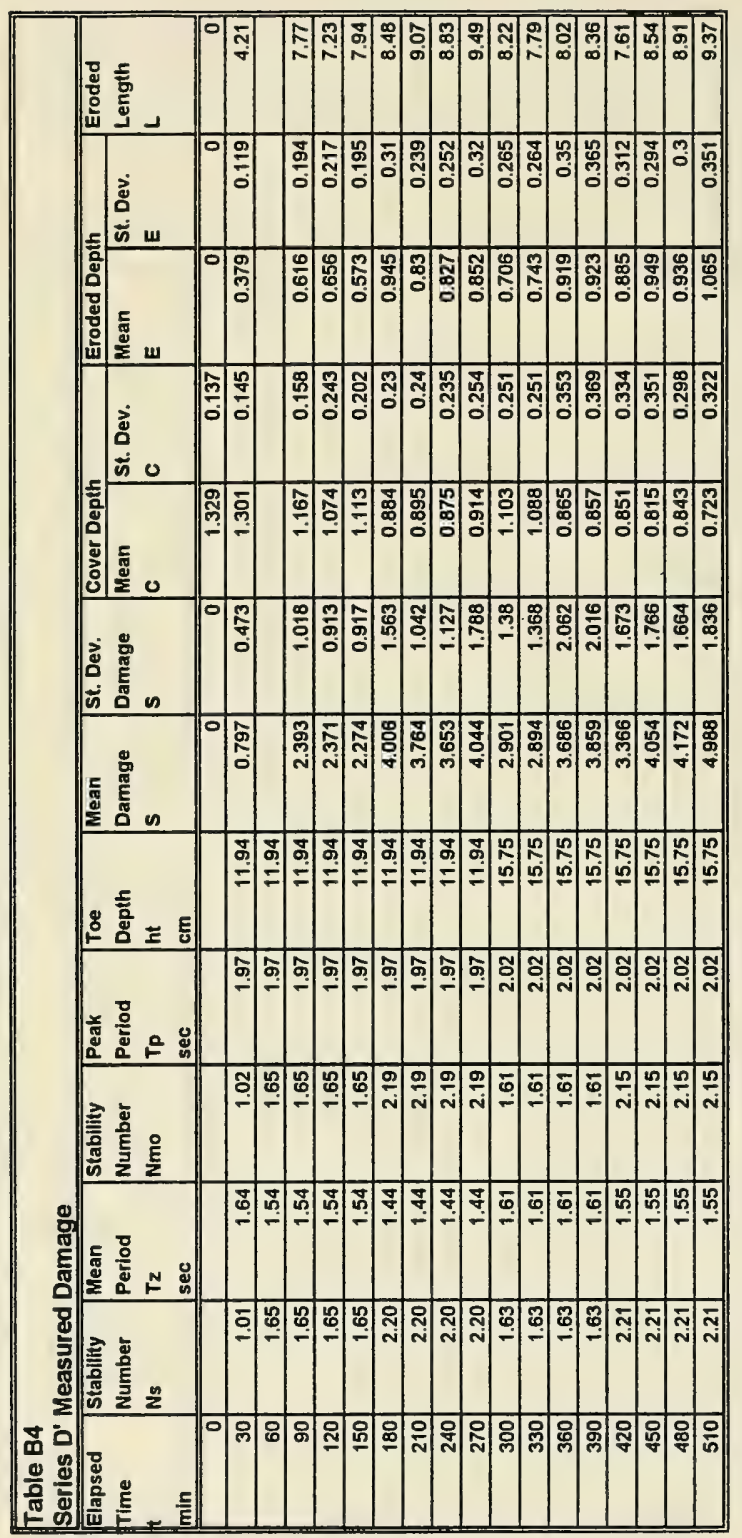




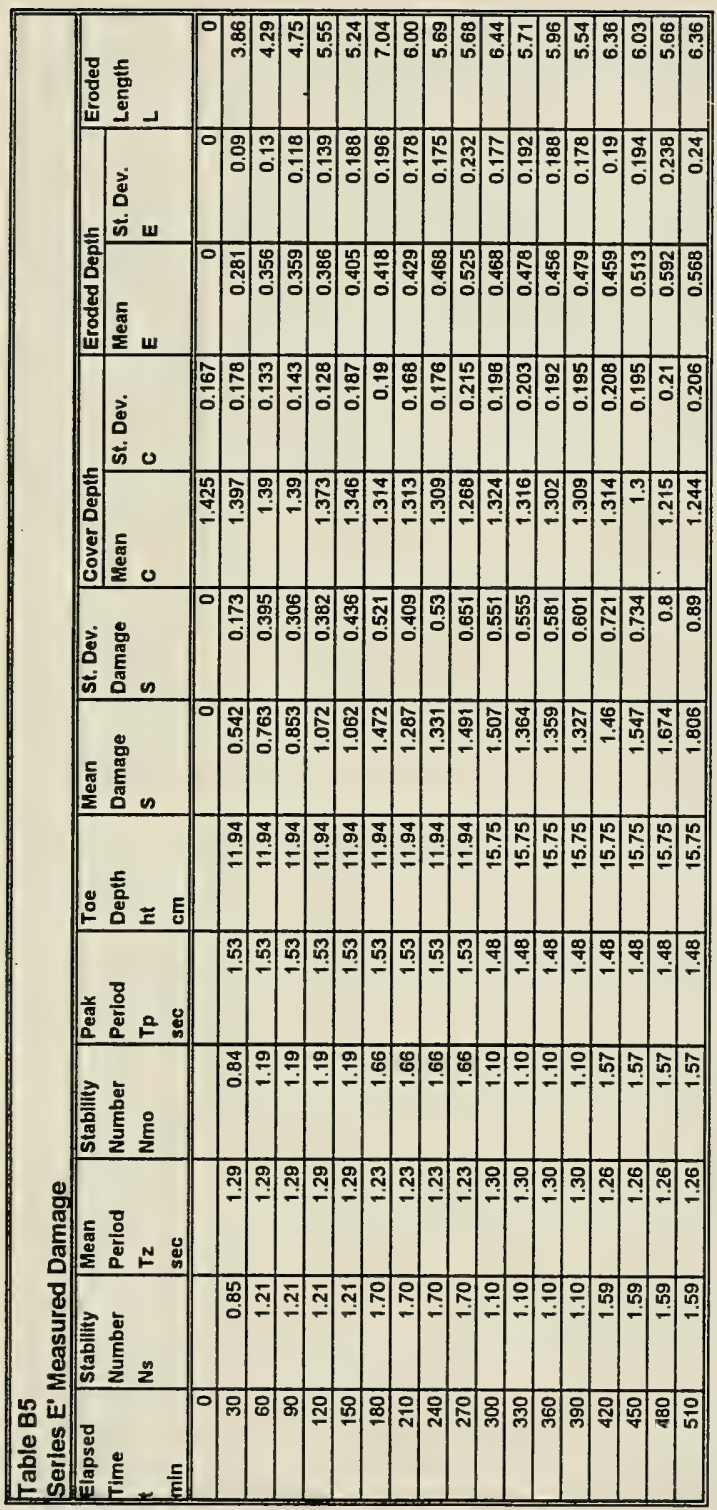




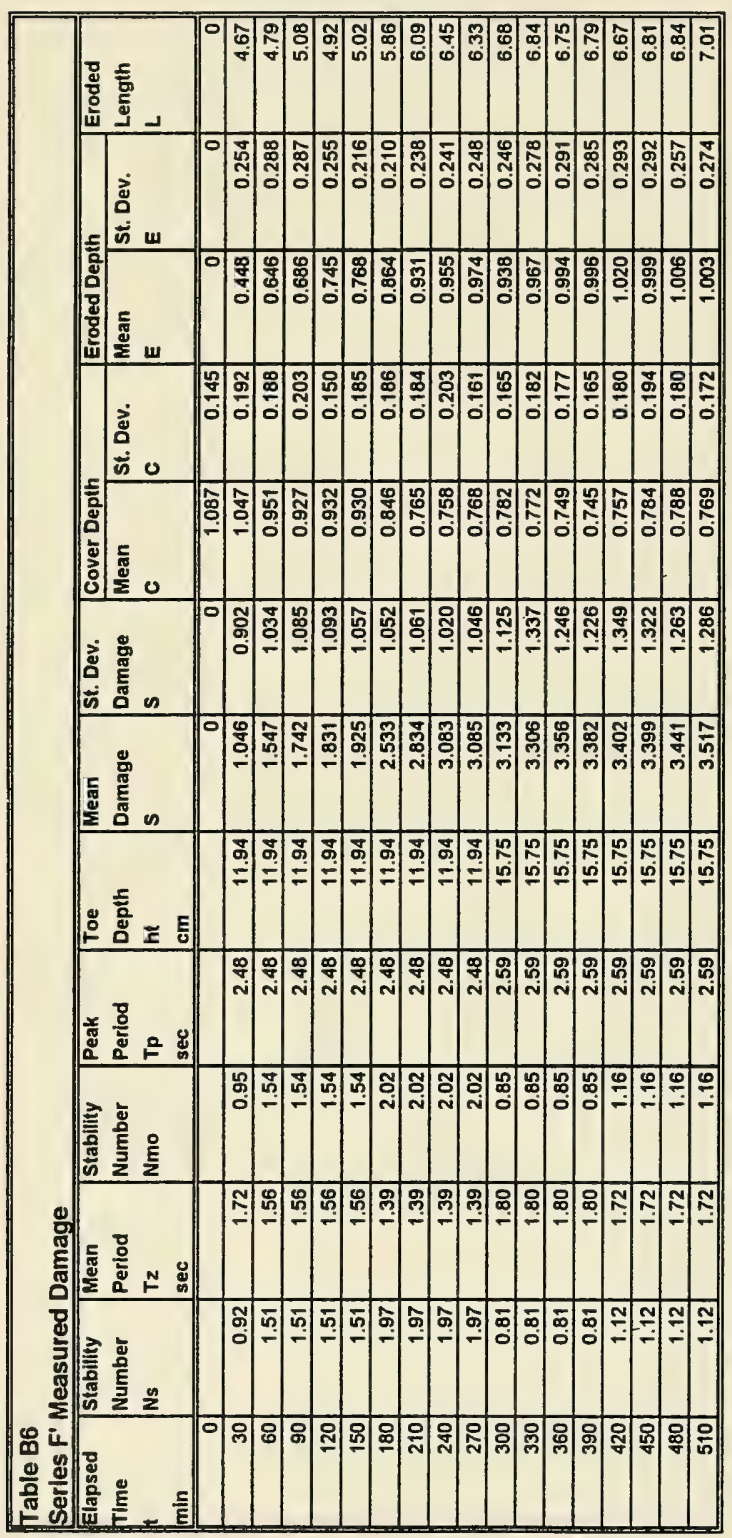




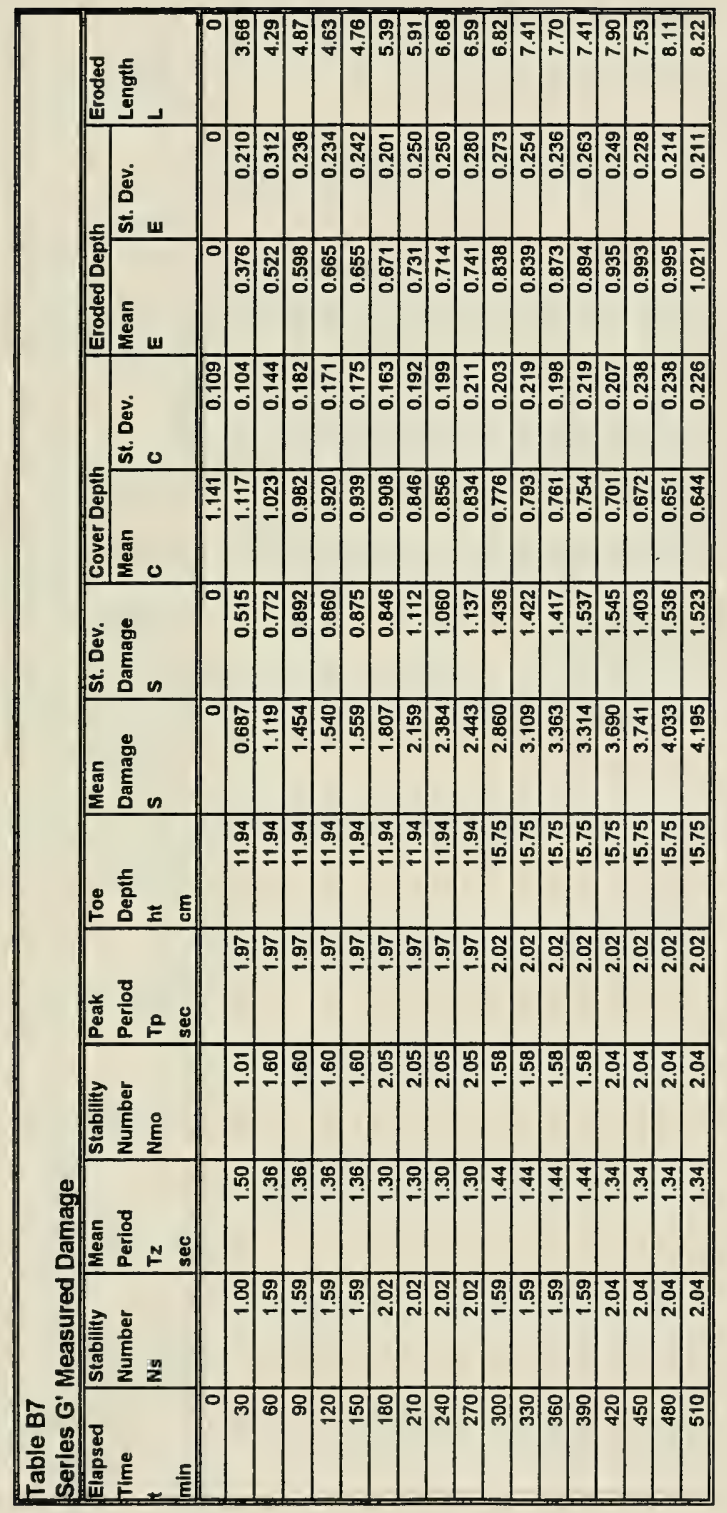




\section{REFERENCES}

Ahrens, J. P. (1975). "Large wave tank tests of riprap stability," Technical Memorandum N. 51, U.S. Army Engineer Waterways Experiment Station, Coastal Engineering Research Center, Vicksburg, MS.

Ahrens, J. P. and McCartney, B. L. (1975). "Wave period effect on the stability of riprap," Proc., Civ. Engrg. in the Oceans III, ASCE, 1019-1034.

Baquerizo, A., Losada, M. A., Smith, J. K., and Kobayashi, N. (1997). "Cross-shore variation of wave reflection from beaches," J. Wtrwy., Port, Coast., and Oc. Engrg., ASCE, 123(5), 274-279.

Battjes, J. A. (1974). "Surf similarity," Proc., 14th Coast. Eng. Conf., ASCE, Vol. 1, 466-480.

Battjes, J. A., and Stive, H. J. F. (1985). "Calibration and verification of a dissipation model for random breaking waves," J. Geophys. Res. 90(C5), 9159-9167.

Bouws, E., Gunther, H., Rosenthal, W., and Vincent, C. L. (1985). "Similarity of the wind wave spectrum in finite depth water. 1 . Spectrum form," J. Geophys. Res. 90 (C1), 975-986.

Broderick, L., and Ahrens, J. P. (1982). "Rip-rap stability scale effects," Technical Paper 82-3, U.S. Army Engineer Waterways Experiment Station, Coastal Engineering Research Center, Vicksburg, MS.

Bruun, P. (1985). Design and Construction of mounds for breakwaters and coastal protection. Elsevier Science Publishing Co., Inc., New York, NY.

Carver, R. D., and Wright, B. L. (1991). "An investigation of random variations in the stability response of stone armored, rubble mound breakwaters," Technical Report CERC-91-17, U.S. Army Engineer Waterways Experiment Station, Vicksburg, MS. 
Cornett, A. M., and Mansard, E.P.D. (1994). "Wave stresses on rubble-mound armor" Proc., 24th Coast. Eng. Conf., ASCE, Vol. 1, 986-1000.

Cornett, A. M. (1995). "A study of wave-induced forcing and damage of rock armour on rubble-mound breakwaters," Ph.D. diss., Technical Report HYD TR005, Canadian Hydraulics Centre, National Research Council Canada, Ottawa, Ontario.

Dai, Y. B., and Kamel, A. M. (1969). "Scale effect tests for rubble mound breakwaters," Research Report H-69-2, U.S. Army Engineer Waterways Experiment Station, Vicksburg, MS.

Dally, W. R. (1992). "Random breaking waves: Field verification of a wave-by-wave algorithm for engineering application," Coast. Engrg. 16, 369-397.

Davies, M. H., Mansard, E. P. D., and Cornett, A. M. (1994). "Damage analysis for rubble mound breakwaters," Proc., 24th Coast. Eng. Conf., ASCE, Vol. 1, 1001-1015.

Font, J. B. (1968). "The effect of storm duration on rubble mound breakwater stability," Proc., 11th Coast. Eng. Conf., ASCE, Vol. 1, 779-786.

Goda, Y. (1970). "Numerical experiments on wave statistics with spectral simulation," Report of the Port and Harbor Research Institute, Tokyo, Japan.

Goda, Y. (1985). Random seas and design of maritime structures. University of Tokyo Press, Tokyo, Japan.

Goda, Y., and Suzuki, Y. (1976). "Estimation of incident and reflected waves in random wave experiments," Proc., 17th Coast. Eng. Conf., ASCE, Vol. 1, 201-220.

Hedar, P. A. (1960). "Stability of rock-fill breakwaters," PhD. diss., University of Goteborg, Sweden.

Hedar, P. A. (1986). "Armor layer stability of rubble mound breakwaters," J. Wtrwy., Port, Coast., and Oc. Engrg., ASCE, 112(3), 343-350.

H. R. Wallingford, Ltd. (1990). "Rock armouring for coastal and shoreline structures," Report EX 1989, Wallingford, United Kingdom. 
Hudson, R. Y. (1958). "Design of quarry-stone cover layers for rubble-mound breakwaters," Research Report No. 2-2, ¿..S. Army Engineer Waterways Experiment Station, Vicksburg, MS.

Hudson, R. Y. (1959). "Laboratory investigation of rubble-mound breakwaters," J. Wtrwy. and Harb. Div., ASCE, 85(WW3), 93-121.

Hudson, R. Y., Hermann, F. A., Sager, R. A., Whalin, R. W., Keulegan, G. H., Chatham, C. E., and Hales, L. Z. (1979). "Coastal hydraulic models," Special Report No. 5, U.S. Army Engineer Waterways Experiment Station, Vicksburg, MS.

Hughes, S. A. (1993). Physical models and laboratory techniques in coastal engineering. World Scientific Pub. Co., River Edge, NJ.

Iribarren, R. (1938). "Una formula para el calculo de los diques en escoller (A formula for the calculation of rock-fill dikes)," Revista de Obras Publicas, Madrid, Spain. Translated by D. Heinrich, Tech. Rep. HE-116-295, Fluid Mech. Lab., Univ. of Calif., Berkeley, CA, 1948.

Jackson, R. A. (1968). "Design of cover layers for rubble-mound breakwaters subjected to nonbreaking waves," Research Report No. 2-11, U.S. Army Engineer Waierways Experiment Station, Vicksburg, MS.

Jensen, O. J. (1984). A monograph on rubble-mound breakwaters, Danish Hydraulic Institute, Hørsholm, Denmark.

Jensen, T., Andersen, H., Grønbeck, J., Mansard, E. P. D., and Davies, M. H. (1996). "Breakwater stability under regular and irregular wave attack," Proc., 25th Coast. Eng. Conf., ASCE, Vol. 2, 1679-1692.

Kaplan, P. (1979) "Impact forces on horizontal members," Proc., Civ. Engrg. In the Oceans IV, ASCE, San Francisco, CA, Sept. 716 - 731.

Kaplan, P., and Silbert, M. N. (1976) "Impact forces on platform horizontal members in the splash zone," Proc., Offshore Techn. Conf., Paper OTC 2498, Houston, TX, 749-758.

Kobayashi, N., Wurjanto, A., and Cox, D. (1990). "Rock slopes under irregular wave attack," Proc., 22nd Coast. Eng. Conf., ASCE, 1306-1319. 
Kobayashi, N., Cox, D. T., and Wurjanto, A. (1990). "Irregular wave reflection and runup on rough impermeable slopes," J. Wtrwy., Port, Coast., and Oc. Engrg, ASCE, 116(6), 708-726.

Long, C. E. (1986). "Laboratory wave generation and analysis: An instructional report for unidirectional wave generation and analysis," U.S. Army Engineer Waterways Experiment Station, Vicksburg, MS.

Losada, M.A., and Giménez-Curto, L. (1982). "Mound breakwaters under oblique wave attack," Coast. Engrg. 6, 83-92.

McDougal, W. G., Melby, J. A. and Tedesco, J. W. (1988). "Wave forces on concrete armor units,"J. Wtrwy., Port, Coast., and Oc., Engrg., ASCE, 114(5), 582598.

Medina, J., and McDougal, W. G. (1988). Discussion of "Deterministic and probabilistic design of breakwater armor layers," J. Wtrwy., Port, Coast., and Oc., Engrg., ASCE, 116(4), 508-510.

Melby, J.A. (1987). "Wave induced dynamic response of dolos concrete armor units," M.S. Thesis, Dept. of Civ. Engrg., Oregon State University, Corvallis, OR.

Melby, J. A., and Mlakar, P. F. (1997). "Reliability assessment of breakwaters," Technical Report CHL-97-9, U.S. Army Engineer Waterways Experiment Station, Vicksburg, MS.

Mizutani, N., Iwata, K., Rufin, T. M., and Kurata, K. (1992). "Laboratory investigation of the stability of a spherical armor unit of a submerged breakwater," Proc., 23rd Coast. Eng. Conf. ASCE, Vol. 2, 1400-1413.

Morison, J., O'Brien, M., Johnson, J., and Scaaf, S. (1950). "The force exerted by surface waves on piles," Petroleum Trans. 189, TP 149-154.

Owen, M. W., and Alisop, N. W. (1983). "Hydraulic modelling of rubble mound breakwaters," Proc., Breakwaters: Design and Construction, Inst. of Civil Engineers, London, U.K., 71-78.

Pilarczyk, K.W., and Den Boer, K. (1983). "Stability and profile development of coarse materials and their application in coastal engineering," Proc., Int. Conf. On Coastal and Port Eng. In Developing Countries, 43-61. 
Pfeiffer, H. L. (1991). "Comparison of four rubble-mound stability equations with prototype data from Burns Harbor breakwater," M.S. Thesis, Civ. Engrg. Dept., Texas A\&M Univ.

PIANC (1976). "Final report of the International Commision for the Study of Waves," Annex to PIANC Bull. N. 25, V. III, Brussels, Belgium.

PIANC (1992). "Analysis of rubble mound breakwaters," Supplement to PIANC Bull. N. 78/79, Brussels, Belgium.

Raudkivi, A.J. (1990). Loose boundary hydraulics, 3rd Ed., Pergammon Press, New York, NY.

Sakakiyama, T., and Kajima, R. (1992). "Scale effect of wave force on armor units," Proc., 22nd Coast. Eng. Conf., ASCE, Vol. 2, 1716-1729.

Sawaragi, T., Iwata, K., and Kobayashi, N. (1982). "Conditions and probability of occurrence of resonance on steep slopes of coastal structures," Coastal Engineering in Japan, 25, 75-90.

Sigurdsson, G. (1962). "Wave forces on breakwater capstones," J. Wtrwy. and Harb. Div., ASCE, WW3, 27-60.

Shore Protection Manual (1984). 4th Ed., 2 Vol, U.S. Army Engineer Waterways Experiment Station, U.S. Government Printing Office, Washington, DC.

Smith, W. G., Kobayashi, N., and Kaku, S. (1992). "Profile changes of rock slopes by irregular waves," Proc., 23rd Coast. Eng. Conf., ASCE, Vol. 2, 1559-1572.

Thompson, D. M., and Shuttler, R. M. (1976). "Design of rip-rap slope protection against wind waves," Report No. 61, CIRIA, London, U.K.

Torum, A., Mathiesen, B., and Escutia, R. (1979). "Reliability of breakwater model tests," Proc., Coastal Structures '79, ASCE, 454-469.

Torum, A., and Van Gent, M. (1992). "Water particle velocities on a berm breakwater," Proc., 23rd Coast. Eng. Conf., ASCE, 1651-1665.

Torum, A. (1994). "Wave-induced forces on armor units on berm breakwaters," J. Wtrwy, Port, Coast., and Oc. Engrg., ASCE, 120(3), 251-268. 
Van der Meer, J. W. (1988). "Rock slopes and gravel beaches under wave attack," Ph.D. diss., Delft Hydraulics Communication No. 396, Delft Hydrulics Laboratory, Emmeloord, The Netherlands.

Van der Meer, J. W., and Daemen I. F. R. (1994). "Stability and wave transmission at low-crested rubble mound structures," J. Wtrwy., Port, Coast., and Oc. Engrg., ASCE, 120(1), 1-19.

Vidal, C., Losada, M. A., and Medina, R. (1991). "Stability of mound breakwater's head and trunk," J. Wtrwy., Port, Coast., and Oc. Engrg., ASCE, 117(6), 570-587.

Vidal, C., Losada, M. A., and Mansard, E. P. D. (1995). "Suitable wave height parameter for characterizing breakwater stability," J. Wtrwy., Port, Coast., and Oc. Engrg., ASCE, 121(2), 88-97.

Winkelman, J. (1998). "Rubble mound damage measurement," M.S. thesis, Dept. of Civ. Engrg., Univ. of Rhode Island, Kingston, R.I. 


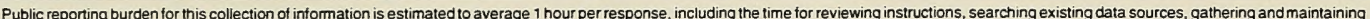

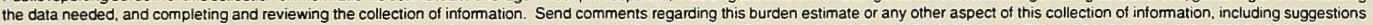

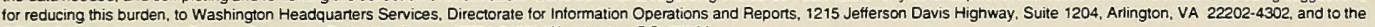
Otfice of Management and Budget. Paperwork Reduction Project (0704-0188), Washington, DC 20503.

1. AGENCY USE ONLY (Leave blank)

2. REPORT DATE July 1999
3. REPORT TYPE AND DATES COVERED

Final report

\section{TITLE AND SUBTITLE}

Damage Progression on Rubble-Mound Breakwaters

\section{FUNDING NUMBERS}

\section{AUTHOR(S)}

Jeffrey A. Melby

\section{PERFORMING ORGANIZATION NAME(S) AND ADDRESS(ES)}

U.S. Army Engineer Waterways Experiment Station

3909 Halls Ferry Road, Vicksburg, MS 39180-6199
8. PERFORMING ORGANIZATION REPORT NUMBER

Technical Report CHL-99-17

\section{SPONSORING/MONITORING AGENCY NAME(S) AND ADDRESS(ES)}

U.S. Army Corps of Engineers

10. SPONSORINGMONTORING AGENCY REPORT NUMBER

\section{SUPPLEMENTARY NOTES}

Available from National Technical Information Service, 5285 Port Royal Road, Springfield, VA 22161.

12a. DISTRIBUTION/AVAILABILITY STATEMENT

12b. DISTRIBUTION CODE

Approved for public release; distribution is unlimited.

\section{ABSTRACT (Maximum 200 words)}

This report addresses depth-limited breaking-wave damage on rubble-mound breakwaters. Few generalized studies have been conducted on this topic; so no engineering methods exist for determining deterioration rates of breakwaters exposed to sequences of storms. A new experiment is discussed measuring incipient motion on both stone and sphere armor layers. An incipient motion criterion is derived for the dominant mode of motion: vertical lift under the steep breaking-wave face. Previous breakwater damage experiments and measurement techniques are thoroughly reviewed. A new experiment is described consisting of seven relatively long-duration breakwater damage test series. The test series were conducted in a flume using irregular waves. Wave height, wave period, water depth, storm duration, storm sequencing, and stone gradation were varied systematically. The experiment yielded relationships for both temporal and spatial damage development. Maximum eroded depth, maximum eroded length, and minimum remaining cover depth are introduced to describe the damaged profile. The mean and standard deviation of these profile parameters are shown to be a function of mean eroded area. An equation is also provided to predict the standard deviation of eroded area as a function of mean damage. Relations for predicting temporal variations of mean eroded area with wave height and period varying with time in steps are shown to describe damage reasonably well.

14. SUBJECT TERMS

$\begin{array}{lll}\text { Armor } & \text { Flume } & \text { Rubble mound } \\ \text { Breakwater } & \text { Life-cycle costs } & \text { Stability } \\ \text { Damage } & \text { Riprap } & \end{array}$

17. SECURITY CLASSIFICATION OF REPORT

18. SECURITY CLASSIFICATION OF THIS PAGE

UNCLASSIFIED
UNCLASSIFIED

NSN 7540-01-280-5500
15. NUMBER OF PAGES

216

16. PRICE CODE
19. SECURITY CLASSIFICATION OF ABSTRACT
20. LIMITATION OF ABSTRACT

Standard Form 298 (Rev. 2-89)

Prescribed by ANSI Std. 239-18 298-102 

Destroy this report when no longer needed. Do not return it to the originator. 

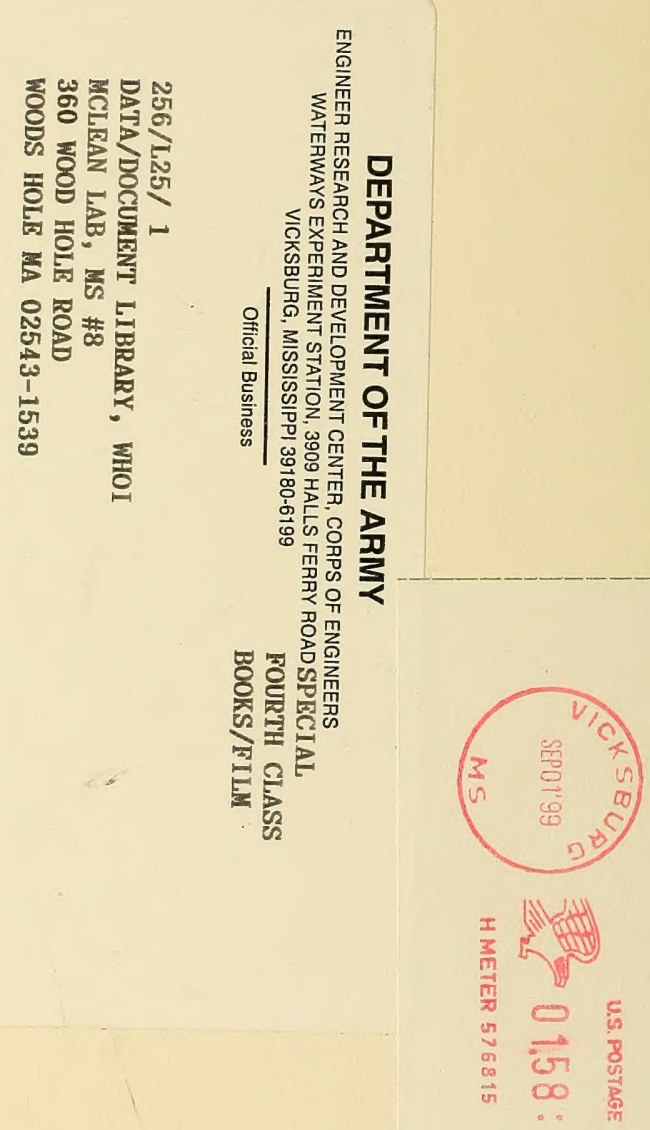

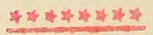

